\title{
Modeling the Oil Transition: A Summary of the Proceedings of the DOE/EPA Workshop on the Economic and Environmental Implications of Global Energy Transitions
}

February 2007

David L. Greene, Editor 


\title{
DOCUMENT AVAILABILITY
}

Reports produced after January 1, 1996, are generally available free via the U.S. Department of Energy (DOE) Information Bridge:

Web site: http://www.osti.gov/bridge

Reports produced before January 1, 1996, may be purchased by members of the public from the following source:

\author{
National Technical Information Service \\ 5285 Port Royal Road \\ Springfield, VA 22161 \\ Telephone: 703-605-6000 (1-800-553-6847) \\ TDD: 703-487-4639 \\ Fax: 703-605-6900 \\ E-mail: info@ntis.fedworld.gov \\ Web site: http://www.ntis.gov/support/ordernowabout.htm
}

Reports are available to DOE employees, DOE contractors, Energy Technology Data Exchange (ETDE) representatives, and International Nuclear Information System (INIS) representatives from the following source:

Office of Scientific and Technical Information

P.O. Box 62

Oak Ridge, TN 37831

Telephone: 865-576-5728

Fax: 865-576-5728

E-mail: reports@osti.gov

Web site: http://www.osti.gov/contact.html

This report was prepared as an account of work sponsored by an agency of the United States Government. Neither the United States government nor any agency thereof, nor any of their employees, makes any warranty, express or implied, or assumes any legal liability or responsibility for the accuracy, completeness, or usefulness of any information, apparatus, product, or process disclosed, or represents that its use would not infringe privately owned rights. Reference herein to any specific commercial product, process, or service by trade name, trademark, manufacturer, or otherwise, does not necessarily constitute or imply its endorsement, recommendation, or favoring by the United States Government or any agency thereof. The views and opinions of authors expressed herein do not necessarily state or reflect those of the United States Government or any agency thereof. 


\title{
MODELING THE OIL TRANSITION A DOE/EPA WORKSHOP ON THE ECONOMIC AND ENVIRONMENTAL IMPLICATIONS OF GLOBAL ENERGY TRANSITIONS
}

\author{
David L. Greene, Editor \\ Oak Ridge National Laboratory \\ Oak Ridge, Tennessee
}

February 2007

Prepared by

OAK RIDGE NATIONAL LABORATORY

P.O. Box 2008

Oak Ridge, Tennessee 37831-6285

managed by

UT-Battelle, LLC

for the

U.S. DEPARTMENT OF ENERGY

under contract DE-AC05-00OR22725 



\section{CONTENTS}

Page

LIST OF FIGURES ......................................................................................... vii

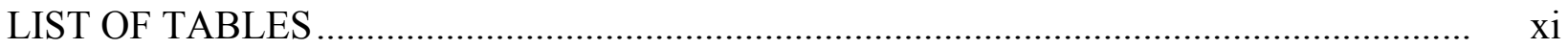

ACRONYMS .................................................................................................

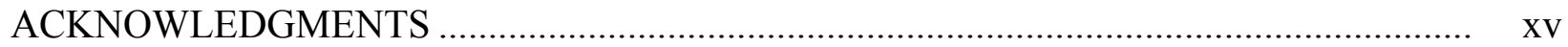

REFLECTIONS ON THE WORKSHOP ................................................................. xvii

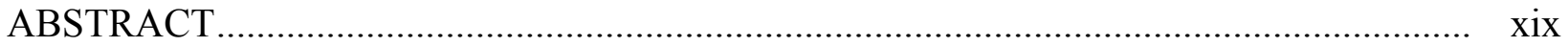

\section{PART 1: IDENTIFYING THE ISSUES}

1. KEYNOTE: GLOBAL OIL RESOURCES .......................................................... 1

Peter McCabe, United States Geological Survey

SESSION 1: ISSUES IN THE GLOBAL ENERGY TRANSITION FROM CONVENTIONAL OIL

David L. Greene, Oak Ridge National Laboratory, Chair

2. ECONOMIC EFFECTS OF THE PEAKING OF CONVENTIONAL OIL SUPPLY .... Hill Huntington, Energy Modeling Forum, Stanford University

3. WHAT CAN WE EXPECT FROM OPEC?

Dermot Gately, New York University

4. ENVIRONMENTAL ISSUES IN PEAKING AND TRANSITION

David Hawkins, Natural Resources Defense Council

SESSION 2: FORCES DRIVING THE TRANSITION FROM CONVENTIONAL OIL Sam Baldwin, U.S. Department of Energy, Chair

5. THE WORLDWIDE DEMAND FOR MOBILITY AND ITS IMPACT ON THE DEMAND FOR “CONVENTIONAL” OIL

George C. Eads, Vice President, Charles River Associates International

6. ENERGY SECURITY AS A DRIVER IN THE TRANSITION FROM OIL

Wil Kohl, The Johns Hopkins University School of Advanced International Studies

7. CLIMATE CHANGE - ARE WE APPROACHING A TIPPING POINT? Janet Peace, Senior Fellow in Economics, Pew Center on Climate Change 
8. AN HISTORICAL PERSPECTIVE ON GLOBAL ENERGY TRANSITIONS.

Arnulf Grübler, Institute for Applied Systems Analysis (IIASA) and Yale University

SESSION 3: TECHNOLOGY AND ENERGY TRANSITION

Robert Dixon, International Energy Agency, Chair

9. TECHNOLOGY OF CONVENTIONAL OIL SUPPLY

Tom O’Gallagher, Schlumberger

10. TECHNOLOGY AND RESOURCE POTENTIAL OF ENHANCED OIL RECOVERY

Vello Kuuskraa, Advanced Resources International, Inc.

11. BIOFUELS' POTENTIAL TO REPLACE OIL

Bob Perlack, Environmental Sciences Division, Oak Ridge National Laboratory

12. ENERGY EFFICIENCY....

Dolf Gielen, International Energy Agency

SESSION 4: ENVIRONMENTAL EFFECTS

Keith Sargent, U.S. Environmental Protection Agency, Chair

13. GREENHOUSE GAS EMISSIONS FROM A TRANSITION TO OIL SUBSTITUTES

Alex Farrell, University of California, Berkeley

14. WELL-TO-WHEEL GREENHOUSE GAS ASSESSMENT.

M. Q. Wang, Argonne National Laboratory

15. HYBRID MODELS OF INPUT-OUTPUT/LIFECYCLE ENVIRONMENTAL IMPACTS.

Heather MacLean, University of Toronto

16. A LONG-TERM VIEW OF AIR POLLUTION AND CLIMATE

Steve Smith, Pacific Northwest National Laboratory

SESSION 5: WHAT ARE THE IMPORTANT QUESTIONS?

William Fulkerson, Oak Ridge National Laboratory, Retired, Chair

17. WHAT ARE THE IMPORTANT QUESTIONS? 


\section{PART 2: METHODS \& MODELS: CAPABILITIES, CHALLENGES AND OPPORTUNITIES}

18. KEYNOTE: DYNAMICS OF GLOBAL ENERGY TRANSITIONS

Nebojsa Nakićenović, IIASA and Vienna University of Technology

SESSION 6: MODELING GLOBAL ENERGY TRANSITIONS \& THEIR ENVIRONMENTAL EFFECTS: PART I: MODELING OIL DEPLETION Dolf Gielen, International Energy Agency, Chair

19. RESOURCE DEPLETION: MODELING AND FORECASTING OIL PRODUCTION

Michael R. Smith, Energyfiles

20. MONTE CARLO SIMULATION OF DEPLETION AND MARKETS

David L. Greene, Oak Ridge National Laboratory

SESSION 7: MODELING GLOBAL ENERGY TRANSITIONS \& THEIR

ENVIRONMENTAL EFFECTS: PART II: MODELING THE ECONOMY, THE ENERGY SECTOR AND ENVIRONMENTAL IMPACTS

Michael Shelby, U.S. Environmental Protection Agency, Chair

21. OIL MARKET: TRANSITION OR EVOLUTION? THE EMISSIONS PREDICTION AND POLICY ANALYSIS MODEL

John Reilly and Sergey Paltsev, Massachusetts Institute of Technology; and

Frederic Choumert, Massachusetts Institute of Technology and TOTAL

22. REMI (MARKAL/TIMES).

George Treyz, Regional Economic Models, Inc.

23. THE CONTRIBUTION OF ECONOMIC MODELS TO THE OIL TRANSITION AND TO CLIMATE POLICY: A REVIEW OF THE AMIGA MODELING SYSTEM

Skip Laitner, American Council for and Energy-Efficient Economy, AMIGA

SESSION 8: MODELING GLOBAL ENERGY TRANSITIONS \& THEIR ENVIRONMENTAL EFFECTS. PART III: HYBRID MODELS AND SCENARIO ANALYSIS

Hill Huntington, Stanford University, Energy Modeling Forum, Chair

24. UNDERSTANDING AND MODELING THE EFFECTS OF HIGH OIL PRICES

AND THE DEVELOPMENT OF SAGE AT EIA

Glen Sweetnam, U.S. Department of Energy, Energy Information Administration 
25. ENERGY SECTOR EVOLUTIONS: A SCENARIO PERSPECTIVE FROM MINICAM

Leon Clarke, Pacific Northwest National Laboratory

26. SCENARIO ANALYSIS UNDER DEEP UNCERTAINTY

Robert Lempert, RAND Corporation

ROUNDTABLE DISCUSSION: METHODOLOGICAL CHALLENGES AND OPPORTUNITIES FOR IMPROVING ENERGY TRANSITION MODELING

Francisco C. de la Chesnaye, Chief Climate Analysis Branco, U.S. Environmental Protection Agency, Facilitator

27. ENDOGENOUS TECHNOLOGICAL CHANGE

Nebojsa Nakićenović, IIASA and Vienna University of Technology

28. ENDOGENOUS MARKET TRANSITIONS.

Paul Leiby, Oak Ridge National Laboratory

29. MODELING GROWTH IN NEW ENERGY TECHNOLOGIES: THE IMPORTANCE OF CONSTRAINTS

Carmen Difiglio, U.S. Department of Energy

30. RESOURCE DEPLETION: THE GLOBAL PEAK IN THE PRODUCTION OF CONVENTIONAL OIL

Roger Bentley, Visiting Research Fellow, Department of Cybernetics, University of Reading 


\section{LIST OF FIGURES}

Figure

Page

1.1 The Resource Pyramid ............................................................................................ 2

1.2 World Oil Discoveries by 5-Year Intervals, 1945-2000 ............................................ 3

1.3 ExxonMobil's Outlook for World Oil Supply to 2030 and the "Call on OPEC"........ 3

2.1 Changes in World Oil Consumption since 1980....................................................... 5

2.2 Three Oil Peaking Concepts: U.S. Statistics................................................................. 6

3.1 World Oil Market Projections of EIA and IEA Using Call on OPEC Method ............ 8

3.2 AEO 2003-2006 Reference Case Projections of OPEC Output and Oil Prices............ 8

3.3 Three Alternative Paths for OPEC's Market Share ...................................................... 9

3.4 Sensitivity Analysis of Net Present Value of OPEC Revenue as a Function of

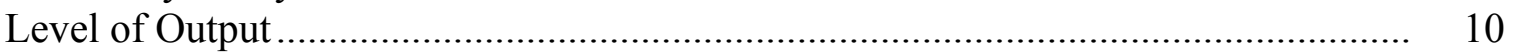

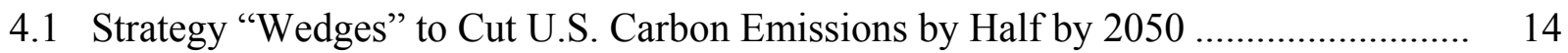

4.2 Impacts of Strip Mining on the Landscape ………..................................................... 15

5.1 Projected Personal Transportation Demand, 2000-2050 by Country/Region .............. 19

5.2 Projected Goods Transport Demand, 2000-2050 by Country/Region........................... 19

5.3 Projected Personal Transport Demand, 2000-2050 by Mode....................................... 20

5.4 Projected Goods Transport Demand, 2000-2050 by Mode …………………….......... 21

5.5 Relationship between Real per Capita Income and per Capita Personal Travel by Country/Region, 2000 ……………............................................................... 23

5.6 Projected Change in Real per Capita Personal Transport Demand vs. Projected Change in Real GDP per Capita (PPP Basis), 2000-2050 …………………............. 24

5.7 Total Increment to World Population and Total World Population,

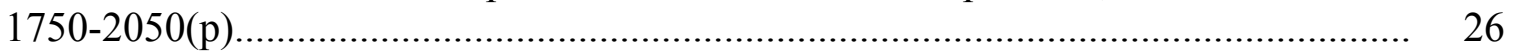

5.8 Daily Trips in the Paris Region by Mode Trips to, from, or within Central Paris....... 32

5.9 Mumbai Showing Density of Built-Up Area (pop/ha) ............................................... 37

5.10 Personal Transport Modal Splits, London (1841) and Shanghai (1995) ..................... 38

5.11 Shanghai Regional Population Density ………………………………………...... 39

5.12 Tax Added to Price of Vehicle (\%) ....................................................................... 41

5.13 Passenger Cars per 1000 Inhabitants vs. GDP/Capita as of 2000, EU-15 and

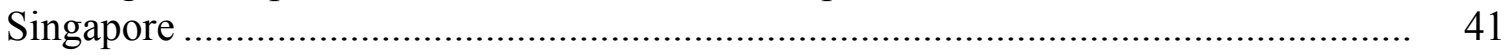

6.1 History and Outlook for the U.S. Petroleum Situation ................................................ 47

6.2 Peaking of non-OPEC Oil Demand and the "Call on OPEC:" ExxonMobil's

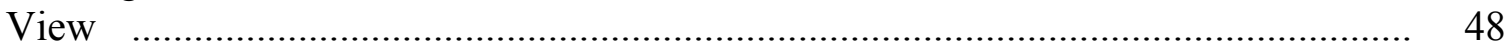

6.3 Middle East Exports Through "Dire Straits" ................................................................. 49

7.1 U.S. Greenhouse Gas Emissions by Energy End Use Sector ..................................... 51

7.2 States Belonging to Regional Climate Change Initiatives in 2005 ............................. 52 
8.1 Population and per Capita Energy Use Trends in Industrialized and Developing Regions ........................................................................................ 53

8.2 U.S. Energy Transitions: Market Shares and Absolute Energy Use............................. 54

8.3 The Two "Grand" Historical Energy Transitions and Possible Future Scenarios ........ 55

8.4 The Diffusion of Automobiles and Their Infrastructure in the United States: Gasoline Price Learning Curve and Average Car Price and Length of Road

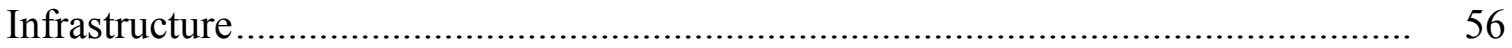

8.5 Decarbonization of the U.S. Energy System .......................................................... 58

8.6 Annual Catch of Sperm Whales, 1800-1900 ………............................................... 59

8.7 North American Oil Production Predicted by Energy in a Finite World and Actual Development.......................................................................................... 59

9.1 World Conventional and Unconventional Oil and the Cost of Recovery.................... 61

9.2 3-D "Virtual Reality" Imaging of Oil-Bearing Geologic Structures ............................ 62

9.3 Ocean Oil Development will Move from Floating to Integrated Subsea

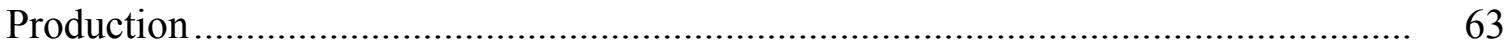

$10.1 \mathrm{CO}_{2}$ Enhanced Oil Recovery in the United States ................................................. 65

10.2 Alternative Estimates of Oil Economically Recoverable by $\mathrm{CO}_{2}$-EOR ...................... 67

11.1 Alternative Estimates of Biomass Feedstock Available from U.S. Cropland .............. 70

11.2 Impact of Tillage Practices on Availability of Corn Stover as Biomass Feedstock .... 71

11.3 Progress in State-of-the-Art and R\&D Targets for Ethanol Production from

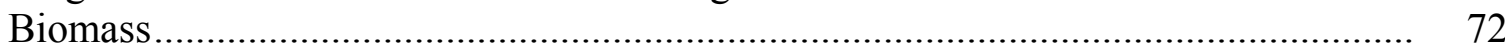

12.1 Light-Duty Vehicle Fuel Consumption Trends in Selected Countries, 1980-2005..... 75

12.2 Impacts of Available Technologies on Energy Use by Road Vehicles in 2050 ........... 76

12.3 Alternatives to Conventional Petroleum and Their Impacts on Energy Security and Greenhouse Gas Emissions ............................................................................ 77

12.4 IEA Estimates of Bioethanol Supply Curves: 2010, 2030, 2050.............................. 78

12.5 Optimal Strategies for Displacing Petroleum Demand with Energy Efficiency, Biofuels and Hydrogen

13.1 Upstream Emissions of $\mathrm{CO}_{2}$ and Costs of Conventional Oil Fossil Alternatives......... 79

13.2 Emissions of $\mathrm{CO}_{2}$ from Fuel Combustion and Upstream Processes for Gasoline and Diesel from Conventional Petroleum and Alternatives

14.1 Well-to-Pump Energy Efficiency of Gasoline and Diesel Production from Crude Oil

14.2 Upstream Emissions from the Production of Gasoline from Oil Sands ..................... 84

14.3 Well-to-Wheel Greenhouse Gas Emissions from Hydrogen Fuel Cell and Petroleum Fueled Light-Duty Vehicles .

15.1 Schematic Diagram of a Hybrid EIO-LCA Model for Canadian Oil Sands................. 88

16.1 Global Anthropogenic $\mathrm{CO}_{2}$ Emissions in Two MiniCAM Scenarios .......................... 90

16.2 Radiative Forcing by Greenhouse Gases in the Reference Case ................................. 91 
16.3 Radiative Forcing by Greenhouse Gases in the Climate Policy Case ......

17.1 Historical Oil Peaks in the United Kingdom and North America ............................. 94

17.2 The Effect of Post-Peak Rates of Decline on the Oil Supply Shortfall ..................... 95

17.3 Effect of a Crash Program to Close the Post-Peak Oil Supply Gap ......................... 95

18.1 The Fossil Fuel Era on a Scale of 10,000 Years .................................................... 99

18.2 U.S. Final Energy Use by Form ...................................................................... 100

18.3 World Energy Use to 2100: Alternative Scenarios............................................. 101

18.4 Resource Classification Using the McKelvey Diagram ..................................... 102

18.5 Oil Extraction and Depletion in Four Global Energy Scenarios.............................. 103

18.6 The World's Carbon Reservoirs ....................................................................... 104

19.1 Ideal Model of Oil Production from an Oil-Bearing Sedimentary Basin .................. 108

19.2 Ideal Model of Oil Field Discovery and Production in a Sedimentary Basin ............ 109

19.3 Ideal Model of Cumulative Discovery and Cumulative Production.......................... 109

19.4 Oil Production from Egyptian Fields in Order of Discovery................................. 110

19.5 United Kingdom Oil Discoveries and Production .............................................. 111

19.6 Global Oil Production and Discovery Forecast ............................................ 112

19.7 Global Oil Peaking and the Demand Gap ...................................................... 113

20.1 Estimated Unconventional Oil Resources ........................................................ 117

20.2 Typical Depletion Cost Curves for Unconventional Oil Resources ........................ 117

20.3 Equations for Predicting the Cost of Synthetic Petroleum from Coal ...................... 118

20.4 World Conventional and Unconventional Oil Production to 2050: Base Case .......... 119

20.5 Base Case Coal-to-Liquids Production by Region ............................................... 119

20.6 U.S. Liquid Hydrocarbon Production through 2050: Base Case ............................. 120

20.7 U.S. Oil Imports in Base Case ........................................................................ 121

20.8 Middle East Share of World Oil Supply through 2050: Base Case......................... 121

20.9 Distribution of ROW Peak Year for Conventional Oil Production ........................... 122

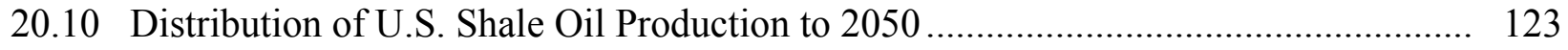

20.11 Distribution of U.S. Coal-to-Liquids Production to 2050 ..................................... 123

21.1 Upstream Processes Represented in the EPPA Model ......................................... 127

21.2 Primary Energy Production for World Liquid Fuels: Reference Case ..................... 128

21.3 Upgrading Capacity Additions Required to Use Heavier Crudes and Unconventional Oil ..................................................................................... 128

21.4 Change in Carbon Emissions due to Upgrading of Heavier Crudes and Unconventional Oil in Annex 1 and non-Annex 1 Countries................................. 129

22.1 Basic Structure of the REMI Model ................................................................. 132

22.2 Basic Structure of the MARKAL Model ........................................................... 132

22.3 Determination of Supply-Demand Equilibrium in MARKAL and Technology Detail

22.4 Schematic Diagram of the Linkage between REMI and MARKAL/TIMES .............. 133 
23.1 Structure of the AMIGA Model.......................................................................... 136

23.2 Analysis of Impact of Energy Efficiency Improvements on Energy Use................... 137

23.3 Refrigerator Price, Size and Efficiency in the U.S., 1947-2002 ……........................ 139

24.1 AEO 2006 and IEO 2005 Reference Case Oil Price Projections................................. 142

24.2 World Oil Prices in Three AEO 2006 Cases, 1980-2030 ……................................. 142

24.3 U.S. GDP in High and Low World Oil Price Cases ................................................ 143

24.4 Unconventional Liquids Production in 2025 in the 2006 AEO.............................. 144

24.5 U.S. $\mathrm{CO}_{2}$ Emissions in Three Oil Price Cases, 2003 and $2030 \ldots \ldots \ldots \ldots \ldots \ldots \ldots \ldots \ldots \ldots \ldots \ldots \ldots . . . .144$

25.1 Schematic Diagram of the MiniCAM Model ......................................................... 148

25.2 Demographic and Economic Changes by Region in the Reference Scenario .............. 148

25.3 Global Energy Use by Sector, Reference Scenario .................................................. 149

25.4 World Primary Energy Use, Reference Scenario ....................................................... 149

25.5 Global Evolution of Resources Converted to Liquid Fuels ....................................... 150

25.6 Annual Global $\mathrm{CO}_{2}$ Emissions and Resulting Atmospheric Concentrations............... 151

25.7 Pattern of Global Primary Energy Use Stabilizing $\mathrm{CO}_{2}$ Concentration at $550 \mathrm{ppm} . . . . \quad 151$

25.8 Global Liquid Fuels Supply in Reference and 550 ppm Stabilization Scenarios ........ 152

25.9 Implications of Stabilization Scenarios for Terrestrial $\mathrm{CO}_{2}$ Emissions ....................... 152

26.1 The Unexpected Decoupling of U.S. Energy Use and GNP after 1973 ...................... 154

26.2 Distributions of Regret for Two Alternative, Fixed Strategies................................... 155

26.3 Distributions of Regret for Adaptive "Safety Valve” Strategy.................................... 156

27.1 Cost of Lighting by Alternative Technologies in the United Kingdom, 1800-2000.....

27.2 Market Shares of Alternative Lighting Technologies in the United Kingdom, 1900-1950

27.3 Distribution of Historical Rates of Learning-by-Doing ............................................. 159

$27.4 \mathrm{CO}_{2}$ Emissions from Scenarios with Technological Uncertainty ............................... 159

28.1 Alternative Fuel Vehicle Market Predictions Without (left) and With (right) Market Barrier to Transition

28.2 One Scenario of Vehicle Technology Transitions in Which a Transition to Hybrid Electric Vehicles is Driven by Pure Technological Change and a Transition to Hydrogen Fuel Cell Vehicles is Aided by Public Policies

29.1 Growth of Gasification Plants Worldwide: 1952-2010 ........................................... 163

29.2 Growth in Nuclear Electricity Generation in Four Countries.................................... 164

29.3 Growth of Ethanol Production in the United States: 1998-2006 ….......................... 165

29.4 Growth of Global Wind Generating Capacity: 1986-2008 ...................................... 165

30.1 Uppsala/Campbell Oil and Gas Production Forecast, 2002 Base Case Scenario ........ 168

30.2 Alternative Global Oil (Conventional + Non-Conventional) Production

Projections. 


\section{LIST OF TABLES}

Table

Page

5.1 Level and Growth in Real GDP per Capita, Actual 2000 and Projected 2025

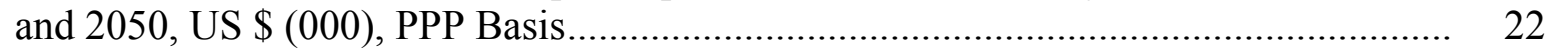

5.2 Population and Population Growth Rates by Country/Region .................................. 27

5.3 World Urbanization Trends, 1950-2030(p) ........................................................ 28

5.4 London Urbanized Area and Population Density ................................................. 29

5.5 Evolution of Shopping Travel in the United Kingdom, 1965-1995 _........................... 30

5.6 Percent of "Daily" or "Short Distance" Personal Travel, United States

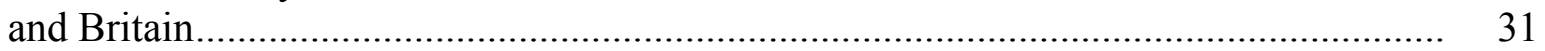

5.7 Main Mode of Travel to Work, London, Autumn 2003 .......................................... 32

5.8 How Personal Transportation Demand is Influenced by Urban Form (1)................... 33

5.9 How Transport Demand is Influenced by Urban Form (2) ...................................... 34

5.10 Comparison of Personal Transport Characteristics in Shanghai and Mumbai .............. 36

5.11 Composition of Household Transportation Expenditures, United States, Britain,

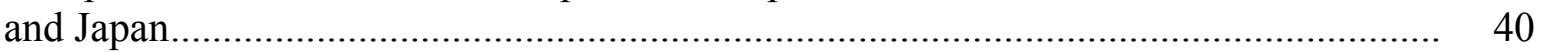

5.12 London and Singapore Personal Transport Characteristics ..................................... 43

8.1 Energy Efficiency and Emissions for Horses and Automobiles.............................. 57

10.1 Oil Technically Recoverable by Advanced $\mathrm{CO}_{2}$-EOR in 10 U.S. Basins .................... 66

10.2 Oil in Six U.S. Basins Recoverable by "State-of-the-Art" and "Next

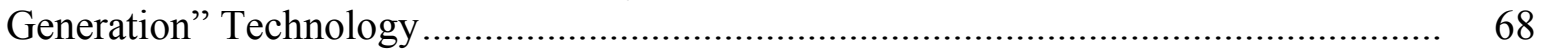

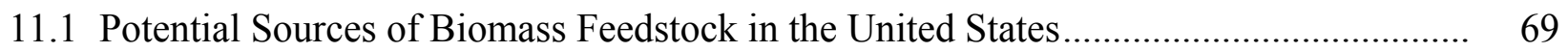

17.1 Predictions of the Timing of Global Oil Peaking from a Dozen Sources..................... 94

18.1 Key Attributes of Global Energy Scenarios Compared with History.......................... 101

18.2 Hydrocarbon Reserves and Resources (Energy in zetajoules $=10^{21}$ joules) .............. 103

19.1 Countries Whose Oil Production Had Peaked before 2006..................................... 111

20.1 USGS 2000 Estimates of Ultimate Oil and Petroleum Resources............................. 116

21.1 Regions, Sectors and Factors Represented in the EPPA Model .............................. 126

24.1 Impacts of Oil Prices in the 2006 AEO Projections ........................................... 143 


\section{ACRONYMS}

ACT

AEO

AMIGA

BP

C

CAFE

CBD

CGE

CHP

$\mathrm{CO}$

$\mathrm{CO}_{2}$

COE

CRA

CTL

DOE

E-GRID

EJ

EIA

EIO-LCA

EOR

EPA

EPPA

ETP

EU

FSU

GDP

GNP

GREET

GtC

HEV

ICEV

IEA

IEO

IIASA

I/O

IPCC

LAM

LCA

LDV

LPG

MAGICC

MARKAL/TIMES

MARS
Accelerated Adoption of Advanced Technologies

Annual Energy Outlook

All-Modular Industry Growth Assessment

British Petroleum

Celsius

Corporate Average Fuel Economy

Central Business District

Computable General Equilibrium

Combined Heat and Power

Carbon monoxide

Carbon Dioxide

Certificate of Entitlement

Charles River Associates, International

Coal-to-liquids

U. S. Department of Energy

Electricity Grid

Exa-joule

Energy Information Administration

Economic Input-Output, Life Cycle Assessment

Enhanced Oil Recovery

U.S. Environmental Protection Agency

Emissions Prediction and Policy Analysis

Energy Technology Prospectives

European Union

Former Soviet Union

Gross Domestic Product

Gross National Product

Greenhouse Gases, Regulation Emissions, and Energy

Use in Transportation

Gigatons C

Hybrid Electric Vehicle

Internal Combustion Engine Vehicle

International Energy Agency

International Energy Outlook

Institute for Applied Systems Analysis

Input/Output

Intergovernmental Panel on Climate Change

Latin America

Lifecycle Analysis

Light-Duty Vehicle

Liquid Petroleum Gases

Model for the Assessment of Greenhouse Gas Induced Climate Change

MARKet ALlocation/The Integrated MARKAL-EFOM System

Macro Analysis of Refining System 


\begin{tabular}{|c|c|}
\hline MEA & Middle East and North Africa \\
\hline $\mathrm{MCF}$ & Million Cubic Feet \\
\hline MIT & Michigan Institute of Technology \\
\hline MMBO & Million Barrels of Oil \\
\hline NEMS & National Energy Modeling System \\
\hline NCGA & National Corn Growers Association \\
\hline NGCC & Natural Gas Combined Cycle \\
\hline NGL & Natural Gas Liquids \\
\hline $\mathrm{NO}_{\mathrm{X}}$ & Nitrogen Oxides \\
\hline NPV & Net Present Value \\
\hline OECD & Organization for Economic Cooperation and Development \\
\hline OMV & Open Market Value \\
\hline OPEC & Organization of the Petroleum Exporting Countries \\
\hline OS & Oil Sands \\
\hline PAO & Pacific OECD \\
\hline ppm & Parts per Million \\
\hline PPP & Purchasing Power Parity \\
\hline $\mathrm{R} \& \mathrm{D}$ & Research and Development \\
\hline RDM & Robust Decision Making \\
\hline RFF & Resources for the Future \\
\hline $\mathrm{R} / \mathrm{P}$ & Reserve-to-Production \\
\hline REMI & Regional Economic Models, Inc. \\
\hline $\mathrm{RS}$ & Reference Scenario \\
\hline RFG & Reformulated Gasoline \\
\hline SAGE & System for the Analysis of Global Energy Markets \\
\hline SAIC & Science Applications International Corporation \\
\hline SMP & Sustainable Mobility Project \\
\hline $\mathrm{SO}_{2}$ & Sulfur Dioxide \\
\hline $\mathrm{SO}_{\mathrm{X}}$ & Sulfur Oxides \\
\hline TCF & Trillion Cubic Feet \\
\hline U.K. & United Kingdom \\
\hline UN & United Nations \\
\hline U.S. & United States \\
\hline USGS & U. S. Geological Survey \\
\hline VMT & Vehicle Miles Traveled \\
\hline VOC & Volatile Organic Compound \\
\hline WBCSD & World Business Council for Sustainable Development \\
\hline WEC & World Energy Council \\
\hline WEO & World Energy Outlook \\
\hline WTW & Well-to-wheel \\
\hline
\end{tabular}




\section{ACKNOWLEDGMENTS}

The editor gratefully acknowledges the invaluable contributions made by the participants of this workshop, and thanks them for reviewing the summaries of their presentations. Any remaining errors are the responsibility of the editor.

As workshop chair, the editor is pleased to acknowledge the members of the workshop steering committee who deserve the credit for structuring the workshop, as well as identifying and recruiting speakers: Guy Caruso, Energy Information Administration; Sarah Dunham, Environmental Protection Agency; Jae Edmonds, Pacific Northwest National Laboratory; Dolf Gielen, International Energy Agency; Arnulf Grübler, Institute for Applied Systems Analysis (IIASA); and Paul N. Leiby, Oak Ridge National Laboratory

The editor also thanks the sponsors of this workshop, John Davidson and Keith Sargent of the U.S. Environmental Protection Agency and Philip Patterson of the U.S. Department of Energy. Additional support provided by Oak Ridge National Laboratory, the Battelle Memorial Institute, UT-Battelle, LLC and the Pew Center on Global Climate Change is gratefully acknowledged. The views expressed in this document are not necessarily endorsed nor disavowed by those agencies.

The editor also thanks Debbie Bain, Sheila Moore and Janet Hopson for ensuring that the workshop ran smoothly and efficiently. Debbie Bain is also owed a debt of gratitude for the preparation of this manuscript. 


\section{REFLECTIONS ON THE WORKSHOP}

\section{David L. Greene, Oak Ridge National Laboratory, Editor}

This workshop's premise, that the global energy system faces sweeping changes in the next few decades with potentially critical implications for the global economy and the global environment, seems to have been generally accepted by the participants. But there is far less agreement about the key questions raised by a transition from conventional oil. When will it occur? Will it be sudden and disruptive or gradual and orderly? How will it affect global greenhouse gas emissions? Will local and regional environmental issues interfere with the expansion of alternative energy sources? Will it help or hurt energy security? How will the developing world cope with the transition?

A good deal of the disagreement is because we are asking complex questions about the future, and the future is inherently uncertain. But this workshop has also revealed that we do not have the analytical tools necessary to predict, analyze and plan for such a massive change in the global energy system. The analytical tools at our disposal are not able to provide satisfactory answers to many of the important questions about a transition from conventional oil.

In general, oil resource models can be divided into two classes: (1) Hubbertian peaking models, and (2) economic resource depletion models. The Hubbertian models are essentially deterministic, driven by data on oil discoveries, the history of production, and estimates of ultimate oil resources in each oil-bearing region. Hubbertian models imply but do not explicitly model a compounding rate of capital investment that would be required to continue increasing the rate of oil production once a region passes its production peak. The economic resource depletion models treat ultimate oil resources as a pool that supply functions dip into to deliver oil to the market. Functions may be calibrated to raise the cost of oil recovery as resources are depleted but there is no explicit modeling of geologic factors that might limit the rate of production as regions are depleted, nor is there an explicit modeling of the capital investment that would be required to maintain or increase rates of extraction as resources are depleted.

This appears to be the key methodological issue for modeling oil depletion or oil peaking: what does it take to achieve a given rate of oil production from an oil region as a function of its state of depletion? Those on opposing sides of the peak oil debate agree on a great many things. They agree that reserve growth occurs, but they differ on the rate at which reserve growth can add to existing resources. They agree that technological advances in exploration and development can expand the realm of economical oil resources and reduce costs but they disagree on whether the rate of change can keep up with depletion once $50 \%$ of the oil in a reservoir has been produced. They agree that substantial amounts of conventional oil remain to be discovered but they disagree about how much and how quickly it can be brought to market.

There is clearly a gap between the peak oil models and the economic resource depletion models. The gap might be filled by an explicit modeling of the investment required to maintain or increase the rate of production from reservoirs as a function of their state of depletion. Such a model seems possible and could greatly reduce the scope for disagreement and lead to a better understanding of the timing and rate of the oil transition. 
Rates are the critical factors in the oil transition. At what rate can oil production be expanded (at what rate will it decline)? At what rate will demand grow (at what rate will it be destroyed)? At what rate can alternative energy resources be brought on line? At what rate will technology advance? Modeling rates is inherently more difficult than modeling levels. In addition, rates of change during normal circumstances may not be representative of rates of change for a system under stress. The rates at which change will occur in a crisis may be far higher than the rates observed during normal periods.

Technological change, which is critical to understanding how the global energy system will respond and adapt to the oil transition, is extremely complex and poorly understood. Technological change affects all aspects of an oil transition from the quantity and cost of conventional resources to the quantity and cost of alternatives and their environmental impacts. In such circumstances, technological pessimism may seem a prudent assumption, but it is almost certainly incorrect. Given sufficient technological change, the oil transition might well be driven by preference rather than scarcity. Models of learning-by-doing, though widely used, are essentially descriptive rather than predictive. At present, there are no adequate tools for predicting which technologies will succeed or at what rate they will improve once introduced into the market.

Another critical area in which existing modeling methods appear to be deficient is modeling disrupted markets and disruptive changes. Yet if global energy markets are surprised by oil peaking, energy markets will almost certainly be disrupted. What will the consequences be? It does not appear that existing models are adequate to predict the consequences of a disruptive transition for world economic growth and to understand what might be done to mitigate the damage.

Finally, it appears that there will be significant local and regional environmental and social impacts of the massive energy developments that are likely to be necessary to avoid large-scale demand destruction during an oil transition. Local and regional objections to these impacts could slow or halt their development. Existing models do not appear to be able to predict these impacts or analyze options for mitigation.

Modeling the oil transition presents significant methodological challenges for energy analysts. Although existing energy models can provide many useful insights, fundamental questions about the timing, rate and nature of the transition remain unanswered. This workshop has taken an initial step toward a deeper understanding of the issue by surveying the current state of knowledge and by identifying the key challenges that remain. 


\section{ABSTRACT}

The global energy system faces sweeping changes in the next few decades, with potentially critical implications for the global economy and the global environment. It is important that global institutions have the tools necessary to predict, analyze and plan for such massive change. This report summarizes the proceedings of an international workshop concerning methods of forecasting, analyzing, and planning for global energy transitions and their economic and environmental consequences. A specific case, it focused on the transition from conventional to unconventional oil and other energy sources likely to result from a peak in non-OPEC and/or global production of conventional oil. Leading energy models from around the world in government, academia and the private sector met, reviewed the state-of-the-art of global energy modeling and evaluated its ability to analyze and predict large-scale energy transitions. 
PART 1

IDENTIFYING THE ISSUES 


\title{
1. KEYNOTE: GLOBAL OIL RESOURCES
}

\author{
Peter McCabe \\ United States Geological Survey
}

Some predict the sudden "end of oil" followed by dire consequences for global society. Others, particularly energy companies, foresee continued abundance. Which is correct? In the workshop's opening presentation, Dr. Peter McCabe, senior research geologist with the U.S. Geological Survey (USGS) reviewed the geology of world oil resources. While geologic facts alone cannot provide a definitive answer to the question of future oil supplies, they are an essential foundation for analyses of the subject.

The global economy is consuming vast quantities of oil at an increasing rate. By 1995, the world had consumed 710 billion barrels of oil according to the USGS 2000 assessment. By 2005 the world had consumed a total of 979 billion barrels: 269 billion barrels; more than $25 \%$ of all the oil ever consumed was consumed in the last ten years. How much is left and how long will it last?

The concept of the resource pyramid (Figure 1.1) is useful for understanding the nature of oil resources. At the top are the most easily discovered and extracted resources. Over time, technological advances make more and more of the pyramid available to the world economy at an affordable cost. Both resource and reserve numbers measure inventory, not the ultimate resource, in that both concepts are premised on the technological practicality and economic affordability of extraction and use now or in the near future. U.S. oil reserve estimates, for example, have stood at twelve times annual production for nearly a century. This reflects the fact that the industry requires approximately twelve years of inventory for efficient operation. The most recent, striking example of how the resource pyramid works is the incorporation of Canadian oil sands (OS) into reserve estimates.

However, the central question is how large future resources will be and at what date? In its 2000 Oil Inventory study, the USGS arrived at mean estimates of cumulative world production of 539 billion barrels, remaining reserves of 859 billion barrels, undiscovered conventional oil of 649 billion barrels and reserve growth of 612 billion barrels. Undiscovered oil resources are estimated by means of geologic analogs to better known basins. The potential contributions of four key resource categories must be considered: (1) Reserve Growth, (2) Conventional in Small Fields, (3) Conventional Frontier, and (4) Unconventional Oil Resources. 


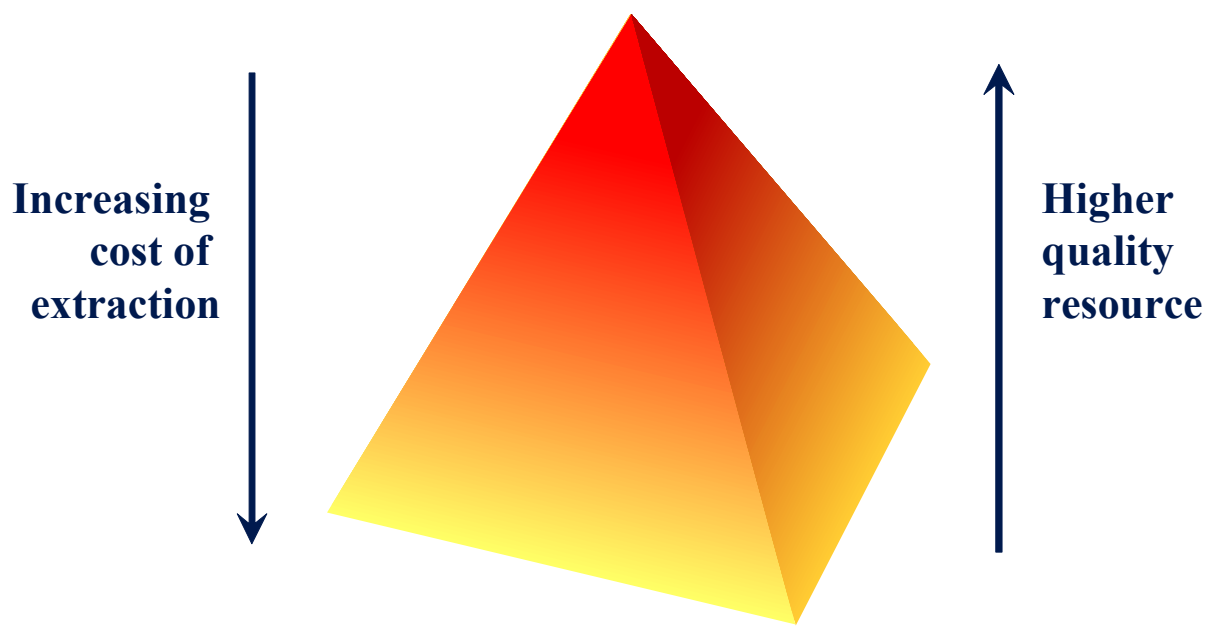

Figure 1.1 The Resource Pyramid

Reserve growth occurs as the full stratigraphic and geographic extent of newly discovered fields is learned in the process of producing oil. Technological advances during the life of a field in both exploration and production methods further increase the amount of oil recoverable. Finally, there is a tendency, albeit one that varies from country to country, for initial estimates to be conservative for political, financial or other reasons. Reserve growth in the United States is well documented. Over the past 15 years $86 \%$ of additions to reserves were the result of reserve growth, not new discoveries. Reserve growth is a worldwide phenomenon, as well. Reserve growth in giant fields ( $>500$ million barrels of oil (MMBO)) outside the United States and Canada amounted to 160,385 MMBO from 1981 to 1996 , more than one fourth of the total reserves of these fields in 1981 (an average rate of growth of 1.55\%/year). Data from the North Sea oil fields indicate an even faster rate of reserve growth (approximately $3 \%$ per year). Certainly discoveries of new oil have been declining significantly and consistently (Figure 1.2) but reserve growth has offset these declines by making existing oil resources larger.

The main problem with the world's remaining oil resources is less how much oil exists but rather who controls it and where it is located. The median age of a country's population can be used as an indicator of stability: the younger the country, the less stable. By this metric, most of the world's conventional oil is in countries with median ages of 26 or less. In addition, most of the world's oil resources are owned not by international energy companies but rather by national oil companies that do not act as competitive producers in an open market. Less than three percent of the world's proven reserves of conventional oil are owned by ExxonMobil, British Petroleum (BP), Total, Chevron and Shell combined. The vast majority is controlled by Organization of the Petroleum Exporting Countries (OPEC). The "call on OPEC," the quantity of projected worldwide demand that cannot be met by non-OPEC producers, is expected to grow dramatically over the next 25 years (Figure 1.3). There is substantial potential for finding oil in non-OPEC countries as well as for reserve growth, and hence non-OPEC production will plateau rather than peak, still leaving a widening gap between growing world demand and non-OPEC supply. 
Discovered Oil - Billions of barrels

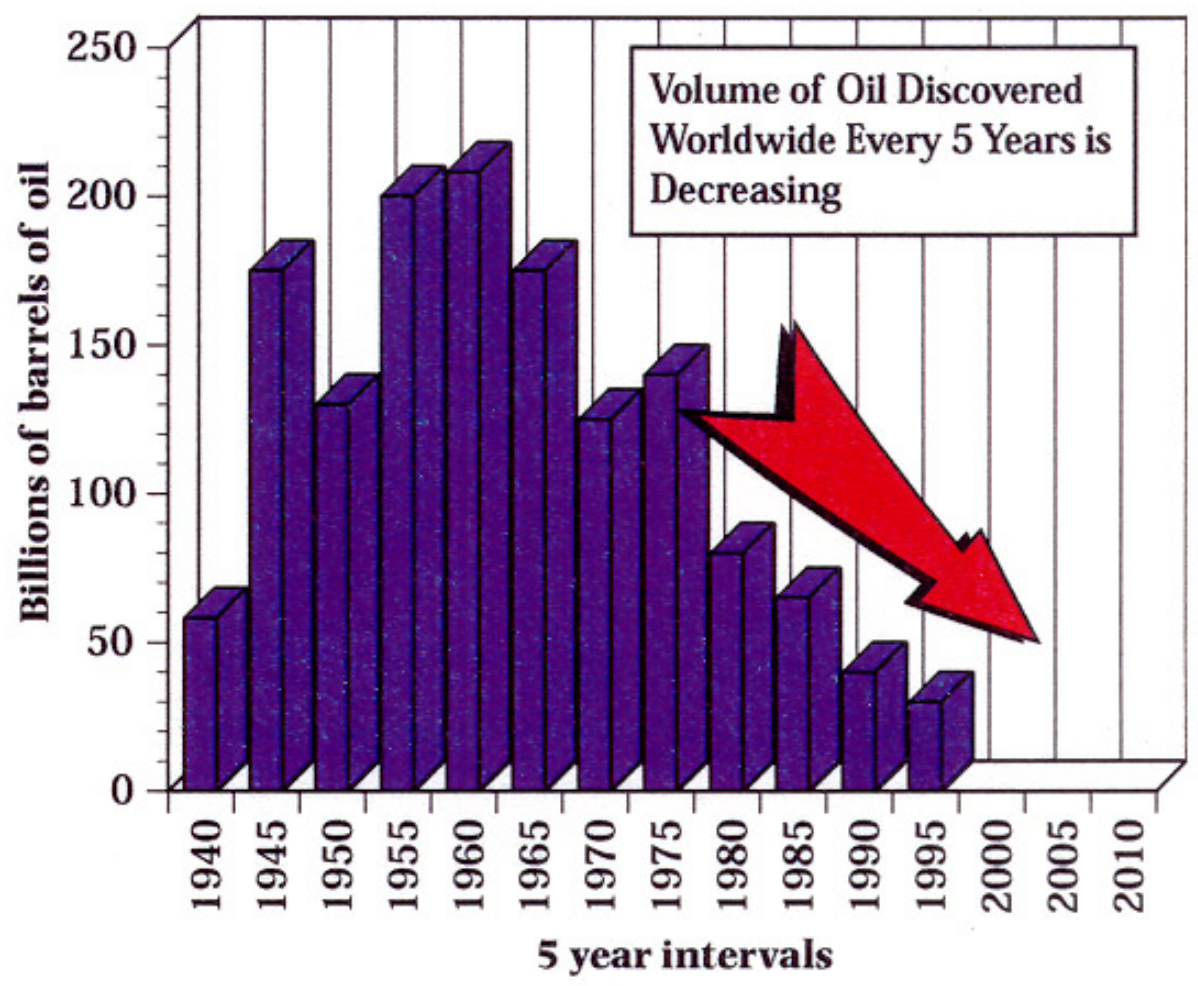

Figure 1.2 World Oil Discoveries by 5-Year Intervals, 1945-2000

\section{Call on OPEC}

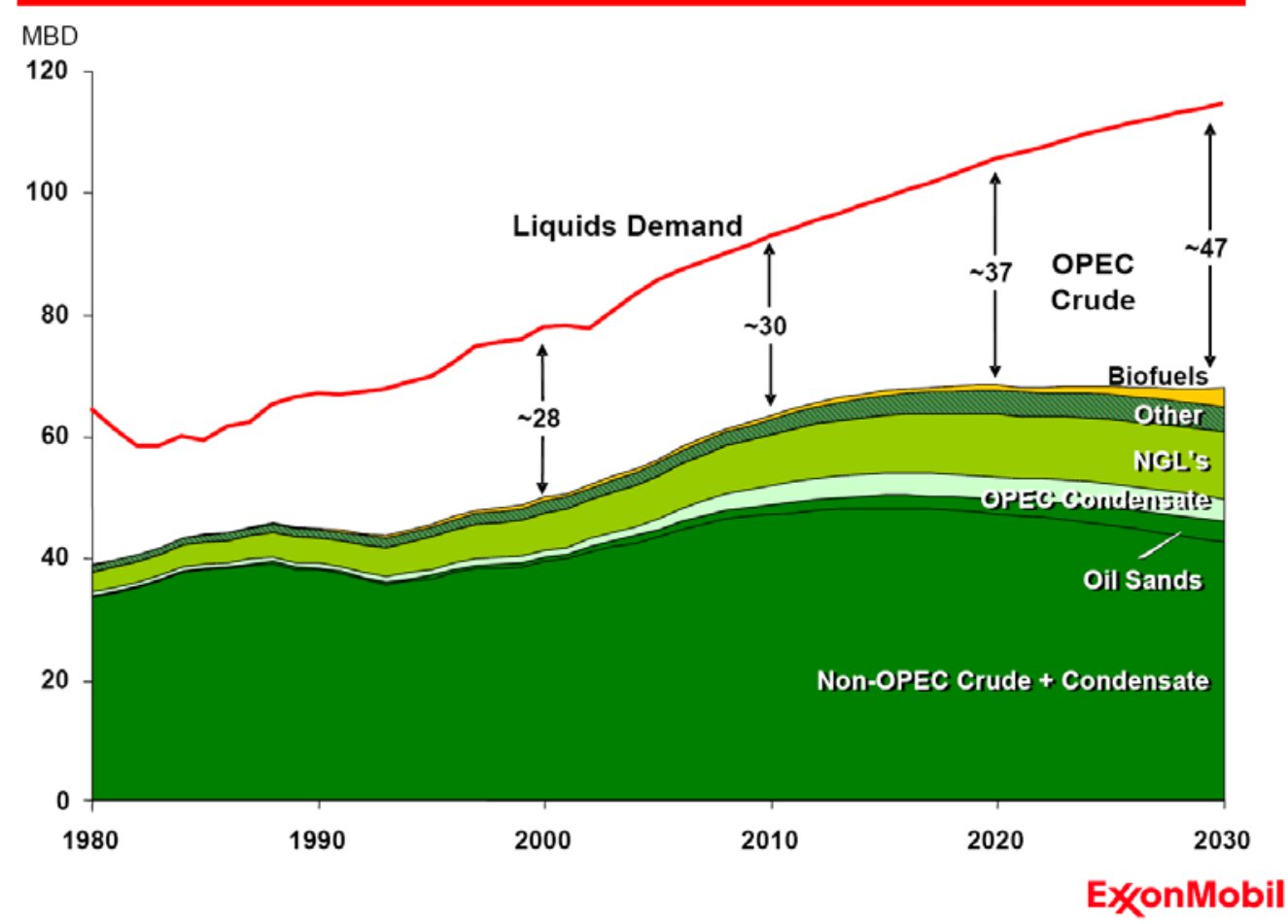

Figure 1.3 ExxonMobil's Outlook for World Oil Supply to 2030 and the "Call on OPEC" 
There are also promising frontier regions where significant oil discoveries are likely: the Arctic, South America, the Indian Ocean and Australasia. Many major basins around the arctic have not yet been drilled. How much oil these regions produce will be primarily determined by the price of oil and whether society allows exploration and drilling in these remaining frontier areas.

In conclusion, there is a substantial amount of conventional oil remaining. In addition, increasing amounts of unconventional oil are becoming conventional (i.e., economic). For these reasons, world oil production will not soon reach a peak. But there are serious problems. Most of the world's oil supplies are in politically unstable countries and are controlled by national oil companies that do not behave as competitive market agents. Thus, oil supply will present a continuing challenge for the global economy. 


\title{
SESSION 1: ISSUES IN THE GLOBAL ENERGY TRANSITION FROM CONVENTIONAL OIL
}

David L. Greene, Oak Ridge National Laboratory, Chair

\section{ECONOMIC EFFECTS OF THE PEAKING OF CONVENTIONAL OIL SUPPLY}

\author{
Hill Huntington \\ Energy Modeling Forum, Stanford University
}

The question of whether or not the world's economy is about to run out of a certain resource and what the impacts would be has come up repeatedly throughout economic history and that history can provide a useful perspective for the current debate about peak oil.

Oil peaking may not be about resource scarcity. The peak and decline in the use of any resource can be driven by the emergence of superior alternatives or by changes in the technologies that use energy. Rising prices can also produce temporary or permanent peaks in resource use. For example, from 1980 to 1985 world oil consumption declined in response to greatly increased oil prices (Figure 2.1). However, world oil consumption increased again when prices fell in 1986.

World Consumption Trends (MMBD Change from 1980 or 2000)

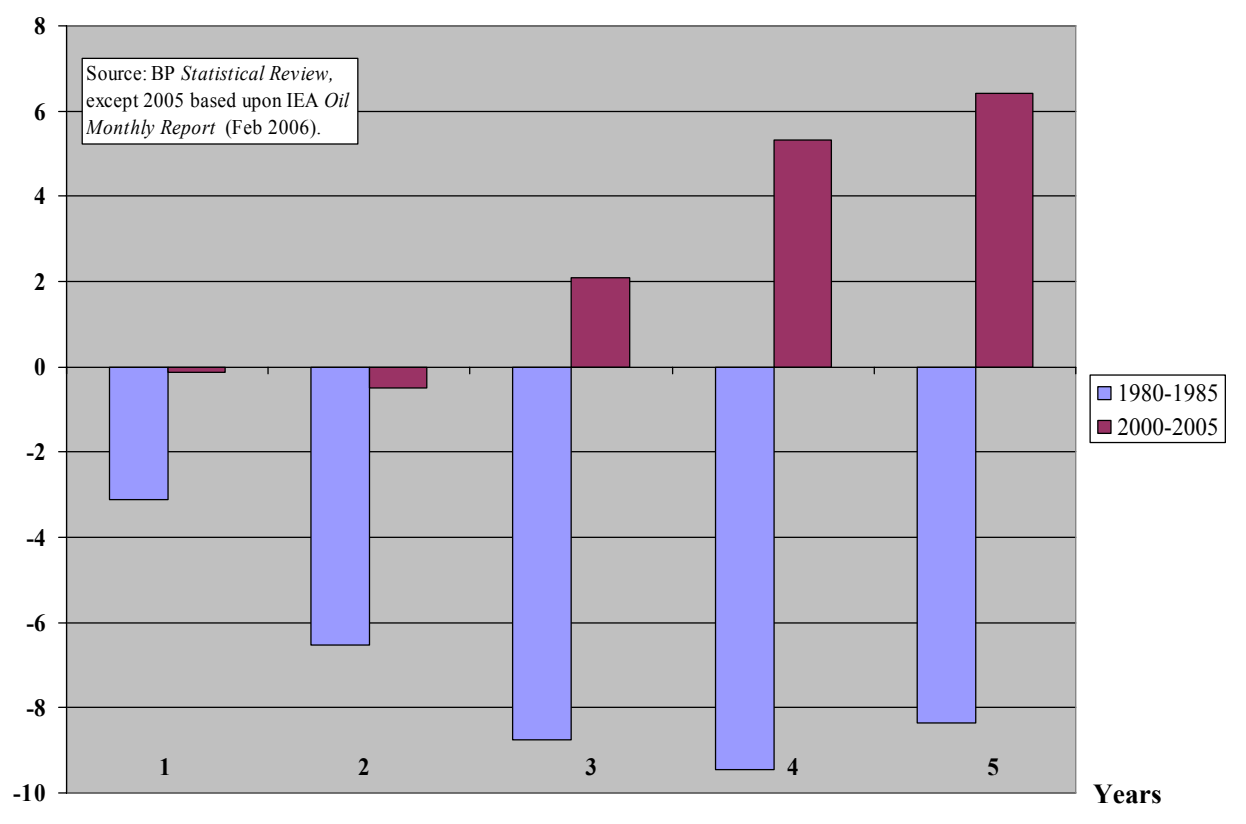

Figure 2.1 Changes in World Oil Consumption since 1980

When viewed from an economic perspective, there can be several peaking concepts. Peaking of the total quantity of oil produced and consumed, the focus of this workshop, is only one of them. Per capita consumption may peak, as may oil as a share of total energy use. Each peaking concept has a different meaning. Oil as a share of total energy may have already peaked, possibly 
reflecting an underlying trend that may lead to an eventual peaking of total oil use unrelated to resource scarcity (Figure 2.2).

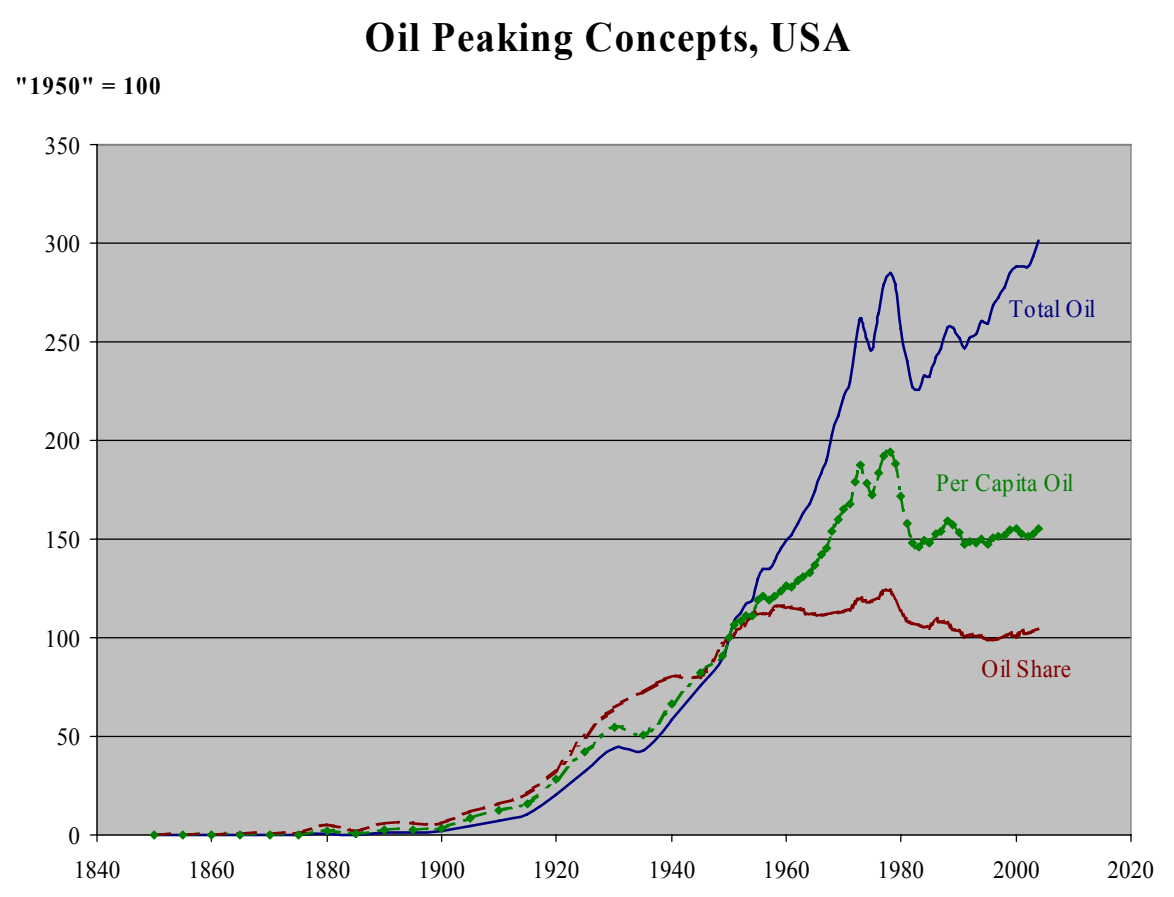

Figure 2.2 Three Oil Peaking Concepts: U.S. Statistics

With respect to the economic consequences of an oil peak, these will depend on whether the peak is gradual and the transition smooth, or whether it is disruptive. Significant changes in oil prices and availability harm the economy in three ways:

1. by reducing purchasing power in international markets;

2. by lowering productivity by reducing energy use; and

3. by temporarily depressing economic activity through macroeconomic frictions, such as,

a. idling capacity in key sectors (e.g., automobiles),

b. wage and price stickiness causing underemployment of resources, and

c. scary energy price shocks causing misallocation of resources.

Even today it is not clear precisely how sensitive the economy is to changes in oil prices. As the oil share of energy declines, it is most likely that the impacts of oil prices on the economy decrease.

The economic impacts of an oil transition may be small if the transition is gradual rather than abrupt. The period in which coal production peaked was a period of rapid economic growth (with the exception of WW I). This transition was driven by technological change and the availability of plentiful and inexpensive oil. In this sense, the transition from conventional oil may have already begun, as unconventional substitutes such as Canadian OS, are entering the market on at competitive prices. There is good reason for optimism as long as we allow the market system to function and avoid a policy panic. 


\title{
3. WHAT CAN WE EXPECT FROM OPEC?
}

\author{
Dermot Gately \\ New York University
}

A revised and more detailed version of Professor Gately's presentation will appear in a forthcoming issue of The Energy Journal.

Understanding how the OPEC cartel will act in future world oil markets is critical to understanding the potential impacts of oil peaking and even to determining whether and when oil production will peak. What can be expected from OPEC and its key producers over the next 25 years, and what are the implications for world oil supplies and oil prices? The U.S. Department of Energy's (DOE's) National Energy Modeling System (NEMS) and the International Energy Agency's (IEA) World Energy Outlook (WEO) estimate future OPEC supply as the difference between world oil demand and rest-of-world oil supply at a given oil price. This approach contains almost no information about how the most critical agents in the world oil market will shape its future.

To understand how OPEC is likely to act in the future, three key questions must be answered:

1. What oil output path makes OPEC best off under given assumptions about the world oil market?

2. What output strategy is robustly optimal, so that it will serve OPEC well relative to other strategies regardless of the underlying assumptions about the world oil market?

3. Given an expected output path for OPEC, what will be the effect on OPEC behavior,

a. If the peaking of non-OPEC supplies becomes a greater concern than at present?

b. If oil reserve depletion within OPEC becomes a greater concern than at present?

Projections of world oil market trends made in 2000 by both the Energy Information Administration (EIA) and IEA were implausible because they failed to consider alternative OPEC production paths that could produce greater profits for OPEC (Figure 3.1).

As Gately (2001) demonstrated, OPEC could generate substantially more revenue by producing less oil than the "call on OPEC' method predicted. The 2006 Annual Energy Outlook (AEO) projection foresees much higher world oil prices and a much smaller call on OPEC. The 2003 AEO Reference Case Projection indicated OPEC production increasing at an average annual rate of $3.5 \%$ per year to double its 2005 level by 2025. The 2006 AEO, on the other hand, anticipates only a $1.4 \%$ annual rate of increase (Figure 3.2 ). 


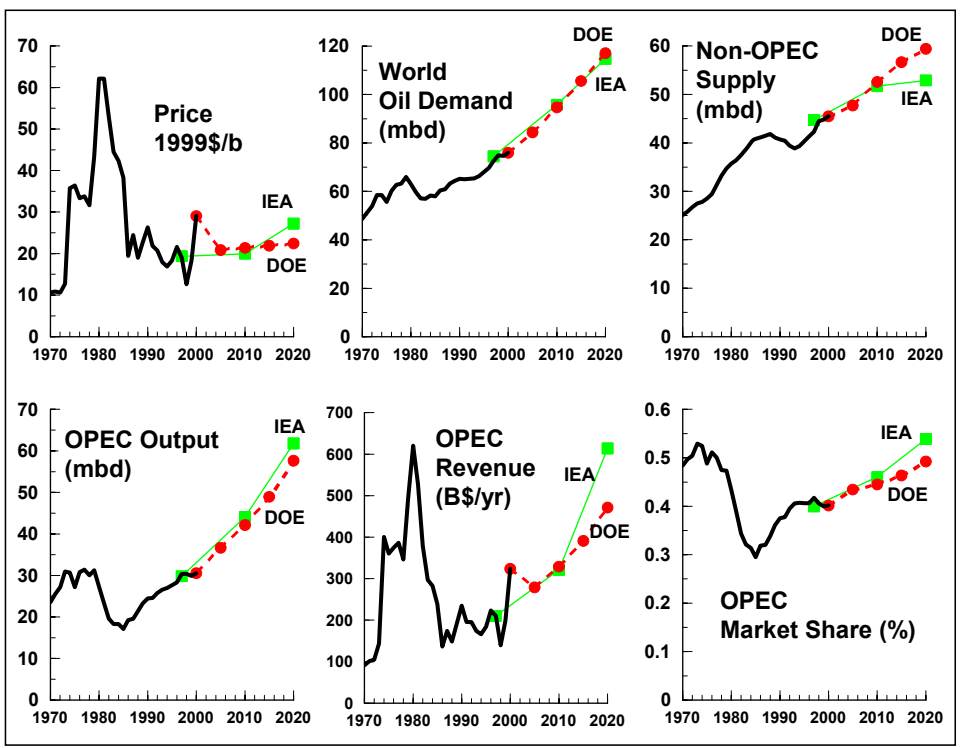

Figure 3.1 World Oil Market Projections of EIA and IEA Using Call on OPEC Method

\begin{tabular}{|c|c|c|c|c|c|c|c|c|c|} 
& \multicolumn{4}{c}{ year 2005 projection } & \multicolumn{4}{c|}{ year 2025 projection } \\
\cline { 2 - 11 } & Real Price & $\begin{array}{c}\text { World Oil } \\
\text { Demand } \\
(\mathrm{mbd})\end{array}$ & $\begin{array}{c}\text { Non-OPEC } \\
\text { Oil Supply } \\
(\mathrm{mbd})\end{array}$ & $\begin{array}{c}\text { OPEC Oil } \\
\text { Output } \\
(\mathrm{mbd})\end{array}$ & Real Price & $\begin{array}{c}\text { World Oil } \\
\text { Demand } \\
(\mathrm{mbd})\end{array}$ & $\begin{array}{c}\text { Non-OPEC } \\
\text { Oil Supply } \\
(\mathrm{mbd})\end{array}$ & $\begin{array}{c}\text { OPEC Oil } \\
\text { Output } \\
(\mathrm{mbd})\end{array}$ \\
\hline AEO 2003 & $\$ 23.27$ & 80.5 & 49.7 & 30.8 & $\mathbf{2 6 . 5 7}$ & 122.9 & 61.7 & $\mathbf{6 1 . 2}$ \\
AEO 2004 & $\$ 23.86$ & 81.9 & 50.4 & 31.5 & $\mathbf{\$ 2 7 . 0 0}$ & 117.5 & 63.9 & $\mathbf{5 3 . 7}$ \\
AEO 2005 & $\$ 33.99$ & 83.8 & 50.7 & 33.1 & $\mathbf{\$ 3 0 . 3 1}$ & 120.2 & 65.0 & $\mathbf{5 5 . 1}$ \\
AEO 2006 & $\$ 49.70$ & 84.2 & 52.0 & 32.2 & $\mathbf{\$} 47.99$ & 110.6 & 67.8 & $\mathbf{4 2 . 8}$ \\
\hline
\end{tabular}

Figure 3.2 AEO 2003-2006 Reference Case Projections of OPEC Output and Oil Prices

Is the new projection a superior strategy for OPEC? Is it robust to uncertainties about the growth rates and price-sensitivities of non-OPEC supply and world oil demand? Insight can be gained by considering three OPEC supply strategies under a range of assumptions about the growth in world oil demand and non-OPEC supply and the price elasticities of both supply and demand. The three assumptions about OPEC output are illustrated in Figure 3.3. OPEC is assumed to either maintain its market share at the current level of about $38 \%$, increase its share to $43 \%$ or decrease its share of the world oil market to $33 \%$. 


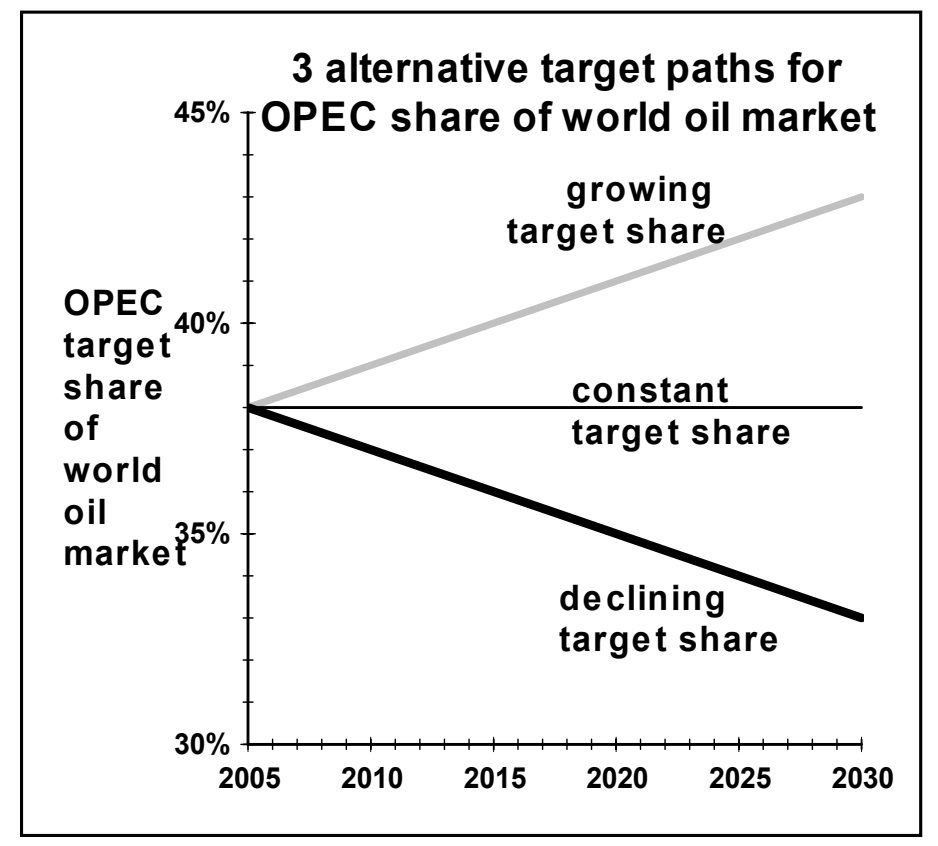

Figure 3.3 Three Alternative Paths for OPEC's Market Share

The call on OPEC can be reduced either by a faster growth of non-OPEC supply or slower growth of world oil demand. Conversely, if world oil demand grows more rapidly or non-OPEC supply grows more slowly, as it would if a peak in non-OPEC supply were imminent, then the call on OPEC will increase. World oil demand and supply elasticities may turn out to be higher or lower (especially if the response to price is constrained by oil peaking). Figure 3.4 shows the net present value (NPV) to OPEC of the three alternative output paths under a range of assumptions. In the reference case with standard assumptions (shown in the center of the table and circled in yellow), there is a slight incentive for OPEC to prefer an increased market share. If there is slower growth in non-OPEC supply (shown two graphs to the right and circled in yellow), the NPV of OPEC revenues increases substantially and the incentive to increase market share is somewhat greater. In general, a peaking of non-OPEC oil supply would lead to a higher call on OPEC, higher oil prices, and a greater incentive for OPEC to increase output. But if supply or demand are more inelastic and the call on OPEC grows more slowly (shown in the bottom left corner of Figure 3.4) reducing output could be a more profitable strategy for OPEC. 


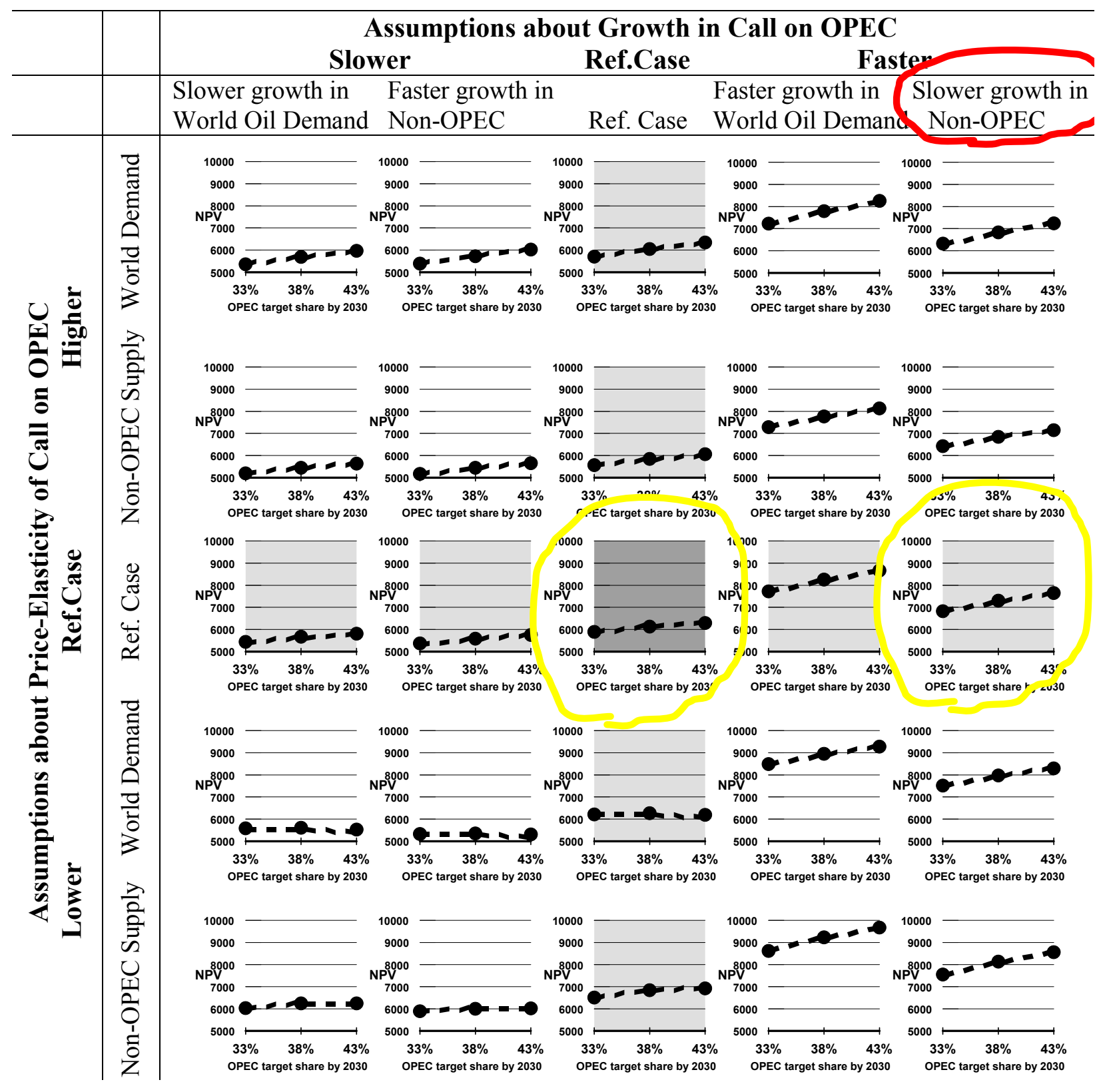

Figure 3.4 Sensitivity Analysis of Net Present Value of OPEC Revenue as a Function of Level of Output

This analysis demonstrates that it is possible to understand what future production strategies are in OPEC's best economic interest. By understanding what is in OPEC's interest we can make better predictions of future oil market conditions, including predictions of how markets will behave if oil supply outside of OPEC should peak. The most widely used and cited world energy models, however, fail to take advantage of this method of analysis. As a result, their projections shed little light on how world oil markets may react to the peaking of oil production either outside of OPEC or for OPEC as well.

The analysis presented here indicates that oil peaking outside of OPEC may have two conflicting influences on OPEC supply. By decreasing non-OPEC production, a non-OPEC oil peak will 
increase the call on OPEC, creating an incentive for OPEC to increase output. But if the peak also decreases the price-sensitivity of non-OPEC supply, that will create an incentive for OPEC to decrease its market share. In either case, the price of oil will increase versus cases in which non-OPEC supply does not peak. This result implies that it is necessary to understand not only how the quantity of non-OPEC production would be affected by peak oil, but also how the price responsiveness of non-OPEC supply would be affected as well. 


\title{
4. ENVIRONMENTAL ISSUES IN PEAKING AND TRANSITION
}

\author{
David Hawkins \\ Natural Resources Defense Council
}

"Two roads diverged in a yellow wood, and I-

I took the one less traveled by, And that has made all the difference." Robert Frost, 1920.

Moving beyond oil can have very different impacts, depending on which road the world chooses to follow. The coming transition from conventional oil to other sources of energy presents the world with two alternative paths into the future:

1. A "green" path that relies on efficient use of energy by motor vehicles, hybrids and plugin hybrids, biofuels, hydrogen produced using renewable energy or fossil energy with carbon capture and storage, as well as $\mathrm{CO}_{2}$ sequestration in enhanced oil recovery (EOR), or

2. a "brown" path that relies on a massive transition to synthetic petroleum products made from unconventional fossil fuels such as tar sands, oil shale and coal, continued reliance on corn ethanol with energy inputs from coal, or hydrogen produced from fossil fuels without carbon capture and storage.

Following the brown path will lead to intensified global warming pollution, more conventional air pollution and local impacts from massive mining operations.

The challenge of global climate change presents the world with three energy imperatives.

1. The use of fossil fuels must fit within a finite carbon emissions budget.

2. Cuts in carbon emissions of $60-80 \%$ from current levels will likely be needed this century.

3. Large reductions in transport $\mathrm{CO}_{2}$ emissions relative to petroleum fuels will be needed.

Avoiding a $2^{\circ} \mathrm{C}$ increase in global temperature is likely to require cutting $\mathrm{CO}_{2}$ emissions by 60 $80 \%$. A comprehensive, strong policy strategy could reduce U.S. carbon emissions from 1.8 gigatons $\mathrm{C}(\mathrm{GtC})$ to $0.9 \mathrm{GtC}$ by mid-century (Figure 4.1). Among the key strategies are improvements in transportation energy efficiency, increased use of renewable energy and carbon capture and storage. 


\section{Cutting U.S. emissions in half}

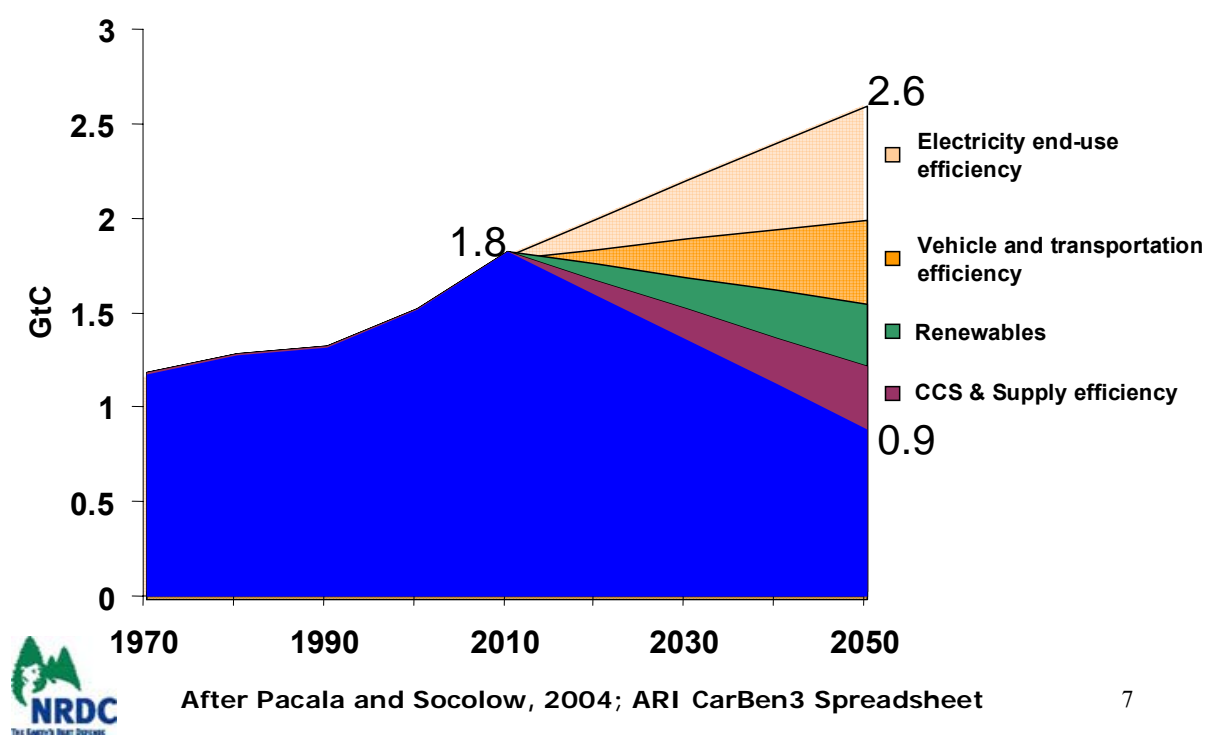

Figure 4.1 Strategy "Wedges" to Cut U.S. Carbon Emissions by Half by 2050

If the "brown" path is chosen, the use of transportation fuels made from OS, oil shale or coal-toliquids (CTL) will exacerbate the climate problem. Without carbon capture and storage, conventional fuels made from these fossil resources will have substantially higher well-to-wheel (WTW) greenhouse gas emissions than petroleum-based fuels. And even with upstream carbon capture and storage, continued use of fossil carbon based fuels may be incompatible with climate protection.

It is important that significant efforts to reduce carbon emissions from transportation begin now, in order to avoid the necessity of more expensive, crash efforts if we procrastinate. To achieve the carbon reduction goals outlined above would require a $2.4 \%$ average annual decrease in from 2010 to 2050 if programs were implemented now. Delaying until 2025 would increase the rate of reduction required to achieve the same goals to $6.9 \%$ per year.

Because existing regulatory caps on conventional pollutants do not apply to most substitute oil production, there is a risk of increasing conventional air pollution from energy production and conversion if the brown path is followed. In particular, large-scale CTL production would result in significant sulfur oxides ( $\mathrm{SOx}$ ), nitrogen oxides (NOx), particulate and mercury pollution unless stringent new standards were quickly implemented.

Large scale mining operations using current operating practices are already taking an enormous toll on the environment (Figure 4.2). The potentially vast expansion of OS, oil shale, and coal mining could produce major land and water impacts and, as a consequence, face significant local environmental opposition. 


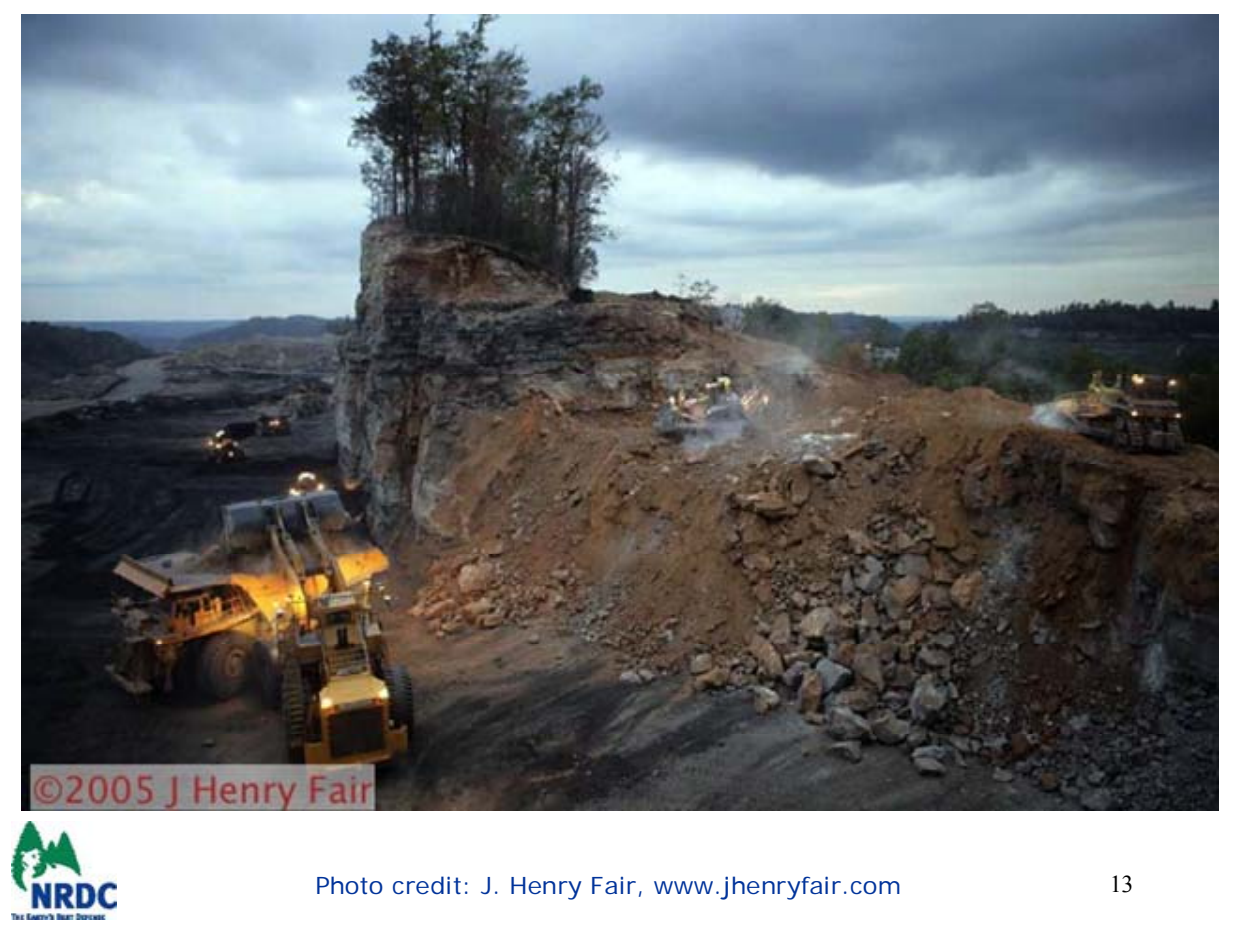

Figure 4.2 Impacts of Strip Mining on the Landscape

The transition from conventional oil forces a choice of energy path for future transportation. The path taken will have major implications for the health of the global environment. Decisions made today will lead to investments in infrastructure that will be locked in for decades. Making the right decisions now, choosing the green path, can make all the difference. 


\title{
SESSION 2: FORCES DRIVING THE TRANSITION FROM CONVENTIONAL OIL
}

\author{
Sam Baldwin, U.S. Department of Energy, Chair
}

\section{THE WORLDWIDE DEMAND FOR MOBILITY AND ITS IMPACT ON THE DEMAND FOR “CONVENTIONAL” OIL}

\author{
George C. Eads \\ Vice President, Charles River Associates International ${ }^{1}$
}

The transport sector currently accounts for approximately $60 \%$ of final oil demand - a percentage almost three times as great as the next largest end use sector. Oil-based products such as gasoline, diesel, and jet fuel account for about $98 \%$ of the energy used by the transport sector. ${ }^{2}$ Due to this close correspondence between transport oil demand and the demand for transport services, anyone seeking to understand the future evolution of the former also must understand how (and why) the demand for the latter is likely to evolve. The purpose of this paper is to provide information that will contribute to that understanding.

The tight linkage that exists today between transport demand and oil demand is not immutable. A wide range of primary energy sources can produce fuels capable of powering transportation vehicles. But fuels produced from primary energy sources other than oil are, generally speaking, more expensive than oil-based fuels, some very much so.

The linkage between transport demand and oil demand also can be weakened by improving the energy efficiency of transport systems. However, focus in this paper is on factors driving personal and goods transport demand. I won't be dealing with the transport vehicle efficiency question.

I begin by presenting a set of "reference case projections" of the growth in demand for transportation services developed by the World Business Council on Sustainable Development's Sustainable Mobility Project (SMP). ${ }^{3}$ These projections should not be viewed as forecasts of

1 This paper is based on a presentation made at a workshop, "Modeling the Oil Transition," held at Resources for the Future (RFF) on April 20-21, 2006. The workshop was sponsored by the U.S. EPA, the U.S. DOE, and RFF. Portions of the material used in this presentation were developed during research sponsored by BP plc. I want to thank BP plc. for this support and for permitting me to use this material.

2 International Energy Agency, World Energy Outlook 2004, pp. 430-431. (data for 2002)

3 The SMP was a member-led project undertaken in 1999 by a dozen WBCSD members: BP, DaimlerChrysler, Ford, General Motors, Honda, Norsk Hydro, Michelin, Nissan, Renault, Shell, Toyota, and Volkswagen. The SMP published two major reports. The first, Mobility 2001, was the joint work of Michigan Institute of Technology (MIT) and CRA International. It assessed the state of worldwide mobility at the end of the $20^{\text {th }}$ century and its sustainability. The second, Mobility 2030, was the work of the project members and was signed by their CEOs. The energy and demand projections presented in this paper were generated using a spreadsheet model developed jointly by the International Energy Agency and CRA International for the SMP. The spreadsheet model and the reference projections were benchmarked to the reference case in the IEA's World Energy Outlook 2002 (WEO2002). The projections in WEO2002 extend only through 2030. The IEA/SMP model extrapolated these through 2050. Both the reference projections and the spreadsheet model were extensively documented. This documentation, as well as the spreadsheet model itself, is available for downloading at www.sustainablemobility.org. The principal developer 
what is likely to happen. Rather they are mechanical calculations of what the demand for transport energy and the demand for transport services will be at certain points in the future "if present trends [were to] continue.",

\subsection{THE SUSTAINABLE MOBILITY PROJECT'S REFERENCE CASE PROJECTIONS OF PERSONAL AND GOODS TRANSPORT DEMAND}

The SMP projects that personal transport demand, which in 2000 totaled 32.3 trillion passengerkilometers (pkm), will grow to 74.0 trillion pkm by 2050 (Figure 5.1). ${ }^{5}$ Goods transport demand, which in 2000 totaled 14.4 trillion tonne-kilometers (tkm), will grow to 45.9 tkm (Figure 5.2). ${ }^{6}$ Increases of this magnitude and timing would reflect average annual rates of growth of $1.7 \%$ for personal transport demand and $2.3 \%$ for goods transport demand.

Figures 5.1 and 5.2 also suggest that growth in transport demand is likely to vary widely across countries/regions. At present, the majority of both personal and goods transport occurs within and/or between countries that are members of the Organization for Economic Cooperation and Development (OECD). ${ }^{7}$ However, over the next half-century, transport demand is projected to grow much more rapidly in those countries that are not presently OECD members. These higher growth rates, if achieved, imply that non-OECD personal transport demand will exceed OECD

of the spreadsheet model was Dr. Lewis Fulton of the IEA. However, neither Dr. Fulton nor the IEA is responsible for the opinions presented here or for the conclusions reached.

4 Mobility 2030 contains the following comment concerning just what the report means by the phrase "present trends continue":

"Mobility and its sustainability is the end result of a complex mix of human behavior, economic growth, and public policy. When the SMP states that its reference case projections assume that 'present trends continue,' it is assuming that this behavioral/technical/economic/policy mix continues essentially unchanged. Change, however, is occurring constantly. In order to produce a reference case, it is therefore necessary to decide what to single out as 'change' and what to include in the continuing flow of history. This does not present major difficulties when dealing with trends in human behavior and economic growth. But it is a challenge when dealing with formal and informal policy actions undertaken by governments. The promulgation of a new regulation by an authority empowered to enforce it probably qualifies as a 'change.' Just when this 'change' takes place is less clear. Informal actions by governments present an even greater challenge. Suppose a governmental authority announces that it is 'considering' promulgating a regulation or it reaches a 'voluntary agreement' with an industry that might in the future become a legally enforceable regulation. Has a 'change' occurred? If so, when has it occurred? When the announcement of intent to consider is made? When the 'voluntary agreement' is reached? In ambiguous cases, the SMP has been pragmatic. If it is likely that a possible future action already has had significant impact on a firm, an industry or consumer' behavior, it is included in our reference case. That is, it is included among the 'present trends' that are assumed to 'continue." If a future action, though possible, has not yet affected behavior significantly, it is not included in our reference case. If that action later produces a significant impact on behavior, it will be deemed a 'change' and outside our reference case. Mobility 2030, p. 27, Box 2.1 .

5 "Passenger-kilometer" (pkm) is defined as the transportation of one passenger a distance of one kilometer.

6 "Tonne-kilometer" (tkm) is defined as the transportation of one metric ton (tonne) of freight a distance of one kilometer.

7 The OECD was formed in 1961 by the following countries: Austria, Belgium, Canada, Denmark, France, Germany, Greece, Iceland, Ireland, Italy, Luxembourg, the Netherlands, Norway, Portugal, Spain Sweden, Switzerland, Turkey, the United Kingdom, and the United States. The following countries have joined subsequently: Japan (1964), Finland (1969), Australia (1971), New Zealand (1973), Mexico (1994), the Czech Republic (1995), Hungary (1996), Poland (1996), the Republic of Korea (1996), and Slovakia (2000). 
personal transport demand by about 2025. The crossover point for goods transport demand will be even sooner - about 2015.

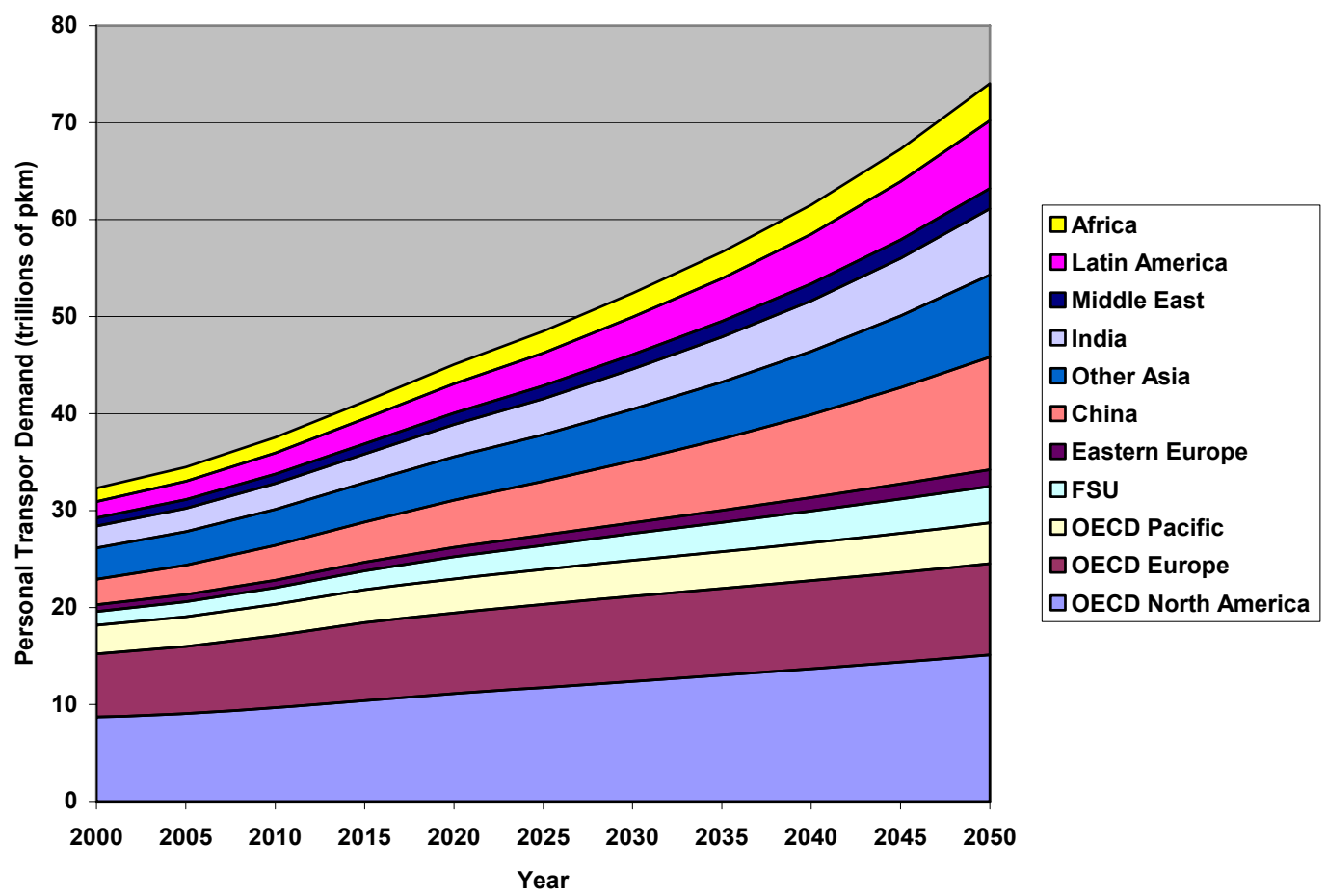

Figure 5.1 Projected Personal Transportation Demand, 2000-2050 by Country/Region (trillions of pkm)

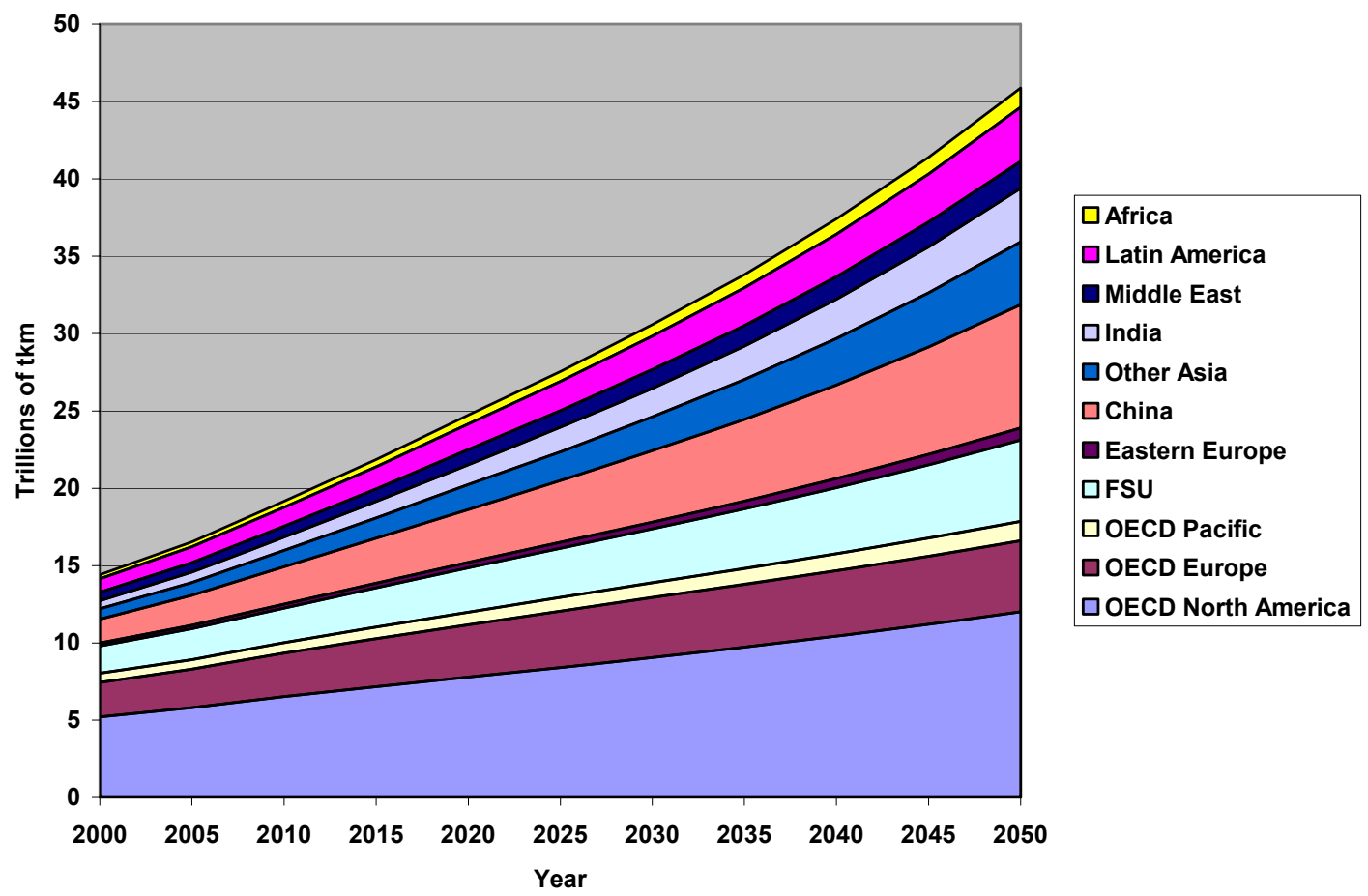

Figure 5.2 Projected Goods Transport Demand, 2000-2050 by Country/Region (trillions of tkm) 
The modal composition of transport demand growth also will vary (Figures 5.3 and 5.4). For the OECD countries as a group, demand growth for nearly all modes is projected to be less than one percent per year. Air transport, with a projected growth rate of $2.5 \%$ per year, is the most conspicuous exception. The modal growth rates for the non-OECD countries as a group provide a sharp contrast. In all but one case, buses demand growth is projected to exceed $2 \%$ per year and in two important cases (LDVs and air transport) it is projected to be roughly double that. By 2050 , the number of passenger kilometers generated by LDVs in the non-OECD countries will exceed that generated by LDVs in the OECD countries (20 trillion pkm vs. 16 trillion pkm.) Air transport demand will be nearly equal in the two regions -8.2 trillion pkm for the non-OECD countries vs. 8.6 trillion pkm for the OECD countries.

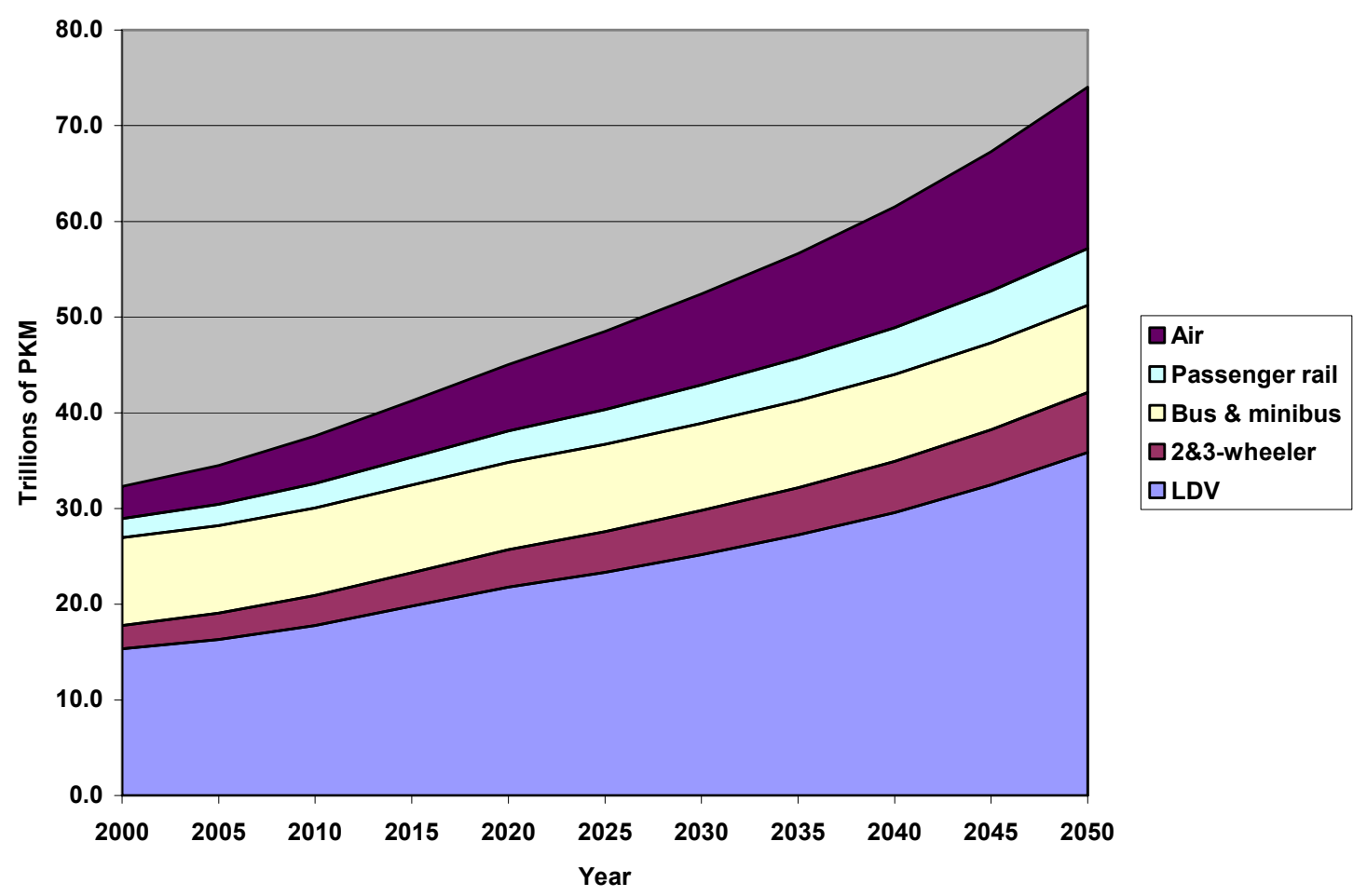

Figure 5.3 Projected Personal Transport Demand, 2000-2050 by Mode (trillions of pkm) 


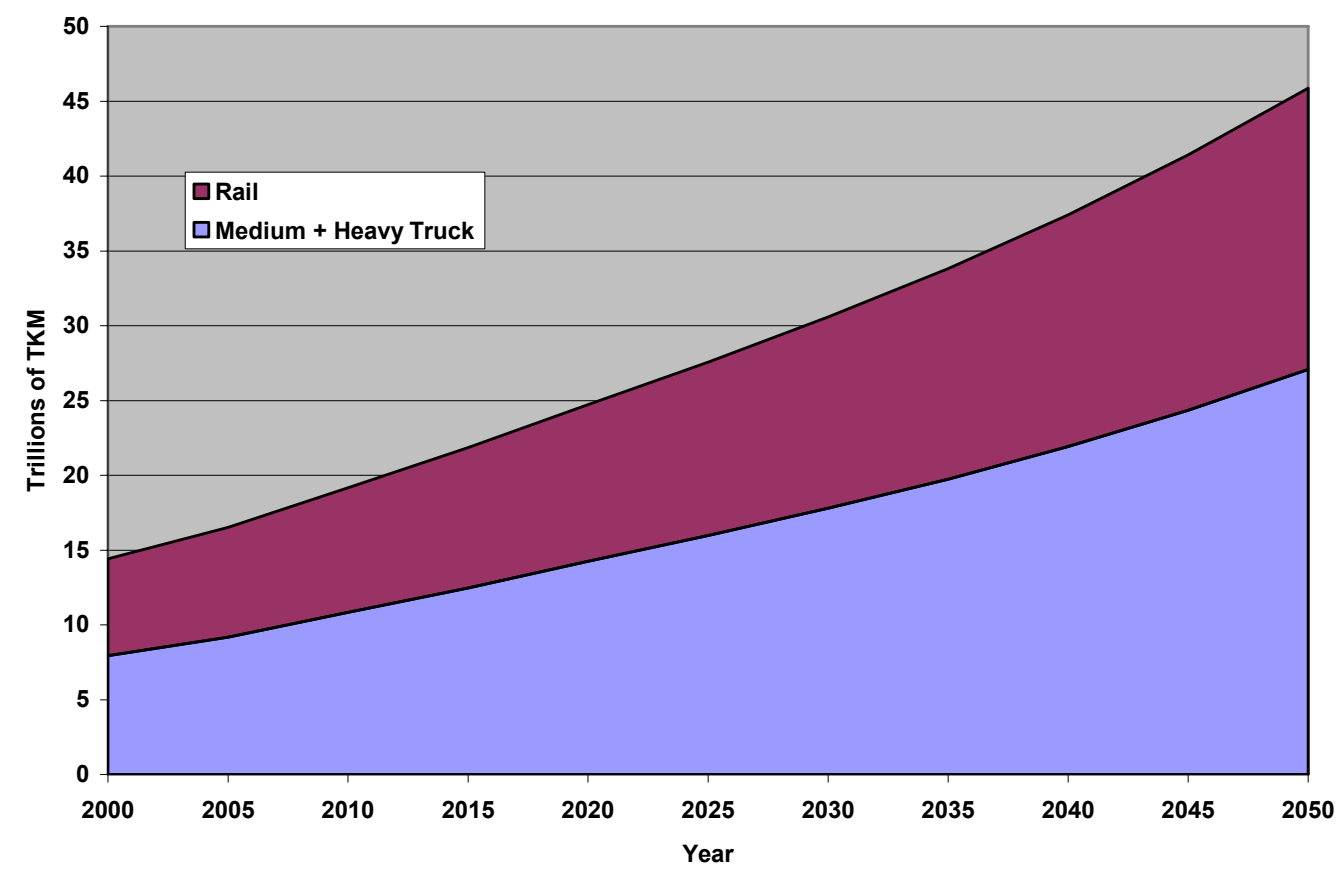

Figure 5.4 Projected Goods Transport Demand, 2000-2050 by Mode (trillions of tkm)

\subsection{DRIVERS OF TRANSPORT DEMAND GROWTH}

What lies behind these projections? While numerous factors are believed to influence the rate of growth of personal and goods transport demand, in this paper I will concentrate five major ones: (1) the level and rate of growth in real per capita income; (2) the rate of population growth; (3) the share of population residing in urban areas; (4) the residential and employment composition of urban areas ("urban form"); and (5) the level and composition of outlays that households devote to the purchase of transportation services.

\subsubsection{The Level and Rate of Growth of Real per Capita Income}

Transportation demand both drives and is driven by the level and the rate of growth of a country's real per capita income. This should not be surprising. Transportation services are a major enabler of economic growth. And as people become wealthier, they find more reasons to travel.

In 2000, the average level of real per capita gross domestic product (GDP) ${ }^{8}$ of the OECD countries as a group was 6.3 times the average level of real GDP per capita of the non-OECD countries as a group. (Table 5.1) Over the next 50 years, the size of this gap is projected to

8 The GDP figures Table 5.1 are adjusted for differences in purchasing power among countries (i.e., they are reported on a Purchasing Power Parity, or PPP, basis) and are also corrected for inflation (i.e., they are "real" as opposed to "nominal.") 
narrow, with non-OECD country economic growth being projected to average more than one percentage point per year greater than OECD country economic growth.

Table 5.1 Level and Growth in Real GDP per Capita, Actual 2000 and Projected 2025 and 2050, US\$ (000), PPP Basis

\begin{tabular}{|c|c|c|c|c|c|}
\hline & 2000 & 2025 & 2050 & AAGR 2000-2025 (\%) & AAGR 2025-2050 (\%) \\
\hline OECD North America & $\$ 26.0$ & $\$ 35.9$ & $\$ 47.2$ & $1.30 \%$ & $1.10 \%$ \\
\hline OECD Europe & $\$ 18.8$ & $\$ 30.7$ & $\$ 45.1$ & $1.99 \%$ & $1.55 \%$ \\
\hline OECD Pacific & $\$ 22.1$ & $\$ 35.7$ & $\$ 57.7$ & $1.93 \%$ & $1.94 \%$ \\
\hline OECD average & $\$ 22.0$ & $\$ 33.7$ & $\$ 48.0$ & $1.72 \%$ & $1.43 \%$ \\
\hline FSU & $\$ 5.6$ & $\$ 12.3$ & $\$ 24.4$ & $3.23 \%$ & $2.76 \%$ \\
\hline Eastern Europe & $\$ 4.6$ & $\$ 12.1$ & $\$ 29.9$ & $3.99 \%$ & $3.67 \%$ \\
\hline China & $\$ 3.8$ & $\$ 11.1$ & $\$ 27.4$ & $4.37 \%$ & $3.66 \%$ \\
\hline Other Asia & $\$ 3.3$ & $\$ 6.0$ & $\$ 10.8$ & $2.43 \%$ & $2.34 \%$ \\
\hline India & $\$ 2.2$ & $\$ 5.3$ & $\$ 11.7$ & $3.51 \%$ & $3.19 \%$ \\
\hline Middle East & $\$ 5.7$ & $\$ 6.2$ & $\$ 7.1$ & $0.32 \%$ & $0.56 \%$ \\
\hline Latin America & $\$ 6.3$ & $\$ 9.8$ & $\$ 16.1$ & $1.78 \%$ & $2.01 \%$ \\
\hline Africa & $\$ 1.9$ & $\$ 2.8$ & $\$ 4.0$ & $1.47 \%$ & $1.46 \%$ \\
\hline Non-OECD average & $\$ 3.5$ & $\$ 7.0$ & $\$ 13.1$ & $2.83 \%$ & $2.56 \%$ \\
\hline World Average & $\$ 6.9$ & $\$ 11.2$ & $\$ 17.8$ & $1.94 \%$ & $1.88 \%$ \\
\hline
\end{tabular}

Source: SMP Spreadsheet Model

Projected OECD real per capita income growth rates are clustered relatively tightly together. But the projected non-OECD average conceals major regional differences. By 2050, in several non-OECD regions - the Former Soviet Union (FSU), Eastern Europe, and China - the level of real per capita GDP is projected to exceed today's OECD average. However, real per capita GDP growth in the Middle East and Africa is projected to lag, with the gap between these two regions and the OECD regions continuing to grow. Latin America (LAM), with an average real per capita GDP in 2000 that exceeded any other non-OECD region, will manage to narrow its gap relative to the OECD countries, but only in the second quarter of the $21^{\text {st }}$ century.

Table 5.1 demonstrates that what might appear to be relatively small differences in economic growth rates between two regions can, in time, result in surprisingly large differences in the level of real per capita GDP between the regions. Consider the cases of China and India. During the period 2000 to 2050, both are projected to grow significantly faster than the OECD average. But China's real per capita GDP growth is projected to average about $0.75 \%$ per year faster than India's between 2000 and 2025 and about $0.4 \%$ per year faster between 2025 and 2050 . If this indeed occurs, India's real per capita GDP in 2050 will be only $43 \%$ of China's, compared to $58 \%$ in 2000 .

\subsubsection{The Relationship between Real per Capita Income and Personal Travel Demand}

Most analysts consider real per capita GDP growth to be the single most important "driver" of personal (and, possibly also goods) transport demand. Figure 5.5 shows the relationship between real per capita GDP and per capita personal travel in the year 2000 for the countries/regions 
included in the SMP's work. ${ }^{9}$ In 2000, the average resident of an OECD country traveled 5.7 times as many kilometers per year as did the average resident of a non-OECD country - a slightly lower ratio than the one between the average real per capita incomes of the two country groupings described in the section immediately above.

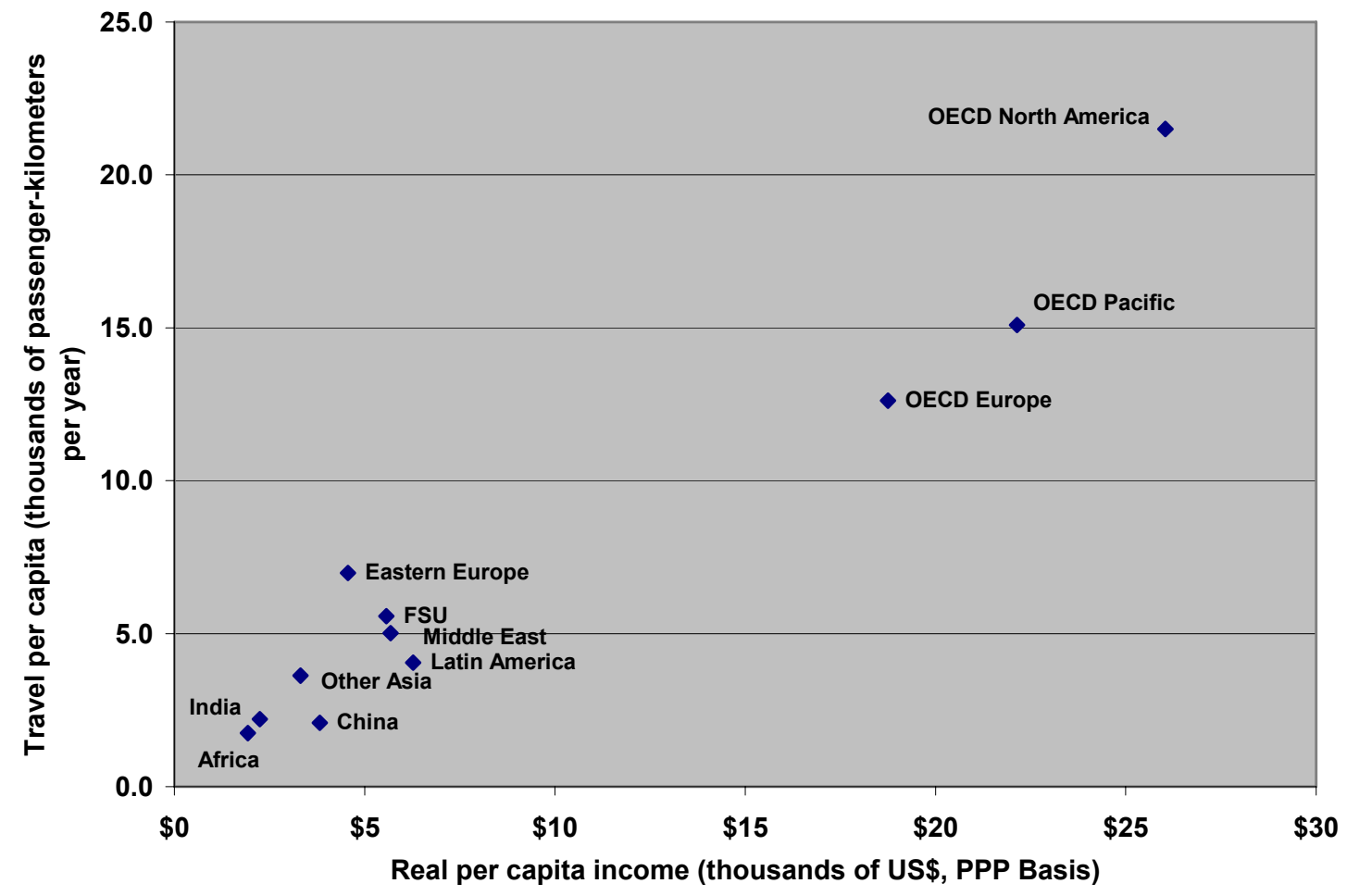

Figure 5.5 Relationship between Real per Capita Income and per Capita Personal Travel by Country/Region, 2000

Figure 5.6 shows the relationship between the projected rate of change in real per capita income and the projected rate of change in per capita personal travel over the period 2000-2050 implied by the SMP's analysis. Note the difference in the relative positions in the two exhibits of the OECD regions and those non-OECD countries/regions in which economic growth is projected to grow the most rapidly. The rapid rates of real per capita economic growth projected for China, Eastern Europe, India, and the FSU are associated with comparably-rapid rates of growth in personal travel. Over time, this causes the difference between average per capita travel demand in these particular non-OECD countries/regions and average per capita travel demand in the OECD regions to narrow significantly. If these relationships hold, by 2050 the level of per capita personal travel demand for Eastern Europe will be very close to the OECD average of that year. The gap between personal travel demand in the FSU and the OECD will have narrowed substantially.

9 We do not show similar data for goods transport demand because we lack the information on waterborne origin-destination pairs to assign that important transport activity to countries/regions. 


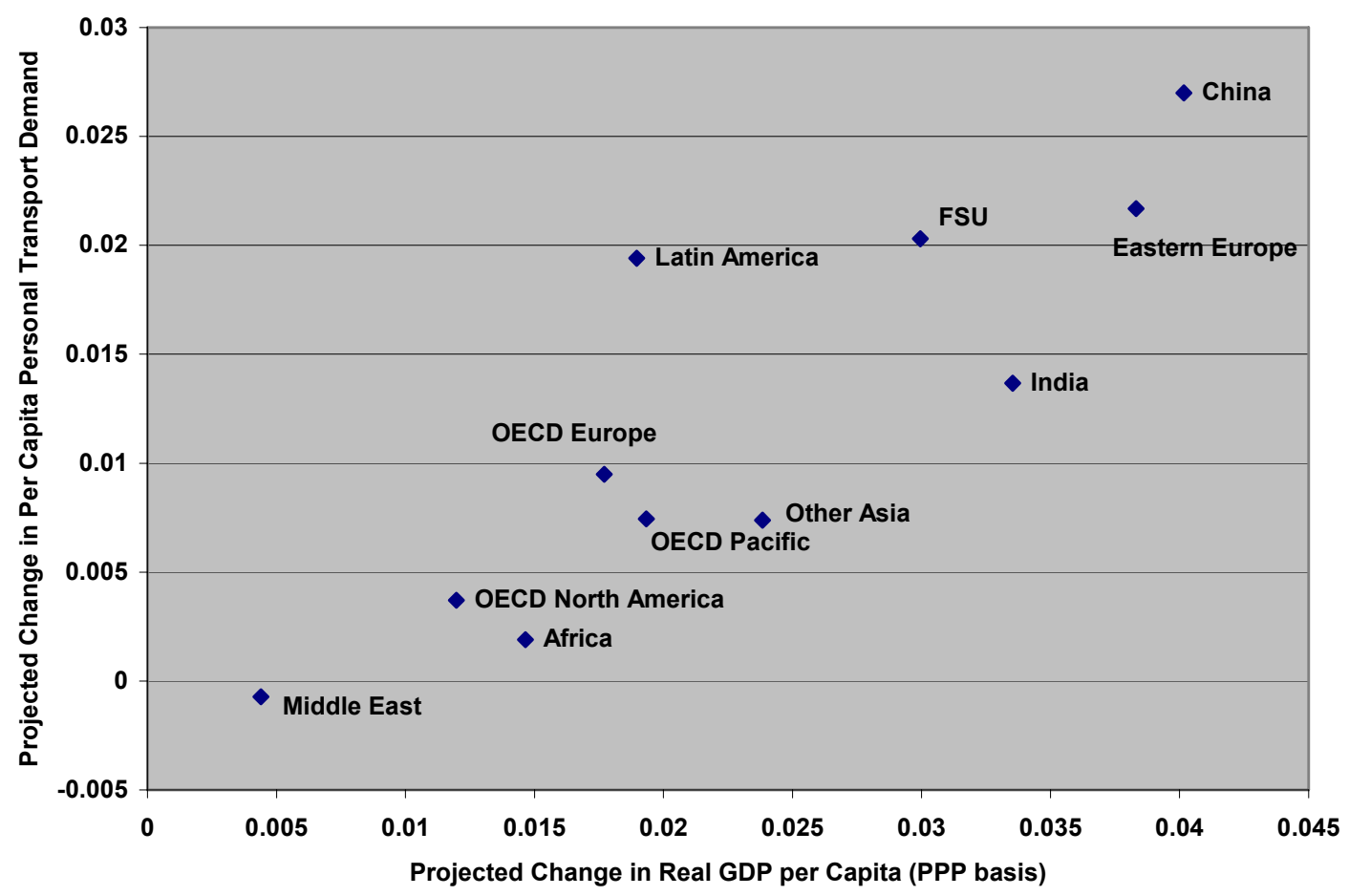

Figure 5.6 Projected Change in Real per Capita Personal Transport Demand vs. Projected Change in Real GDP per Capita (PPP Basis), 2000-2050

Failure of real per capita incomes to grow rapidly in some non-OECD countries/regions will cause incomes - and transport demand - to fall further and further behind the OECD and rapidlygrowing non-OECD countries/regions. This can be illustrated by comparing the situations of OECD North America and Africa. Figure 5.6 shows that the projected growth rates in real per capita income and personal travel demand are roughly similar in both over the 2000 to 2050 time period. ${ }^{10}$ But Figure 5.5 shows that the current levels of real per capita income and per capita personal travel in Africa are so low that roughly similar growth rates between 2000 and 2050 lead to the gaps in both real per capita income and personal transport demand to grow, not only relatively, but absolutely. ${ }^{11}$

\subsubsection{Poor Transport Systems Seriously Inhibit Economic Growth}

In places such as Africa and India, the poor quality of transport networks (especially freight transport networks) has been identified as a major barrier to faster economic growth. Two recent studies highlight the potential magnitude of the problem.

10 Projected average annual per capita real income growth rates for OECD North America and Africa over $2000-2050$ is $1.2 \%$ and $1.6 \%$ respectively. Projected average annual per capita transport demand growth is $0.4 \%$ for OECD North America and $0.2 \%$ for Africa.

11 In 2000, average real per capita income in OECD North America was \$26,000 per year while it was \$1,900 per year in Africa - a gap of $\$ 24,100$. At the growth rates shown, the gap in real per capita income in 2050 will be $\$ 43,200$. The gap in personal transport demand per capita grows from 20,000 pkm per year in 2000 to 24,000 pkm per year in 2050 . 
Clark, Dollar and Micco have analyzed relationship between port efficiency, maritime transport costs, and the volume of bilateral trade between the United States and various countries. ${ }^{12}$ Containers are a very efficient method of transporting finished and semi-finished goods, while large bulk carriers can transport bulk commodities (including petroleum and petroleum products) at remarkably low costs. But port inefficiencies can offset a large share of these potential cost savings. Indeed, ports that are too inefficient won't even be called on by large containerships. They also sometimes are unable to handle the largest bulk carriers.

These researchers have estimated that an improvement in port efficiency from the $25^{\text {th }}$ percentile to the $75^{\text {th }}$ percentile (i.e., from a situation in which $75 \%$ of the world's ports are more efficient than the given country's ports to a situation in which only $25 \%$ of the world's ports are more efficient) reduces shipping costs by more than $12 \%$ - the equivalent to a reduction of 5000 miles in distance between the country and its trading partners. They also find that an increase in country-specific transport costs from the $25^{\text {th }}$ to the $75^{\text {th }}$ percentile implies a reduction in bilateral trade by around $22 \% .^{13}$

Inefficient road and rail transport systems also dampen economic growth. Limao and Venables develop a model that explains variations in the cost of shipping a 40 foot ocean container from Baltimore (MD) to different countries around the world, both countries having seaports and countries that are landlocked. The model employs several explanatory variables, including distance, infrastructure quality, and whether a country is landlocked. Not surprisingly, distance turns out to be a significant determinant of transport costs. But it only explains about $10 \%$ of the variation across country pairs. In contrast, poor infrastructure explains $40 \%$ of the variation for coastal countries and up to $60 \%$ of the variation for landlocked countries. They calculate that an improvement in the quality of own and transit countries' infrastructure from the $25^{\text {th }}$ percentile to the $75^{\text {th }}$ percentile overcomes more than half of the transport cost disadvantage associated with being landlocked. ${ }^{14}$

The ability to move goods efficiently from overseas to and from a developing country's ports, from the ports to and from its cities, and within these cities is critical to enabling the country's economy to grow. Countries that cannot move goods efficiently may still grow economically. India represents the classic case of this situation. But their development will be stunted. It also will be geographically distorted. With efficient ports but inefficient inland transport, economic development is likely to be heavily concentrated in coastal enclaves. And without efficient means of distributing goods within these coastal enclaves, they are unlikely to be able to grow large enough to realize the agglomeration economies that otherwise ought to enjoy.

\subsection{GROWTH IN POPULATION}

Personal transport involves the movement of people. Goods transportation involves the movement of goods to and/or from people. Generally speaking, the larger the number of people living in a country/region, the greater the demand for personal and goods transport.

12 Ximena Clark, David Dollar, and Alejandro Micco, "Port Efficiency, Maritime Transport Costs and Bilateral Trade," Journal of Development Economics 75 (2004), pp. 417-450.

13 Ximena Clark, David Dollar, and Alejandro Micco, p. 441.

14 Nuno Limao and Anthony J. Venables, "Infrastructure, Geographical disadvantage, Transport Costs and Trade.” The World Bank Economic Review, Vol. 15, No. 3 (2000). 
Population growth rates are falling almost everywhere. Figure 5.7, from a 1999 United Nation's (UN's) publication titled The World at Six Billion, shows total world population and the annual increase in world population from 1750 through 1999 and projections to 2050. It emphasizes how extraordinary the population growth during the last half of the $20^{\text {th }}$ century truly was. This increase was caused by a reduction in mortality in the less developed regions - a reduction that was not accompanied (at least initially) by reduction in fertility rates in these regions. One of the major things that enabled this growth in population was the increased ability to transport food, especially by ship and rail. The growth in population also stimulated the demand for finished goods. Again, this was stimulated by improved transport. During the last quarter of the $20^{\text {th }}$ century, the rate of population growth began to decline, largely due to declines in fertility.

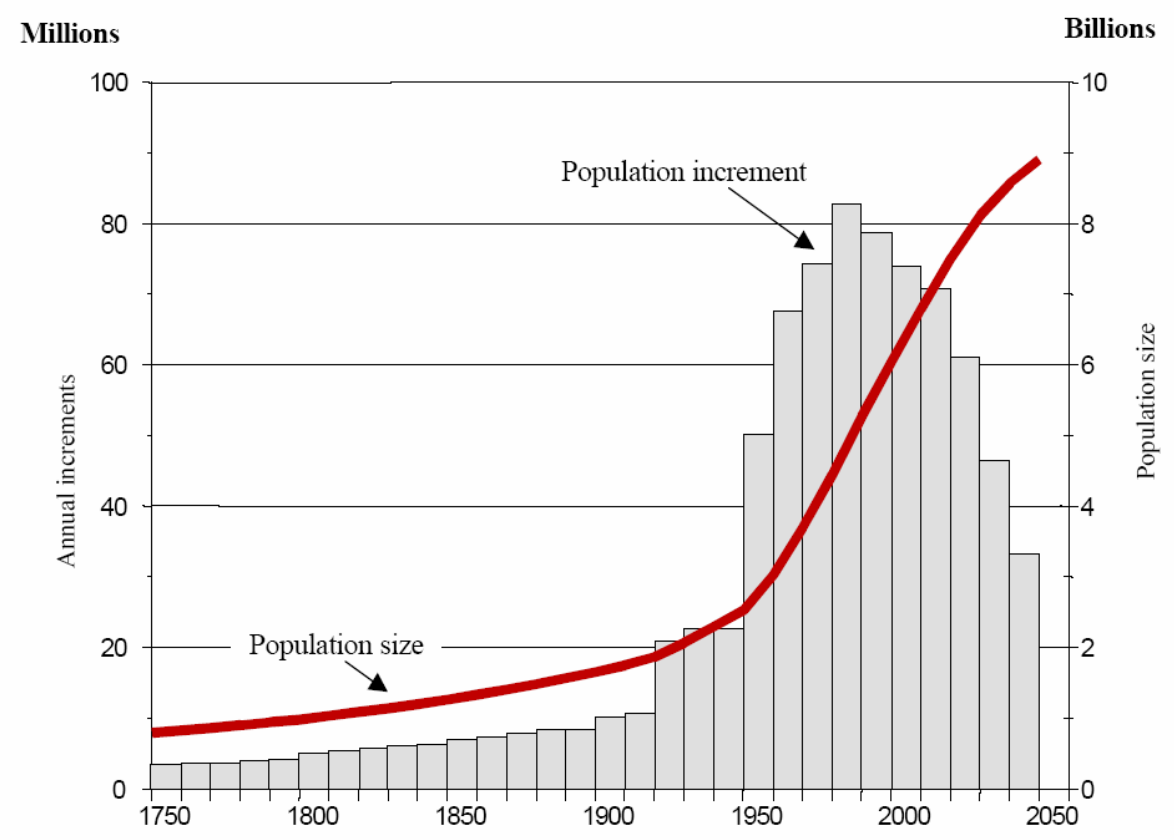

Source: United Nations Population Division.

Figure 5.7 Total Increment to World Population and Total World Population, 1750-2050(p)

As was true in the case of real per capita income growth, the pattern of population growth over the period 2000-2050 will differ by region (Table 5.2). On average, population in the nonOECD countries will grow faster than population in the OECD regions. But population growth in two of the three OECD regions - OECD Europe and OECD Pacific (especially Japan) will be negative - i.e., total population will decline. In contrast, population in the third OECD region (OECD North America, consisting of the United States, Canada, and Mexico) will grow at an average annual rate of nearly $0.75 \%$ per year. Immigration largely accounts for this difference. 
Table 5.2 Population and Population Growth Rates by Country/Region

\begin{tabular}{lrrc}
\hline & \multicolumn{2}{c}{ Year } & AAGR(\%) \\
\cline { 2 - 3 } & 2000 & 2050 & $2000-2050$ \\
\hline OECD North America & 405 & 584 & $0.73 \%$ \\
OECD Europe & 514 & 466 & $-0.20 \%$ \\
OECD Pacific & 197 & 192 & $-0.06 \%$ \\
OECD Total & 1,116 & 1,242 & $0.21 \%$ \\
& & & \\
FSU & 254 & 248 & $-0.04 \%$ \\
Eastern Europe & 100 & 85 & $-0.32 \%$ \\
China & 1,272 & 1,472 & $0.29 \%$ \\
Other Asia & 891 & 1,611 & $1.19 \%$ \\
India & 1,014 & 1,572 & $0.88 \%$ \\
Middle East & 168 & 431 & $1.91 \%$ \\
Latin America & 415 & 660 & $0.93 \%$ \\
Africa & 794 & 2,001 & $1.87 \%$ \\
Non-OECD Total & 4,907 & 8,080 & $1.00 \%$ \\
& & & \\
World Total & 6,023 & 9,322 & $0.88 \%$ \\
\hline
\end{tabular}

Source: SMP Spreadsheet Model

Among the non-OECD regions, population growth in the FSU and Eastern Europe will be negative - something recently underscored with alarm by Russian President Putin. ${ }^{15}$ Due to the success of its "one child" policy, China's rate of population growth will be extremely low - an average of only $0.3 \%$ per year. In 2050, China's population will be smaller than it was in 2025 and just about the level it will be in 2015. However, the average rate of population growth for all other non-OECD regions will be near or exceed $1 \%$ per year. Indeed, population growth rates in the Middle East and Africa will approach $2 \%$ per year.

As a result of sharp fertility declines, the average age of the population in many countries will be rising. In 1950, the median age of the world's population was 23.5 years. It increased to 26.4 years in 1999. By 2050, the median age is projected to reach 37.8 years. ${ }^{16}$

\subsection{URBANIZATION}

Most personal travel is within or between urban areas. Urban areas also depend on transport to supply them with food, energy, raw materials, and finished goods. In 1950, about half of the people in the more developed regions lived in cities (Table 5.3). ${ }^{17}$ By 2000 this had increased to

15 "Putin urges plan to reverse slide in the birthrate," The New York Times, May 11, 2006.

16 UN, "The World at Six Billion," Box 4, p. 30.

17 The categorization of countries into those located in "more developed regions" and those located in "less developed regions" is used by the United Nations "for statistical convenience and do not necessarily express a judgment about the stage reached by a particular country or area in the developing process." (UN, World Population Prospects: the 2004 Revision, p. ii. Generally speaking, countries in the "more developed regions" are members of the OECD while countries in the "less developed regions" are not OECD members. But there are some important exceptions. Russia and the European portions of the Former Soviet Union are included in the "more developed regions" but are not OECD members. Mexico, South Korea, and Turkey are OECD members but are designated by the UN as countries in "less developed regions." 
nearly $75 \%$. However, the growth in urbanization is tapering off in the countries of the more developed regions. In the next 30 years, the percentage of people living in urban areas in these countries will increase only to $82 \%$. The total urban population in these regions will experience only a relatively small increase, with most of that increase occurring in Northern America (i.e., the United States and Canada).

Table 5.3 World Urbanization Trends, 1950-2030(p)

\begin{tabular}{|c|c|c|c|c|c|c|c|c|}
\hline & \multicolumn{5}{|c|}{ Urban Population (billions) } & \multicolumn{3}{|c|}{ Average Annual Rate of Change (\%) } \\
\hline & 1950 & 1975 & 2000 & $2030(p)$ & $\begin{array}{c}\text { Change } \\
2000-2030\end{array}$ & $1950-1975$ & $1975-2000$ & $2000-2030(p)$ \\
\hline More Developed Regions & 0.43 & 0.70 & 0.88 & 1.01 & 0.13 & 2.0 & 0.9 & 0.5 \\
\hline Europe & 0.28 & 0.45 & 0.53 & 0.55 & 0.02 & 1.9 & 0.7 & 0.1 \\
\hline Northern America & 0.11 & 0.18 & 0.25 & 0.35 & 0.10 & 2.0 & 1.3 & 1.2 \\
\hline Japan & 0.03 & 0.06 & 0.08 & 0.09 & 0.01 & 3.2 & 1.1 & 0.2 \\
\hline Less Developed Regions & 0.31 & 0.81 & 1.97 & 3.93 & 1.96 & 3.9 & 3.6 & 2.3 \\
\hline China & 0.07 & 0.16 & 0.60 & 0.88 & 0.28 & 3.4 & 5.4 & 1.3 \\
\hline India & 0.06 & 0.13 & 0.28 & 0.59 & 0.31 & 3.1 & 3.1 & 2.5 \\
\hline \multicolumn{9}{|c|}{ Percentage Urban } \\
\hline & 1950 & 1975 & 2000 & $2030(p)$ & $\begin{array}{c}\text { Change } \\
2000-2030\end{array}$ & & & \\
\hline More Developed Regions & 53 & 67 & 74 & 82 & 8 & & & \\
\hline Europe & 51 & 66 & 73 & 80 & 7 & & & \\
\hline Northern America & 64 & 74 & 79 & 87 & 8 & & & \\
\hline Japan & 35 & 57 & 65 & 73 & 8 & & & \\
\hline Less Developed Regions & 18 & 27 & 41 & 57 & 16 & & & \\
\hline China & 13 & 17 & 36 & 61 & 25 & & & \\
\hline India & 17 & 21 & 28 & 41 & 13 & & & \\
\hline \multicolumn{9}{|c|}{$(p)=$ projected } \\
\hline \multicolumn{9}{|c|}{ Source: United Nations, World Urbanization Prospects: The 2003 Revision. } \\
\hline japan -- total pop & 0.083 & 0.111 & 0.127 & 0.121 & & & & \\
\hline
\end{tabular}

The urbanization picture in the countries of the less developed regions will be quite different. In 1950 , the populations of these countries were overwhelmingly rural. Less than $20 \%$ of their populations lived in urbanized areas. By 2000, the share of population of the less developed regions living in urbanized areas had reached approximately $40 \%$. By 2030 this is projected to increase to nearly $60 \%$.

The more rapid rates of population growth, combined by the more rapid rates of urbanization, will mean that the urban population of countries in the less developed regions will double - from 2.0 billion to 3.9 billion. In 1950, the combined urban population of countries in the less developed regions was only $75 \%$ of the urban population of the more developed regions -0.3 billion versus 0.4 billion. By 2030, the combined population of the less developed regions will exceed the combined population of the more developed regions by almost four times -3.9 billion versus 1.0 billion.

I mentioned above that China's total population will not grow much over the next several decades. However, its urban population will grow significantly - by 280 million between 2000 and 2030. This growth will be double the growth in urban population being projected for the all countries of the more developed region combined.

One of the most important challenges facing the governments of countries in the less developed regions over the next decades is to meet the massive growth in demand for transportation that is expected to accompany the rapid growth of their cities. I will return to this topic later in the paper. 


\subsection{URBAN FORM}

Like income growth, urban form - the residential and employment composition of an urbanized area - both impacts and is impacted by transport demand. Throughout history, the size of cities has been constrained by the ability of their transport systems to supply them with food and raw materials, to enable their residents to congregate in numbers sufficient to transport these raw materials into finished goods efficiently and/or to conduct other business requiring face-to-face interaction, and to transport their finished goods to distant market. The development of inexpensive waterborne transportation eased the first and third of these constraints. But until the mid-to later-1800s, cities were still severely limited in size by their ability to move people from their homes to work and back on a daily basis.

Table 5.4 shows the urbanized area and population density of London from the year 1680 through 2001. Until the roughly the middle of the $19^{\text {th }}$ century, the population and area of London (and other large cities) was constrained by the distance people could walk from home to work. Indeed, the first ever traffic count of people coming into the one square mile City of London between 8 am and $8 \mathrm{pm}$ (1854) found that horse-drawn omnibuses were the means by which the largest number of people $(44,000)$ were transported into town. Thirty-one thousand arrived by train. Twenty-six thousand people entered using private carriages or hackney cabs. But all these modes of transport were dwarfed by the 200,000 who walked. 18

Table 5.4 London Urbanized Area and Population Density

\begin{tabular}{cccc}
\hline Year & Population & Area $(\mathrm{km} 2)$ & Population $/ \mathrm{km} 2$ \\
\hline 1680 & 450,000 & 10 & 43,436 \\
1720 & 600,000 & 14 & 42,120 \\
1770 & 700,000 & 18 & 38,610 \\
1821 & $1,350,000$ & 39 & 34,749 \\
1841 & $1,900,000$ & 62 & 30,566 \\
1901 & $5,000,000$ & 285 & 17,550 \\
1951 & $8,100,000$ & 1186 & 6,828 \\
2001 & $8,279,000$ & 1624 & 5,098 \\
\hline
\end{tabular}

Urbanized land area estimated for 1720-1901 based upon street maps; Data for 2001, Office of National Statistics

Source: www.demographia.com

The development of suburban railways and the Underground enabled Londoners to live much greater distances from their work. As a result, the size of the London metropolitan region grew enormously and the population density fell dramatically. However, the availability of high speed public transport didn't change the need for people's activities other than commuting to be located within a relatively short distance of where they lived. It wasn't until automobile availability became widespread that the location constraints on these other activities eased (Table 5.5). Indeed, non-commute activities now constitute a large majority of personal trips and miles traveled in most high-income countries (Table 5.6).

18 Christian Wolmar, The Subterranean Railway, p. 22. 
Table 5.5 Evolution of Shopping Travel in the United Kingdom, 1965-1995

\begin{tabular}{|c|c|c|c|c|c|}
\hline Year & Car Ownership & $\begin{array}{c}\text { Shopping Trips } \\
\text { per Person per } \\
\text { Year* }^{\star}\end{array}$ & $\begin{array}{l}\text { Average } \\
\text { Shopping Trip } \\
\text { Length (mi.)* }\end{array}$ & $\begin{array}{l}\text { Annual } \\
\text { Shopping } \\
\text { Mileage* }^{*}\end{array}$ & $\begin{array}{l}\text { Number of Purpose Built } \\
\text { Shopping Centers (not } \\
\text { town center) }\end{array}$ \\
\hline 1965 & $42 \%$ & 77 & 3.5 & 268 & 50 \\
\hline 1975 & $53 \%$ & 115 & 3.8 & 440 & 300 \\
\hline 1985 & $62 \%$ & 125 & 4.6 & 577 & 500 \\
\hline 1995 & $68 \%$ & 145 & 5.2 & 747 & 990 \\
\hline
\end{tabular}

* Excludes shopping trips $<1$ mile

** British Council Shopping Centers (1993). Numbers are rounded up. Final number is for 1993 Source: Jane Gould, Thomas F. Golob, and Patrick Barwise, "Why Do People Drive to Shop?" Institute for Transportation Studies, University of California, Irvbine, January 1998, UCI-ITS-AS-WP-98-1.

Prior to the advent of the automobile and the truck, nearly all large cities had a single, relatively compact central business district (CBD) where a large share of the city's employment was concentrated. The locations of these CBDs were usually determined by their proximity to waterborne (and, later, to rail) transportation. The development of the motorized truck freed CBDs from these locational constraints. The development of the automobile allowed workers to live and work almost anywhere they wished within a metropolitan region. Although some cities have retained their strong CBDs, most haven't. The resulting fall in average residential and employment densities has undermined the viability of public transport, especially rail-based public transport.

Even in large cities with strong CBDs - cities such as New York, London, Paris, and Tokyo -the automobile is the main form of transportation used for going to work by people whose jobs are located other than in the CBD. Car ownership and use rates are relatively low among residents of these CBDs and their closest suburbs. Regardless of where they live, the share of workers taking cars to work in these strong CBDs is quite low - only $11 \%$ in the case of those going to work in Manhattan. But the level of commuting by car - as well as the use of cars for all non-commuting purposes - is high outside the CBD. 


\section{Table 5.6 Percent of "Daily" or "Short Distance" Personal Travel, United States and Britain}

\begin{tabular}{|c|c|c|c|c|}
\hline & \multicolumn{2}{|c|}{ US (2001) } & \multicolumn{2}{|c|}{ Britain (2003) } \\
\hline & Trips & Miles & Trips & Miles \\
\hline Annual travel (per capita) & 1481 & 15,098 & 998 & 6,855 \\
\hline Purpose of travel & & & & \\
\hline Commuting/business & $18 \%$ & $26 \%$ & $18 \%$ & $29 \%$ \\
\hline School, Church* & $10 \%$ & $6 \%$ & $7 \%$ & $3 \%$ \\
\hline Shopping & $19 \%$ & $13 \%$ & $20 \%$ & $12 \%$ \\
\hline Family, Personal Business, Escort** & $25 \%$ & $20 \%$ & $25 \%$ & $15 \%$ \\
\hline $\begin{array}{l}\text { Social/rec, Vacation, Visit Friends, and } \\
\text { Other }\end{array}$ & $28 \%$ & $35 \%$ & $31 \%$ & $41 \%$ \\
\hline
\end{tabular}

* For Britain, excludes "church"

**Escort includes "education escort"

Sources: US: CRA International compilation from NHTS 2001 travel day dataset; Britain: Focus on Personal Travel -- 2005 edition

\begin{tabular}{|l|l|}
\hline Britain & \\
\hline Commuting/business & $0 \%$ \\
\hline Education & $0 \%$ \\
\hline Shopping & $0 \%$ \\
\hline $\begin{array}{l}\text { Escort education, other escort, personal } \\
\text { business }\end{array}$ & $0 \%$ \\
\hline Leisure, other & $0 \%$ \\
\hline \hline Total Purpose & $0 \%$ \\
\hline
\end{tabular}

\begin{tabular}{|l|c|}
\hline US & Percent Purpose \\
\hline Commuting/business & $18 \%$ \\
\hline School, Church & $10 \%$ \\
\hline Shopping & $19 \%$ \\
\hline Family, Personal Business, Escort & $25 \%$ \\
\hline Social/rec, Vacation, Visit Friends & $27 \%$ \\
\hline Other & $1 \%$ \\
\hline \hline Total Purpose & $100 \%$ \\
\hline
\end{tabular}

Source: NHTS 2001 travel day dataset

\begin{tabular}{|l|c|}
\hline Britain & \\
\hline Commuting/business & $18 \%$ \\
\hline Education & $7 \%$ \\
\hline Shopping & $20 \%$ \\
\hline $\begin{array}{l}\text { Escort education, other escort, personal } \\
\text { business }\end{array}$ & $25 \%$ \\
\hline Leisure, other & $31 \%$ \\
\hline \hline Total Purpose & $100 \%$ \\
\hline
\end{tabular}

Table 5.7 provides detailed information on travel to work data for London in $2003 .{ }^{19}$ Only $12 \%$ of those who work in Central London travel by either car or van. Five percent walk. Five

19 Greater London: the area administered by the Greater London Authority and the London boroughs. Central London: the Greater London Conurbation Centre or Central Statistical Area - an area roughly rectangular in shape, bounded by Regent's Park to the north, Whitechapel to the East, Elephant \& Castle and Vauxhall to the South, and Kensington Gardens to the West. It is a larger area than the Central London Congestion Charging Zone, and includes the inner ring road and Paddington, Marylebone, Euston and King's Cross rail stations. Inner London: City of London, and the London boroughs of Camden, Hackney, Hammersmith and Fulham, Haringey, Islington, Kensington and Chelsea, Lambeth, Lewisham, Newham, Southwark, Tower Hamlets, Wandsworth, Westminster. A distinction is sometimes made between those parts of these boroughs in central London, and the rest of Inner 
percent take a bicycle, motorbike, moped, or scooter. The remainder use public transport. However in Outer London, the share of commuters using cars or vans rises to $66 \%$.

Table 5.7. Main Mode of Travel to Work, London, Autumn 2003

\begin{tabular}{|c|c|c|c|c|c|c|c|c|c|}
\hline \multirow[b]{2}{*}{ Main mode } & \multicolumn{6}{|c|}{ Area of workplace } & \multicolumn{3}{|c|}{ Area of residence } \\
\hline & $\begin{array}{l}\text { Central } \\
\text { London }\end{array}$ & $\begin{array}{l}\text { Rest of } \\
\text { inner } \\
\text { London }\end{array}$ & $\begin{array}{l}\text { Outer } \\
\text { London }\end{array}$ & $\begin{array}{c}\text { All } \\
\text { London }\end{array}$ & $\begin{array}{c}\text { Rest of } \\
\text { Great } \\
\text { Britain }\end{array}$ & $\begin{array}{c}\text { Great } \\
\text { Britain }\end{array}$ & $\begin{array}{l}\text { Inner } \\
\text { London }\end{array}$ & $\begin{array}{l}\text { Outer } \\
\text { London }\end{array}$ & $\begin{array}{c}\text { All } \\
\text { London }\end{array}$ \\
\hline Car and van & 12 & 36 & 66 & 42 & 76 & 71 & 26 & 53 & 43 \\
\hline Motorbike, moped, scooter & 2 & 2 & 1 & 2 & 1 & 1 & 2 & 2 & 2 \\
\hline Bicycle & 3 & 4 & 2 & 2 & 3 & 3 & 5 & 1 & 3 \\
\hline Bus and coach & 10 & 17 & 13 & 13 & 7 & 8 & 21 & 11 & 15 \\
\hline National rail & 38 & 12 & 4 & 17 & 2 & 4 & 9 & 12 & 11 \\
\hline Underground, tram, light rail & 28 & 17 & 4 & 15 & - & 2 & 22 & 13 & 16 \\
\hline Walk & 5 & 11 & 10 & 9 & 11 & 10 & 13 & 8 & 10 \\
\hline All modes & 100 & 100 & 100 & 100 & 100 & 100 & 100 & 100 & 100 \\
\hline
\end{tabular}

Paris displays a similar pattern of motor vehicle use. Sixty-three percent of trips either within Central Paris or going from the First or Second Ring to Central Paris are by public transport (Figure 5.8). ${ }^{20}$ But such trips account for only about one-third of daily trips within the Paris region. For the two-thirds of trips originating and terminating outside Central Paris, the public transport share is only about $17 \% .^{21}$

$\frac{\text { Trips by Car }}{\text { Trips by Public Transport }} \quad 20,717,000$ Total Trips $\frac{14,099,000}{6,618,000} \quad(68 \%)$

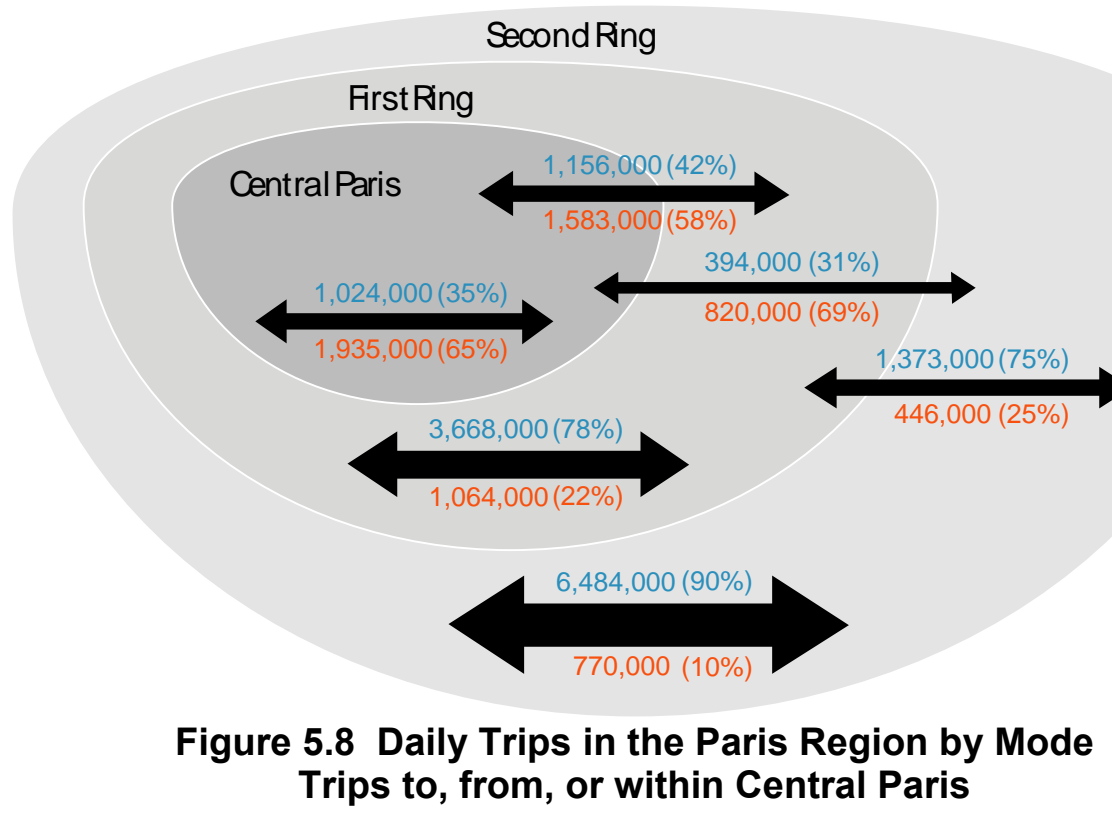

London. Outer London: the London boroughs of Barking and Dagenham, Barnet, Bexley, Brent, Bromley, Croydon, Ealing, Enfield, Greenwich, Harrow, Havering, Hillingdon, Hounslow, Kingston upon Thames, Merton, Redbridge, Richmond upon Thames, Sutton, Waltham Forest. Source: Transport for London, London Travel Report 2004 , p. 62.

20 Central Paris $=$ ArrondissementsI-XX; First Ring $=$ Departments of Hauts de Seine, Seine Saint Denis, and Val de Marne; Second Ring = Remainder of the Ile de France region.

21 Mobility 2030, p. 139. 


\subsubsection{How Urban Form Influences the Demand for Transportation}

Many people use the term "sprawl" to characterize the process of residential and employment "suburbanization" described above. Sprawl has been blamed for many things - the destruction of a sense of community, the fostering of a sense of isolation, the segregation of society by income. But the aspect of sprawl that we will focus on here is its impact on transport demand.

Sprawl is hard to define with analytical precision. However, a few researchers have developed measures of sprawl that capture not only residential density but the neighborhood mix of homes, jobs and services; the strength of activity centers and downtowns; and the accessibility of street networks. I will report here the results of two such studies.

Ewing, Pendall and Chen rank 83 United States Cities in terms of a "sprawl index" composed of the four components just identified. They compile information on the rate of vehicle ownership, the share of commuters taking transit to work, the share of commuters walking to work, the average commute time, and the vehicle miles traveled (VMT) per household per day for each of these cities. Table 5.8 shows the average of these values, and the average sprawl index, ${ }^{22}$ for the ten "most sprawling" and the ten "least sprawling" cities, with the latter excluding two conspicuous outliers, New York City and Jersey City.

Table 5.8 How Personal Transportation Demand is Influenced by Urban Form (1)

\begin{tabular}{|c|c|c|c|c|c|c|}
\hline MSA/PMSA Name & $\begin{array}{l}\text { Sprawl } \\
\text { Index }\end{array}$ & $\begin{array}{c}\text { Vehicles per } \\
100 \mathrm{HH}\end{array}$ & $\begin{array}{l}\text { Transit to } \\
\text { Work (\%) }\end{array}$ & $\begin{array}{l}\text { Walk to } \\
\text { Work (\%) }\end{array}$ & $\begin{array}{c}\text { Commute } \\
\text { Time (min.) }\end{array}$ & $\begin{array}{l}\text { VMT per } \mathrm{HH} \\
\text { (mi./day) }\end{array}$ \\
\hline Average -- ten most sprawling & 89.08 & 180 & 2.6 & 2.11 & 26 & 72.23 \\
\hline $\begin{array}{l}\text { Average -- ten least sprawling } \\
\text { (excluding outliers) }\end{array}$ & 132.29 & 162 & 7.0 & 3.56 & 26 & 54.45 \\
\hline \multicolumn{7}{|c|}{$\begin{array}{l}\text { Difference -- ten most sprawling } \\
\text { and ten least sprawling (excluding }\end{array}$} \\
\hline \multicolumn{7}{|l|}{ Excluded Outliers } \\
\hline Jersey City, NJ PMSA & 162.27 & 93 & 34.2 & 8.71 & 33 & n.a. \\
\hline New York, NY PMSA & 177.78 & 74 & 48.5 & 9.61 & 39 & 40.19 \\
\hline
\end{tabular}

Source: Derived from Reid Ewing, Rolf Pendall and Don Chen, "Measuring Sprawl and Its Impact," Smart Growth America

Table 5.8 also shows the difference in the averages of these various measures for the ten "most sprawling" and the ten "least sprawling" cities (excluding the outliers). The range in the researchers' sprawl index between these two groups of cities, 73.43, is almost three standard deviations. Yet there is only an $11 \%$ difference in the number of cars per household (180 vs. 162 ) and a $22 \%$ difference in the number of VMT per household per day ( 72.23 vs. 54.45$)$ between the ten "most sprawling" and ten "least sprawling" cities. For both groups of cities the percent of commuters taking public transit to work is below $10 \%$, and the percent of commuters walking to work is less than $5 \%$. The average commute time for commuters in both groups of cities is identical -26 minutes.

The second study is by Bento, Cropper, Mobarak and Vinhad. It covers 114 U.S. urban areas. Rather than a "sprawl index," these researchers include the actual values of different variables

22 The sprawl index is scaled so 25 units is equal to one standard deviation. The index ranges in value from 14.22 to 177.78 , with a lower value indicating greater sprawl. 
that they believe reflect sprawl. Table 5.9 shows the maximum and minimum value for these variables (including New York City). Given these characteristics, they predict the average VMT per household, the average probability of driving to work by workers, and the average annual commute miles for a "typical household" residing in each urban area. Table 5.9 shows these predicted values for six U.S. urban areas: Atlanta, Boston, Chicago, Houston, New York, and San Diego. Comparing Atlanta and Boston (the latter being the "most compact" urban area other than New York City), the different in predicted average VMT per household is 25\%. Again, other than New York City, the predicted average probability of driving to work by workers does not fall below $70 \%{ }^{23}$ And the average commute miles driven per year is between 4500 and 5600 miles.

Table 5.9 How Transport Demand is Influenced by Urban Form (2)

\begin{tabular}{|c|c|c|c|c|c|c|c|c|}
\hline Characteristic & Mimimum $^{\star \star} \Lambda$ & Maximum ${ }^{\star \star}$ & Atlanta & Boston & Chicago & Houston & New York & San Diego \\
\hline $\begin{array}{l}\text { Lane Density (area of roads per } 100 \text { square } \\
\text { miles of land) }\end{array}$ & 1.6 & 10.6 & 3.9 & 4.3 & 4.7 & 5.2 & 5.3 & 4.2 \\
\hline Land Area $\left(\mathrm{km}^{2}\right)$ & 135 & 7,683 & 2,944 & 2,308 & 4,104 & 3,049 & 7,683 & 1,788 \\
\hline Population & 158,553 & $16,044,012$ & $2,157,806$ & $2,775,370$ & $6,792,087$ & $2,901,851$ & $16,044,012$ & $2,348,417$ \\
\hline Density (people/km²) & 446 & 2,240 & 733 & 1,202 & 1,655 & 952 & 2,088 & 1,314 \\
\hline Rail Transit Supply $\left(10,000 \mathrm{mi} / \mathrm{km}^{2}\right)$ & 0 & 5.7 & 0.7 & 1.8 & 1.9 & 0.0 & 5.7 & 0.2 \\
\hline Non-Rail Transit Supply $\left(10,000 \mathrm{mi} / \mathrm{km}^{2}\right)$ & 0.1 & 4.3 & 1.0 & 1.3 & 2.8 & 1.4 & 3.0 & 1.6 \\
\hline Jobs-Housing Balance (standardized) & 0.12 & 0.58 & 0.44 & 0.28 & 0.35 & 0.44 & 0.41 & 0.58 \\
\hline Population Centrality (standardized) & 0.11 & 0.22 & 0.11 & 0.17 & 0.15 & 0.13 & 0.20 & 0.20 \\
\hline City Shape & 0.04 & 0.99 & 0.26 & 0.82 & 0.48 & 0.80 & 0.73 & 0.36 \\
\hline Predicted Average VMT per Household & & & 16,899 & 12,704 & 14,408 & 15,685 & 9,453 & 16,493 \\
\hline Predicted average probability of driving to wo & rk by workers & & 0.87 & 0.73 & 0.74 & 0.90 & 0.40 & 0.84 \\
\hline Predicted average commute miles driven & & & 5,450 & 4,565 & 4,620 & 5,641 & 2,496 & 5,247 \\
\hline
\end{tabular}

The differences among U.S. urban areas in travel by automobile reported in these two studies are not insignificant. But neither are they of the magnitude sometimes claimed (or implied) by those who advocate sharply curtailing sprawl. Moreover, it would take decades to accomplish a significant change in the form of a major urban area - if, indeed, it could be accomplished at all.

\subsubsection{Different Impacts of Urban Form in More Developed and Less Developed Countries}

Generally speaking, urban areas in the United States have average population densities of less than 25 persons per hectare (2500 persons per square kilometer, or 6,475 persons per square mile). ${ }^{24}$ The average population densities of European cities generally range from about 35 persons per hectare to about 90 persons per hectare. LAM cities are similar in average density to European cities. Even some large Asian cities aren't that out of line with Europe. But then there are several Asian cities, primarily in India and China, having average residential densities of 300 or more persons per hectare $\left(30,000\right.$ persons per square kilometer or 77,700 per square mile) ${ }^{25}$

23 Table 5.7 (above) shows that for Great Britain as a whole it is $71 \%$.

24 The only U.S. city having an average population density of greater than 25 people per hectare is New York (40 per hectare; 4000 per square kilometer; 10,360 per square mile.) Los Angeles, often considered to be the paragon of "sprawl," actually has the second highest population density shown for a U.S. urban area (22 per hectare).

25 While these density numbers are high relative to developed region cities today, they are not extraordinary when compared to developed regions cities before the advent of subways and suburban railways. Recall from Table 4 above that London's average population density in 1841 was 30,566 people per square kilometer (79,000 per square mile). It had to be that high because there was no way to move large numbers of people into and out of the city quickly and inexpensively. 
Let's briefly examine two of these very dense Asian cities - Shanghai and Mumbai (formerly Bombay). Table 5.10, compiled from data in the Millennium Cities Database for Sustainable Transportation, compares the two along certain transport-related dimensions.

Mumbai's population in 2000 was about 16 million. $^{26}$ According to Bertaud $^{27}$ its average residential density is about - 390 per hectare $(39,000$ per square kilometer, 101,000 per square mile). Mumbai's development has been heavily influenced by its network of suburban railways. This network, built by the British prior to Indian independence, transports 6 million workers each day. Mumbai's municipal bus system carries over 4.5 million passengers per day, 60 percent of whom make a transfer to rail. Together, rail and bus services carry over 80 percent of the Mumbai region's motorized personal trips. ${ }^{28}$ Mumbai does not have a single, well-defined CBD. Indeed, only $18 \%$ of Mumbai's jobs are located in its CBD. Instead, Mumbai has several "downtowns" connected by its suburban railway network (Figure 5.9).

Almost half of all trips in Mumbai each day are by foot. Most of the rest are by public transport - the rail or rail/bus combination referred to in the paragraph above. It appears that a large share of motorized private trips is by taxi or shared taxi. Because rail is so heavily used, public transport speeds are relatively high - approximately $30 \mathrm{~km} / \mathrm{hr}$ - even though a significant share of these trips are by bus.

Shanghai's population in 2000 was about 13 million. $^{29}$ Bertaud puts its average residential population density at about 290 persons per hectare $(29,000$ per square kilometer; 75,000 per square mile). In contrast to Mumbai, Shanghai has a well-defined CBD. In 1995, 75\% of Shanghai's employment was located there.

In 1995 , nearly $80 \%$ of daily trips were by foot or bicycle. Public transport provided only $15 \%$ of the trips. ${ }^{30}$ Since buses compete with cars, bicyclists, and pedestrians for street space, speeds are slow - in 1995, about $10 \mathrm{~km} /$ hour, or about one-third as great as in Mumbai.

The Shanghai of 1995 seems to us to bear more than a passing resemblance to the London of the mid-1800s - prior to the development of the latter's system of high-speed public transport (Figure 5.10). Just as was true in London in the mid-1800s, a very high share of people walk, though in Shanghai, bicycles supplement walking. Shanghai's buses play the role that London's omnibuses played during that earlier era. Shanghai's autos play the role of London's private carriages and hansom cabs. The high density of Shanghai's CBD appears to be explained in large part by the same transport-related phenomenon that made Central London's population density so high before the mid-1800s.

Although Shanghai has begun to build a subway system, it does not yet have a public transport network capable of moving large numbers of people quickly and inexpensively to and from their homes to jobs in its CBD. It does not have, and appears not to be willing to create, a suburban

26 UN, World Urbanization Prospects: The 2003 Revision, p. 267.

27 Alain Bertaud, "Order Without Design," 2002.

28 World Bank, India's Transport Sector: The Challenges Ahead, Volume II: Background Papers, May 10, 2002, p. 84 .

29 UN, World Urbanization Prospects: The 2003 Revision, p. 264.

30 This is entirely buses, since Shanghai had no subway in 1995. It never has had a suburban railway system. 
rail network. The number of cars is growing, although the Shanghai government is trying to restrict their number using techniques similar to that of Singapore (see below).

\section{Table 5.10 Comparison of Personal Transport Characteristics in Shanghai and Mumbai}

\begin{tabular}{|c|c|c|}
\hline Indicator & Shanghai & Mumbai \\
\hline \multicolumn{3}{|l|}{ Mobility Indicators } \\
\hline \multicolumn{3}{|l|}{ Overall mobility } \\
\hline Daily trips by foot per capita & 1.0 & 0.6 \\
\hline Daily trips by mechanized, non motorised modes per capita* & 1.4 & 0.0 \\
\hline Daily public transport trips per capita & 0.5 & 0.5 \\
\hline Daily private transport trips per capita & 0.2 & 0.1 \\
\hline Total daily trips per capita & 3.2 & 1.3 \\
\hline \multicolumn{3}{|l|}{ Modal split of all trips per capita } \\
\hline By foot & $33 \%$ & $49 \%$ \\
\hline By mechanized, non motorised mode* & $45 \%$ & $1 \%$ \\
\hline By motorized public mode & $15 \%$ & $41 \%$ \\
\hline By motorized private mode & $7 \%$ & $9 \%$ \\
\hline Overall average trip distance & 4.3 & 11.0 \\
\hline Overall average trip distance by car & 7.0 & 14.2 \\
\hline Overall average trip distance by public transport & 10.8 & 17.1 \\
\hline Overall average distance of the journey-to-work $(\mathrm{km})$ & 4.5 & 7.6 \\
\hline Average distance of the journey-to-work by mechanised modes $(\mathrm{km})$ & 6.3 & 16.7 \\
\hline Average time of a car trip (min) & 21.0 & 38.0 \\
\hline Average time of a public transport trip (min) & 60.0 & 36.0 \\
\hline \multicolumn{3}{|l|}{ Travel characteristics } \\
\hline Passenger car passenger kilometres per capita & 378 & 212 \\
\hline Motorcycle passenger kilometers per capita & 132 & 214 \\
\hline Taxi passenger kilometres per capita & 307 & 200 \\
\hline Bus passenger kilometres per capita & 1872 & 612 \\
\hline Suburban rail passenger kilometres per capita & N.A. & 2700 \\
\hline Total motorized passenger kilometers per capita & 2689 & 3938 \\
\hline \multicolumn{3}{|l|}{ Modal share of motorized personal travel per capita ( $\mathrm{pkm} / \mathrm{capita)}$} \\
\hline Passenger car & $14 \%$ & $5 \%$ \\
\hline Motorcycle & $5 \%$ & $5 \%$ \\
\hline Taxi & $11 \%$ & $5 \%$ \\
\hline Bus & $70 \%$ & $16 \%$ \\
\hline Suburban rail & N.A. & $69 \%$ \\
\hline \multicolumn{3}{|l|}{ Transport Energy Use Indicators } \\
\hline Private passenger transport energy use per capita (MJ) & 1690 & 1265 \\
\hline Public transport energy use per capita (MJ) & 273 & 254 \\
\hline Total transport energy use per capita (MJ) & 1963 & 1519 \\
\hline
\end{tabular}

* assumed to be bicycle

Source: Millennium Cities Database for Sustainable Transportation 


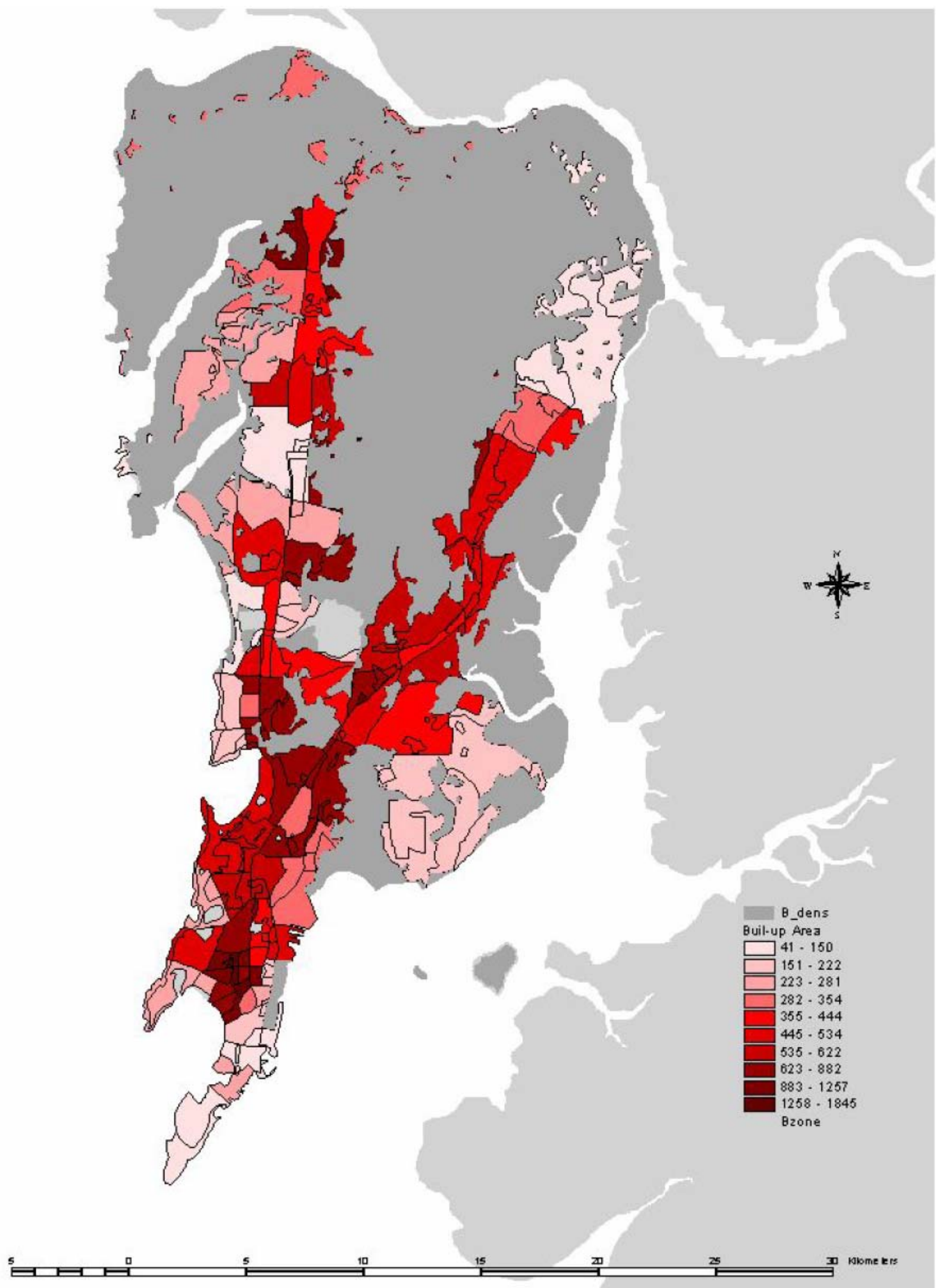

Figure 5.9 Mumbai Showing Density of Built-Up Area (pop/ha)

Source: Alain Bertaud, "Note on Transportation and Urban Spatial Structures," Washington, ABCDE Conference, April 2002, p. 5. 
As Shanghai has increasing difficulty in supporting its mono-centric structure, the metropolitan region appears to be fracturing into multiple "downtowns." But unlike Mumbai, which has been shaped by its suburban railway lines, Shanghai's suburbs are located all around the traditional city center (Figure 5.11). Without good transportation alternatives, each suburb likely draws a large share of its workers from its immediate area.

Whether central Shanghai's residential density remains at its current high level or falls as London's eventually did will depend to a considerable degree on the type of transport systems that develop. Unlike London in the mid-1800s, Shanghai faces competition from the automobile. And although automobiles are no more suited to be the principal providers of mobility for central Shanghai than they are for Central London, they do threaten to drain jobs from Shanghai's city center to its suburbs.
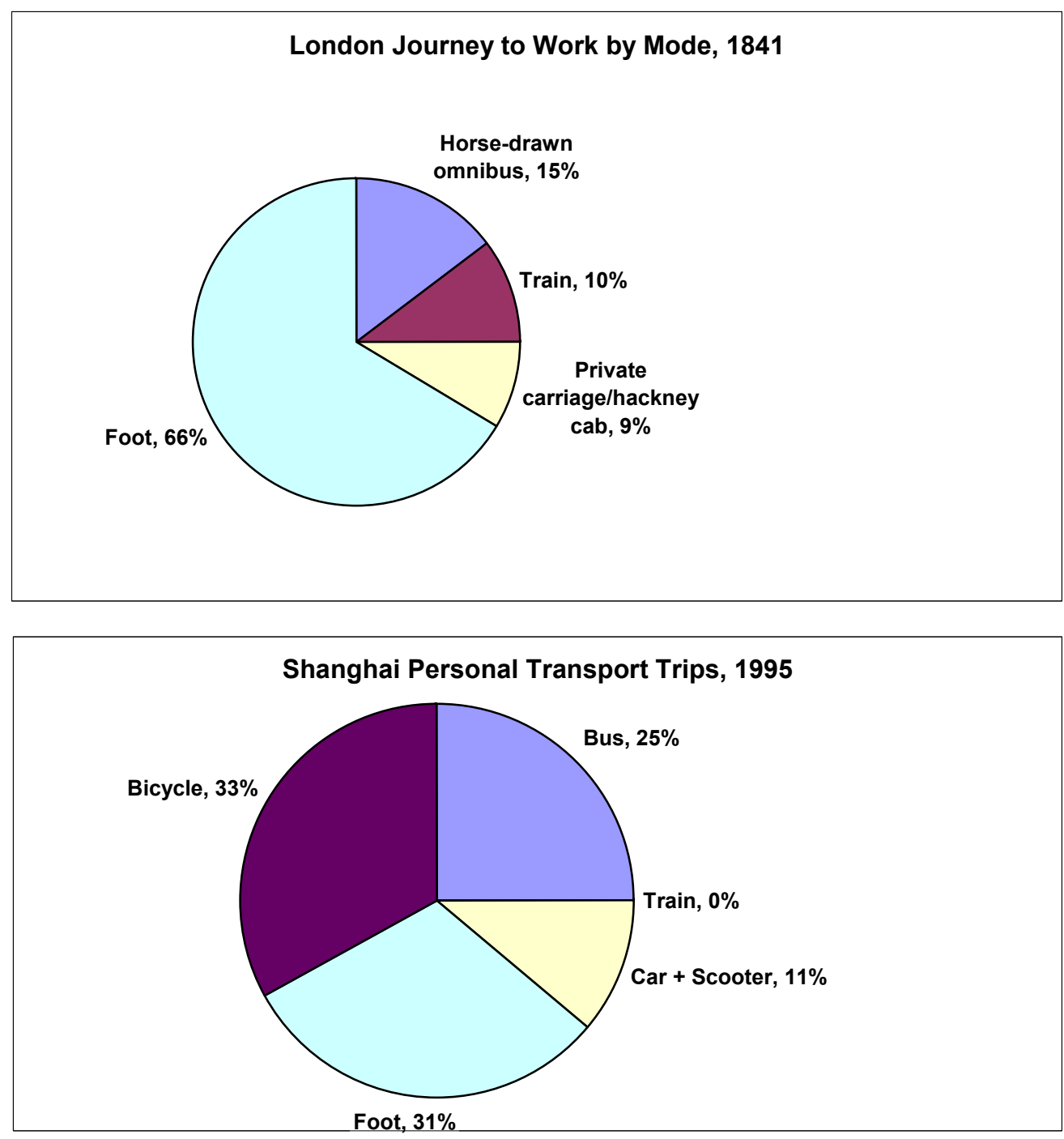

Figure 5.10 Personal Transport Modal Splits, London (1841) and Shanghai (1995) 


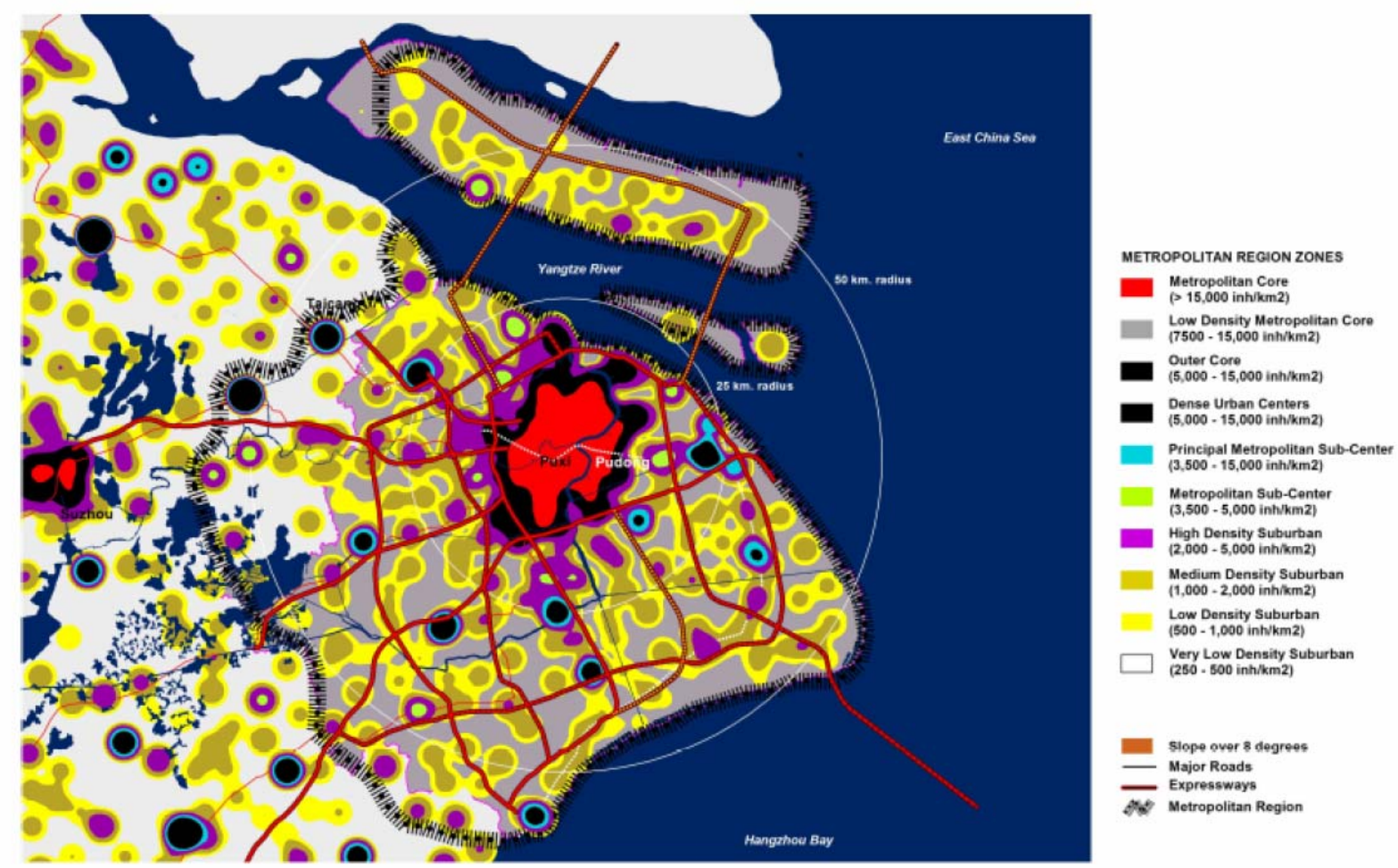

Figure 5.11 Shanghai Regional Population Density

\subsection{TRANSPORT COSTS}

One of the most fundamental propositions of economics that the more costly a good or service is, the less demand there will be for it, all else held equal. Transportation is no exception. Personal transportation is a major item in household budgets. And transportation costs for goods and services are incorporated into the cost of everything that household purchase. In this section I will discuss how transport costs impact transport demand

\subsubsection{Household Expenditures on Personal Transportation}

Table 5.11 shows the share of total household expenditures devoted to personal transportation for the United States, Britain, and Japan. It also shows the relative magnitude of various components making up household transportation expenditures. Cross-national comparisons such as these are difficult to make due to different definitions employed by different governments. I have tried to make the data in Table 5.11 as comparable as possible, though definitional differences may still exist.

The share of total household expenditures accounted for by household transportation expenditures is more than twice as high for the United States as it is for Japan (19.3\% vs. 8.5\%). The composition of household transportation expenditures is also quite different for the United States and Japan. In the case of the United States, 95\% of household transportation expenditures are for private transportation. Only 5\% are for public transport. In Japan, expenditures on private transport account for only $71 \%$ of the total; $29 \%$ goes to public transport. 


\section{Table 5.11 Composition of Household Transportation Expenditures United States, Britain, and Japan}

\begin{tabular}{|c|c|c|c|}
\hline \multirow{2}{*}{$\begin{array}{l}\text { Household Transportation Expenditures as a Share of } \\
\text { Total Household Expenditures }\end{array}$} & US & Britain & Japan \\
\hline & $19.3 \%$ & $16.7 \%$ & $8.5 \%$ \\
\hline \multicolumn{4}{|l|}{ Categories of Costs } \\
\hline Public Transportation & $5.2 \%$ & $13.5 \%$ & $28.7 \%$ \\
\hline Private Transportation & $94.7 \%$ & $86.5 \%$ & $71.3 \%$ \\
\hline Vehicle Purchase & $46.9 \%$ & $36.9 \%$ & $22.7 \%$ \\
\hline Automobile Purchase & $46.3 \%$ & $34.7 \%$ & $21.2 \%$ \\
\hline Two-Wheel/Other Purchase & $0.6 \%$ & $2.2 \%$ & $1.5 \%$ \\
\hline Vehicle Operation and Maintenance & $47.9 \%$ & $49.6 \%$ & $48.6 \%$ \\
\hline Gasoline/Motor Oil & $16.8 \%$ & $24.5 \%$ & $16.6 \%$ \\
\hline Maintenance/Repairs/Parts & $8.7 \%$ & $9.6 \%$ & $8.3 \%$ \\
\hline Parking & n.a. & n.a. & $7.1 \%$ \\
\hline Insurance & $10.7 \%$ & $12.7 \%$ & $11.5 \%$ \\
\hline Other* & $11.7 \%$ & $2.8 \%$ & $5.0 \%$ \\
\hline
\end{tabular}

\footnotetext{
* For Britain, "Insurance" includes Vehicle Taxation

** For the US, "Other" includes "vehicle finance charges; and "vehicle rental, leases, licenses, other charges"

Sources: Japan Family Income and Expenditure Survey; UK DfT 2003; US BLS 2003
}

In the United States, household outlays for transportation are split roughly equally into automobile purchase costs and expenditures for vehicle operation and maintenance expenditures. Japanese households spend a much lower percentage of household transport expenditures (21\%) on vehicle purchase.

Somewhat surprisingly, vehicle operation and maintenance expenditures constitutes just about half of all household transportation expenditures in all three countries. Britain stands out in terms of the share of vehicle operating and maintenance expenses that go toward the purchase of gasoline and motor oil. This reflects Britain's very high taxes on gasoline and automotive diesel. ${ }^{31}$ Only the Japanese data includes specific information on parking costs. But they are significant $-7.1 \%$ of total household transport expenditures. In Japan, a personal vehicle cannot be registered unless the owner can show that he or she has secured a permanent off-street parking place. The parking costs shown for Japan may reflect this requirement.

Countries can exert considerable influence over personal transportation decisions - and associated household expenditure on transportation - through their taxation and related policies. One of the most significant - and variable - influence relates to the cost of purchasing and using private motorized vehicles. Figure 5.12 shows the extent to which taxes in several European Union (EU) countries were estimated in April 2001 to add to the final price of a new car. ${ }^{32}$ The size of the tax burden seems to make a difference in the rate of private car ownership. Figure

31 According to the Transportation Energy Data Book - Edition 24 (2004), in 2003 the cost of gasoline in US\$ per gallon was $\$ 1.65$ for the US, $\$ 3.36$ for Japan, and $\$ 4.95$ for the UK. The proportion of this represented by taxes was $24 \%$ for the US, $54 \%$ for Japan, and $76 \%$ for the UK. The comparable figures for automotive diesel were US: $\$ 1.49$ per gallon ( $31 \%$ of which represents tax), Japan: $\$ 2.67$ per gallon ( $41 \%$ of which represents tax), and UK: $\$ 4.76$ per gallon (74\% of which represents tax.) pp. $10-2$ to 10.5 .

32 We understand that since 2001, there has been a considerable narrowing of these intra-EU differences in vehicle taxes. 
5.13 shows the relationship between cars per capita and GDP per capita for different European countries in 1998. Denmark is notable for its low car ownership rates relative to its income level. ${ }^{33}$

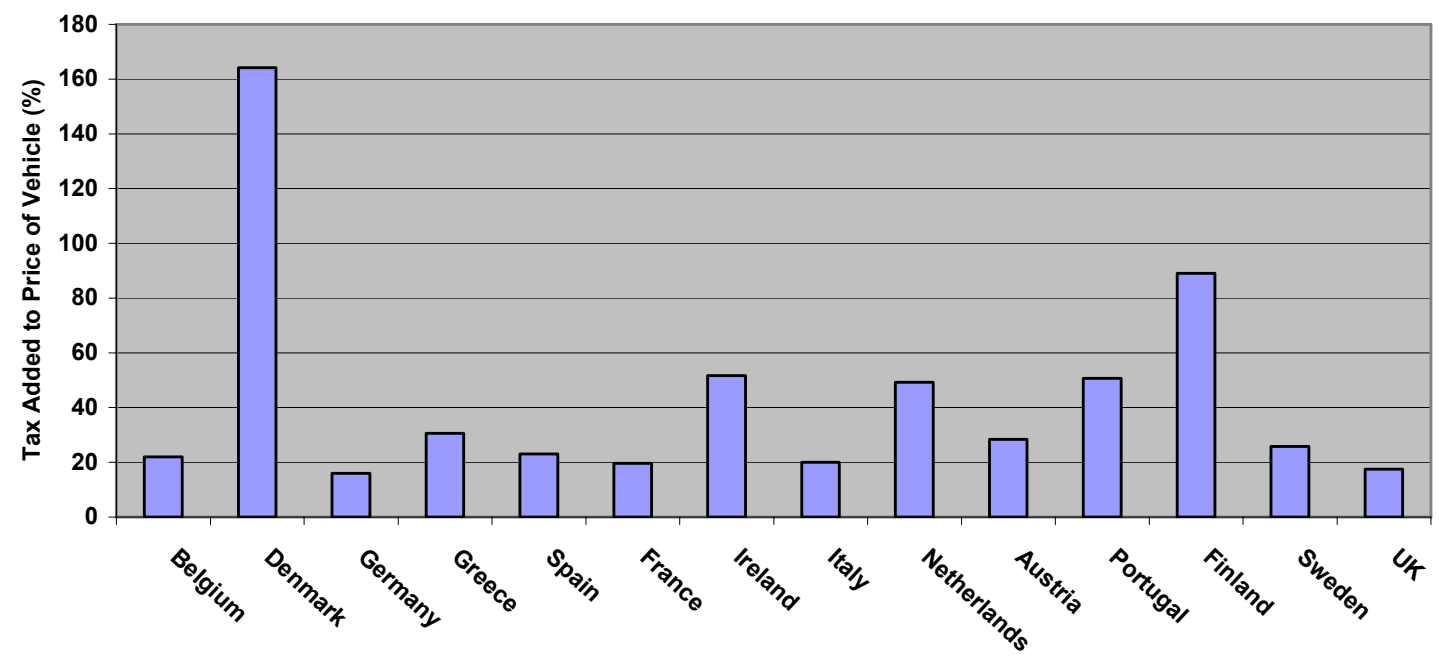

Figure 5.12 Tax Added to Price of Vehicle (\%)

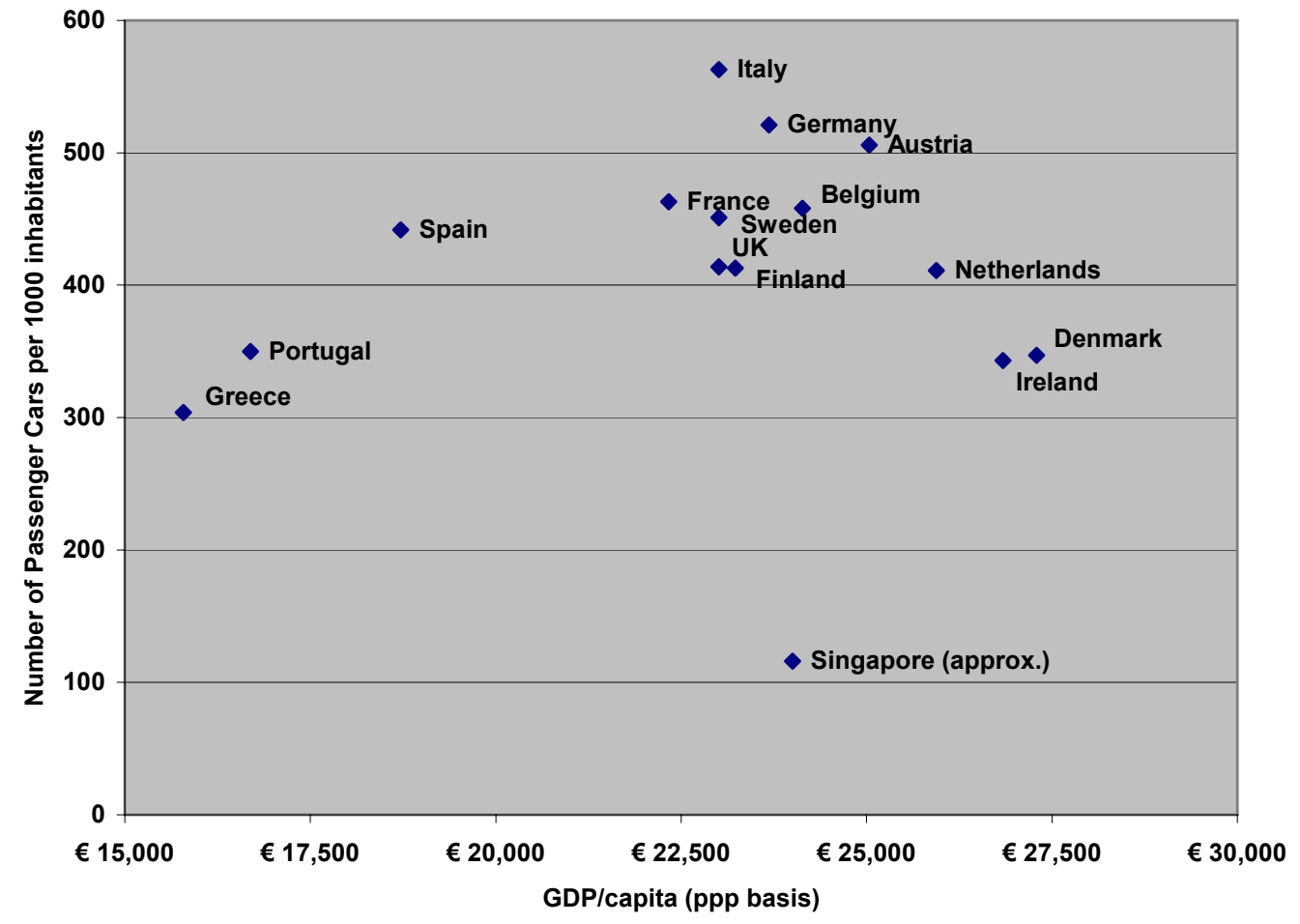

Figure 5.13 Passenger Cars per 1000 Inhabitants vs. GDP/Capita as of 2000 EU-15 and Singapore*

33 The relatively low level of automobile ownership in Ireland seems to reflect the rapid rate at which Ireland has developed economically. It takes time for a country's automobile stock to increase. The number of private cars in Ireland rose from 1 million in 1996 to 1.6 million in 2004, a growth rate of over 5\% per annum. http://www.finfacts.com/irelandbusinessnews/publish/article_10005281.shtml. 
The country that imposes perhaps the highest acquisition and ownership costs on private automobiles is Singapore. To acquire a private motor vehicle in Singapore, one must pay an import duty equivalent to $31 \%$ of the vehicles open market value (OMV), an "Additional Registration Fee" of $110 \%$ of OMV, and various other fees and taxes. One also must purchase a "Certificate of Entitlement" (COE). The number of COEs that will be made available at any time is limited by the government. The limited number of COEs is allocated by means of an auction. One estimate we have seen of how these various taxes and other charges add up is that in mid-2003, an Audi A4 with a 1.8L engine that cost approximately US\$25,000 in the U.S. cost US\$182,000. I have plotted Singapore's approximate private vehicle ownership rate and per capita income in Figure 5.12. Singapore is even more of an outlier in Figure 5.12 than is Denmark.

Singapore transportation planners emphasize that Singapore's low private car ownership rate is not only due to high acquisition and ownership costs. Singapore also has a system of electronic tolls with the tolls being set to assure that traffic will flow freely. Singapore also has made major investments in its public transport system. Originally confined to buses, it now includes a metro and local "people movers." Finally, Singapore has encouraged its citizens to purchase housing in large apartment blocks whose location is designed to provide access to public transport and shopping. In short, Singapore has undertaken almost everything that urban planners suggest should reduce "automobile dependence."

What is the impact of these various actions? In Table 5.12 I provide comparisons of transport choices and outcomes in Singapore and London. ${ }^{34}$ The area of both is nearly the same. Singapore's residential density is nearly $60 \%$ higher, though it is quite low by Asian standards. The proportion of jobs in the CBD is higher in London than in Singapore. And the metropolitan GDP in US\$ is comparable in the two areas.

Not surprisingly, private automobile ownership in Singapore is extremely low - only 35\% of that of London - 116 per 1000 inhabitants versus 332 per 1000 inhabitants. $^{35}$ Utilization per vehicle (measured by kilometers per car per year) is 50\% higher in Singapore than in London. While not many people in Singapore own private cars, those that do own them use them intensively.

Personal transport patterns are surprisingly similar in London and Singapore. The number of trips per day per capita, the average trip length, the average trip distance by car and by public transport, and the overall average distance of the journey to work are not all that different. Both car and public transport trips are faster, possibly reflecting the impact of Singapore's electronic tolling. The number of passenger car kilometers per capita for Singapore is much less than for London, while the number of kilometers per capita by motorcycle, taxi, and public transport are all considerably greater. Overall, the amount of personal travel per capita is surprisingly similar - $7092 \mathrm{~km}$ for London and $7859 \mathrm{~km}$ for Singapore.

34 "London" in this case refers to Inner London (including Central London). Thirty nine percent of London's population of 7.4 million resides in Inner London. Inner London is the registration "home" of 29\% of London's 2.2 million private cars. TfL, London Travel Report 2004, p. 42.

35 In 2003, car ownership in the "London Boroughs" (which we understand includes not only Central London and Inner London but also Outer London) was 0.47 per adult of age 17+. For all of Britain the comparable figure was 0.60. Source: http://www.dft transtats_031842.xls. 
Table 5.12 London and Singapore Personal Transport Characteristics

\begin{tabular}{|c|c|c|c|}
\hline & London & Singapore & Singapore/London \\
\hline \multicolumn{4}{|l|}{ Characteristics of the Urban Area } \\
\hline Area (sq. km.) & 321 & 312 & $97 \%$ \\
\hline Urban density (persons/ha) & 59.07 & 93.53 & $158 \%$ \\
\hline Proportion of jobs in CBD (\%) & 28.04 & 16.38 & $58 \%$ \\
\hline Metropolitan gross domestic product per capita (US\$) & $22,362.90$ & $28,577.93$ & $128 \%$ \\
\hline \multicolumn{4}{|l|}{ Private Vehicle Ownership } \\
\hline Passenger cars per 1000 people & 332 & 116 & $35 \%$ \\
\hline Motor cycles per 1000 people & 9 & 43 & $490 \%$ \\
\hline \multicolumn{4}{|l|}{ Private Vehicle Utilization } \\
\hline Passenger car kilometres per car & 12,393 & 18,486 & $149 \%$ \\
\hline Motor cycle kilometres per motor cycle & 9,325 & 5,000 & $54 \%$ \\
\hline \multicolumn{4}{|l|}{ Trips per Day per Capita } \\
\hline Total & 2.8 & 2.6 & $93 \%$ \\
\hline \multicolumn{4}{|l|}{ Trip Length } \\
\hline Overall average trip distance $(\mathrm{km})$ & 8.5 & 8.1 & $95 \%$ \\
\hline Overall average trip distance by car $(\mathrm{km})$ & 11.3 & 9.4 & $83 \%$ \\
\hline Overall average trip distance by public transport $(\mathrm{km})$ & 12.6 & 10.6 & $84 \%$ \\
\hline Overall average distance of the journey-to-work ( $\mathrm{km}$ ) & 7.2 & 7.5 & $104 \%$ \\
\hline \multicolumn{4}{|l|}{ Trip Time } \\
\hline Average time of a car trip (minutes) & 24 & 16 & $67 \%$ \\
\hline Average time of a public transport trip (minutes) & 35 & 30 & $86 \%$ \\
\hline \multicolumn{4}{|l|}{ Annual Passenger Travel per Capita by Mode } \\
\hline Passenger car passenger kilometres per capita & 5,463 & 3,570 & $65 \%$ \\
\hline Motor cycle passenger kilometres per capita & 91 & 260 & $287 \%$ \\
\hline Taxi and shared taxi passenger kilometers per capita & 105 & 887 & $841 \%$ \\
\hline Public transport passenger kilometers per capita & 1,434 & 3,142 & $219 \%$ \\
\hline Total & 7,093 & 7,859 & $111 \%$ \\
\hline \multicolumn{4}{|l|}{ Transport Energy Indicators } \\
\hline Private passenger transport energy use per capita $(\mathrm{MJ})$ & 13,223 & 10,375 & $78 \%$ \\
\hline Public transport energy use per capita $(\mathrm{MJ})$ & 1,210 & 1,723 & $142 \%$ \\
\hline Total transport energy use per capita $(\mathrm{MJ})$ & 14,433 & 12,098 & $84 \%$ \\
\hline Price of Fuel (per km, as $\%$ of per capita GDP $* 10^{-5}$ ) & 45 & 26 & $58 \%$ \\
\hline
\end{tabular}

Source: Millennium Cities Database for Sustainable Transportation

Private passenger transport energy use in Singapore is somewhat less than in London, though not as much less as the number of passenger car kilometers per capita. This suggests that the average private car in Singapore may be larger (and less fuel efficient) than the average private car in London. Per capita public transport energy use for Singapore is somewhat greater than for London. However, due to the greater energy efficiency of public transport (when used at high levels), total per capita transport energy use for Singapore is 16\% less than for London. An additional point shown in Table 5.12 that the fuel cost per kilometer in Singapore is about $60 \%$ of that in London. Evidently taxes on transport fuel are lower in Singapore than in London.

I am not claiming that the results achieved by Singapore could - or should - be duplicated elsewhere. For a number of political and social reasons, Singapore probably is unique. But Singapore does, I believe, illustrate what can be achieved in terms of changes in altering the level and mix of personal transport demand as well as the level of transport energy use. What I find surprising is how little difference there is in total personal transport passenger kilometers per year and in total transport energy use between London and Singapore considering the range and intensity of the "carrots" and "sticks" utilized by the Government of Singapore.

\subsection{SUMMARY}

If present trends continue, both personal and goods transport demand will grow rapidly over the next several decades. Given the transportation sector's importance as a user of oil and its near- 
total dependence on oil-based fuels, growth in transport demand at anywhere near the levels projected in this paper will have important implications for the demand for oil.

Probably the most important driver of transport demand is real per capita income. Countries with high levels of real per capita income use much greater amounts of transport services per capita than countries with low levels of real per capita income. And countries experiencing rapid rates of growth in real per capita income can also expect to see per capita transport demand grow rapidly.

At present, the bulk of both personal and goods transport demand is accounted for by the countries making up the OECD. But the non-OECD countries as a group are projected to grow somewhat faster over the next several decades than the OECD countries as a group. A group of non-OECD countries/regions - the FSU, Eastern Europe, China, and India in particular - are projected to experience especially rapid economic growth in the coming years. If this rapid growth indeed occurs, the current gap in per capita transport demand between these non-OECD countries and the OECD countries will narrow significantly or, in some cases, may even disappear.

A second factor influencing transport demand growth is population growth. In the second half of the $20^{\text {th }}$ Century, the world's population grew at an unprecedented rate. This period of extremely rapid population growth now appears to be over. The populations of OECD Europe, OECD Pacific, the FSU, and Eastern Europe are all projected to be less in 2050 than they were in 2000. Only Africa and the Middle East are projected to experience population growth rates averaging above $1.5 \%$ per year. Between 1950 and 1975, world population grew at $1.9 \%$ per year. Between 1975 and 2000 it grew at 1.6\% per year. Slower population growth rates, especially in higher income countries, will reduce upward pressure on transport demand.

Urbanization is a third factor influencing transport demand. Most transportation occurs within or between urbanized areas. And urbanization will grow rapidly in many non-OECD countries/regions. Between 2000 and 2030, urban population in the world's less developed regions is projected to grow by 1.96 billion compared with a projected growth in total world population over the same period of 2.06 billion.

Urban form is also a significant factor influencing transport demand, but the magnitude of its influence and its susceptibility to major change are matters of considerable dispute. Urban areas with low residential density and low job density are often said to "sprawl." Opponents of "sprawl" assert that transport demand in such urban areas is considerably greater than transport demand in more compact urban areas. They also assert that transport demand could be significantly reduced if "sprawl" could be reduced. I cited two studies, both of which are based on data from the United States, indicating that private motor vehicle use per household in the "most sprawling" urban areas is about $25 \%$ greater than in the "least sprawling" urban areas. ${ }^{36}$ However, the difference in the rate of motorized personal vehicle ownership and in the probability of driving to work is only about half that. While these differences are not trivial, it is not clear just how feasible it might be to alter urban form sufficiently to make a significant difference in transport demand patterns.

36 New York City is excluded from both the averages since it is such an extreme outlier. 
A final factor influencing transport demand is the share of a household's budget spent on transportation. This share varies considerably across countries. A not inconsequential share of this variation is explained by different national policies impacting private vehicle ownership and use costs. Raising the price of owning a private vehicle clearly has an influence on the rate of private vehicle ownership, as shown by the example of Denmark in Europe and, especially, by the example of Singapore in Asia. A comparison of transport demand characteristics in Singapore and Inner London, two areas of similar size, residential density, and per capita income, suggests that fiscal measures, if sufficiently stringent and if combined with other policies, can shift the modal mix, if not the total, of personal transport demand. This shift in modal mix is associated with a modest reduction in transport energy use per capita. 


\title{
6. ENERGY SECURITY AS A DRIVER IN THE TRANSITION FROM OIL
}

\author{
Wil Kohl \\ The Johns Hopkins University School of Advanced International Studies
}

Energy security has been defined very generally as reliable supplies of energy at affordable prices. One might also add that secure energy must also be environmentally sound. Of course, there is more to energy security than oil, including the security of electricity and natural gas supply, but this workshop is focused on oil. Oil security is inherently an international problem because the world oil market is one giant pool.

Threats to oil security may be of three types. The first is the market power of the OPEC cartel. By regulating production, OPEC has been able to hold world oil prices well above production costs, most of the time. The second area of concern is oil price shocks. Oil price shocks can be caused by wars, instabilities in produced countries, any action that intentionally or unintentionally causes a significant reduction in world oil supply. Shocks can cause inflation, unemployment and recession. Their impacts depend on an economy's total oil consumption, its imports and its oil intensity. The third is the long-term outlook for oil supplies and the possibility for oil peaking.

Oil security has been a major concern for the United States since the early 1970s when U.S. oil production peaked and the Arab-OPEC oil embargo of 1973-74 tripled world oil prices (Figure 6.1). Strategies for dealing with oil insecurity have included diversifying sources of supply, building strategic oil reserves, cooperating with other oil importing economies in oil crisis management through the IEA (i.e., coordinated release of emergency oil stocks in 1991 and 2005) and sharing information, also coordinated by the IEA.

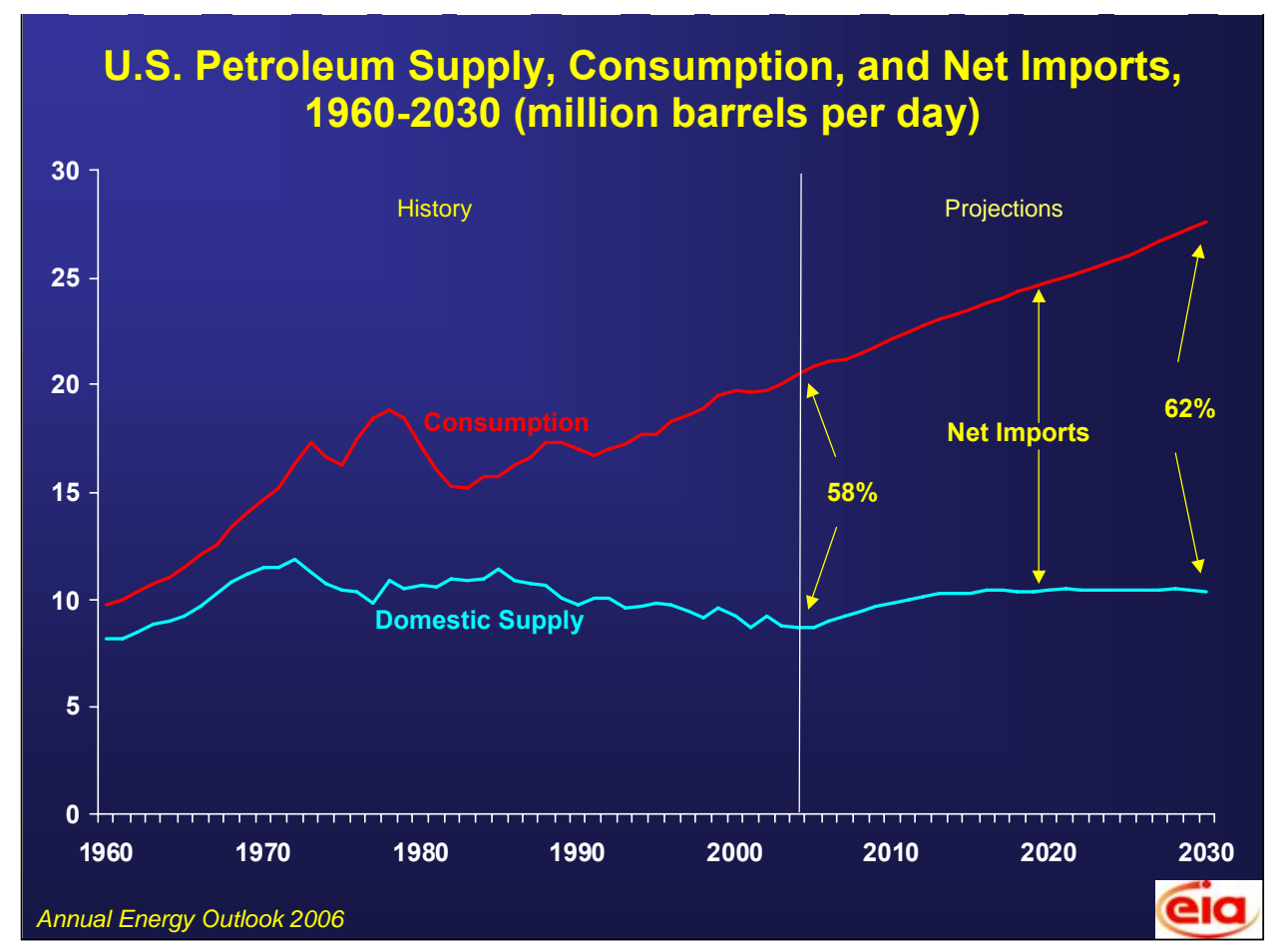

Figure 6.1 History and Outlook for the U.S. Petroleum Situation 
The meaning of energy security needs to be reevaluated in light the current world oil market situation. Energy security as it relates to oil is concerned with the following issues:

1. rapidly increasing demand for oil, especially in developing economies is straining existing production capacity,

2. refining and delivery infrastructure also lacks spare capacity increasing the danger of its vulnerability to terrorist attack or natural disaster,

3. the increasing quantities of oil traded internationally create strategic vulnerabilities to disruption,

4. the increasing emissions of $\mathrm{CO}_{2}$ from oil use poses an unsustainable threat to the global climate,

5. the prospect of peaking of non-OPEC oil supply by 2020 will create an increased requirement for OPEC oil and unconventional oil, magnifying OPEC's market power, and

6. dependence on oil diminishes the United States' foreign policy leverage in several ways.

The surge in oil demand from the motorization of mobility, especially in China and India, as well as continued growth in the United States, has reduced spare oil production capacity in the world. This has pushed oil prices to $\$ 70$ per barrel. With increased prices has also come increased political risk. There is continuing instability in key oil producing countries, such as Venezuela, Nigeria, Iraq, Iran and Russia. In the future, continued growth in oil demand combined with the likely peaking of non-OPEC conventional oil production will greatly increase the "call on OPEC." This is likely to lead to higher prices and increased demand for unconventional sources of oil (Figure 6.2).

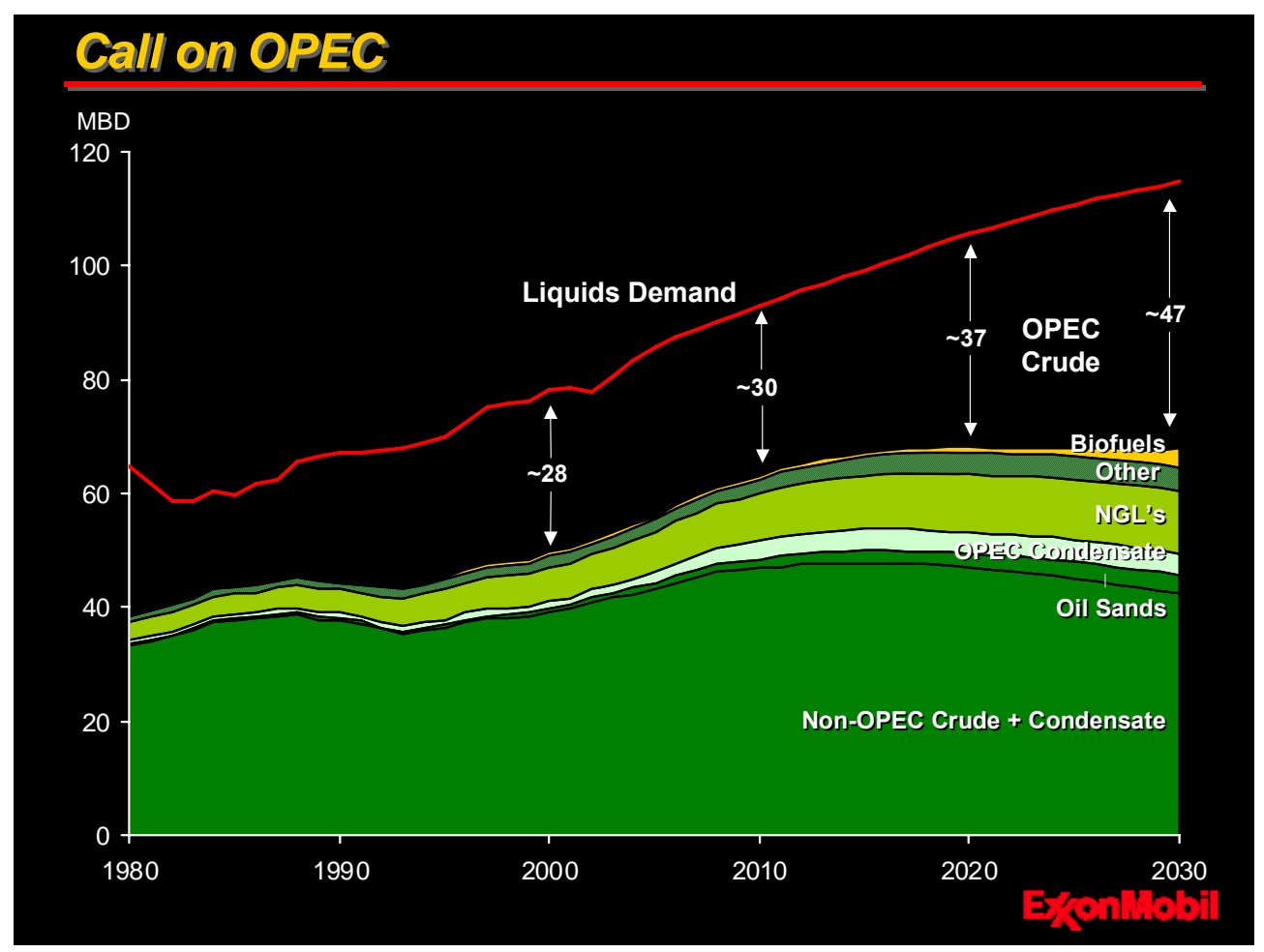

Figure 6.2 Peaking of non-OPEC Oil Demand and the "Call on OPEC:" ExxonMobil's View 
If OPEC responds to the world oil market's increased call for its oil, this will mean even greater international shipments from Middle Eastern nations, especially Saudi Arabia and Iraq. This will imply an even greater need to protect these shipments as they pass through strategically vulnerable straits on their way to Asia, Europe and the Americas (Figure 6.3).

Higher oil prices and greater oil wealth have been seen to feed corruption and slow democratic reforms in nations heavily dependent on oil revenues, a phenomenon often referred to as the "oil curse." Corruption and extreme inequity in the distribution of wealth leads to even greater instability. Oil consuming nations' dependence on oil puts them in the position of helping to finance regimes that may support terrorism.

To date, the United States' view of energy security has been too narrow and its policies have been too willing to accept the results of market forces. Future policies should focus on the need to reduce oil consumption to improve environmental sustainability, to reduce the dangers of oil supply disruptions from all causes, and to remove or lessen the foreign policy constraints that accompany continued dependence on oil. Lower oil imports should follow. All of these problems will benefit from reducing oil use, from which reduced oil imports will surely follow.

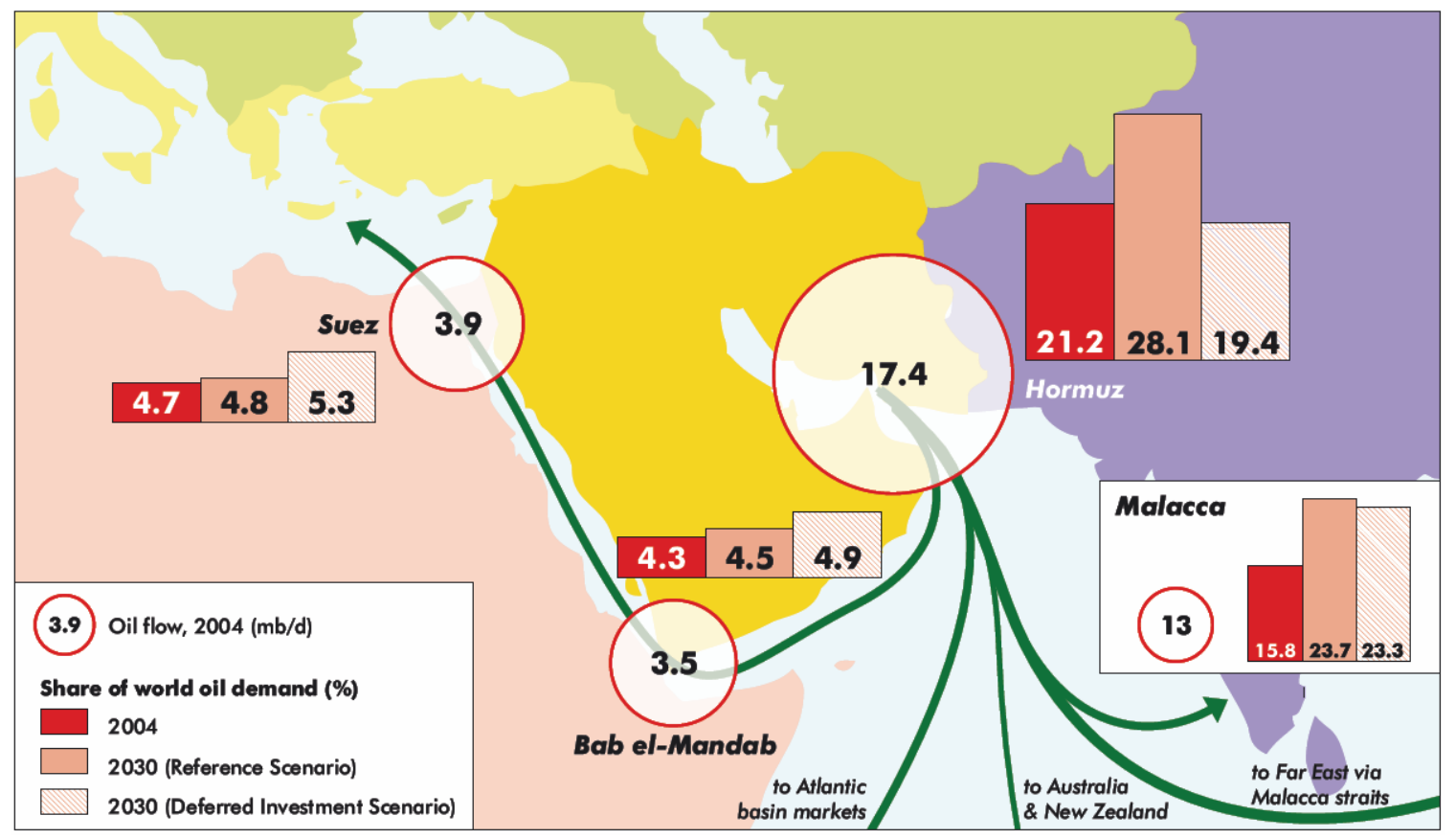

Figure 6.3 Middle East Exports Through "Dire Straits"

In considering how to formulate an energy policy to address the several dimensions of energy security, it is useful to consider what policies other oil-dependent economies have adopted. Japanese energy policy, for example, seeks to simultaneously achieve the following:

1. energy security, defined as a stable supply of energy,

2. economic efficiency, via deregulation and liberalization to reduce supply costs, and

3. environmental protection, especially the reduction of $\mathrm{CO}_{2}$ emissions to meet Kyoto Protocol targets. 
Although Japan reduced oil as a share of its primary energy use from $78 \%$ in 1973 to $52 \%$ in 2000 , it remains heavily dependent on oil, $90 \%$ of which it imports from the Middle East. Japan continues to promote nuclear power, natural gas, renewables, energy efficiency and eventually hydrogen and fuel cell vehicles.

The EU likewise views energy security, sustainability and economic efficiency as strongly linked objectives. The EU 2006 Greenpaper seeks to balance the three objectives:

1. sustainable energy use, via greater energy efficiency and increased use of renewable fuels,

2. economic competitiveness by liberalizing internal energy markets, and

3. security of supply, through increased efficiency, alternative sources, diversity of supply and managing emergency stocks.

The EU is in the process of implementing the Kyoto Protocol, and has set targets for electricity production from renewable energy (21\%) and biofuel use in transport $(5.75 \%)$ to be achieved by 2010. Other key elements of its energy policy strategy are an emissions trading system for power plants and minimum shares of the energy mix to come from secure, low-carbon sources.

China's primary concern is with oil dependence and the reliability, availability and affordability of petroleum supplies. It imports $40 \%$ of its oil needs, mainly from the Middle East and West Africa. With a rapidly expanding fleet of motor vehicles and limited domestic oil resources, China is facing explosive growth in oil imports. China is also concerned about the environmental impacts of expanded motor vehicle use, especially on urban air quality. China has responded to its growing oil dependence by,

1. increasing both domestic oil production and equity in foreign oil resources,

2. building pipelines to allow expanded energy imports,

3. building strategic petroleum reserves,

4. establishing mandatory fuel economy standards,

5. promoting natural gas use,

6. experimenting with coal liquefaction, and

7. conducting research on hydrogen fuel cell vehicles.

There is some evidence that the broader view of energy security is taking hold in the United States, as well, and that energy security may become one of the driving forces for a transition from oil. Both the President and influential members of Congress have recently stressed the importance of reducing oil imports and transitioning to alternative energy sources for transportation. However, U.S. energy policy is overly focused on the supply side and on technology and has placed too little emphasis on efforts to reduce demand and to achieve sustainability. 


\title{
7. CLIMATE CHANGE - ARE WE APPROACHING A TIPPING POINT?
}

\author{
Janet Peace \\ Senior Fellow in Economics, Pew Center on Climate Change
}

The need to reduce greenhouse gas emissions from the oil dependent transport sector, in and of itself is a sufficient reason to begin a transition away from petroleum. Transport accounts for $33 \%$ of U.S. $\mathrm{CO}_{2}$ emission and is the fastest growing source of $\mathrm{CO}_{2}$ and total greenhouse gas emissions (Figure 7.1).

Moreover, the United States has reached a tipping point for greenhouse gas policy. The combination of steadily increasing scientific certainty, public pressure and voluntary actions by industry will soon lead to a serious and sustained effort to control greenhouse gas emissions. In the past few years the Intergovernmental Panel on Climate Change (IPCC), the U.S. National Academy of Sciences and numerous other scientific bodies have made strong statements affirming the reality of climate change and of the central role of humans through emissions of greenhouse gases. Mounting evidence from melting polar ice caps, receding mountain glaciers around the world, impacts on species and increased severe storm activity have raised public awareness about climate change and the seriousness of its potential impacts. Since 1998, the percent of the public that believes climate change is happening has increased from $80 \%$ to $85 \%$. The fraction that views it as very or extremely important increased from $31 \%$ in 1998 to $49 \%$ in 2005. Still, misinformation persists, as $64 \%$ still believe that scientists disagree about climate change, down only $3 \%$ from 1998 . Once the public realizes that there is a nearly unanimous scientific consensus on climate change, policy change must follow.

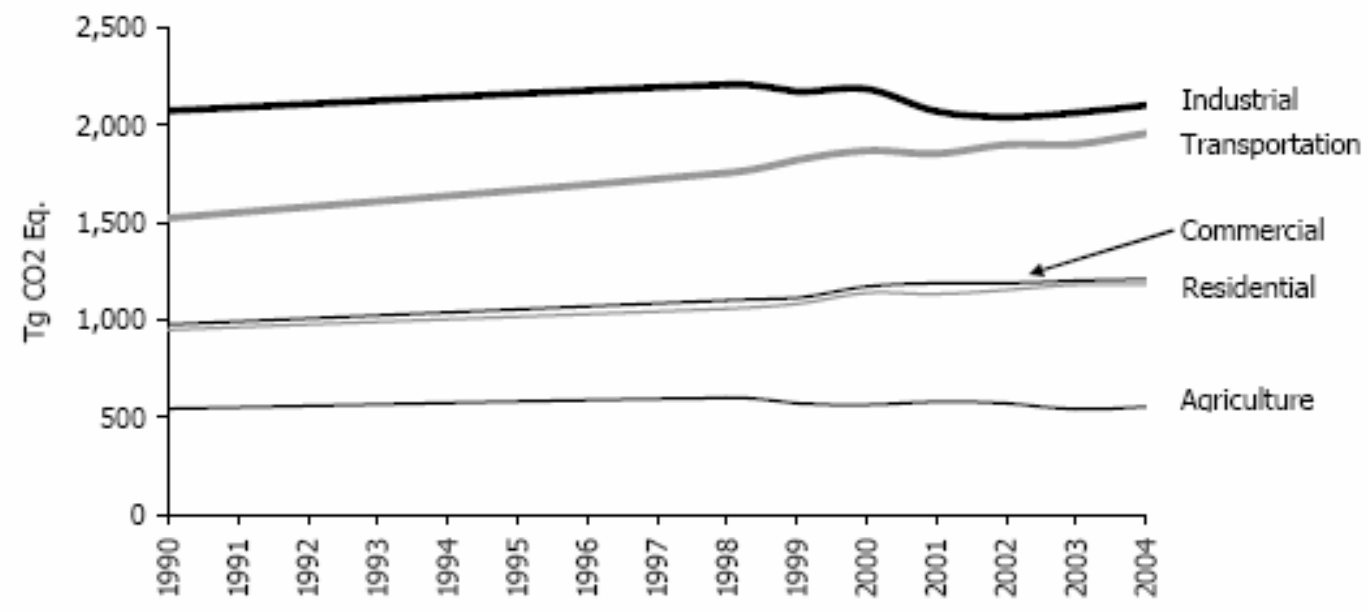

Figure 7.1 U.S. Greenhouse Gas Emissions by Energy End Use Sector

In the absence of an appropriate national climate change policy, state and local governments are seizing the initiative. The majority of states participate in regional climate change initiatives (Figure 7.2). In the Northeast, eight states have formed a Regional Greenhouse Gas Initiative and agreed to a memorandum of understanding calling for a stabilization of emissions over the period 2009-2015 and a 10\% reduction between 2015 and 2020. Initially, the cap on emissions 
applies only to electricity generators. California is implementing an ambitious plan aimed at an $80 \%$ reduction in emissions below current levels by 2050 . The plan includes not only a carbon cap but greenhouse gas emissions standards for cars and light trucks. Nine northeastern states that have "opted in" to California's air pollution standards are poised to implement California's greenhouse gas emissions standards, as well. At the time of the workshop, 28 states and numerous local governments had adopted their own climate action plans.

Businesses have also taken actions ranging from voluntary commitments to reduce emissions, to public outreach, to designing and marketing climate friendly products. Toyota plans to increase its sales of hybrid vehicles from 3\% to $10 \%$ of total light-duty vehicles (LDVs) by 2010. Walmart has pledged to improve its vehicle fleet's fuel economy by $50 \%$ by 2015 . Several significant legislative initiatives have been introduced in the U.S. Congress with growing but as yet inadequate support.

A transition from conventional oil has many positive implications for protecting the climate, including increased use of renewable and low-carbon fuels, increased emphasis on energy efficiency, and stimulation of technological change in transportation. However, it also raises concerns. If the transition is to unconventional fossil carbon resources, such as oil shale or CTL, transport's impact on the climate world worsen. If carbon policy becomes disconnected from energy policy, if energy security policies are formulated in a way that is disconnected from climate policy, a transition from oil could actually exacerbate climate change.

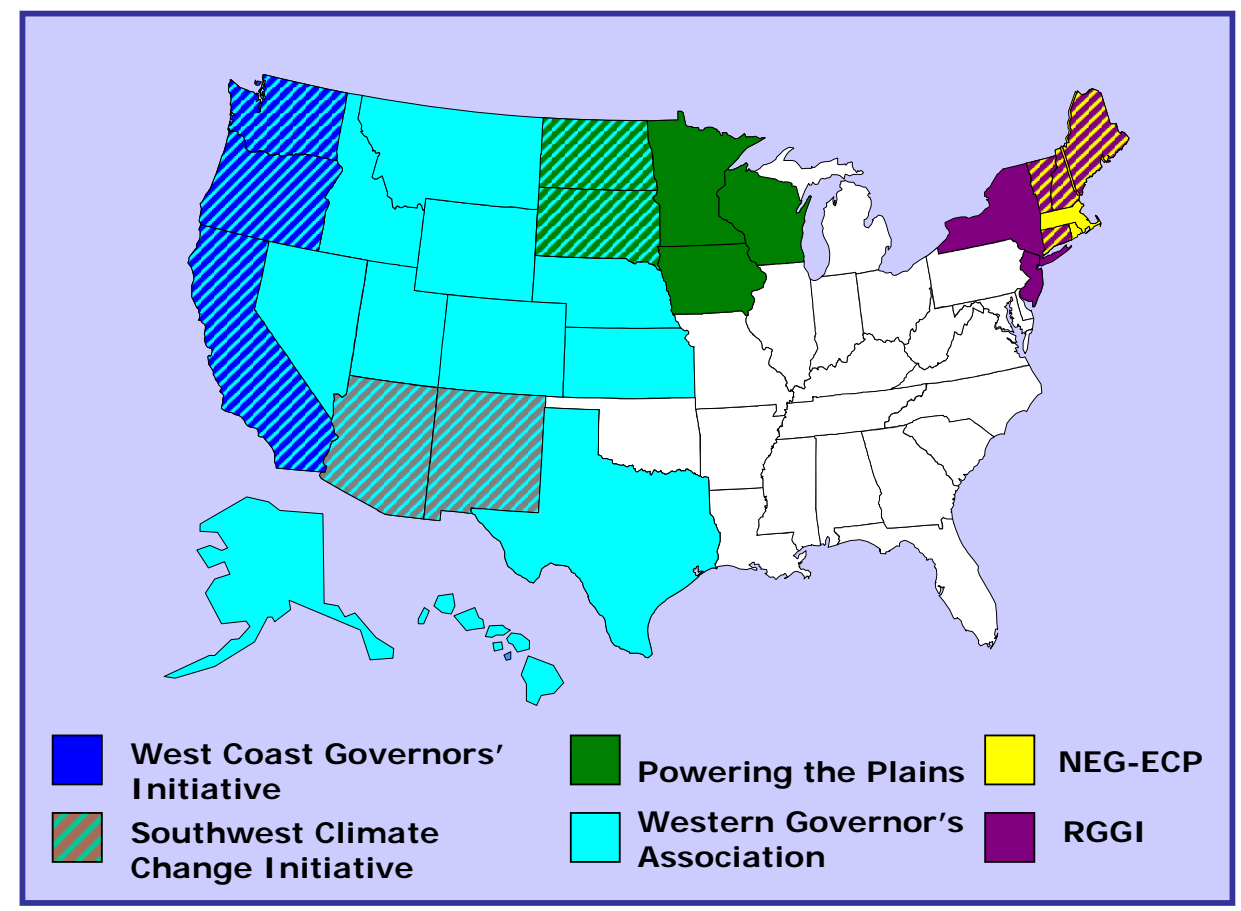

Figure 7.2 States Belonging to Regional Climate Change Initiatives in 2005 


\title{
8. AN HISTORICAL PERSPECTIVE ON GLOBAL ENERGY TRANSITIONS
}

\author{
Arnulf Grübler \\ IIASA and Yale University
}

An energy transition can be defined as a change from one state of an energy system to another with respect to the quantity, quality or structure of either energy supply or use. Of course, energy transitions are specific with respect to time and place. With that in mind, nine major energy transitions can be identified in history:

1. Non-commercial to commercial energy

2. Renewable to fossil energy

3. Rural to urban use of energy

4. From the southern to the northern and back to the southern hemisphere

5. Low exergy to high exergy energy sources (higher $\mathrm{H}: \mathrm{C}$ ratios)

6. To increased efficiency and productivity

7. To deeper conversion (e.g., electricity)

8. Toward increasing supply and demand density

9. To cleaner energy via desulfurization and decarbonization

The dynamics of energy use over time are quite different between industrialized and developing regions. In industrialized regions, per capita energy use took off in 1850 and reached a plateau in 1975. In developing regions, per captia energy use began to take off in 1975. When that explosion of energy use will reach a plateau is unknown. Over the past two centuries, the population of developing regions increased dramatically with little change in per capita energy use prior to 1975 (Figure 8.1).

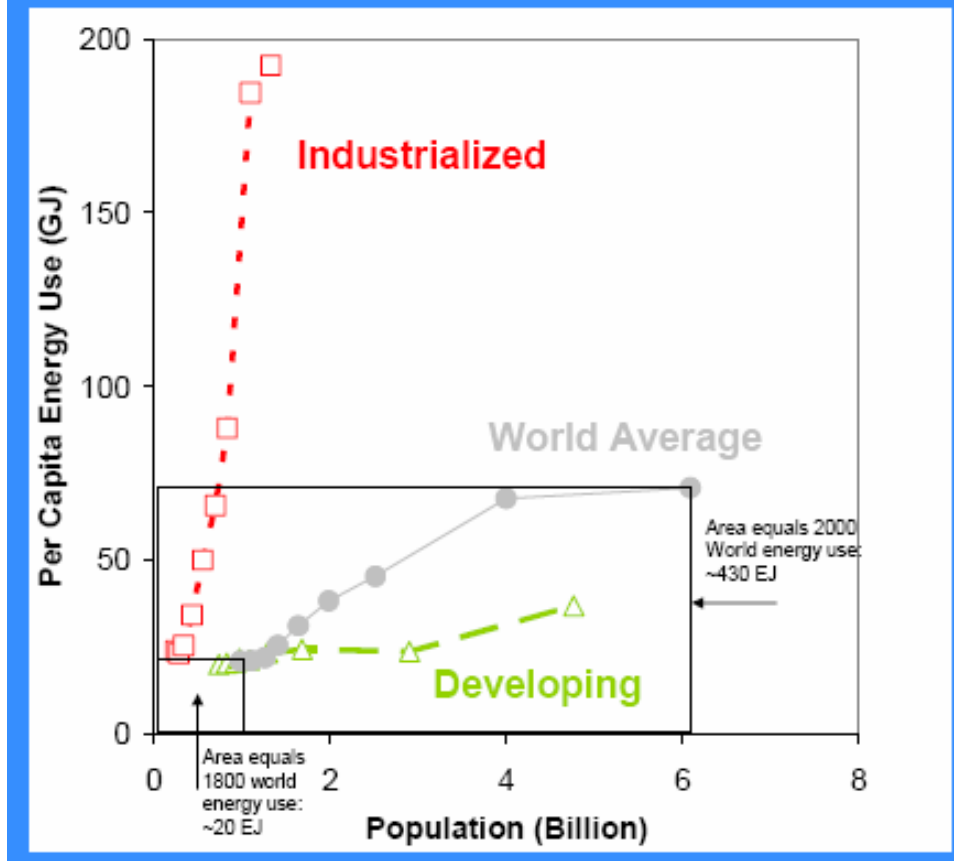

Figure 8.1 Population and per Capita Energy Use Trends in Industrialized and Developing Regions 
From 1950 onward, use of all energy resources grew. Absolute energy use trends therefore mask the important structural changes and transitions that were taking place. Examining the trends in market shares is therefore more revealing. As a rule, a peak in market share precedes and absolute peak by about 60 years. In the United States, the peak in the energy share of wood occurred in 1800, while total wood energy use peaked in about 1860 (Figure 8.2). The share of animal energy (horses, oxen, etc.) as measured by animal feed, peaked in 1860, with a subsequent peak in total feed energy at about 1920. Since petroleum's share appears to peak in 1975 , it is tempting to conclude that total oil use will peak in 2035 , but that would be a dangerous prediction. Note that coal's share peaked in 1920 but total coal use continues to rise.
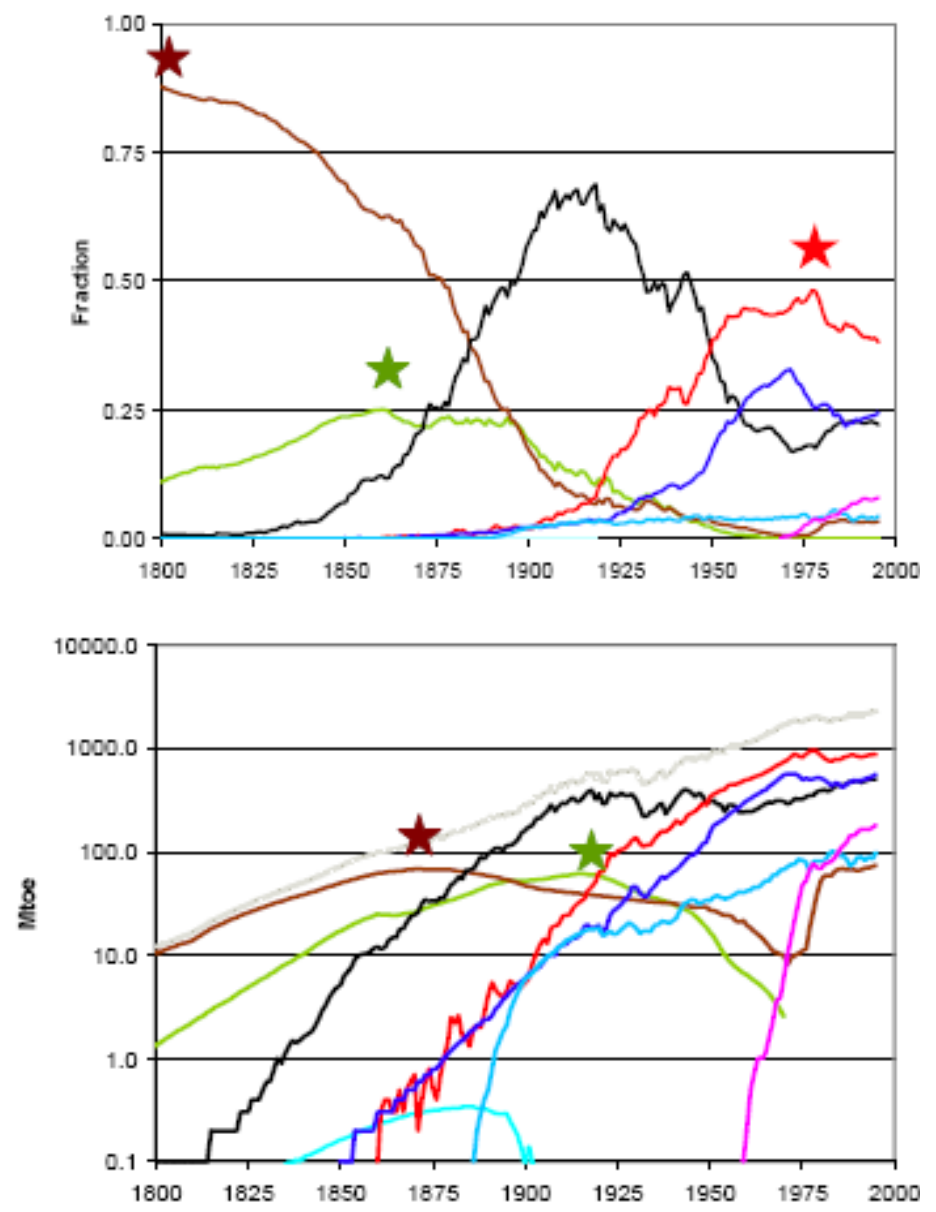

Figure 8.2 U.S. Energy Transitions: Market Shares (top) and Absolute Energy Use (bottom).

Since the onset of the Industrial Revolution there have been two "grand" energy transitions (Figure 8.3):

1. from $80 \%$ renewable energy in 1850 to $75 \%$ fossil coal by 1910 , and

2. from $80 \%$ coal to $60 \%$ petroleum and natural gas, again 60 years later.

The first question is where we will go from here. Numerous scenarios have been explored, from a return to coal, to even greater reliance on gas and oil, to a more radical shift to renewable and nuclear energy. The answer may lie in understanding what drives major energy transitions. 


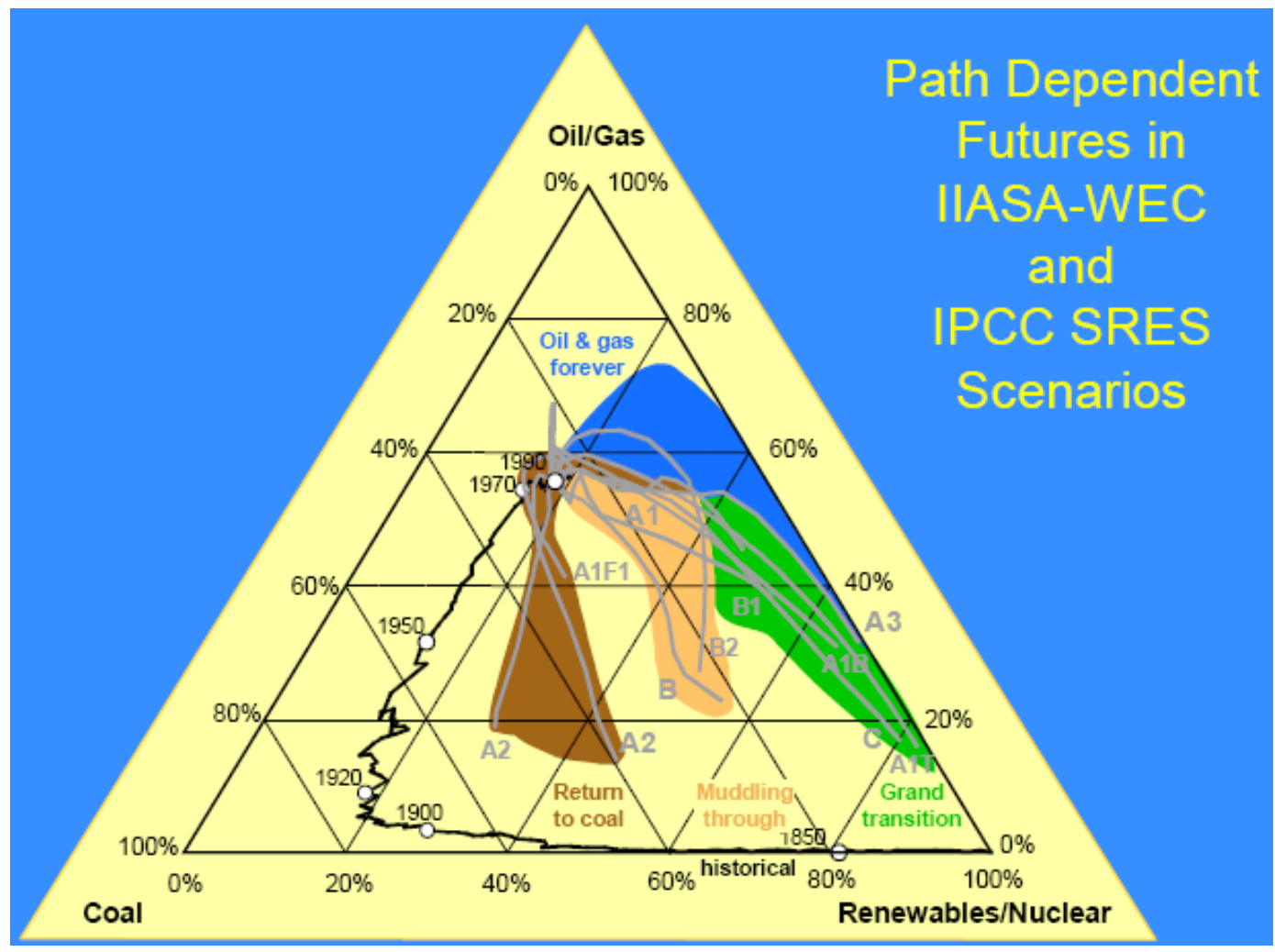

Figure 8.3 The Two "Grand” Historical Energy Transitions and Possible Future Scenarios

History reveals that energy transitions are always driven by innovations in energy end use technology. Examples include the steam engine encouraging the transition to coal, the automobile (internal combustion engine) and the transition to petroleum, and the electric motor and light bulb and the transition to electricity. The historical record contains no evidence of resource scarcity driving energy transitions. To the contrary, there is plenty of evidence that technological change expands resource availability over time.

The question is what instigates the technological changes that lead to energy transitions? Unfortunately, technological change is very poorly understood and even more poorly modeled. Useful generalizations can be inferred from history but prediction of technological change remains elusive. Price volatility appears to be an important trigger of technological change and structural change in energy systems. Policy, on the other hand, has had many failures and only a few successes.

The transition from horses to cars in the United States illustrates several lessons. First, the transition was rapid. It took about two decades to go from a horse-dominated transportation system to an automobile dominated one. This is because the speed of the transition is a function (approximately 2-times) the useful lifetime of the capital stock, in this case horses. At the time, about $25 \%$ of U.S. agricultural land was devoted to feeding horses, an impressive use of biomass energy in transport. Second, prices of the new technology and also of the form of energy it required declined as the technology moved from a niche market to pervasive diffusion (Figure 8.4). Third, the full diffusion of the automotive transport system lasted more than half a century, as shown by the saturation of road infrastructure (Figure 8.4). Fourth, the new technology, if 
successful, will create its own, new problems. At the time the automobile began to replace the horse, city streets were thoroughly polluted by animal waste. The automobile was hailed as a clean alternative. Later, as automobiles proliferated, pollution of the air by their exhaust emerged as the new environmental problem. By and large, technical solutions to automotive pollution have now been identified for all major pollutants save one, carbon dioxide $\left(\mathrm{CO}_{2}\right)$ (Table 8.1).
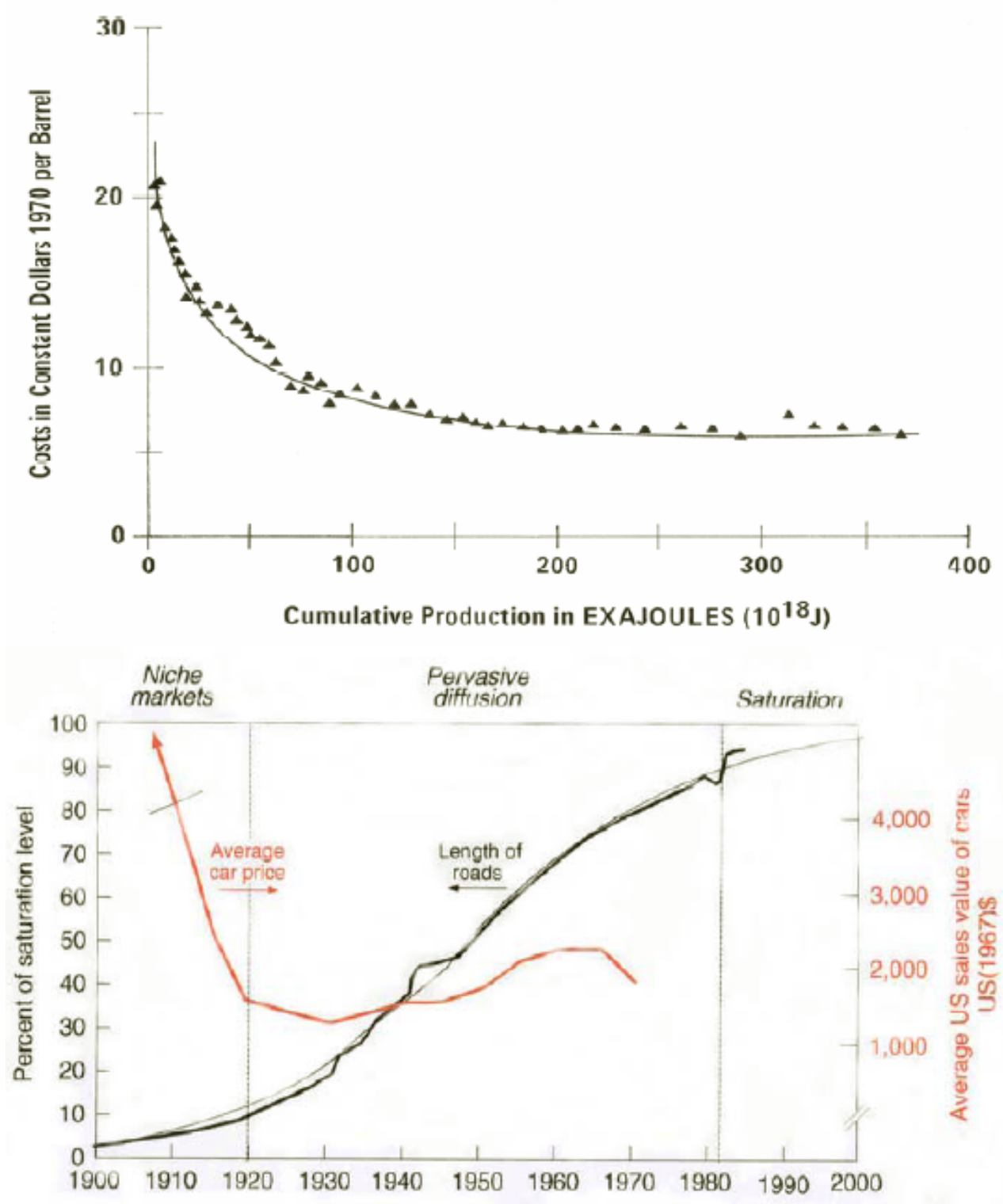

Figure 8.4 The Diffusion of Automobiles and Their Infrastructure in the United States: Gasoline Price Learning Curve (top) and Average Car Price and Length of Road Infrastructure (bottom). 
Table 8.1 Energy Efficiency and Emissions for Horses and Automobiles

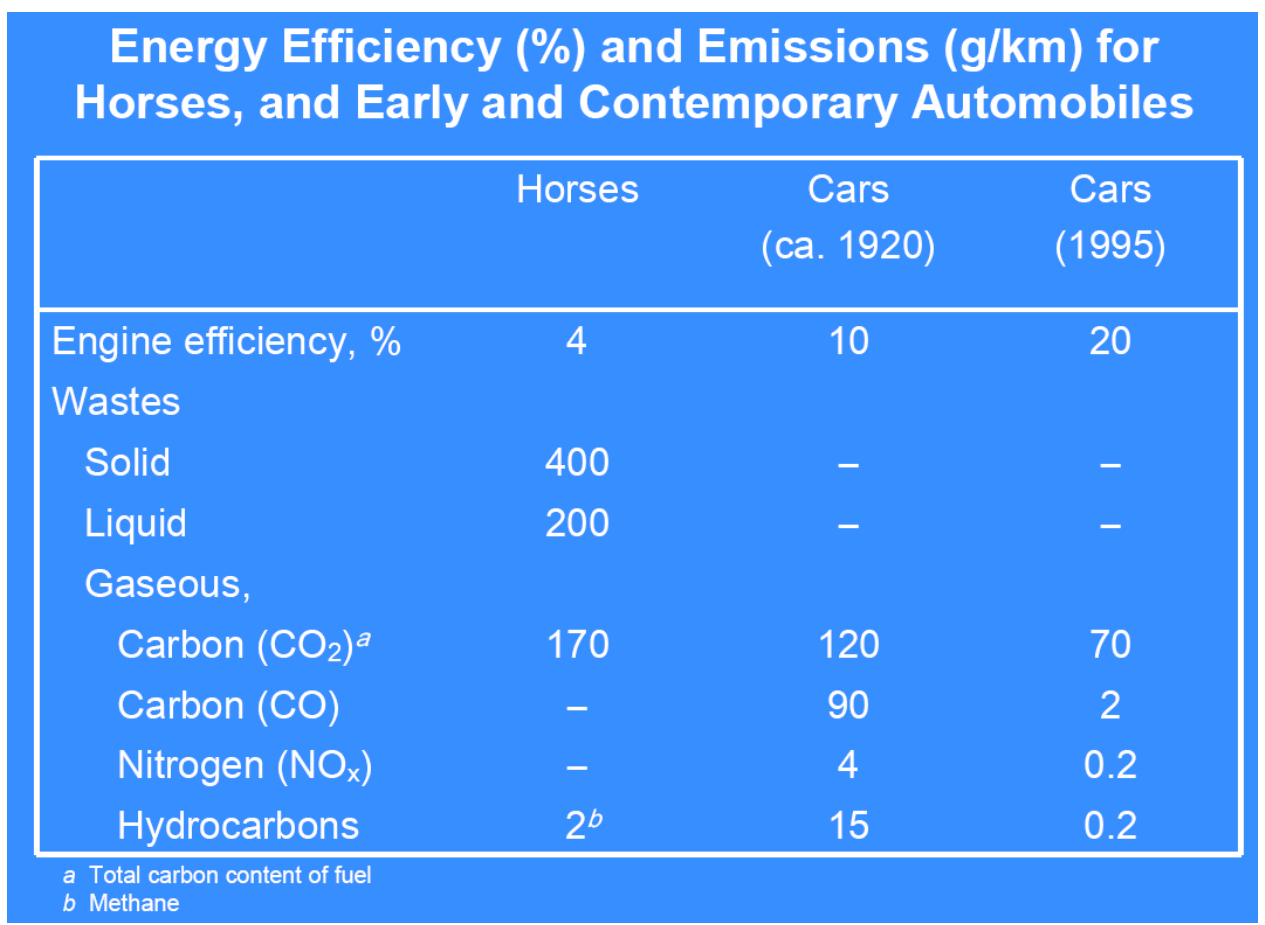

Energy transitions are driven as much or more by the quality of energy than by only its price. There have been few studies of this important fact, and it is largely ignored in energy models. In a successful energy transition, the trade-off between quality and price is resolved in favor of quality. Price subsequently declines by means of learning-by-doing. Quality is valued at end use, which is why end use technology is usually the driver of energy transitions. Energy quality has many dimensions including, exergy (form value), emissions, and $\mathrm{H}: \mathrm{C}$ ratios. One of the most significant trends in energy use since the beginning of the industrial revolution has been the trend toward decarbonization of energy sources. Energy end use demands are steadily driving the market toward higher quality and cleaner energy. Energy supply follows but at a slower rate (Figure 8.5).

Resource scarcity has rarely been a driver of energy transitions. Only one example can be found in history: whale oil. The annual catch of sperm whales followed an approximately bell-shaped Hubbert curve (Figure 8.6). The peaking and decline of whale oil occurred just before the invention of kerosene lamps and the refining of kerosene oil making whale oil supplies obsolete in terms of energy supply.

In addition to the sparse historical evidence to support the Hubbert curve, the concept has several other deficiencies. The symmetry requirement of the Hubbert curve has not been confirmed, either empirically or theoretically. The need to assume a fixed ultimate resource ignores the fact that resources are defined by technology and prices and will expand as a result of technological change or price changes, or both. In addition, the Hubbert curve ignores market responses via innovation and substitution. For all these reasons, the Hubbert curve is not a useful tool for predicting energy transitions. The literature contains many attempts to predict energy transitions based on a variety of models of resource scarcity, all of which have turned out to be wrong. The 1981 hallmark study, Energy in a Finite World, based on the first globally balanced modeling of 
energy supply and demand, concluded that North American conventional oil production would steadily decline after peaking in 1970, and that a transition to enhanced recovery, deepwater and polar oil, and tar sands and oil shale would begin. By 2000, most of North American oil production was projected to come from these alternative sources (Figure 8.7). In fact, North American conventional oil production reached an historical maximum in 1985 and even today, very little is being produced from unconventional sources.

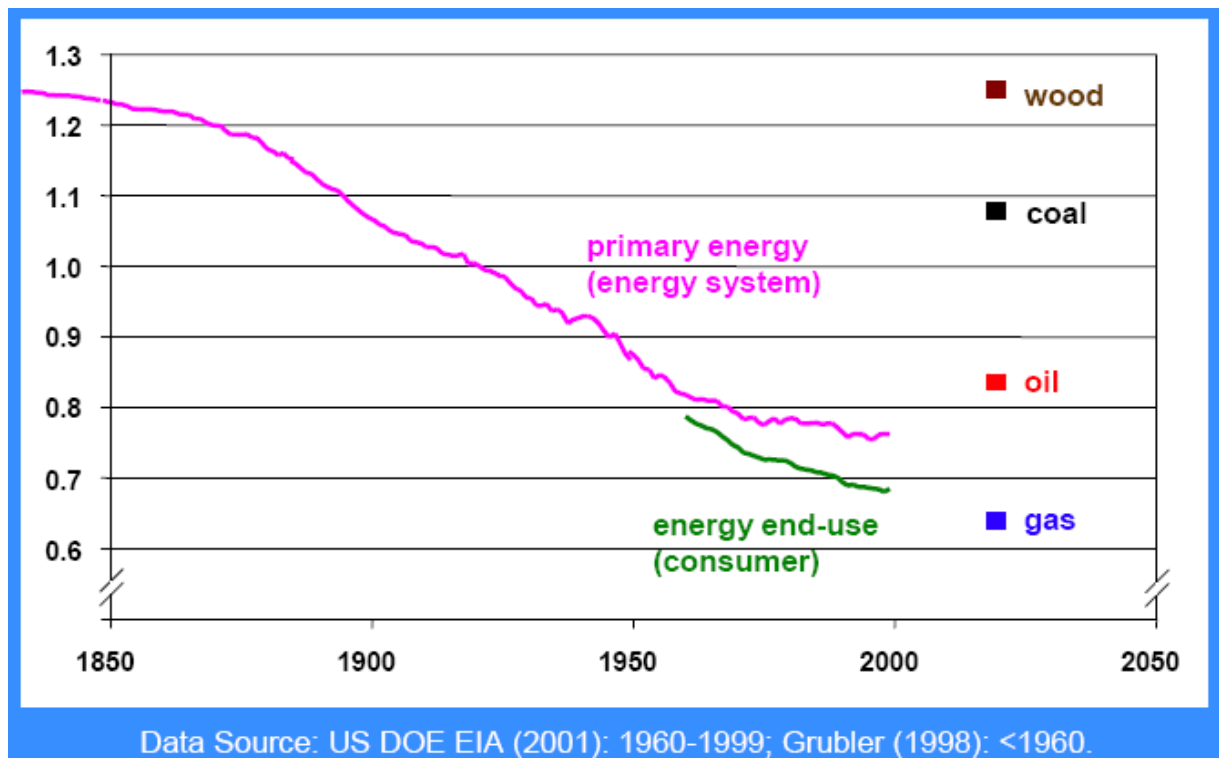

Figure 8.5 Decarbonization of the U.S. Energy System

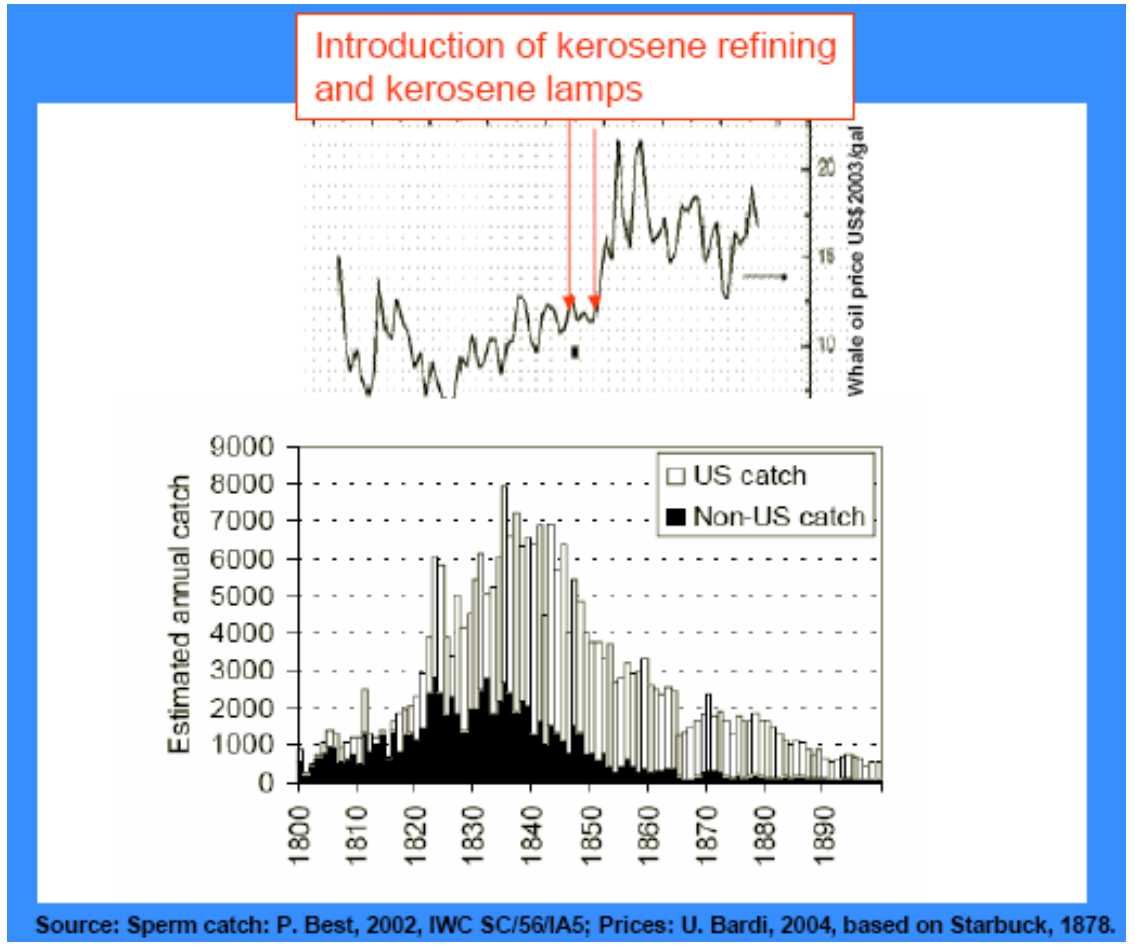

Figure 8.6 Annual Catch of Sperm Whales, 1800-1900 


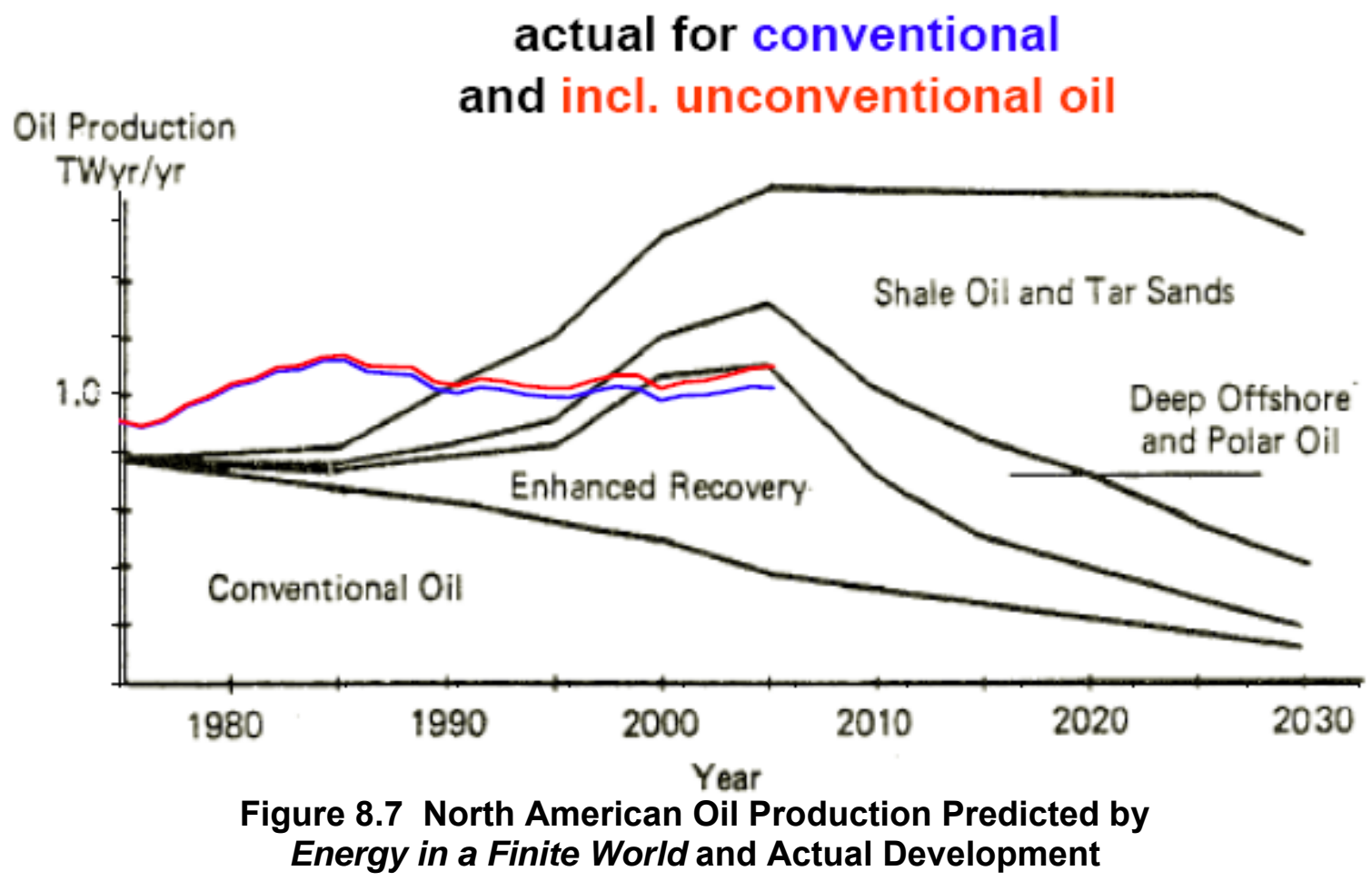

The history of global energy transitions has taught us several important lessons, even though we may have forgotten some of them. Energy transitions are more often driven by innovations in end use technology and the demand for energy quality; transitions driven by supply scarcity are extremely rare. This is because resource availability is a dynamic concept, constructed by economics and technology, as well as geologic knowledge. Our ability to predict energy transitions is very limited. In part this is because they are usually driven by technological change which is inherently difficult to predict. But it is also because responses to technological change and feedbacks within the energy system are more complex and more dynamic than our brains (or our models) expect. Historical predictions driven by geologic depletion, relying on the midpoint of ultimate resources to drive a transition, but ignoring the potential for alternatives, and the roles of technological change, and market responses and human behavioral changes have been not only incorrect but have offered bad policy advice. 


\section{SESSION 3: TECHNOLOGY AND ENERGY TRANSITION}

Robert Dixon, International Energy Agency, Chair

\section{TECHNOLOGY OF CONVENTIONAL OIL SUPPLY}

\section{Tom O'Gallagher}

Schlumberger

Technological advances are enabling the oil industry to access resources once considered inaccessible and to increase recovery rates from existing fields. An IEA assessment of conventional and unconventional oil resources and the costs of bringing them to the market illustrate the challenges facing the oil industry today. The 2005 WEO estimates that the world economy will consume almost a trillion barrels of oil through 2030, an amount roughly equal to total oil production to date. While OPEC possesses enough oil to supply that demand at a relatively low cost, it will in fact supply only a fraction for reasons outlined by Dermot Gately earlier in the workshop. This means that the rest of the world's supplies must come increasingly from hostile environments, such as deep and super-deep $(>3,000 \mathrm{~m})$ water or from Arctic Regions, as well as from enhanced recovery from existing fields (Figure 9.1).

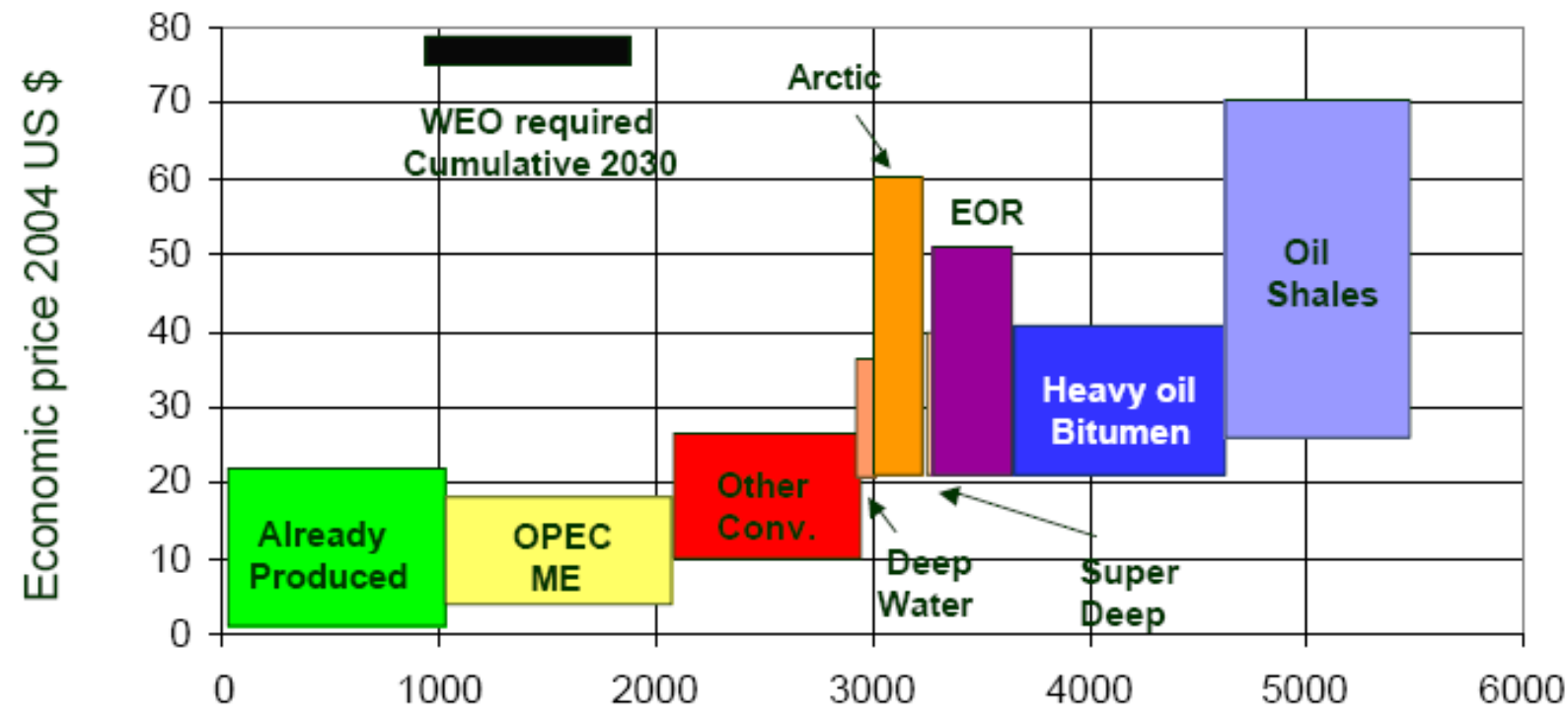

Figure 9.1 World Conventional and Unconventional Oil (billions of barrels) and the Cost of Recovery

Today's oil and gas industry faces significant challenges. Decades of underinvestment must be overcome with a major ramp-up in capacity. An aging workforce, a significant proportion of which will retire within 10 years, is likely to create a shortage of trained personnel. The extreme environments in which oil development is increasingly taking place are amplifying health, safety security and environmental risks. The more complex geologic structures being developed require more detailed modeling and greater precision in drilling. At the same time, productivity and recovery rates must be increased. The industry is moving faster, to more extreme climates, 
operating at higher pressures, and developing heavier more viscous oil, with higher levels of sulfur, water and gas.

The answer to these problems is technology. Tremendous advances have been made over the past several decades and more are needed. In exploration, advanced data acquisition will allow greater resolution of subsurface features. The vertical resolution of seismic data is 100 feet but the thickness of oil bearing structures, for example in the oil rim in the Troll field, may be only 15 feet. Greater resolution and improved methods of data interpretation and imaging will allow more precise targeting of drilling. Probabilities of success can be improved from 1 in 10 to 6-7 in 10. New methods of virtual reality allow engineers to get inside the 3-D image of subsurface geology to better understand how and where to drill (Figure 9.2).

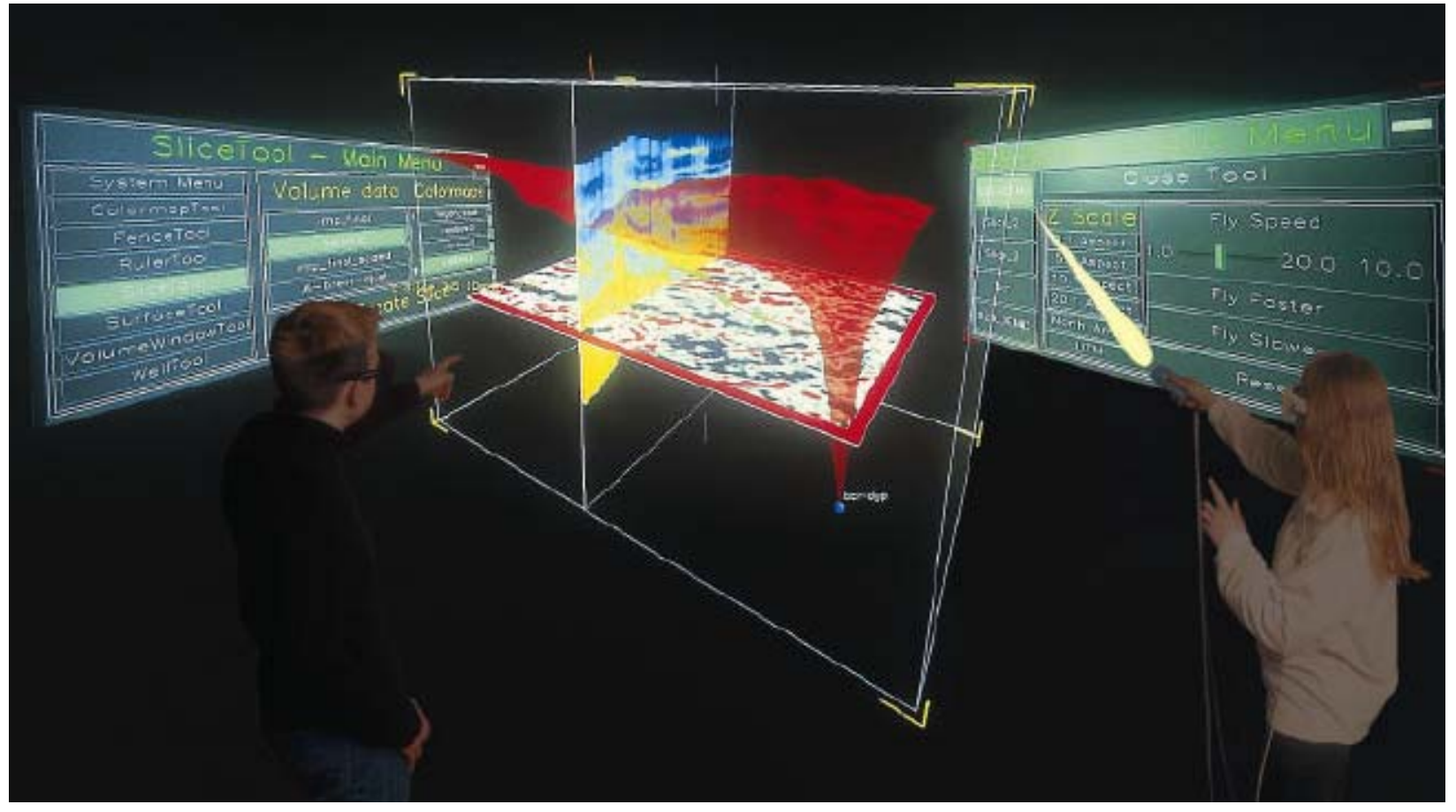

Figure 9.2 3-D “Virtual Reality” Imaging of Oil-Bearing Geologic Structures

Tomorrow's solutions for development will increase the agility and minimize the footprint of surface operations. Deep water development will be transferred from platforms to subsea operation on the ocean floor. For some operations, extraction, separation and transport will all take place on the ocean floor (Figure 9.3). Advances are also needed to allow continuous operation in extremely cold climates.

Advances in drilling technology will increase both efficiency and recovery rates. Geosteering will make use of intelligent drill bits that can sense the geology around them and conform to oil bearing structures. Extended reach horizontal drilling will allow wells to be extended laterally as far as $10 \mathrm{kms}$. This will not only allow for more convenient location of surface operations but will reduce the number of holes that must be drilled to fully exploit a play. Multillateral drilling allows several extensions out of the same drill hole and can be used to increase recovery from old wells. Data from wells around the world can be transmitted in digital form to high-tech 
operations centers where processes can be optimized with aid of supercomputers and expertise not normally available at the remote field locations.

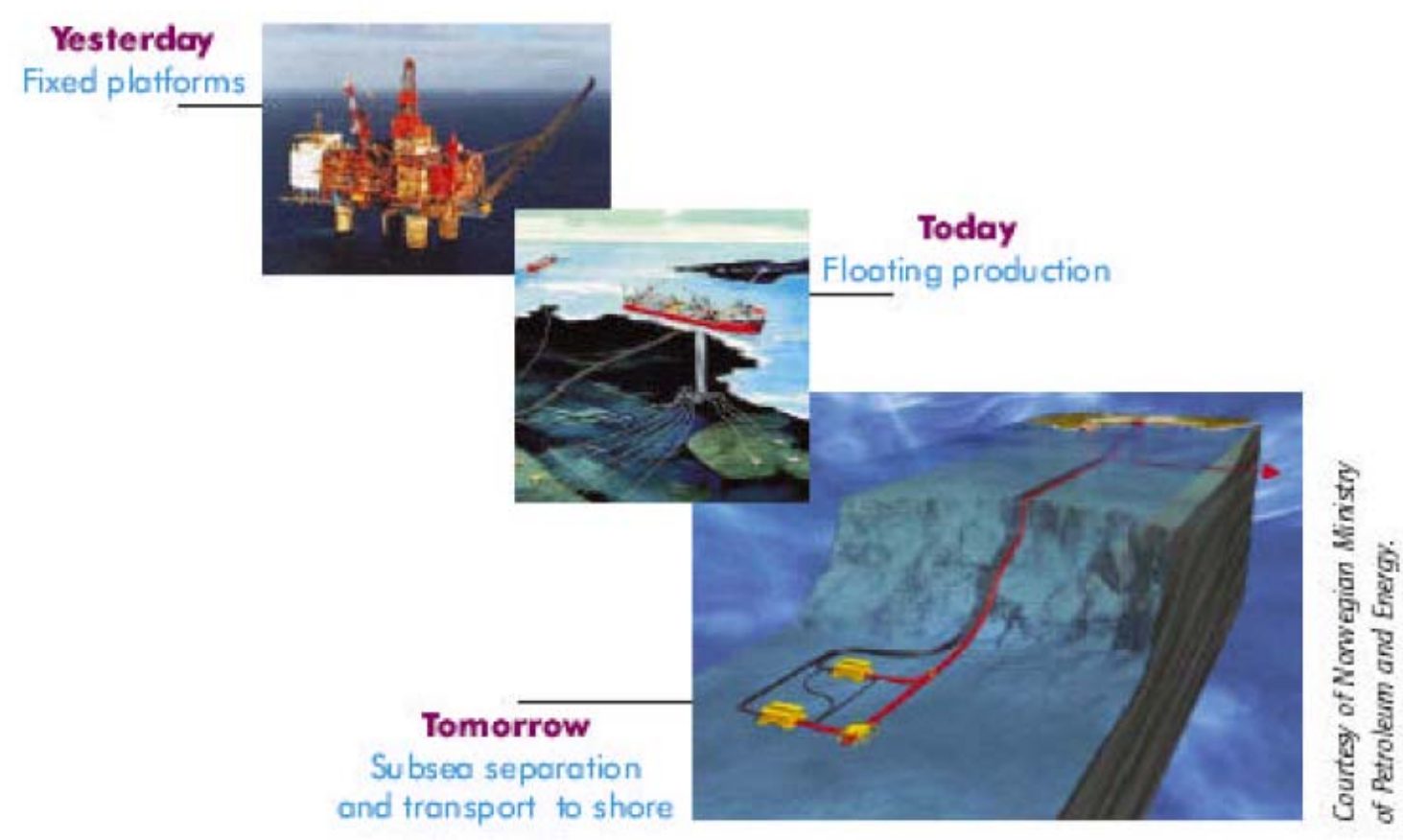

Figure 9.3 Ocean Oil Development will Move from Floating to Integrated Subsea Production

Technological advances have and will continue to improve efficiency, reduce costs and increase recovery rates. At the same time, exploration and development in extreme environments is becoming more capital intensive and the industry continues to face substantial risks ranging from extreme weather to volatile markets. 


\title{
10. TECHNOLOGY AND RESOURCE POTENTIAL OF ENHANCED OIL RECOVERY
}

\author{
Vello Kuuskraa \\ Advanced Resources International, Inc.
}

A transition from conventional oil to unconventional fossil resources, such as liquids from coal and oil shale, would greatly increase upstream greenhouse gas emissions, unless these emissions are captured and sequestered. For example, producing and consuming liquid hydrocarbon fuels from coal would emit nearly twice as much $\mathrm{CO}_{2}$ as producing and consuming conventional oil. However, if the $\mathrm{CO}_{2}$ from CTL or oil shale production is captured and used for enhanced oil recovery (EOR), two benefits occur - the carbon footprint of the CTL/oil shale process would be reduced and domestic oil production would be increased.

Because current primary and secondary recovery methods extract only about one-third of the oil in the ground, on average, about 400 billion barrels of oil remains unrecoverable in already discovered U.S. oil fields. A significant fraction of this remaining oil could be extracted with $\mathrm{CO}_{2}$-EOR technology. Currently, $\mathrm{CO}_{2}$-EOR contributes about 240,000 barrels per day to U.S. oil supply (Figure 10.1). Importantly, increased production of domestic oil from $\mathrm{CO}_{2}-\mathrm{EOR}$ is today constrained by the lack of available and affordable "EOR-Ready" $\mathrm{CO}_{2}$.

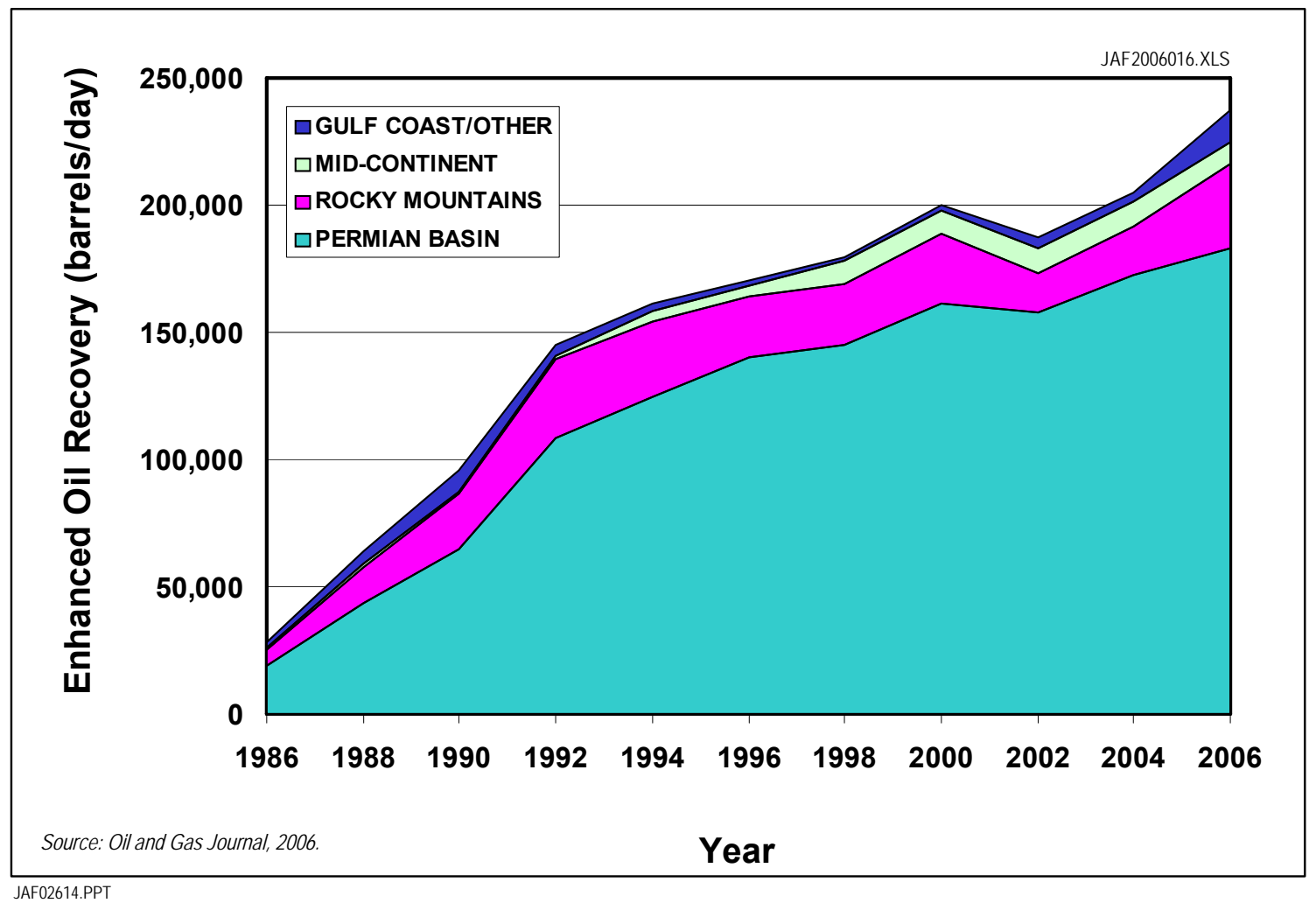

Figure $10.1 \mathrm{CO}_{2}$ Enhanced Oil Recovery in the United States

In 2004, the U.S. Congress tasked the Fossil Energy program of the U.S. DOE to conduct "basin oriented" studies to identify steps that could be taken to accelerate the application of $\mathrm{CO}_{2}-\mathrm{EOR}$, 
particularly using industrial sources of $\mathrm{CO}_{2}$ emissions. Advanced Resources International, Inc. (ARI) was requested to conduct these "basin studies" for DOE and to address two key questions:

1. What is the size of the potential $\mathrm{CO}_{2}$-EOR resource and what policies and economic conditions would induce its accelerated development?

2. How much could advanced ("next-generation") $\mathrm{CO}_{2}$-EOR technology expand this potential?

In response to these two questions, Advanced Resources published a series of basin studies covering 22 oil producing states and 1,581 reservoirs (accounting for two-thirds of U.S. oil production). The basin studies examined three levels of $\mathrm{CO}_{2}$-EOR technology - traditional, state-of-the-art and "next generation." The estimates of $\mathrm{CO}_{2}$-EOR recovery potential in these ten studies was based on a detailed geological and reservoir data set plus reservoir simulations. The basin reports and the "next generation" study are available on the U.S. DOE's web site at http://www.fe.doe.gov/programs/oilgas/eor/Ten_Basin-Oriented_CO2-EOR_Assessments.html and

http://www.fe.doe.gov/programs/oilgas/publications/eor_co2/Game_Changer_Document.pdf.

The studies established that (with state-of-the-art technology) nearly 89 billion barrels of oil could be technically recovered with $\mathrm{CO}_{2}$-EOR adding $15 \%$ recovery efficiency of original oil inplace (OOIP) for U.S. oil fields (Table 10.1).

Table 10.1 Oil Technically Recoverable by Advanced $\mathrm{CO}_{2}$-EOR in 10 U.S. Basins

\begin{tabular}{|l|c|c|c|c|c|c|}
\hline \multirow{2}{*}{ Basin/Area } & \multicolumn{3}{|c|}{$\begin{array}{c}\text { DATABASE } \\
\text { (Large Reservoirs) }\end{array}$} & \multicolumn{3}{c|}{$\begin{array}{c}\text { ALL RESERVOIRS } \\
\text { (Ten Basins/Areas) }\end{array}$} \\
\cline { 2 - 7 } & $\begin{array}{c}\text { \# of } \\
\text { Reservoirs }\end{array}$ & $\begin{array}{c}\text { \% of } \\
\text { Resource }\end{array}$ & $\begin{array}{c}\text { \# Favorable } \\
\text { For CO } \text {-EOR }^{*}\end{array}$ & $\begin{array}{c}\text { OOIP* } \\
\text { (Billion } \\
\text { Barrels) }\end{array}$ & $\begin{array}{c}\text { ROIP** } \\
\text { (Billion } \\
\text { Barrels) }\end{array}$ & $\begin{array}{c}\text { Technically } \\
\text { Recoverable } \\
\text { (Billion Barrels) }\end{array}$ \\
\hline 1. Alaska & 34 & $97 \%$ & 32 & 67.3 & 45.0 & 12.4 \\
\hline 2. California & 172 & $90 \%$ & 88 & 83.3 & 57.3 & 5.2 \\
\hline 3. Gulf Coast & 239 & $60 \%$ & 158 & 44.4 & 27.5 & 6.9 \\
\hline 4. Mid-Continent & 222 & $59 \%$ & 97 & 89.6 & 65.6 & 11.8 \\
\hline 5. North Central & 154 & $61 \%$ & 72 & 17.8 & 11.5 & 1.5 \\
\hline 6. Permian & 207 & $74 \%$ & 182 & 95.4 & 61.7 & 20.8 \\
\hline 7. Rockies & 162 & $68 \%$ & 92 & 33.6 & 22.6 & 4.2 \\
\hline 8. Texas, East/Central & 199 & $65 \%$ & 161 & 109 & 73.6 & 17.3 \\
\hline 9. Williston & 93 & $72 \%$ & 54 & 13.2 & 9.4 & 2.7 \\
\hline 10. Louisiana Offshore & 99 & $80 \%$ & 99 & 28.1 & 15.7 & 5.9 \\
\hline Total & $\mathbf{1 , 5 8 1}$ & & $\mathbf{1 , 0 3 5}$ & $\mathbf{5 8 1 . 7}$ & $\mathbf{3 9 0 . 0}$ & $\mathbf{8 8 . 7}$ \\
\hline
\end{tabular}

*Original Oil in Place, in all reservoirs in basin/area; ** Remaining Oil in Place, in all reservoirs in basin/area.

Source: Advanced Resources Int'l, 2005.

How much of this technically recoverable oil may be economically produced is a function of technology, oil price and the cost for $\mathrm{CO}_{2}$ :

- Traditional $\mathrm{CO}_{2}$-EOR technology would allow only 4 billion barrels of the 89 billion barrel technical potential to be economically produced, assuming an oil price of $\$ 30$ per barrel, $\mathrm{CO}_{2}$ costs of $\$ 1.20$ to $\$ 1.50$ /million cubic feet $(\mathrm{MCF})$ and a high risk premium. 
- State-of-the-art $\mathrm{CO}_{2}$-EOR technology, using greater volumes of $\mathrm{CO}_{2}$ and more advanced EOR designs, would allow 24 billion barrels to be economically produced at an oil price of $\$ 30$ per barrel, assuming $\mathrm{CO}_{2}$ is available at $\$ 1.20$ to $\$ 1.50 / \mathrm{MCF}$ and the technical and geologic risk premium is reduced.

- Assuming an oil price of $\$ 40$ per barrel and large volumes of $\mathrm{CO}_{2}$ available at $\$ 0.80 / \mathrm{MCF}, 47$ billion barrels could be economically produced, at an accelerated rate (Figure 10.2).

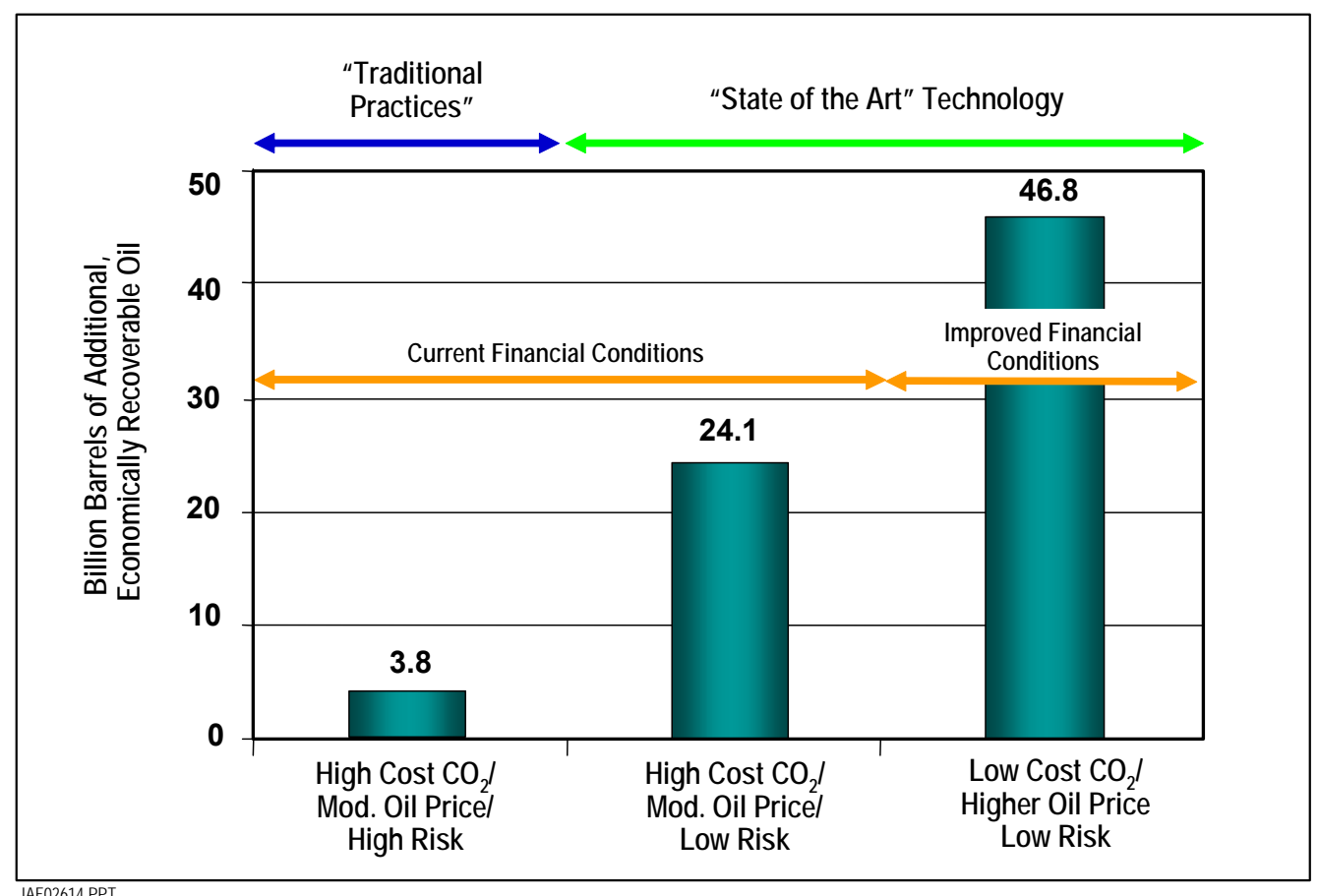

Figure 10.2 Alternative Estimates of Oil Economically Recoverable by $\mathrm{CO}_{2}$-EOR

The market for $\mathrm{CO}_{2}$ emissions offered by $\mathrm{CO}_{2}$-EOR could be substantial. Developing the full potential of $\mathrm{CO}_{2}$-EOR in the United States will require approximately 389 trillion cubic feet (TCF) (20 billion metric tons) of $\mathrm{CO}_{2}$. Natural sources in the United States are capable of supplying only 40-50 TCF, which means that the rest must come from industrial sources. Currently about $2 \mathrm{TCF}$ of $\mathrm{CO}_{2}$ is used per year for $\mathrm{CO}_{2}$-EOR with about $0.5 \mathrm{TCF}$ of $\mathrm{CO}_{2}$ per year produced by industrial sources.

Even in the best designed of the current field projects, $\mathrm{CO}_{2}$-EOR technology faces many barriers:

- One challenge is efficiently targeting the injected $\mathrm{CO}_{2}$ to preferred, high residual oil strata.

- The second challenge is overcoming the inherent limited contact between injected $\mathrm{CO}_{2}$ and residual oil due to the tendency of the less dense $\mathrm{CO}_{2}$ to override the oil and the less viscous $\mathrm{CO}_{2}$ to penetrate the residual oil in "fingers" instead of flowing as a continuous front.

- A third challenge is developing reliable diagnostic and real-time feedback systems for tracking and managing the $\mathrm{CO}_{2}$-EOR process. 
Advanced technologies may be able to greatly increase oil recovery efficiency by more efficiently using the injected $\mathrm{CO}_{2}$, based on continuous monitoring and improved control of the $\mathrm{CO}_{2}$ flooding process. As such, advanced ("next generation") $\mathrm{CO}_{2}$-EOR technology could nearly double $\mathrm{CO}_{2}$-EOR recovery efficiency and the quantity of oil recoverable, as shown by Advanced Resources International study in six of the basins studies (Table 10.2).

\section{Table 10.2 Oil in Six U.S. Basins Recoverable by "State-of-the-Art" and "Next Generation" Technology}

\begin{tabular}{|l|c|c|c|c|}
\hline \multirow{2}{*}{ Basins/Areas } & \multicolumn{2}{|c|}{$\begin{array}{c}\text { ALL RESERVOIRS } \\
\text { (Six Basins/Areas) }\end{array}$} & $\begin{array}{c}\text { "STATE-OF- } \\
\text { THE-ART" }\end{array}$ & $\begin{array}{c}\text { "NEXT } \\
\text { GENERATION" }\end{array}$ \\
\cline { 2 - 5 } & $\begin{array}{c}\text { OOIP* } \\
\text { (Billion Barrels) }\end{array}$ & $\begin{array}{c}\text { Rolp** } \\
\text { (Billion Barrels) }\end{array}$ & $\begin{array}{c}\text { Technically } \\
\text { Recoverable } \\
\text { (Billion Barrels) }\end{array}$ & $\begin{array}{c}\text { Aditional } \\
\text { Technically } \\
\text { Recoverable } \\
\text { (Billion Barrels) }\end{array}$ \\
\hline California & 83.3 & 57.3 & 5.2 & 8.1 \\
\hline Gulf Coast & 60.8 & 36.4 & 10.1 & 8.9 \\
\hline Oklahoma & 60.3 & 45.1 & 9.0 & 11.1 \\
\hline Illinois & 9.4 & 5.8 & 0.7 & 0.9 \\
\hline Alaska & 67.3 & 45.0 & 12.4 & 11.4 \\
\hline Louisiana Offshore (Shelf) & 28.1 & 15.7 & 5.9 & - \\
\hline Total & $\mathbf{3 0 9 . 2}$ & $\mathbf{2 0 5 . 3}$ & $\mathbf{4 3 . 3}$ & $\mathbf{4 0 . 4}$ \\
\hline
\end{tabular}

*Original Oil In-Place, in all reservoirs in basin/area; ${ }^{\star *}$ Remaining Oil in Place, in all reservoirs in basin/area. Source: Advanced Resources International, 2005.

An added benefit of "next generation" technology is its potential to greatly increase the amount of $\mathrm{CO}_{2}$ that can be stored in depleted oil reservoirs. Analysis of a large Gulf Coast reservoir, initially containing $340 \mathrm{MMBO}$, showed that conventional $\mathrm{CO}_{2}$-EOR methods would result in sequestering only 18 million metric tons of $\mathrm{CO}_{2}$. Next generation methods were estimated to sequester 109 million metric tons, utilizing $76 \%$ of the theoretical $\mathrm{CO}_{2}$ storage capacity in this reservoir.

The domestic $\mathrm{CO}_{2}$-EOR potential is large -89 billion barrels technically recoverable with "stateof-the-art" technology, offering a market for 20 billion metric tons (389 Tcf) of "EOR Ready" $\mathrm{CO}_{2}$. Of this large technical resource potential, 47 billion barrels may be economically recoverable. "Next Generation" $\mathrm{CO}_{2}$-EOR technology could add another 40 billion barrels and significantly increase the market for industrial $\mathrm{CO}_{2}$. By 2025, with a concerted $\mathrm{RD} \& \mathrm{D} /$ technology investment and appropriate incentives for using (and sequestering) industrial $\mathrm{CO}_{2}$, the U.S. could produce 3 million barrels per day from $\mathrm{CO}_{2}-\mathrm{EOR}$. 


\title{
11. BIOFUELS' POTENTIAL TO REPLACE OIL
}

\author{
Bob Perlack \\ Environmental Sciences Division \\ Oak Ridge National Laboratory
}

How much of the vast quantities of energy used by the world's transportation systems can be replaced by low-carbon liquid fuels from biomass is an important question. Rosillo-Calle and Walter (2006) estimated that ethanol from sugar cane, grain and cellulose could replace $54 \%$ of the world's gasoline use by 2050 (270 billion gallons). Fulton (IEA, 2004) estimated that 6\% of the world's gasoline use could be displaced by ethanol by 2020 . The U.S. Departments of Energy and Agriculture undertook a study "to determine whether the land resources of the United States were capable of producing a sustainable supply of biomass sufficient to displace $30 \%$ or more of the country's present petroleum consumption." (Perlack et al., 2005). Considering only forestland and cropland and assuming that all food, feed, wood products and export demands would continue to be met, the study concluded that more than 1.3 billion dry tons of biomass feedstock could be sustainably produced per year.

About one-half of the land in the contiguous lower-48 states is forestland (504 million acres of timberland, 91 million acres of other forestland) or cropland (342 million acres cropland, 39 million acres idle cropland, 68 million acres pasture). The most relevant forest and agricultural sources of biomass for conversion to fuel are listed below in Table 11.1. The sources with the greatest potential are in bold.

Table 11.1 Potential Sources of Biomass Feedstock in the United States

\begin{tabular}{|c|c|}
\hline Forest resources & Agricultural resources \\
- Logging residues & - Crop residues \\
- Forest thinnings (fuel & - Grains to biofuels \\
treatments) & - Perennial grasses \\
- Fuelwood & - Perennial woody crops \\
- Primary wood processing mill & - Animal manures \\
$\quad$ residues & - Food/feed processing residues \\
- Secondary wood processing mill & - MSW and landfill gases \\
residues & \\
- Pulping liquors & \\
- Urban wood residues & \\
\hline
\end{tabular}

The quantity of biomass feedstock available from cropland depends on many factors but especially on continued increases in yields and whether and how much agricultural land is converted to the production of perennial biomass crops, such as switchgrass or poplar trees. Assuming moderate increases in yields and no use of perennial crops, about 420 million dry tons of biomass could be produced each year. The majority would come from crop residues (Figure 11.1). With a higher rate of yield growth, feedstock availability would expand to nearly 600 million dry tons. Adding land use conversions to grow perennial crops dedicated to biomass 
feedstock production raises the totals to 580 million dry tons assuming moderate yield increases and nearly 1 billion dry tons assuming more rapid yield growth.

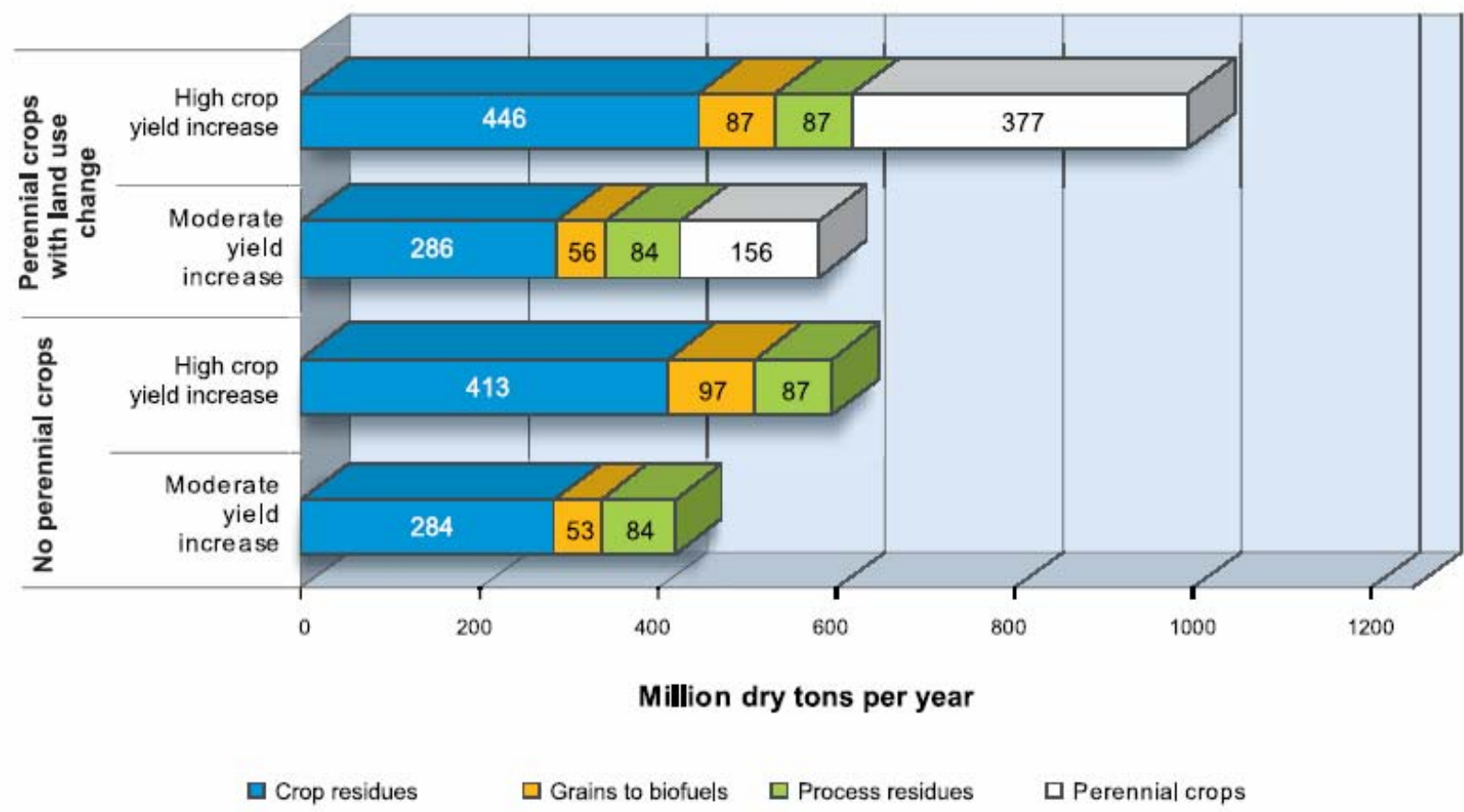

Figure 11.1 Alternative Estimates of Biomass Feedstock Available from U.S. Cropland

The supply of crop residues, a key biomass resource, depends on many factors: yields, the grain to residue ratio, equipment operational constraints, the need to prevent wind and soil erosion, and rotation and tillage practices. The effect of tillage practices on the availability of corn stover is illustrated in Figure 11.2 (Graham et al., 2007). Stover available at less than $\$ 30$ per dry ton increases from 60 million to 106 million annually if no-till corn growing replaces current practices.

U.S. forestlands are capable of producing 368 million dry tons of biomass feedstock annually, comprised of 52 million tons of fuel wood from forests, 144 million dry tons of wood processing and pulp and paper mill residues, 47 million dry tons from urban wood residues, 64 million dry tons from logging and site clearing operations and 60 million dry tons from forest treatment to reduce fire hazards. This assessment excludes biomass resources needed for conventional forest products, takes into consideration equipment recovery limitations and excludes environmentally sensitive forestland and areas not currently accessible by road.

At the current biomass feedstock price of $\$ 53$ per dry ton and using state-of-the-art technology for ethanol production from cellulosic biomass, ethanol can be produced at a cost of $\$ 2.25 /$ gallon. The DOE's research and development (R\&D) goals are to reduce the cost of the most accessible feedstocks to $\$ 35$ per dry ton and, via improvements in conversion processes and enzyme costs, to reduce the cost of ethanol production to $\$ 1.07 /$ gallon by 2012 (Figure 11.3) (Ashworth, 2006). By 2020, the goal is to increase conversion efficiency to 104 gallons of ethanol per dry ton and to reduce production costs to $\$ 0.59$ per gallon. 


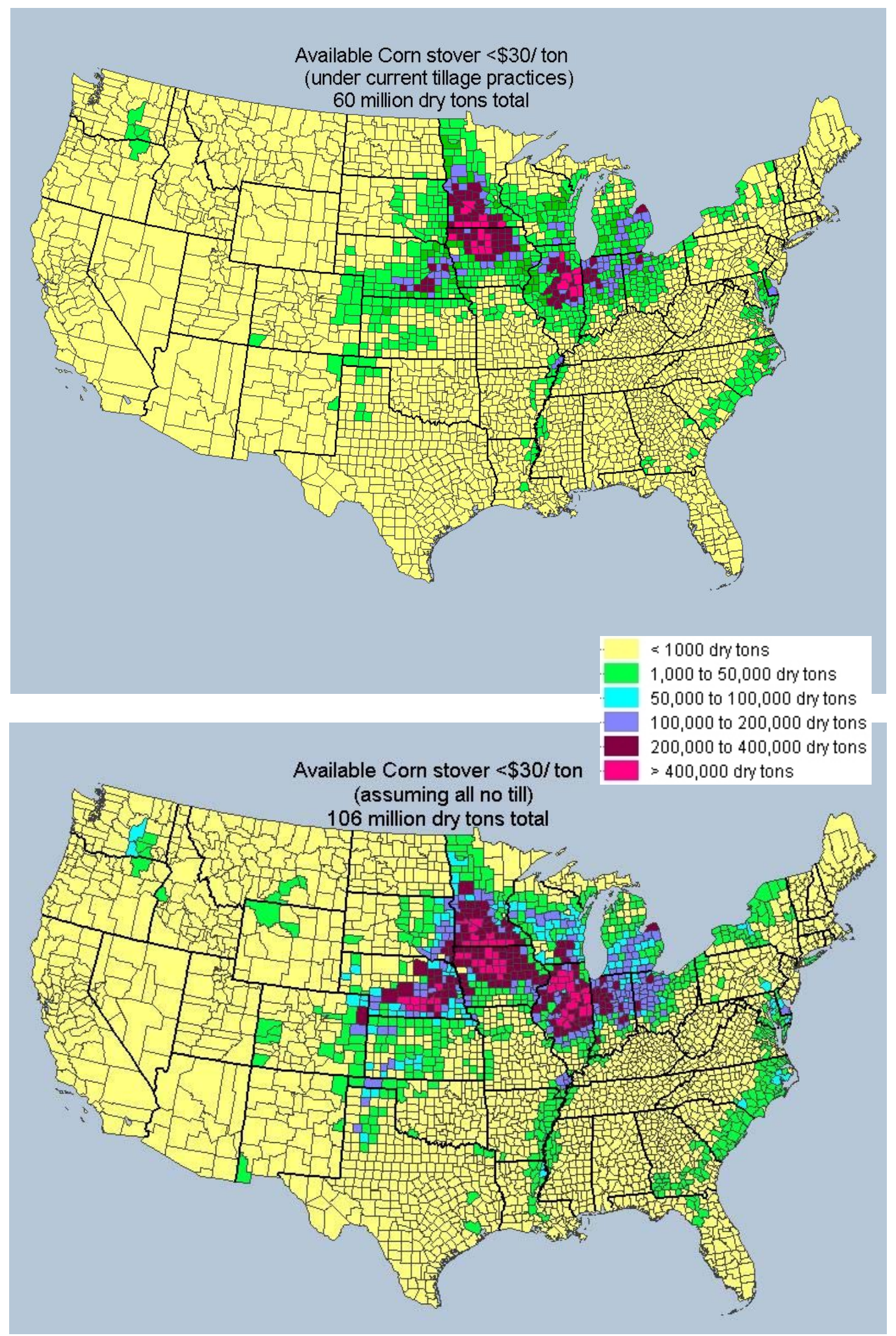

Figure 11.2 Impact of Tillage Practices on Availability of Corn Stover as Biomass Feedstock 


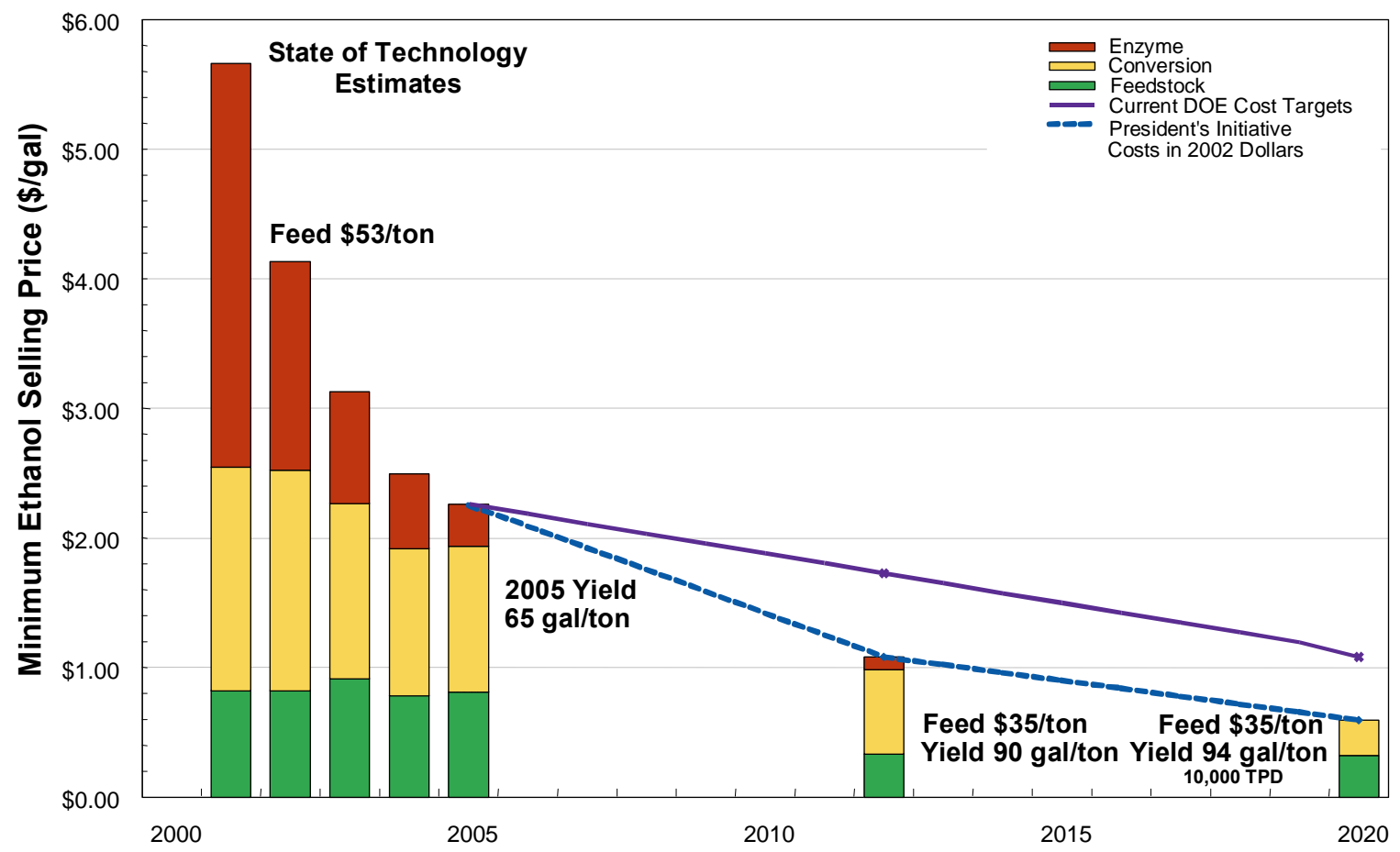

Figure 11.3 Progress in State-of-the-Art and R\&D Targets for Ethanol Production from Biomass

If the R\&D goals for feedstock cost and cellulosic conversion technology can be met, annual biomass fuel production could reach 60 billion gallons by 2030 from grains (principally corn), forest residues, agricultural residues, and energy crops. The corn grain fraction would be about $25 \%$ or $15-16$ billion gallons per year (NCGA, 2006) with the remainder coming from the cellulosic sources.

\section{REFERENCES}

Ashwoth, J. (2006). "Cellulosic Ethanol: Where Are We Now, Where Are We going?" Governor's Ethanol Coalition, Kansas City, http://www.ethanol-gec.org/aboutus/committee repts.htm.

Fulton, L., 2004. "Biofuels for Transport: An International Perspective," International Energy Agency, Trade Implications for Kyoto Implementation: Making It Work, Side Event at UNFCCC COP-10, December 14, 2004, Buenos Aires

Graham, R. L., R. Nelson, J. Sheehan, R.D. Perlack, and L.L. Wright, 2007. "Current and Potential U.S. Corn Stover Supplies,” Agronomy Journal, 99:1-11.

National Corn Growers Association (NCGA), (2006). "How Much Ethanol Can Come From Corn?" http://www.ncga.com/ethanol/main/index.asp,Washington DC. 
Perlack, R.D., L.L. Wright, A. Turhollow, R.L. Graham, B. Stokes, and D.C. Erbach, 2005. "Biomass as a Feedstock for a Bioenergy and Bioproducts Industry: The Technical Feasibility of A Billion-Ton Annual Supply," ORNL/TM-2005/66, Oak Ridge National Laboratory, Oak Ridge, Tennessee.

Rosillo-Calle, F. and A. Walter, 2006. Global Market for Bioethanol: Historical Trends and Future Prospects. Energy for Sustainable Development, 10:1. 


\section{ENERGY EFFICIENCY}

\section{Dolf Gielen}

International Energy Agency

The IEA has studied the possibility of a transition from conventional oil using the WEO model, the Energy Technology Perspectives (ETP) model, and its world transportation demand spreadsheet model, MoMo. This permits integrated analysis of global energy supply and demand, as well as analysis of the roles of advanced technology and alternative fuels in the transition. A focus on the transportation sector is necessary because petroleum markets are driven by transportation's energy needs.

The IEA-WEO foresees peaking of worldwide conventional oil production by 2030 . This implies a transition from conventional oil to other energy resources over the period 2010 to 2050. Energy efficiency improvement can make a major contribution to the transition in an environmentally benign way. However, this will require changing the direction of fuel economy trends. After major reductions in LDV fuel consumption from 1975 to 1990, fuel economy has been relatively flat for the past fifteen years (Figure 12.1). Over this period, technological advances that could have been applied to decreasing fuel consumption have instead been put to use increasing vehicle power and size. In the EU, engine displacement increased almost $10 \%$ while engine power grew by more than $25 \%$ over the $1990-2005$ period. In the United States the power of new vehicles increased $57 \%$ and their weight increased by $19 \%$ over the same period, while fuel economy did not improve.

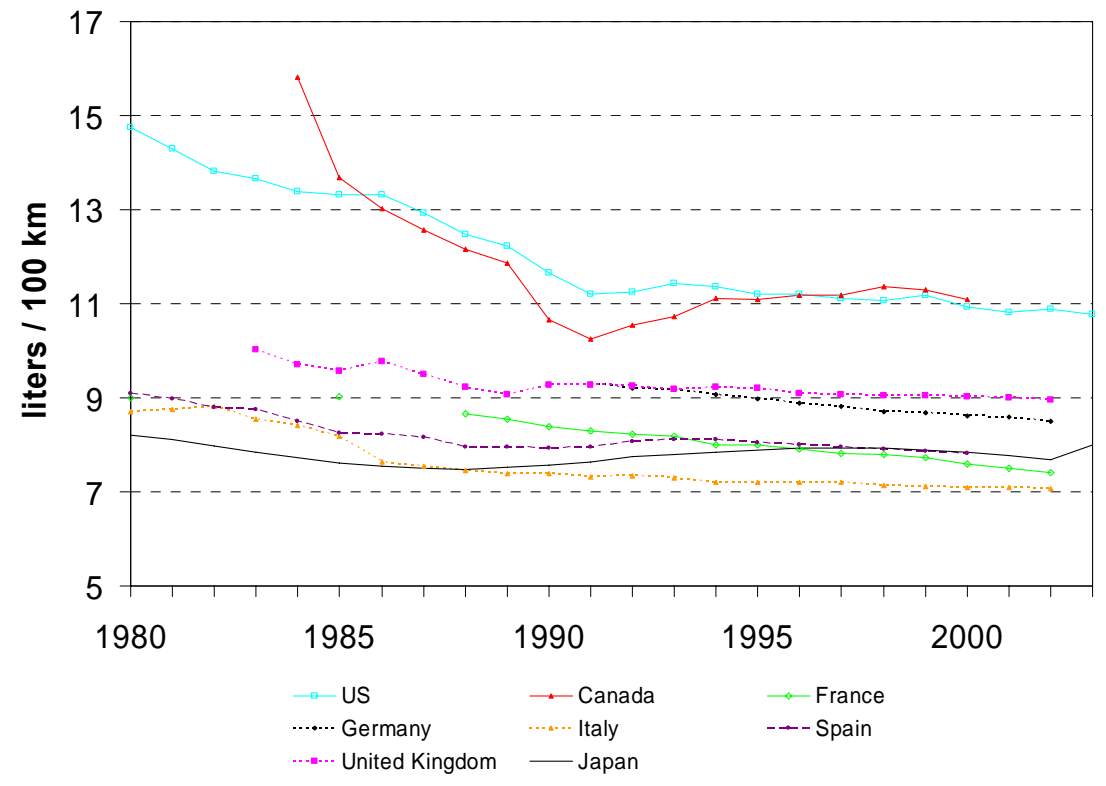

Figure 12.1 Light-duty Vehicle Fuel Consumption Trends in Selected Countries, 1980-2005

A reference scenario (RS) for transportation energy use developed using the MoMo model indicates a $150 \%$ increase in demand for transportation services (passenger kilometers and ton kilometers) by 2050 . Because sector-wide energy efficiency improves by only $18 \%$, on average, 
this produces a doubling of transportation fuel demand. Technologies are and will become available to achieve a far greater improvement in energy efficiency. Currently available technologies could reduce petroleum use in 2050 by 17 million barrels per day and cut greenhouse gas emissions by 2.3 gigatons per year (Figure 12.2).

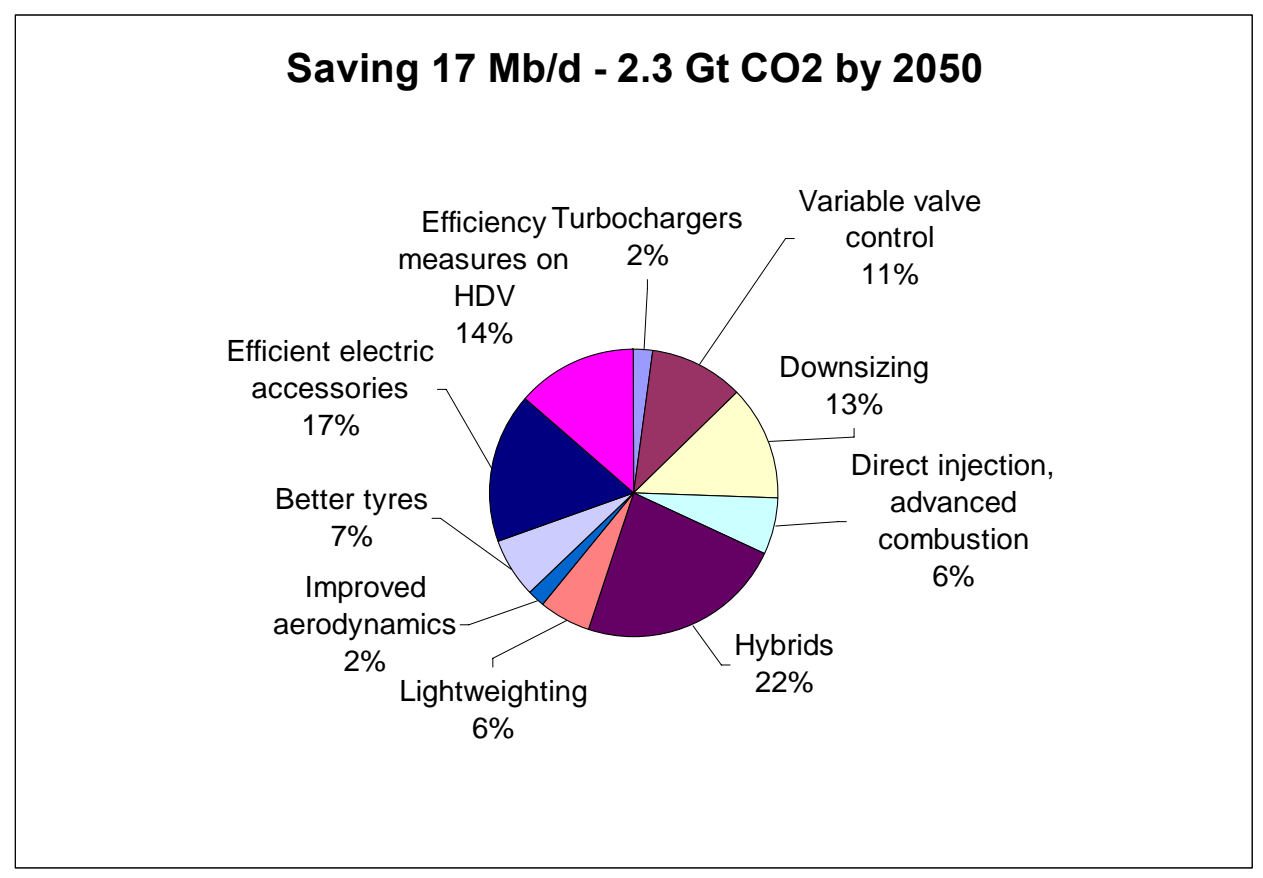

Figure 12.2 Impacts of Available Technologies on Energy Use by Road Vehicles in 2050

Hydrogen fuel cell vehicles have the potential to achieve double or triple the energy efficiency of today's conventional gasoline vehicles. However they are not ready to compete in the marketplace. Costs must be reduced, on-board hydrogen storage problems must be solved and an entirely new fuel infrastructure must be created.

Once conventional oil production nears its peak, a growing gap will emerge between increasing demand for transportation fuels and the supply of conventional oil. In addition to energy efficiency improvements, there are many options for filling the gap with alternative energy sources. Many of them have been mentioned already: biofuels, hydrogen, heavy oil, OS, shale oil, CTL, natural gas-to-liquids, and EOR. But these alternatives do not produce the same benefits in terms of energy security and mitigation of greenhouse gas emissions. Production of synthetic petroleum fuels from other fossil carbon resources will improve the energy security of most oil importing countries, but at the expense of increased emissions of $\mathrm{CO}_{2}$ (Figure 12.3). Energy efficiency improvement is one of the few options that delivers maximum benefits in both dimensions. 


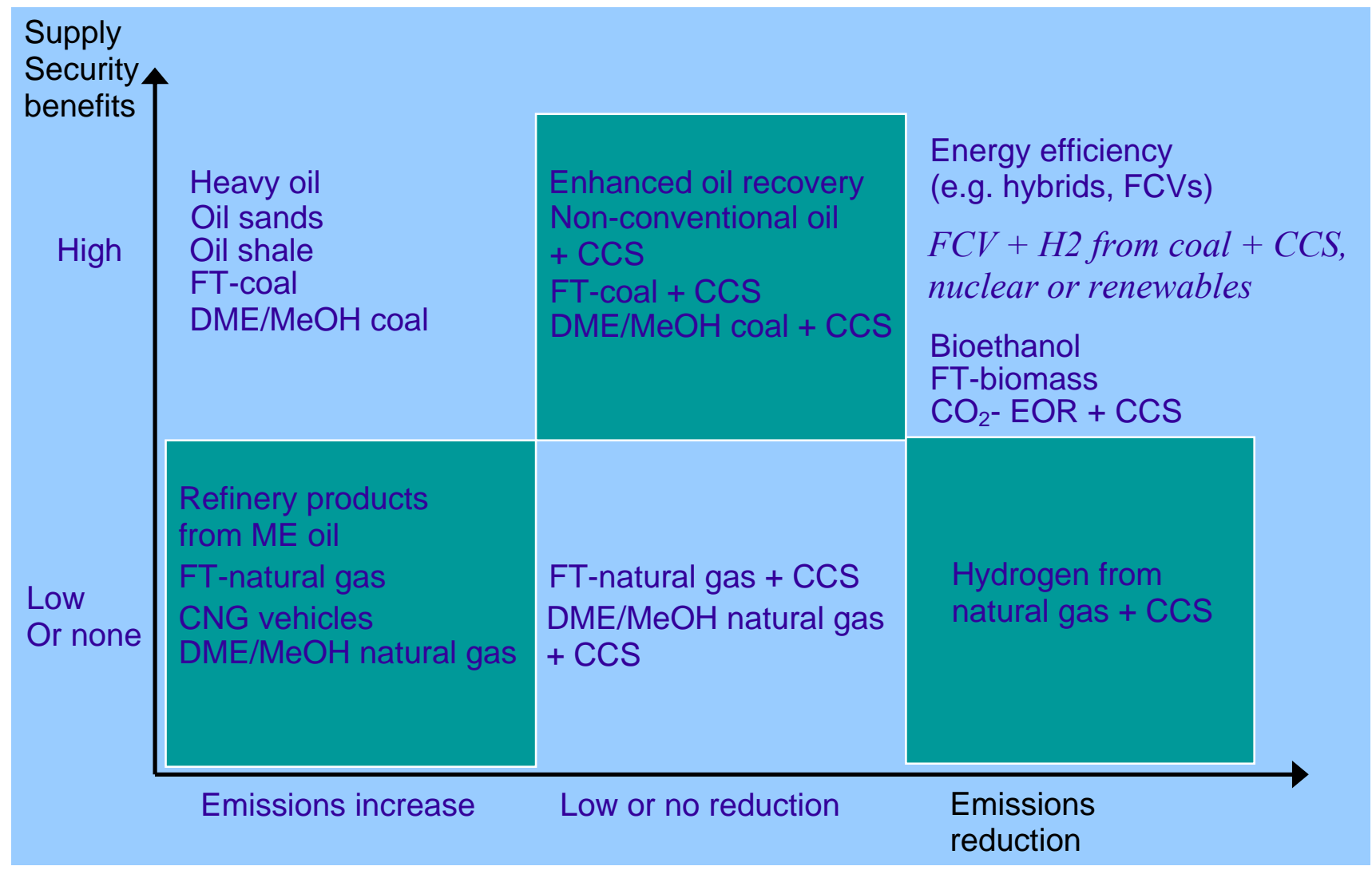

Figure 12.3 Alternatives to Conventional Petroleum and Their Impacts on Energy Security and Greenhouse Gas Emissions

Bioethanol produced from cellulosic feedstocks or sugar cane is another potential petroleum replacement that both enhances energy security and achieves large reductions in greenhouse gases. The IEA estimates that with oil at $\$ 60$ per barrel bioethanol could supply almost $25 \%$ of world transportation fuel demand by 2050 (Figure 12.4).

The ETP model can be used to develop optimal strategies for displacing petroleum use (conventional and unconventional). Accelerated adoption of advanced technologies (ACT) reduces petroleum use in the RS by about 30 exajoules per year. Biofuels and other fuel switching displaces another 30 exajoules. If hydrogen fuel cell vehicles can make the necessary technological advances, yet another 30 exajoules could be displaced through the combination of greater energy efficiency and substitution of hydrogen for petroleum (Figure 12.5). 


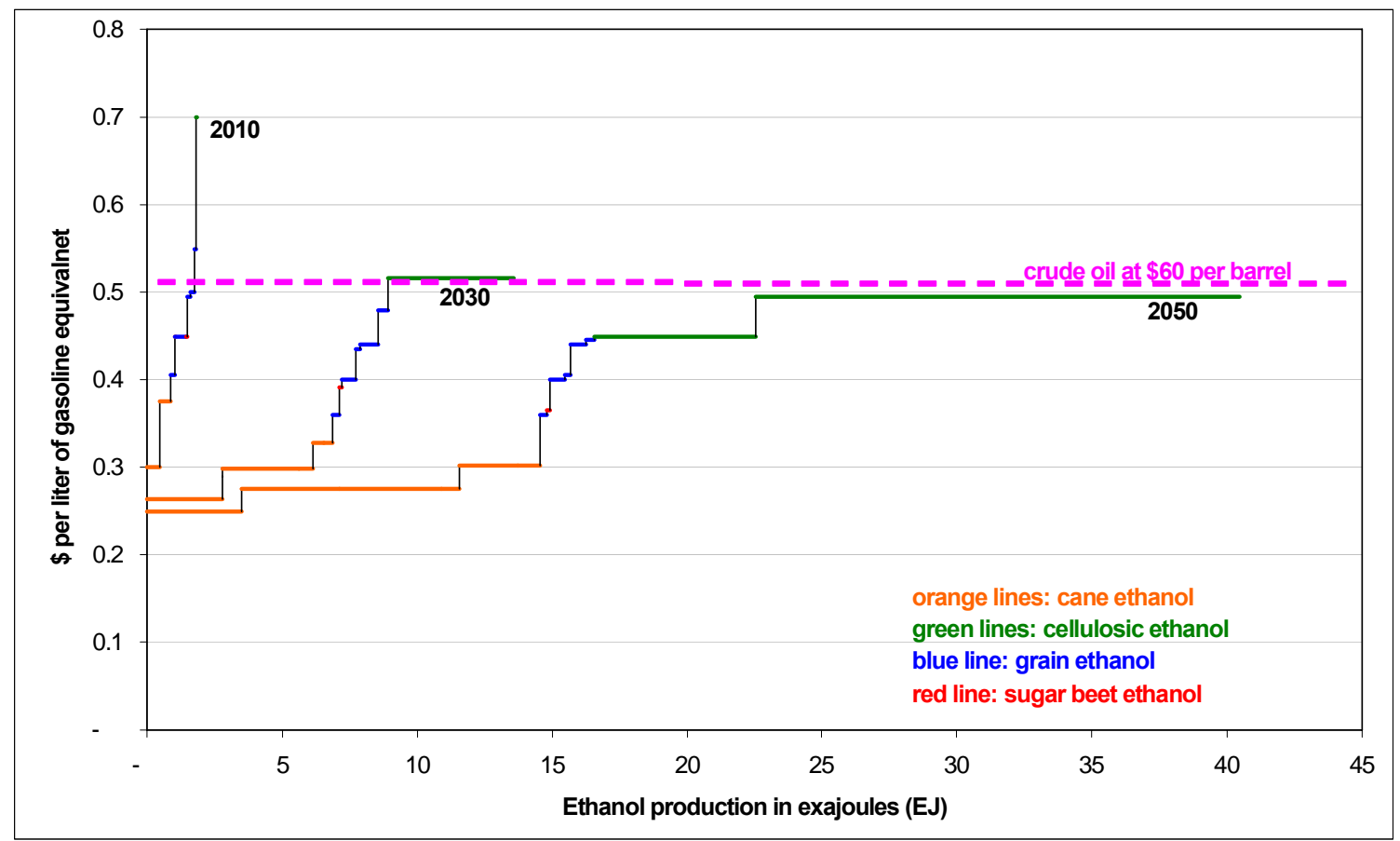

Figure 12.4 IEA Estimates of Bioethanol Supply Curves: 2010, 2030, 2050

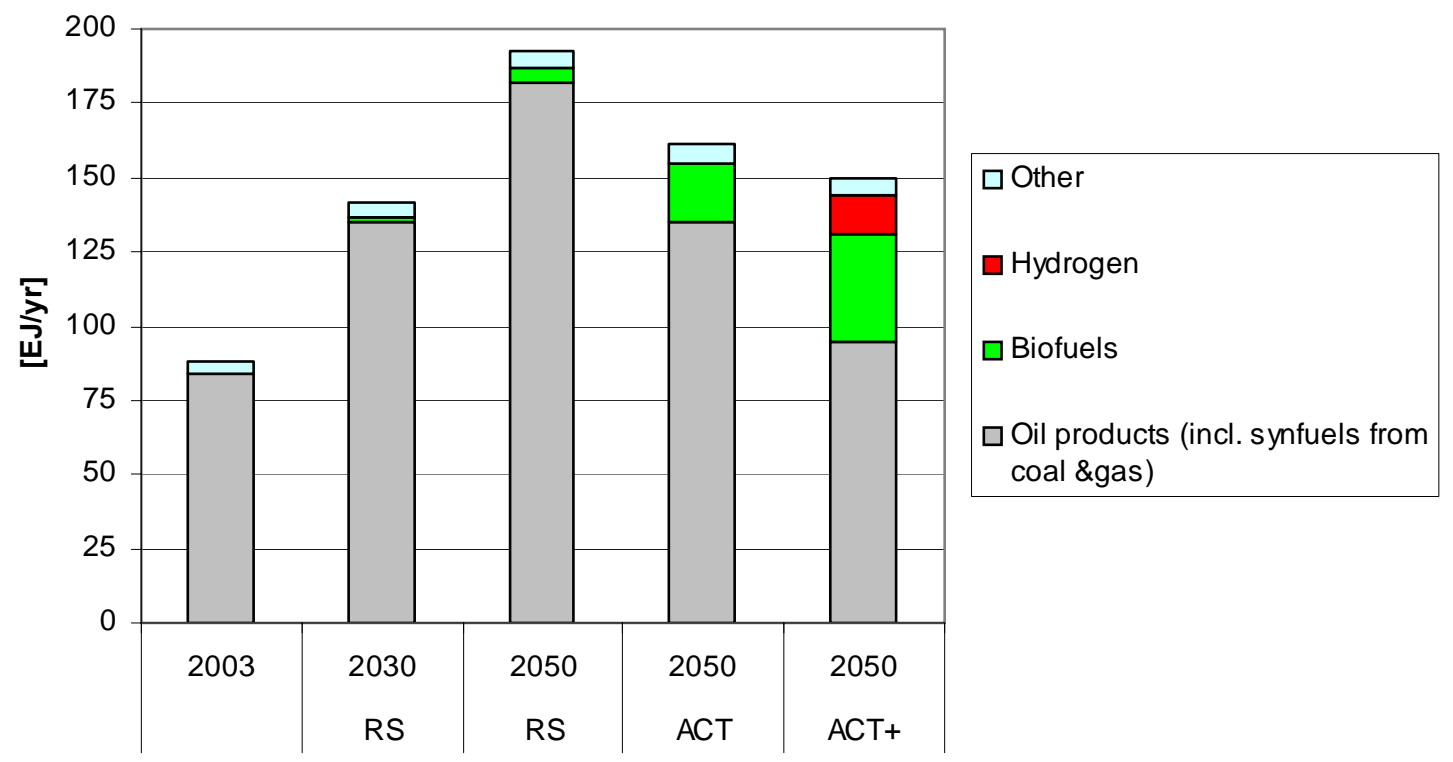

Figure 12.5 Optimal Strategies for Displacing Petroleum Demand with Energy Efficiency, Biofuels and Hydrogen 


\title{
SESSION 4: ENVIRONMENTAL EFFECTS
}

Keith Sargent, U.S. Environmental Protection Agency, Chair

\section{GREENHOUSE GAS EMISSIONS FROM A TRANSITION TO OIL SUBSTITUTES}

\author{
Alex Farrell \\ University of California, Berkeley
}

As conventional oil production peaks, it is very likely that more expensive but plentiful unconventional fossil resources will be exploited to augment the supply of liquid hydrocarbon fuels (Figure 13.1). Indeed, this process is already underway in the production of heavy oil from Venezuela and OS from Canada. Unfortunately, producing conventional transportation fuels from unconventional fossil resources will increase emissions of $\mathrm{CO}_{2}$. Depending on which resources are used, the sources of energy for production and conversion, and whether or not $\mathrm{CO}_{2}$ emissions from production and conversion are captured and stored, the emissions increases may be minor or very substantial. At present, there are few models capable of representing the transition process and none that can be said to adequately represent all its important dimensions.

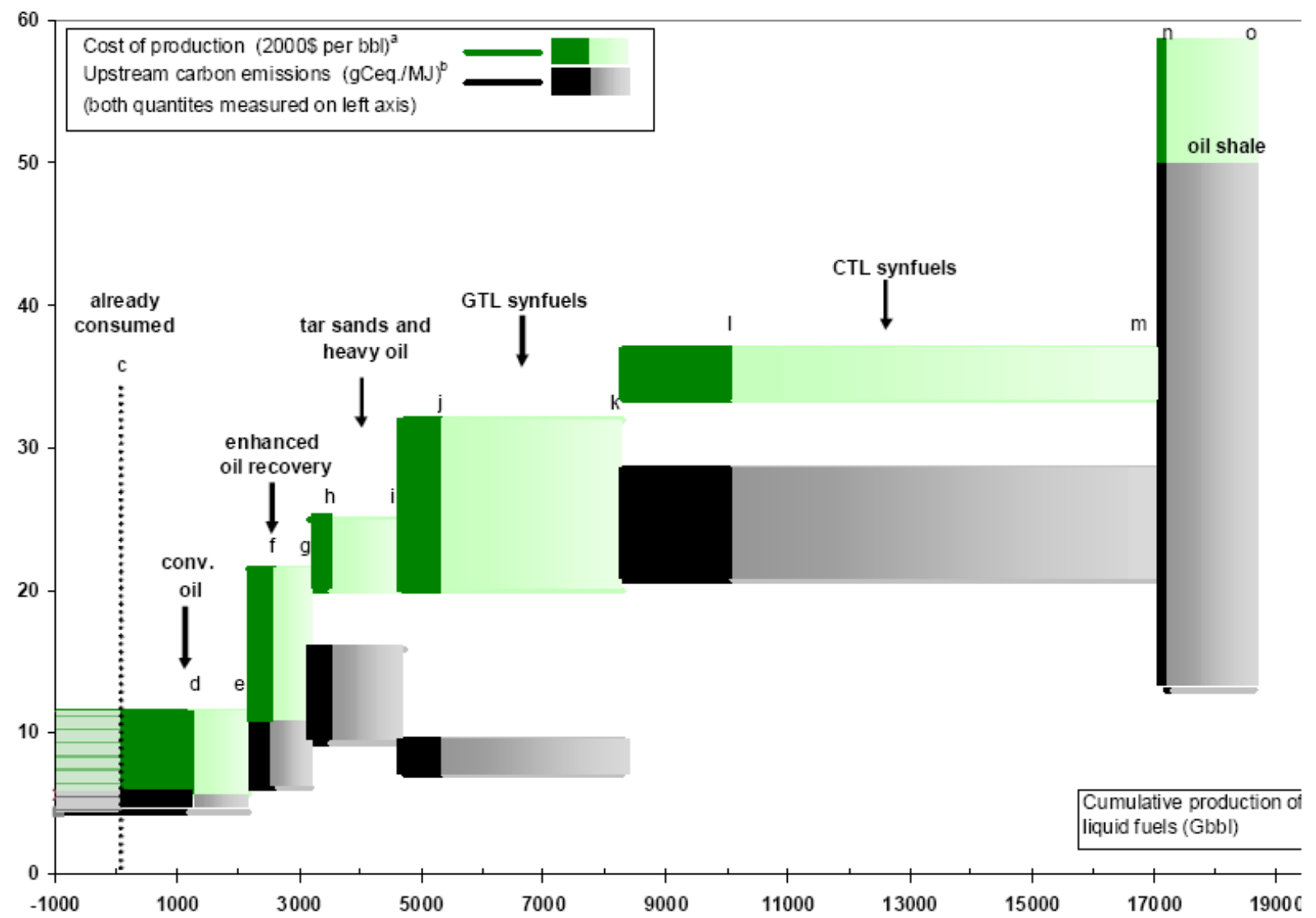

Figure 13.1 Upstream Emissions of $\mathrm{CO}_{2}$ and Costs of Conventional Oil Fossil Alternatives 
All the unconventional alternatives to petroleum produce far greater upstream emissions of $\mathrm{CO}_{2}$ (Figure 13.2). Upstream carbon emissions from the production of synthetic crude from tar sands and heavy oil are on the order of twice the upstream emissions produced by making fuels from conventional petroleum. Synthesis of liquid hydrocarbon fuels from coal or oil shale is likely to generate several times the upstream emissions attributable to conventional oil. In addition to being more energy intensive, producing synthetic petroleum production from unconventional fossil resources is also more expensive.

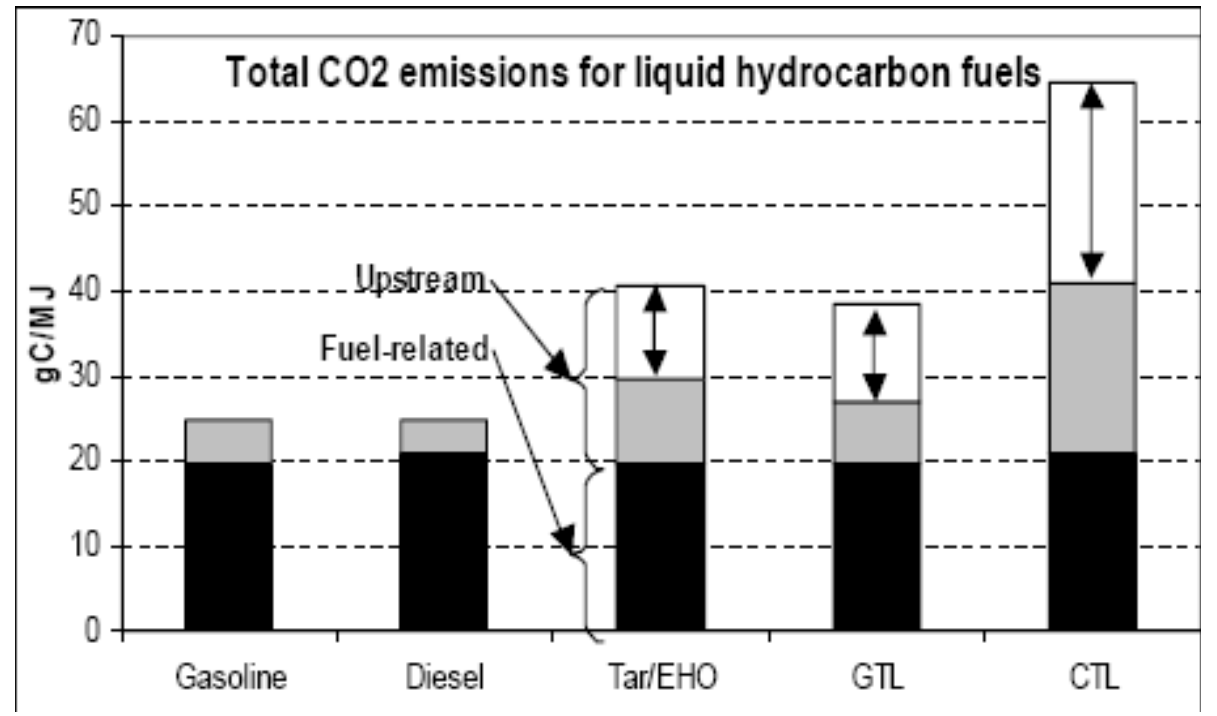

\section{Figure 13.2 Emissions of $\mathrm{CO}_{2}$ from Fuel Combustion and Upstream Processes for Gasoline and Diesel from Conventional Petroleum and Alternatives}

There is considerable uncertainty about what the upstream emissions of fuels derived from unconventional petroleum will be. This is chiefly due to the sensitivity of upstream emissions to the choice of energy sources for production and conversion processes, the efficiency of those processes and whether or not some of the upstream emissions are captured and sequestered. Upstream emissions from the production of tar sands and extra heavy oil could be $50 \%$ to $100 \%$ as large as the emissions from fuel combustion. Upstream emissions from CTL synthesis could double or triple emissions from fuel combustion. These very significant differences make it essential that there be tools for analyzing the transition from conventional oil that incorporate economics, technology, environmental impacts and uncertainty.

The Energy Resources Group at the University of California, Berkeley is constructing a global model for analyzing the transition from petroleum and its impacts on greenhouse gas emissions. The model represents 17 world regions but does not distinguish among economic sectors. It is a linear programming model that minimizes the cost of meeting given demands for petroleum fuels by choosing among petroleum and four fossil substitutes: (1) tar sands and extra heavy oil, (2) CTL, (3) gas-to-liquids, and (4) oil shale. The model estimates additions to production capacities for each substitute, the production volumes of each substitute, and the trade in fuels among regions. Resource depletion is represented by Hubbert curves with peaks at either 50\% or $60 \%$ of estimated ultimately recoverable resources. Learning-by-doing is represented in conversion processes by an $8 \%$ cost reduction for each doubling of cumulative production. Ultimate resource estimates are taken from two sources, high estimates from the USGS 2000 assessment and low estimates from Campbell-Acklett. 
The model is still under development but some interesting preliminary results have been obtained. No firm conclusions should be inferred until further testing of the model has been completed. 


\title{
14. WELL-TO-WHEEL GREENHOUSE GAS ASSESSMENT
}

\author{
M. Q. Wang \\ Argonne National Laboratory
}

Because upstream emissions from fuel production are significant and vary widely across alternatives to conventional petroleum, well-to-wheels (WTW) analysis is essential for meaningful comparisons of environmental impacts of vehicle technologies using different fuels. The Greenhouse Gases, Regulated Emissions, and Energy Use in Transportation (GREET) model was developed in 1995 by Argonne National Laboratory and its continued development and enhancement has been supported by the U.S. DOE since that time. For a wide array of fuels and conversion processes, GREET estimates emissions of all major greenhouse gases and five criteria pollutants and calculates energy use by energy source. The model and its documentation are available to the public at http://www.transportation.anl.gov/software/GREET/index.html.

The extraction and transportation of petroleum is extremely energy efficient, requiring less than $4 \%$ of the energy available in crude oil (Figure 14.1). Refining is the most energy intensive step and the step that produces the most greenhouse gas emissions of the well-to-pump stage of petroleum-based fuels. Overall, gasoline production is about $80 \%$ energy efficient and diesel production about $82 \%$ energy efficient from well to pump.

\section{Petroleum Reco \\ WTP Efficiency (US): \\ Gasoline $80 \%$ \\ Diesel $82 \%$}

Petroleum Transportation and Storage (99\%)

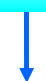

Petroleum Refining to Gasoline (84.5-86\%, Depending on

Oxygenates and Reformulation) and Low-S Diesel (87\%) $\checkmark$

$$
\begin{gathered}
\text { Transportation, Storage, and } \\
\text { Distribution of Gasoline (99.5\%) }
\end{gathered}
$$

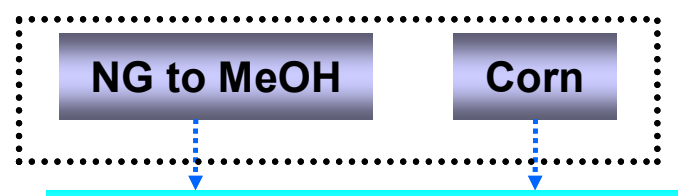

MTBE or EtOH for Gasoline

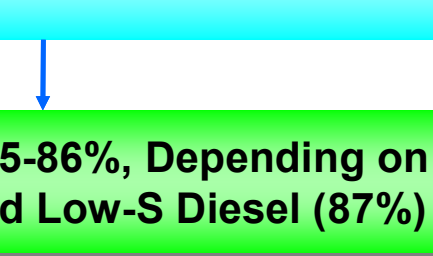

Gasoline and Diesel at Refueling Station

Figure 14.1 Well-to-Pump Energy Efficiency of Gasoline and Diesel Production from Crude Oil

The extraction and refining of unconventional petroleum sources, such as OS, extra heavy oil and oil shale, are more energy and emissions intensive. The GREET model is analysis of OS production shows the potential to more than triple upstream GHG emissions or to not increase 
them at all, depending on the sources of energy used upstream. If OS are mined in situ and nuclear energy is used to produce steam and for other processes, well-to-pump emissions will be no different from those of gasoline from conventional crude oil (Figure 14.2). If, on the other hand, the energy is derived from coal without carbon capture and sequestration, a tripling of upstream emissions can be expected.

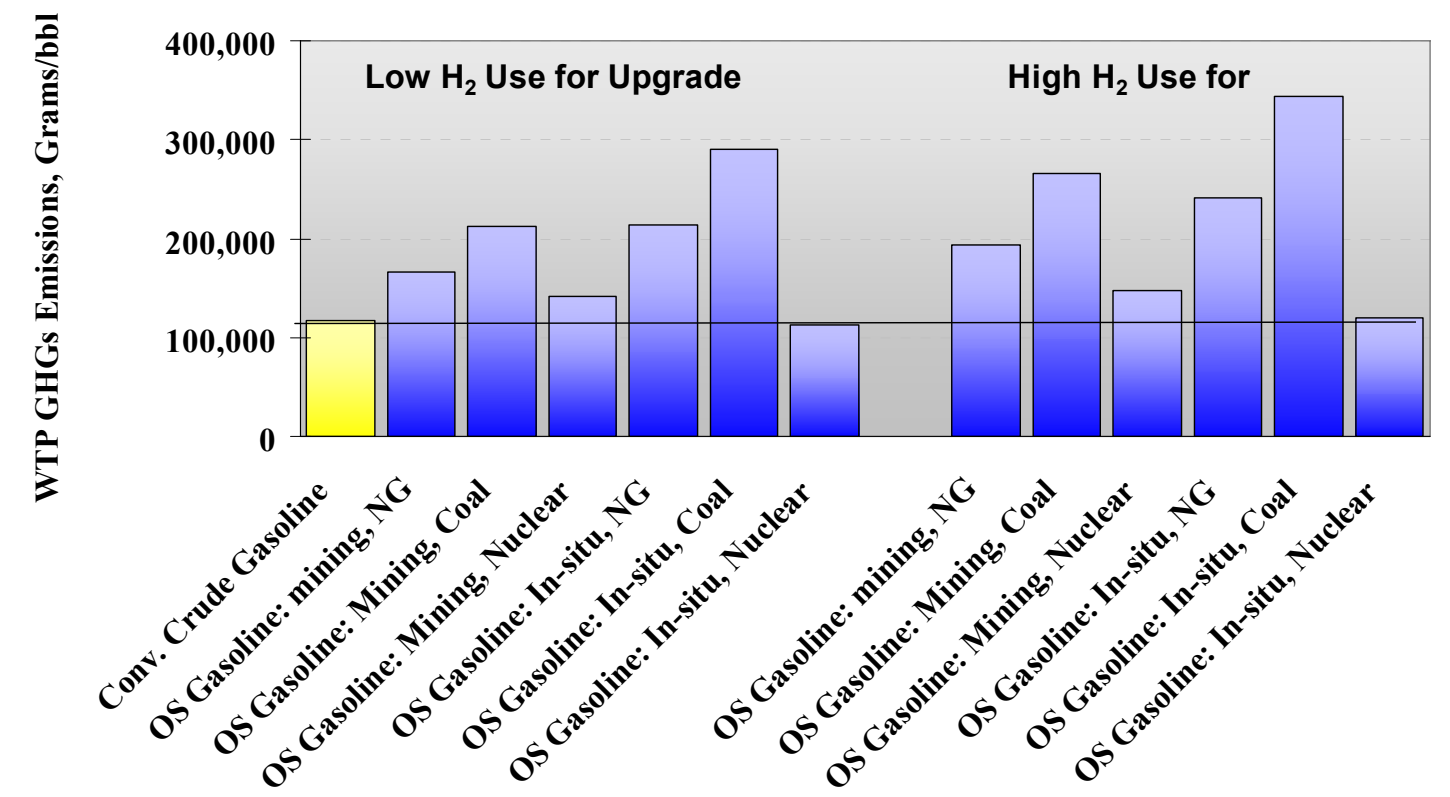

Figure 14.2 Upstream Emissions from the Production of Gasoline from Oil Sands

Should hydrogen replace a significant amount of energy in transportation, upstream emissions will become even more important. Production of hydrogen from even a well-established and relatively efficient process such as steam methane reforming requires $30 \%$ of the energy in the natural gas feedstock. Compression for transport and storage is likely to require another $10 \%$. Liquefaction would require far more energy than compression. Where the energy comes from, what the carbon intensity of the feedstock is, and whether or not carbon emissions are captured and sequestered can determine whether substitution of hydrogen for gasoline would increase or nearly eliminate $\mathrm{CO}_{2}$ emissions on a WTW basis. Fuel cell vehicles powered by hydrogen produced by steam methane reforming would have $25 \%$ to $30 \%$ lower greenhouse gas emissions than a conventional internal combustion engine vehicle (ICEV) using reformulated gasoline (RFG), roughly on a par with hybrid electric vehicles (HEV) (Figure 14.3). If the hydrogen were produced by electrolysis using the U.S. average primary energy sources for electricity generation, greenhouse gas emissions would nearly double. On the other hand, if the electricity were produced from a renewable source like wind energy, greenhouse gas emissions would be nearly zero. 


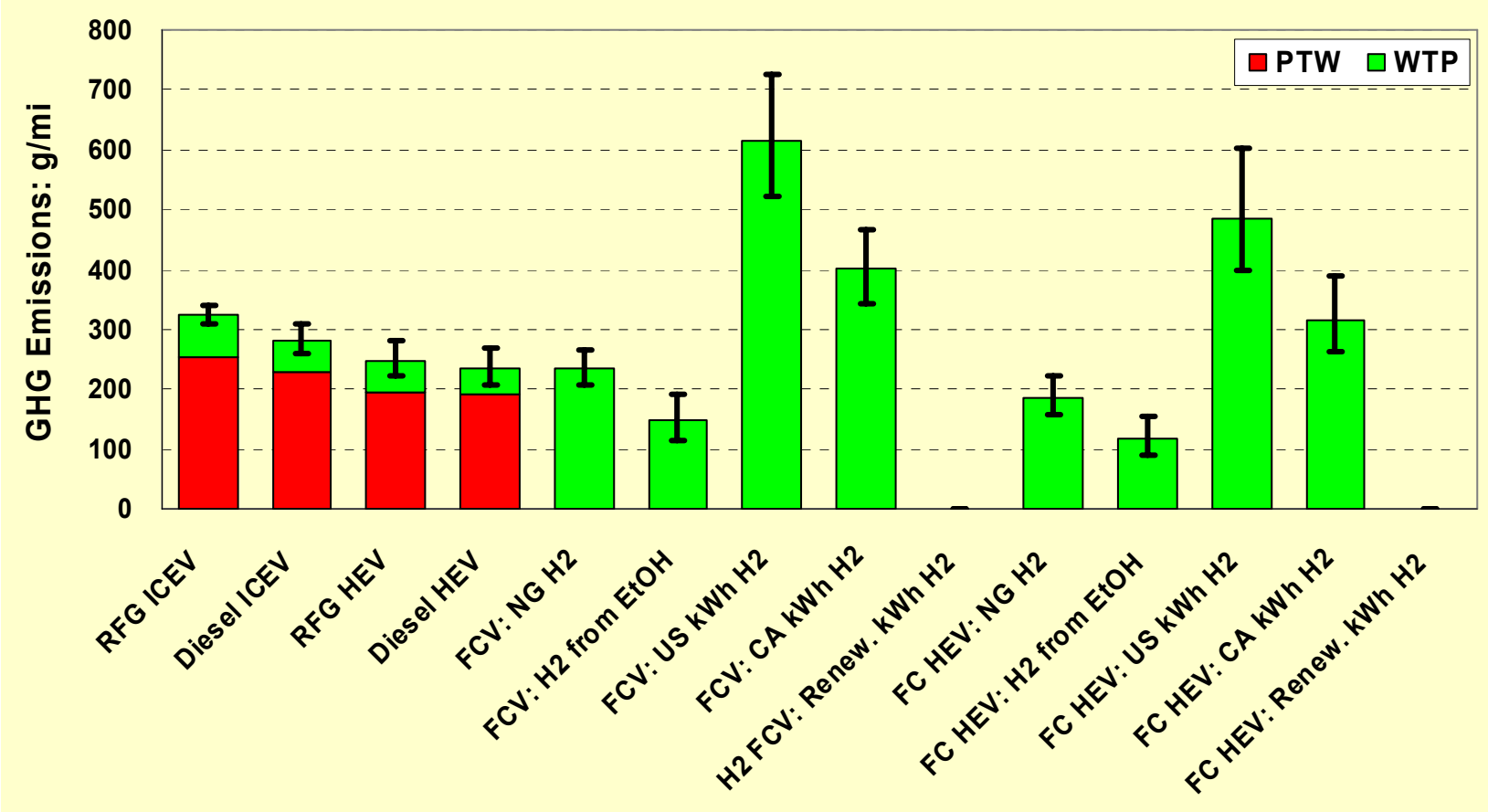

Figure 14.3 Well-to-Wheel Greenhouse Gas Emissions from Hydrogen Fuel Cell and Petroleum Fueled Light-Duty Vehicles

Although WTW analysis has proven to be an essential tool for assessing the environmental impacts of alternative transportation fuels and advanced vehicle technologies, methodological challenges remain. Most relevant to modeling the oil transition is the need to represent technological change and energy system changes in a logically consistent manner. For example, if hydrogen fuel cell vehicles are promoted in an effort to reduce greenhouse gas emissions, is it reasonable to assume that the primary energy sources used for electricity generation will remain unchanged? If carbon emissions from hydrogen or CTL production are captured and stored, will carbon emissions from other pathways such as electricity generation be also? At present, while some of these adjustments are built into GREET for consistent comparisons, others can be made "by hand" according to the judgment of the analyst using the GREET model. Creating methods to insure consistency in technological, economic and policy assumptions across all fuels and processes remains an important area for research. Furthermore, use of consistent methodologies and key assumptions among available life-cycle models and studies would help eliminate some of the inconsistent results among different studies. 


\title{
15. HYBRID MODELS OF INPUT-OUTPUT/LIFECYCLE ENVIRONMENTAL IMPACTS
}

\author{
Heather MacLean \\ University of Toronto
}

The regional and local environmental and social impacts of extraction and conversion of unconventional oil resources may prove to be a more important determinant of their viability than their greenhouse gas emissions. At present, little is known about the local and regional impacts of developing unconventional oil resources on the massive scales that would be necessary during a transition from conventional oil. This appears to be one area in which modeling and analytical tools are inadequate.

Lifecycle analysis (LCA) and WTW environmental assessment models have proven their value in conducting national and international assessments of the environmental impacts of alternative fuel pathways. However, for assessing regional environmental impacts these approaches have two significant limitations. First, LCA and WTW methods do not consider the full ramifications of fuel pathway choices on an economy. They require that a boundary be drawn around the processes and that only those changes within the boundary be considered. Second, they generally do not include the full range of environmental, economic and social impacts of interest in a regional assessment. For example, demands for water or labor, or solid or liquid residuals generated may have significant impacts locally but are rarely considered in WTW assessments.

Hybrid models combining LCA methods with economic input-output models may provide a workable solution. The Economic Input-Output Life Cycle Assessment (EIO-LCA) model developed by Carnegie Mellon's Green Design Institute in 1995 has demonstrated how economy-wide environmental impacts could be estimated for changes in any of 491 economic sectors. The model estimates economy-wide changes in energy use, fuel use, greenhouse gas emissions, air pollutants, toxic releases, and various measures of social costs resulting from technical changes in any sector. A parallel model has been developed for Canada by Dr. Heather MacLean's research group at the University of Toronto. At this time, the Canadian model includes economic impacts, energy use, fuel use, greenhouse gas emissions and water use. The U.S. and Canadian EIO-LCA models have also been linked through trade by the University of Toronto researchers. In spite of these advances, the EIO-LCA models are too aggregated, both geographically and sectorally, for assessing the regional and local impacts of massive energy resource development. The solution may be to create hybrid models that embed adequate geographical and sectoral detail into an EIO-LCA framework. The linkages within such a hybrid model are illustrated in Figure 15.1. Dr. MacLean's research group in collaboration with Dr. David Keith's group at University of Calgary are developing such a model to investigate current and emerging technologies for producing gasoline and diesel fuels from OS in the province of Alberta, Canada. Results are expected to be available later this year (2007). 


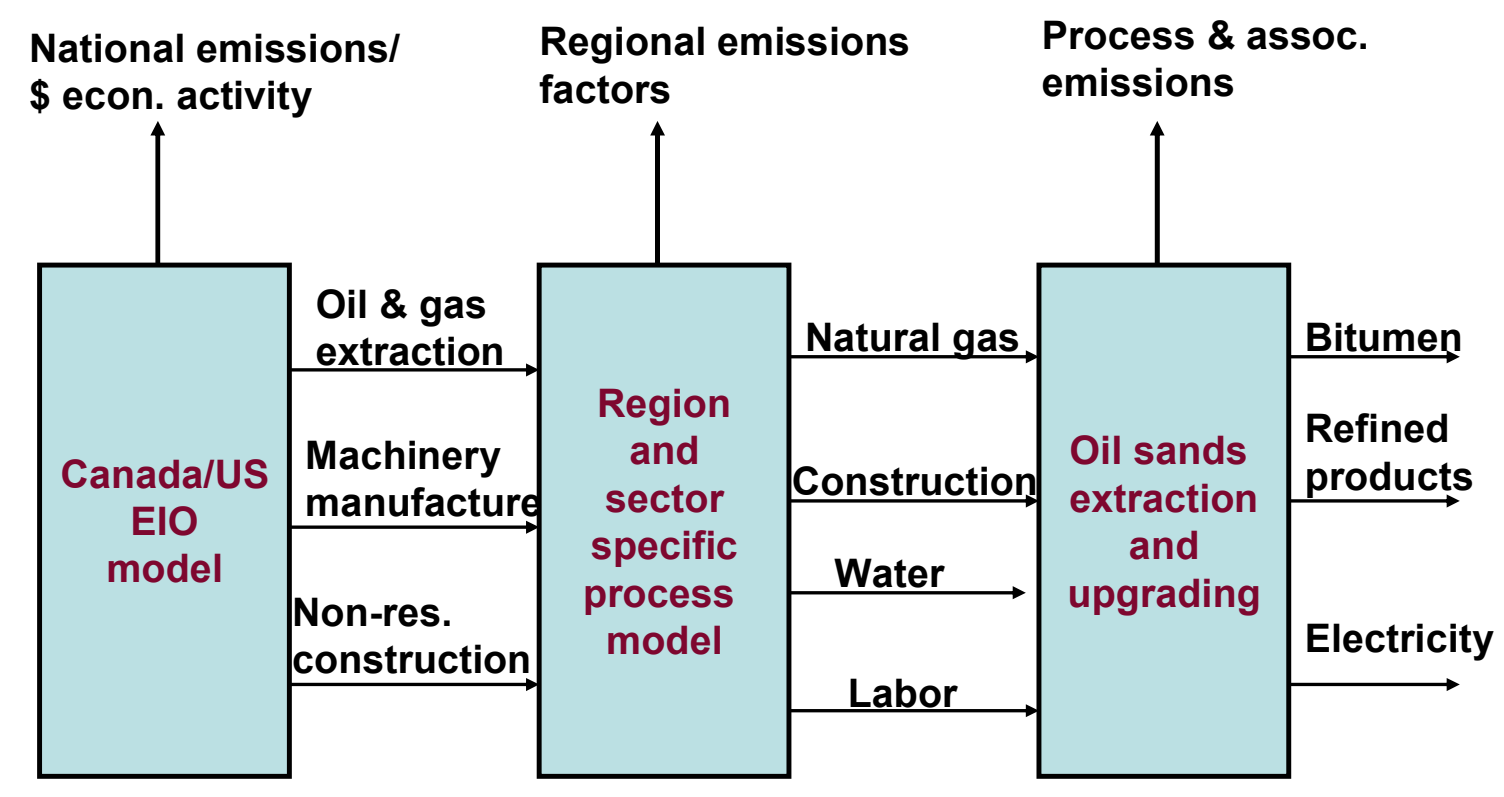

Figure 15.1 Schematic Diagram of a Hybrid EIO-LCA Model for Canadian Oil Sands 


\title{
16. A LONG-TERM VIEW OF AIR POLLUTION AND CLIMATE
}

\author{
Steve Smith \\ Pacific Northwest National Laboratory
}

A transition from petroleum could well be driven by the need to reduce global $\mathrm{CO}_{2}$ emissions from fossil fuel combustion in order to stabilize the concentration of greenhouse gases in the atmosphere at levels that avoid dangerous climate change. An analysis of radiative forcing over the next century using integrated assessment models reveals the critical importance of reducing $\mathrm{CO}_{2}$ emissions in order to avoid potentially dangerous concentrations of greenhouse gases in the earth's atmosphere. Integrated assessment models combine future socio-economic developments and energy supply and demand technologies to create a self-consistent scenario of future greenhouse gas emissions and global climate change. The model used in this assessment, MiniCAM, includes a tracking of resource depletion but does not explicitly model oil peaking. A key conclusion of the assessment is that the earth's fossil fuel resources are enormous and the world's economies are unlikely to be forced away from using them except by deliberate and strong greenhouse gas mitigation policies.

MiniCAM is a long-term (100 year) partial equilibrium model with 14 world regions and representation of markets for energy and agricultural goods and coupled sub-models for energy supply, demand, landuse, and global climate. MiniCAM is not a forecasting model; it is not intended to predict what will happen in the future. Its purpose is to analyze alternative possible futures with different assumptions about economic growth, technological progress, etc., and to calculate greenhouse gas emissions, the impacts on climate, and the costs of mitigation in those futures. The objective is to illuminate the important linkages and to identify the areas where the greatest leverage could be exerted to reduce the risk of dangerous climate change.

Integrated assessment models consider all significant greenhouse gases. MiniCAM calculates emissions for the following greenhouse gases:

1. $\mathrm{CO}_{2}$

2. Methane: 15 Source Sectors (Energy, Human Wastes, Agriculture, Land-Use)

3. Nitrous Oxide:12 Source Sectors (Energy, Human, Industrial, Agriculture, Land-Use)

4. Halocarbons, etc. : 15 Source Sectors ( 7 gases)

5. Carbonaceous aerosols (Black Carbon \& Organic Carbon): 19 Source Sectors each (Energy \& Land-Use Combustion)

6. Reactive Gases: NOx, volatile organic compound (VOC), CO

7. Sulfur Dioxide $\left(\mathrm{SO}_{2}\right)$

A MiniCAM Reference Case scenario, intended to represent an evolution of $\mathrm{CO}_{2}$ emissions in the absence of policy intervention is consistent with an increase in radiative forcing of 5-6 times 1990 levels by 2100 (Figure 16.1). Stabilizing radiative forcing will require substantial changes in the world's energy systems leading to steadily declining $\mathrm{CO}_{2}$ emissions beginning within two or three decades. 


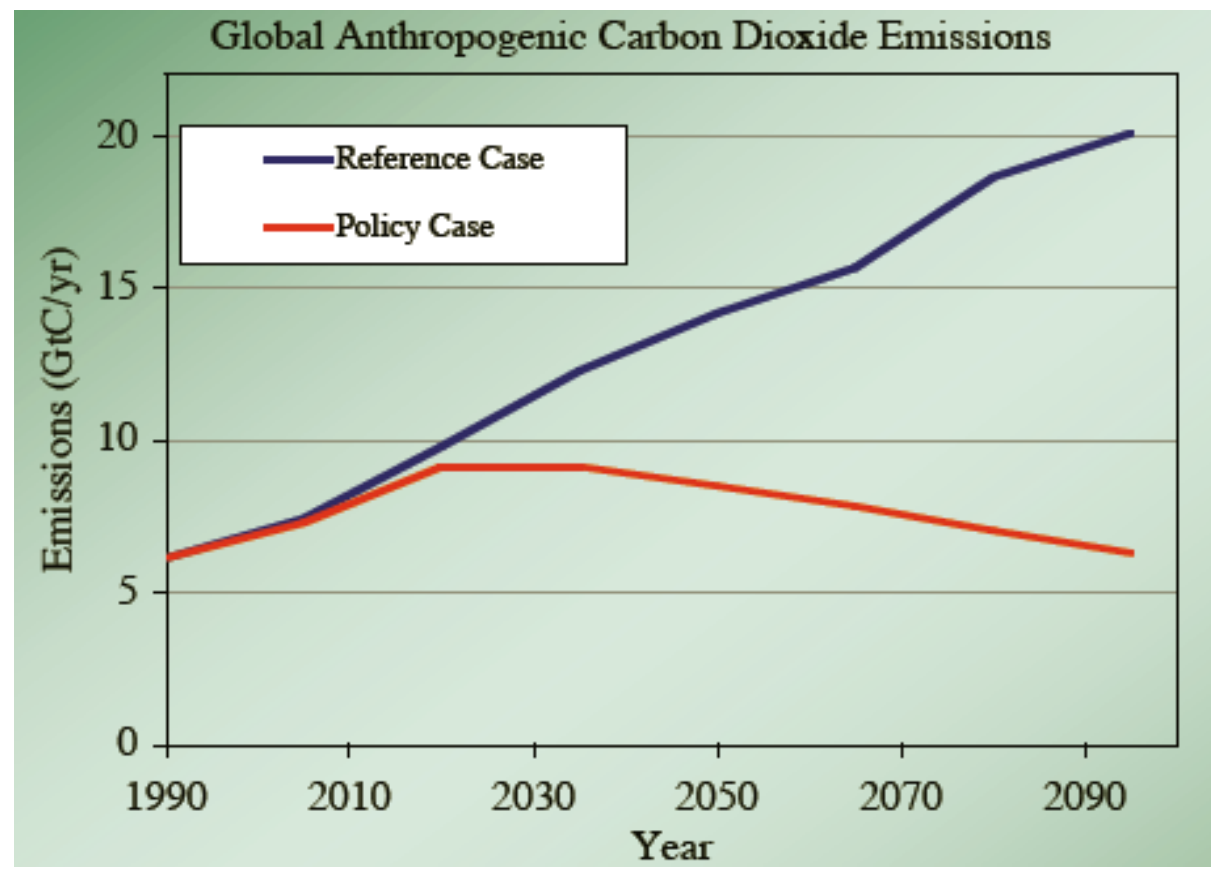

Figure 16.1 Global Anthropogenic $\mathrm{CO}_{2}$ Emissions in Two MiniCAM Scenarios

The Reference Case is based on an IPCC scenario labeled "SRES B2" dubbed "Innovation as Usual" to indicate that it contains substantial economic and technological progress. By the end of the century, incomes in developing economies have increased to approximately the same level as developed economies today. More efficient energy supply and end use technologies are invented and penetrate the marketplace. Agricultural and industrial productivity continue to increase. Air pollutant emissions (many of which are also greenhouse gases) are continuously reduced in developed economies. Pollutant emissions initially increase in developing economies but are later reduced as incomes rise. Greenhouse gas emissions are controlled when it is economic to do so, but there is no explicit mitigation policy. No transformational technological change, such as the emergence of the hydrogen economy, is assumed.

Over time, the importance of $\mathrm{CO}_{2}$ relative to other anthropogenic greenhouse gases increases in the RS (Figure 16.2). By 2100, most of the oil consumed in the world is unconventional oil, conventional resources having been very nearly exhausted. The transition to unconventional oil is not driven by oil peaking. Conventional oil supply is represented by supply curves in which the cost of conventional oil increases as conventional oil resources are depleted.

$\mathrm{SO}_{2}$ emissions, which reduce radiative forcing, decrease with the implementation of more stringent emissions controls (dashed black line in Figure 16.2). This makes the task of reducing total radiative forcing more difficult. Other aerosols, including black carbon, are controlled and so decrease in relative importance over time. There is, however, substantial uncertainty about the effect of aerosols on radiative forcing so that the "un-masking" effect of reducing aerosol emissions could be larger or smaller than shown in Figure 16.2. This will have only a small impact on the overall result: an increase in radiative forcing by a factor of 5 to 6 , driven chiefly by anthropogenic $\mathrm{CO}_{2}$ emissions. 


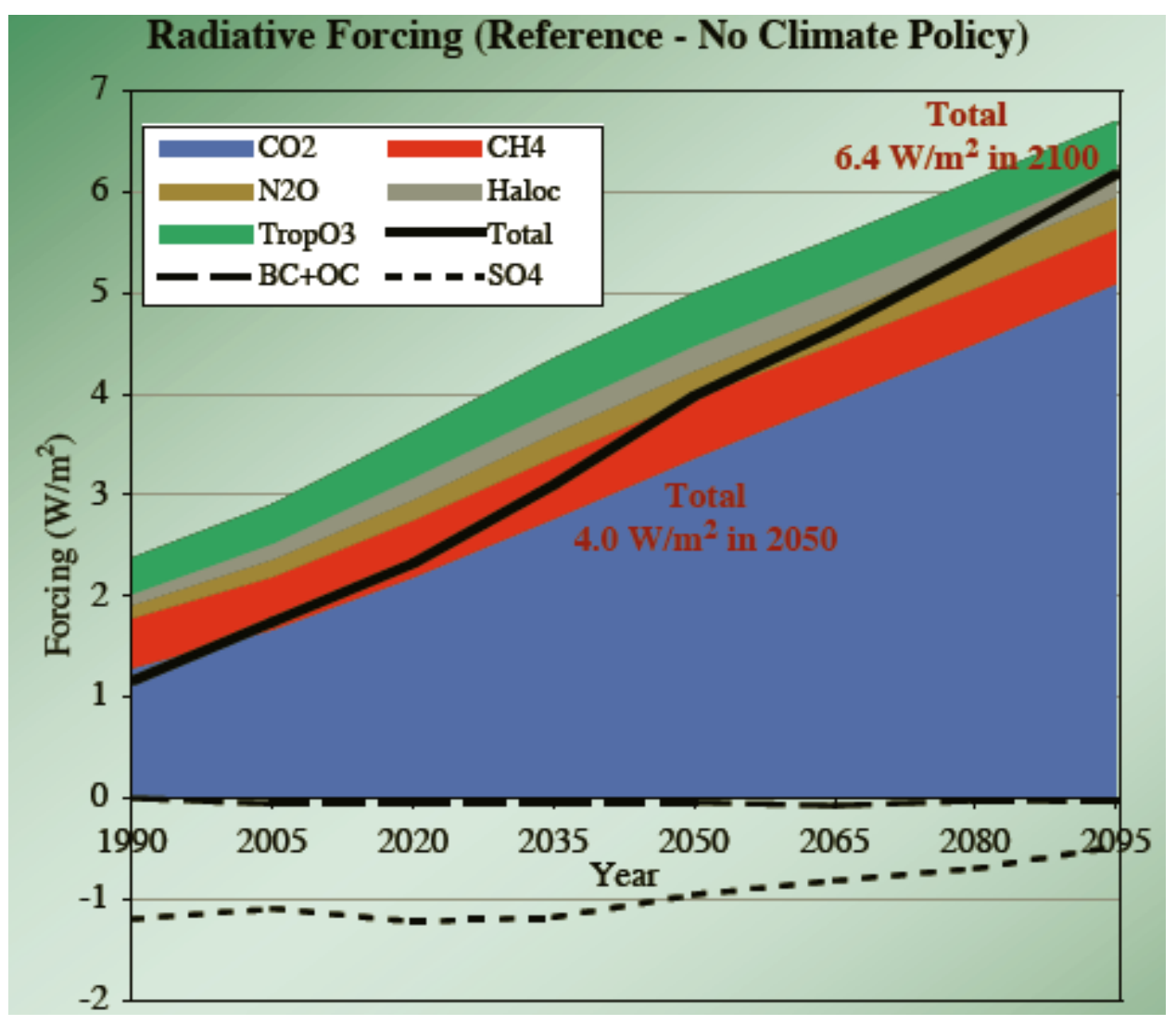

Figure 16.2 Radiative Forcing by Greenhouse Gases in the Reference Case

In the Climate Policy Case, a carbon price is instituted, sufficient to nearly stabilize radiative forcing at $4.5 \mathrm{~W} / \mathrm{m}^{2}$ by 2100 (Figure 16.3). Note that although anthropogenic $\mathrm{CO}_{2}$ emissions are decreasing after 2030 in the Policy Case (Figure 16.1), the radiative forcing effect of $\mathrm{CO}_{2}$ continues to increase as more carbon is added to the atmospheric inventory, although at a reduced rate. Even so, radiative forcing more than triples by 2100 , with about $75 \%$ of that forcing coming from $\mathrm{CO}_{2}$.

Climate change is inevitable; the question is, how severe will it be? Without climate policy, radiative forcing may increase by a factor of 5-6. This is the implication of the Reference Case scenario, in which the world energy system makes a transition from conventional to unconventional oil that is nearly complete by 2100 . The increase in radiative forcing comes primarily from $\mathrm{CO}_{2}$ emissions from the combustion of fossil fuels. Reductions in aerosol emissions (which have a negative effect on radiative forcing) add to the overall radiative forcing. In the Climate Policy Case, carbon prices induce a substantial transition away from fossil carbon as a source of energy, leading to continuous reductions in anthropogenic $\mathrm{CO}_{2}$ emissions after 2030. Even so, radiative forcing more than doubles and $\mathrm{CO}_{2}$ accounts for $75 \%$ of the total forcing in 2100 .

Actions taken over the next 50 years will be critical to stabilizing radiative forcing in the earth's atmosphere. Reducing carbon emissions will be central to achieving stabilization. 


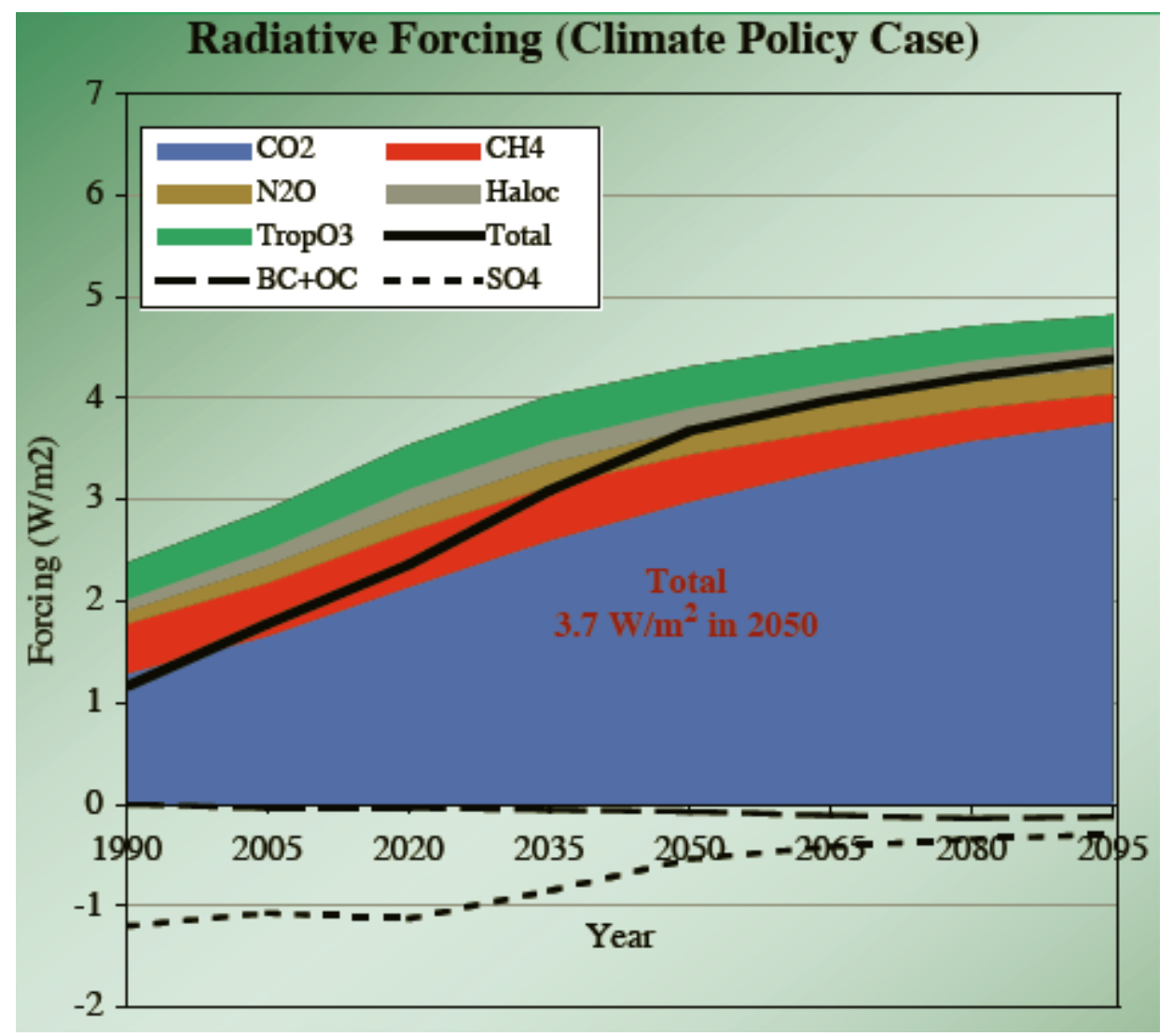

Figure 16.3 Radiative Forcing by Greenhouse Gases in the Climate Policy Case 


\title{
SESSION 5
}

\author{
17. WHAT ARE THE IMPORTANT QUESTIONS? \\ William Fulkerson, Oak Ridge National Laboratory, Retired, Chair \\ Sarah Dunham, U.S. Environmental Protection Agency \\ Robert Hirsch, Science Applications International Corporation (SAIC) \\ Steve Plotkin, Argonne National Laboratory
}

Drawing on the insights about forces that may drive a transition from conventional oil presented in sessions 1-4, Session 5 attempted to identify the important questions for modeling and analysis to address. Session chair William Fulkerson proposed the following list as a starting point for discussion.

1. How will we recognize that the transition is happening?

2. How timely and efficient versus disruptive and costly will the transition be?

3. How can non-equilibrium (disruptive transition) conditions be modeled adequately?

4. How will the transition affect GHG emissions and the climate?

5. Will local environmental concerns significantly retard the use of unconventional resources?

6. How will the developing world manage the increased cost of energy services?

7. How will the transition impact energy security?

8. How can government policies help manage the transition to reduce risks of:

a. Environmental damage?

b. Economic downturn?

c. Energy insecurity?

Sarah Dunham of the U.S. EPA raised questions about the government's role in an energy transition, especially its responsibility to protect the environment. There are clearly environmental implications of the alternative energy sources that modeling and analysis could help to identify and measure. Models could help decision makers understand whether a solution in one area creates a problem in another. Models could help decision makers understand whether the transition is likely to be smooth or whether financial risks and other barriers would lead to a disruptive transition. And if the transition is likely to be disruptive, are there policies that could assist in achieving a smooth transition?

Robert Hirsch of SAIC began with the premise that liquid fuels will be essential to the global economy for the next 30-60 years. Since 1971, world GDP has grown at an average annual rate of $3 \%$, while petroleum use gas grown at $1.5 \%$ per year. The question is, what will happen when the maximum of global oil production is reached? Will it force GDP to decline? Based on experience with regional oil peaking, the peak can come on very quickly, much more quickly than our capital intensive supply and end use systems can respond. If the peak arrives unexpectedly and we are unprepared, the consequences could be very dire.

There is considerable uncertainty about when the global oil peak will arrive. A dozen serious predictions range from now (the peak is upon us) to more than thirty years from now (Table 17.1). It is critically important that we have the best possible estimates of the arrival of the peak 
because energy systems cannot adjust quickly enough to wait until it has arrived and then respond. Based on the regional peaks that have already occurred, the decline in oil production post-peak could be quite rapid (Figure 17.1).

\section{Table 17.1. Predictions of the Timing of Global Oil Peaking from a Dozen Sources}

Forecast

2004

December 2005

2006-2007

2007-2009

After 2007

2010

Before 2010

After 2010

2012

2016

After 2020

2030 or later
Source

CIBC (Canada)

Deffeyes (U.S.)

Bakhitari (Iran)

Simmons (U.S.)

Skrebowski (U.K.)

Campbell (Ireland)

Goodstein (U.S.)

World Energy Council

Weng (China)

Doug-Westwood (U.K.)

CERA (U.S.)

EIA (U.S) / Exxon Mobil

United Kingdom

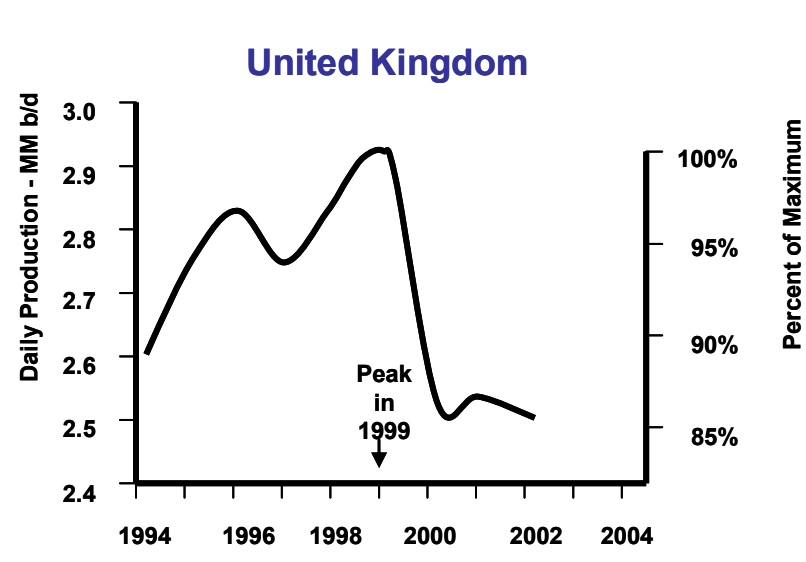

North America

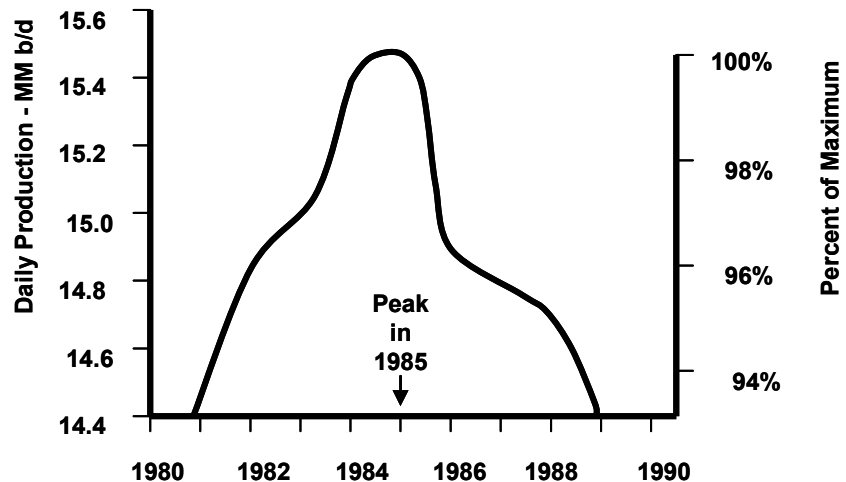

Figure 17.1 Historical Oil Peaks in the United Kingdom and North America

Even if the rate of decline in world oil production is relatively slow, say $2 \%$ per year, the gap between normal demand growth and available conventional oil supply will become very large very soon. Gaps between expected growth in oil use and supply for two rates of decline are illustrated in Figure 17.2. If the post-peak rate of decline is only $2 \%$ per year, a gap of 60 million barrels per day will open within 20 years. If the rate of decline is as large as $8 \%$ per year, the gap increases to nearly 100 million barrels per day. 


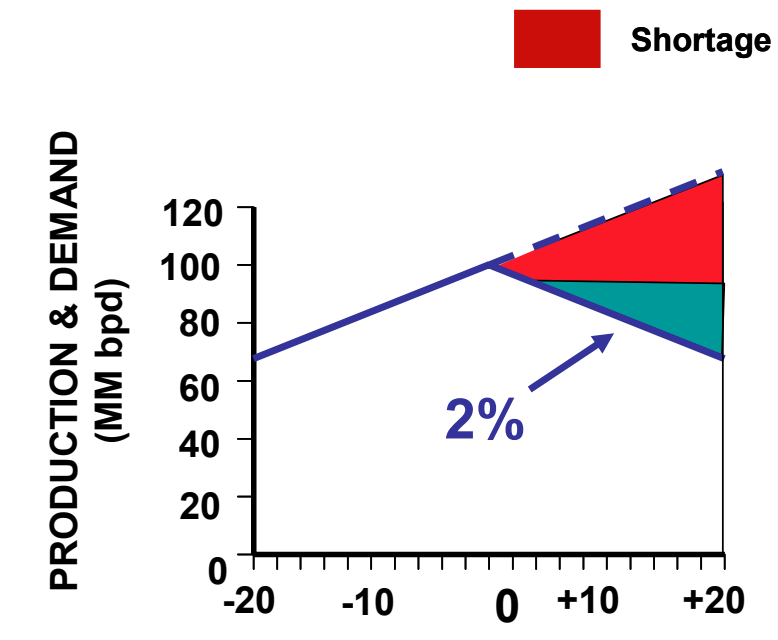

Mitigation

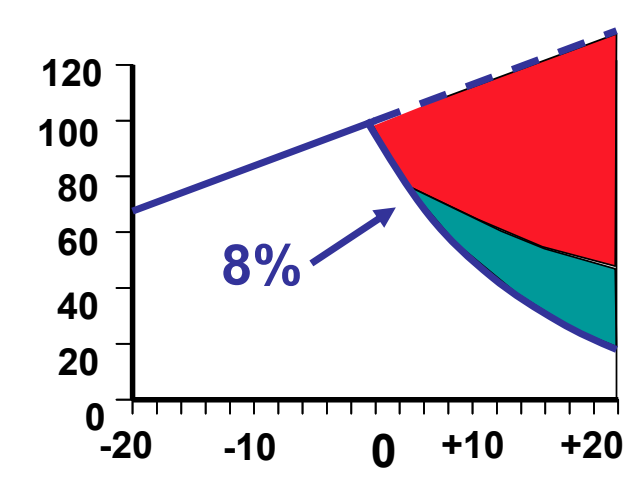

YEARS BEFORE / AFTER OIL PEAK

Figure 17.2 The Effect of Post-Peak Rates of Decline on the Oil Supply Shortfall

It is difficult to imagine how such gaps could be filled. Even if a crash program were implemented to expand EOR, production of liquid fuels from coal, natural gas and heavy oil, and to increase LDV efficiency, only $35 \mathrm{mmbd}$ of the gap could be filled within 20 years (Figure 17.3).

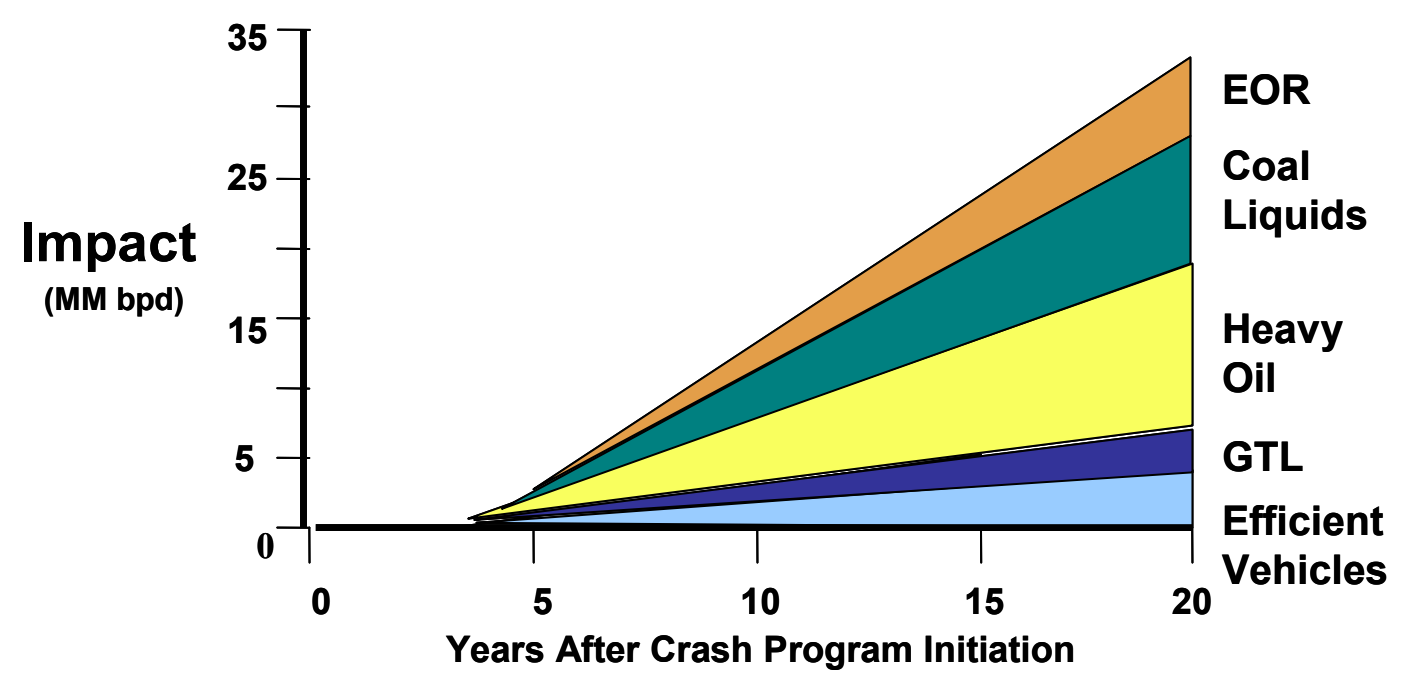

Figure 17.3 Effect of a Crash Program to Close the Post-Peak Oil Supply Gap

This analysis leads to four critical questions that urgently need answers from modelers and analysts. First, when will the global oil maximum occur? Second, how rapidly will oil production drop off after the peak? Third, what will be the economic impacts of different rates of demand destruction? Fourth, what policies can be implemented to mitigate the impacts of massive demand destruction and when should they be implemented? At present, we have few useful answers to these questions. 
Steve Plotkin of Argonne National Laboratory pointed out that the lessons of history for investors in alternative energy sources point to substantial risks and counsel in favor of caution. During the oil crises of the 1970s, many believed that the transition from conventional oil had begun. Those who assumed the oil crisis would continue or worsen were badly burned when oil prices plummeted in 1986. With prices below $\$ 10$ per barrel (temporarily), investments in synfuels became worthless. Oil peak prognosticators have been wrong in the past and so their latest forecasts are not likely to be believed either. The implication is that the oil peak will come upon us unprepared and that because of the magnitude of capital investments required and the risk of falling oil prices, the transition is not likely to be smooth.

The key questions are therefore what the consequences of disruptive transitions are likely to be and what can be done to mitigate them. What might be the effects of a delayed and "rough" transition, in terms of cost escalation for energy development projects and environmental dangers due to hurried implementation? What are the values of alternative pathways, taking into consideration the substantial investment risks? And what are the costs and benefits of policy measures to smooth the transition?

In the ensuing discussion participants asserted that to have a smooth transition, the peak in conventional oil production would have to be anticipated, due to the lead times required for nearly all mitigation options. This implies models must be able to predict the peak (and the rate of decline) reasonably accurately. A smooth transition implies coping effectively with risk, on the demand and supply sides, especially from OPEC's capacity and production decisions. It will also require dealing effectively with local environmental problems because local opposition to large-scale energy developments can stall or defeat energy resource development plans.

Others noted that there were four possible outcomes, depending on whether or not the transition is disruptive or not and whether it takes us in an environmentally beneficial direction or not. The transition could be smooth but lead to significant increases in $\mathrm{CO}_{2}$ emissions at a time when the world needs to be decreasing $\mathrm{CO}_{2}$ emissions. Only one of the four possibilities is desirable: a smooth transition to an environmentally sustainable energy system. It was also pointed out that depending on its direction, the transition could have positive or negative implications for energy security. 
PART 2

METHODS \& MODELS: CAPABILITIES, CHALLENGES

AND OPPORTUNITIES 


\title{
18. KEYNOTE: DYNAMICS OF GLOBAL ENERGY TRANSITIONS
}

\author{
Nebojsa Nakićenović \\ IIASA and Vienna University of Technology
}

The world's energy system faces significant challenges in the $21^{\text {st }}$ Century. The most important are:

1. Providing access to modern forms of energy for developing economies, a necessity to reach the Millennium Development Goals.

2. Satisfying a growing demand for energy services,

3. Making massive investments in energy R\&D and deployment,

4. Insuring the security and reliability of energy supply, and

5. Making deep reductions in $\mathrm{CO}_{2}$ and all greenhouse gases.

Most of the world's energy needs are currently supplied by fossil fuels. However, the fossil energy era will be a tiny blip in human history. M. King Hubbert was among the first to clearly articulate this fact. Viewed on a time scale of 10,000 years, past and future, the several hundred years of fossil energy supply appears as a very brief episode (Figure 18.1).

\section{Fossil Era on Geological Time Scale}

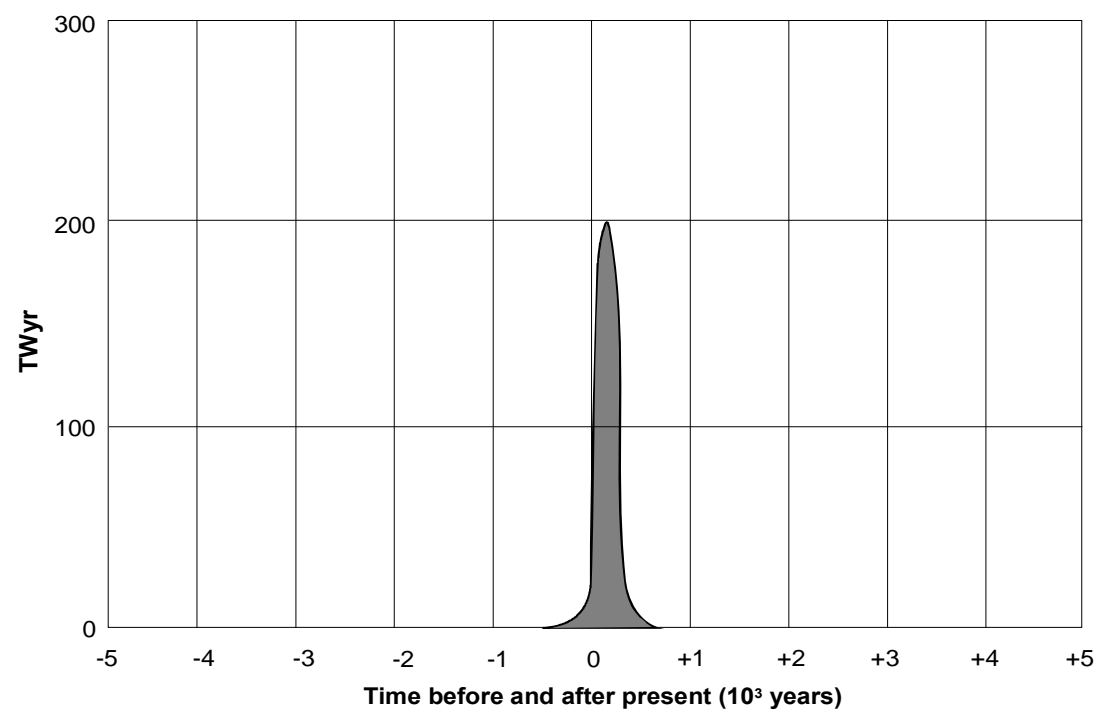

Source: K. Hubbart, 1949

Figure 18.1 The Fossil Fuel Era on a Scale of 10,000 Years

The era of oil too, will end. But the peak of oil production may turn out to be socially constructed, rather than determined by scarcity. Making an analogy to the world's supply of oil, Sheik Yamani is reported to have commented, "The stone age did not come to an end because of a lack of stones." Similarly, the oil age may come to an end because human society prefers 
other, cleaner forms of energy with greater exergy. The history of U.S. final energy use (Figure 18.2) reflects a similar transition: from bulky solid fuels (wood and coal) to more easily stored and higher energy density liquid fuels (petroleum) to cleaner grid based energy (electricity and natural gas).

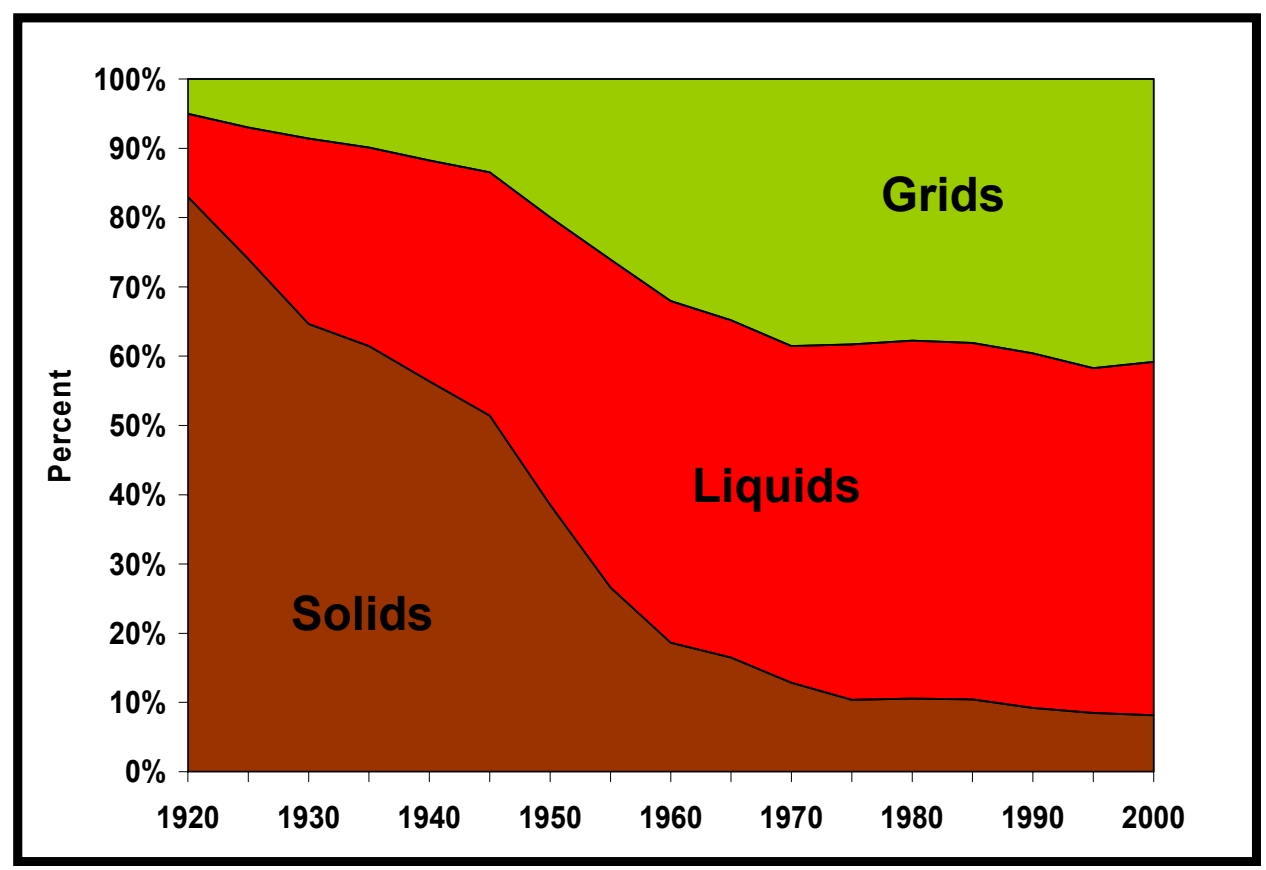

Figure 18.2 U.S. Final Energy Use by Form

How future transitions will evolve is, of course, unknown. However, scenarios, self-consistent descriptions of how the world energy system could evolve, are useful for exploring possibilities and identifying key linkages between driving forces and outcomes. Numerous global energy scenarios have been constructed by IIASA for the World Energy Council (WEC) and for the IPCC. The scenarios span a wide range of assumptions about future economic and population growth, energy use and $\mathrm{CO}_{2}$ emissions (Table 18.1). Generally, population, GDP, and primary energy use follow S-shaped curves with growth slowing over the coming century. In most cases, $\mathrm{CO}_{2}$ growth is slower than the growth of energy use, except in the "return to coal" scenario. Crude oil consumption includes both conventional and unconventional sources.

The A1 and B1 scenarios reflect high rates of economic growth, while the A2 and B2 scenarios represent more moderate economic growth. The A1 and B1 scenarios also reflect a much greater degree of global integration. The rates of technological progress are highest in the A1 scenario, in which primary energy use is high but energy intensity is low. Both energy use and energy intensity are high in scenario A2. B1 combines low primary energy use with low energy intensity, while B2 is moderate on both counts. 
Table 18.1 Key Attributes of Global Energy Scenarios Compared with History

\begin{tabular}{|l|c|c|c|c|c|c|c|}
\hline \multicolumn{1}{|c|}{ Year / Multiple } & $\mathbf{1 8 0 0}$ & $\begin{array}{c}\text { Factor } \\
\mathbf{1 9 0 0 / 1 8 0 0}\end{array}$ & $\mathbf{1 9 0 0}$ & $\begin{array}{c}\text { Factor } \\
\mathbf{2 0 0 0 / 1 9 0 0}\end{array}$ & $\mathbf{2 0 0 0}$ & $\begin{array}{c}\text { Factor } \\
\mathbf{2 1 0 0 / 2 0 0 0}\end{array}$ & $\mathbf{2 1 0 0}$ \\
\hline $\begin{array}{l}\text { Population } \\
\text { (billion) }\end{array}$ & 1 & 1.6 & 1.6 & 3.8 & 6 & 1.2 to 2.5 & $7-15$ \\
\hline $\begin{array}{l}\text { GDP PPP } \\
\text { (trillion 1990\$) }\end{array}$ & 0.5 & 4.0 & 2 & 18 & 36 & $<3$ to 18 & $85-530$ \\
\hline $\begin{array}{l}\text { Primary Energy } \\
\text { (EJ) }\end{array}$ & 13 & 3.3 & 40 & 11 & 440 & 1.1 to 2.5 & $500-2500$ \\
\hline $\begin{array}{l}\text { CO } 2 \text { Emissions } \\
(\text { GtC) }\end{array}$ & $0-0.3$ & 3.0 & $0.5-1.0$ & 6 to 12 & 6.4 & $<0.5$ to 5 & $3-33$ \\
\hline $\begin{array}{l}\text { Crude Oil R/P } \\
\text { (Ratio) }\end{array}$ & $\infty$ & $\infty$ & 45 & 1.0 & 45 & 0.2 to 7.3 & $9-330$ \\
\hline
\end{tabular}

The future composition of final energy use varies widely across scenarios, as well (Figure 18.3). In general, the developed economies make a transition from liquids to grid-based energy, while the developing economies follow the solids to liquids path. In the globally integrated A1 and B1 scenarios, the developing economies also make the liquid-to-grid transition by 2100 . In the coalintensive A2 scenario, coal is transformed into liquid fuels such as methanol to support the very high demand for energy in the form of liquids. Indeed, in most scenarios alcohol fuels become the dominant energy liquids by 2100 . Grid-based energy, including electricity, natural gas and hydrogen, predominates in the $\mathrm{A} 1$ and $\mathrm{B} 1$ scenarios.

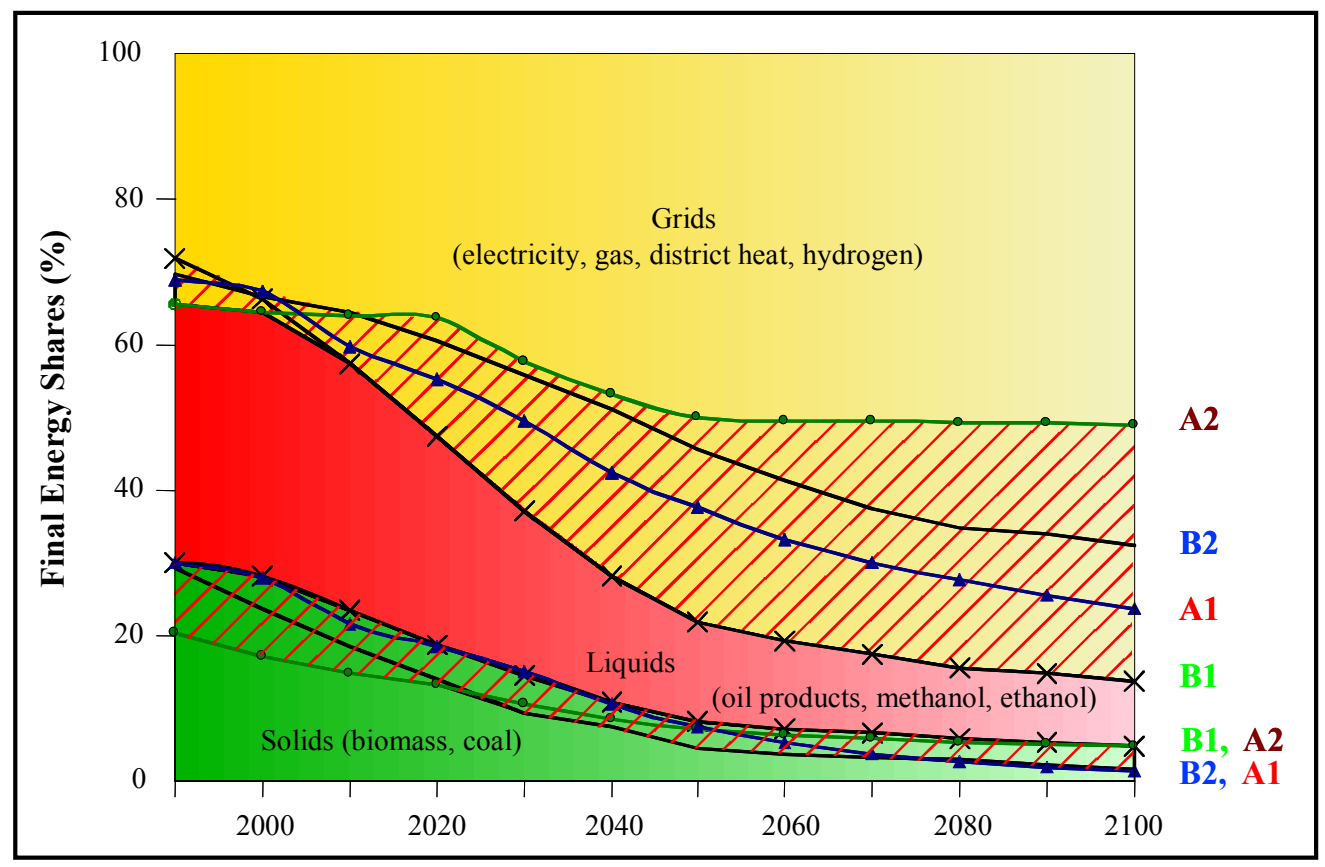

Figure 18.3 World Energy Use to 2100: Alternative Scenarios 
Every scenario shows conventional and unconventional oil peaking by 2100 . In the scenarios requiring the largest quantities of liquid fuels, a massive transition to unconventional fossil resources takes place. Demand for liquid fuels drives the transition which is enabled by technological progress.

The McKelvey diagram classifies resources by degree of assurance that they are in fact present and by the economic feasibility of their recovery. Technological progress, sometimes reinforced by increasing prices for established resources, transforms unconventional and low-grade occurrences into resources and then proven reserves (Figure 18.4). These transformations occur in all scenarios but at different rates.

\section{McKelvey Diagram}

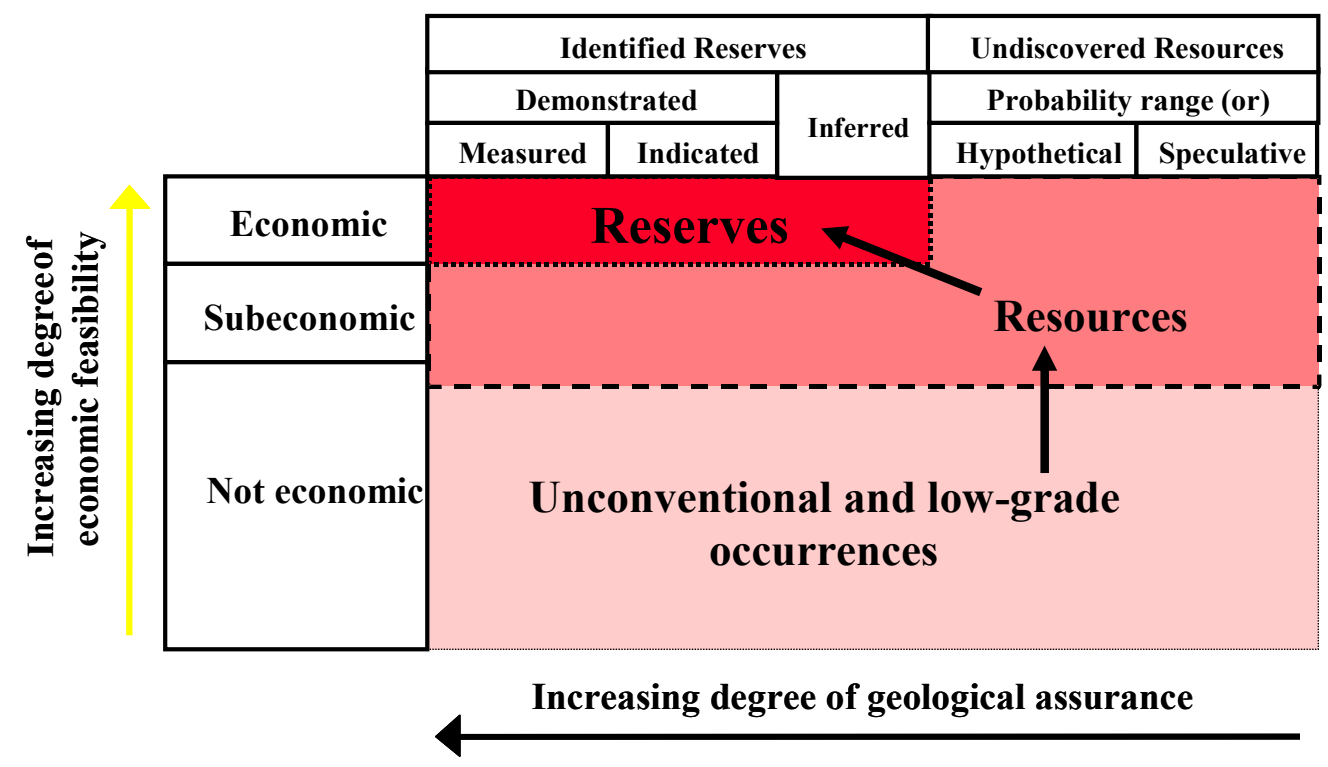

Figure 18.4 Resource Classification Using the McKelvey Diagram

Estimated quantities of hydrocarbon energy resources and their assumed availability in various scenarios are shown in Table 18.2. The classification of resources follows Nakićenović et al. (1998). Estimated recoverable ultimate resources of oil and gas, plus what enhanced recovery methods may be able to derive from the same resource occurrences are shown in the first two rows and first two columns. Unconventional resources known to be recoverable are shown in the next two columns, labeled categories V and VI. Additional occurrences that may or may not ever be economically recoverable are shown under categories VII and VIII. Below, the assumed availability of each resource is shown, by scenario. The different categories of hydrocarbon resources have different costs which are also affected by technological change. Cumulative production is tracked and is subject to resource availability constraints.

In every scenario, production of conventional oil (categories I, II and III) peaks and then declines. The approximate dates of conventional oil peaking are shown for four scenarios (indicated by yellow bars) in Figure 18.5. However, due to technological progress and rising oil prices, it becomes increasingly economical to produce hydrocarbons from unconventional resources. Total oil production (conventional + unconventional) peaks, at some point in each of 
the four scenarios, sometime between 2030 and 2080. Occasionally the peak depends on how much of the unconventional occurrences are assumed to be available. In other scenarios, where environmental concerns are very strong, oil use peaks due to concern for its environmental impacts. Most often, oil use peaks due to a preference for coal-based liquid fuels or grid-based forms of energy.

Table 18.2 Hydrocarbon Reserves and Resources (Energy in zetajoules $=10^{21}$ joules)

\begin{tabular}{|c|c|c|c|c|c|c|c|c|c|}
\hline \multirow[b]{3}{*}{ Category } & \multirow{3}{*}{$\begin{array}{c}\text { Conventional } \\
\text { reserves and } \\
\text { resources }\end{array}$} & \multicolumn{3}{|c|}{ Unconventional } & \multicolumn{2}{|c|}{$\begin{array}{c}\text { Unconventional and } \\
\text { additional } \\
\text { occurrences }\end{array}$} & & & \\
\hline & & $\begin{array}{l}\text { Enhanced } \\
\text { recovery }\end{array}$ & \multicolumn{2}{|c|}{ Recoverable } & & & & \multirow{2}{*}{\multicolumn{2}{|c|}{$\begin{array}{c}\text { Historical } \\
\text { Consumption } \\
1860-1998\end{array}$}} \\
\hline & & IV & $\mathbf{V}$ & VI & VII & VIII & Total & & \\
\hline Oil & 12.4 & 5.8 & 1.9 & 14.1 & 24.6 & 35.2 & 94 & \multicolumn{2}{|c|}{5.1} \\
\hline Gas & 16.5 & 2.3 & 5.8 & 10.8 & 16.2 & 800 & 852 & \multicolumn{2}{|c|}{2.4} \\
\hline Scenario/ & \multicolumn{4}{|c|}{ Scenario assumptions } & & & & \multicolumn{2}{|c|}{$\begin{array}{c}\text { Consumption } \\
1990-2100\end{array}$} \\
\hline Category & I,II,III & IV & $\mathbf{V}$ & VI & VII & VIII & & Oil & Gas \\
\hline \multicolumn{10}{|l|}{ SRES } \\
\hline A1B & gas/oil & gas/oil & gas/oil & gas/oil & gas & --- & & 25.5 & 31.8 \\
\hline $\mathbf{A 1 T}$ & gas/oil & gas/oil & gas/oil & gas/oil & gas & --- & & 20.8 & 24.9 \\
\hline A10\&G & gas/oil & gas/oil & gas/oil & gas/oil & gas/oil & gas & & 34.4 & 49.1 \\
\hline A1C & gas/oil & gas/oil & gas/oil & --- & -- & -- & & 18.5 & 20.5 \\
\hline A2 & gas/oil & gas/oil & gas/oil & gas & --- & --- & & 19.6 & 24.5 \\
\hline B1 & gas/oil & gas/oil & gas & gas & --- & --- & & 17.2 & 23.9 \\
\hline B2 & gas/oil & gas/oil & gas/oil & gas & --- & --- & & 19.4 & 26.9 \\
\hline \multicolumn{10}{|l|}{ WEC } \\
\hline A1 & gas/oil & gas/oil & gas/oil & gas/oil & gas/oil & gas/oil & & 34.0 & 28.9 \\
\hline A2 & gas/oil & gas/oil & gas/oil & --- & -- & -- & & 18.7 & 21.2 \\
\hline A3 & gas/oil & gas/oil & gas & gas & gas & --- & & 17.4 & 36.1 \\
\hline B & gas/oil & gas/oil & gas/oil & --- & -- & --- & & 17.8 & 19.6 \\
\hline C1 & gas/oil & --- & --- & --- & --- & --- & & 12.4 & 14.9 \\
\hline $\mathrm{C2}$ & gas/oil & --- & --- & --- & --- & --- & & 12.4 & 14.2 \\
\hline
\end{tabular}
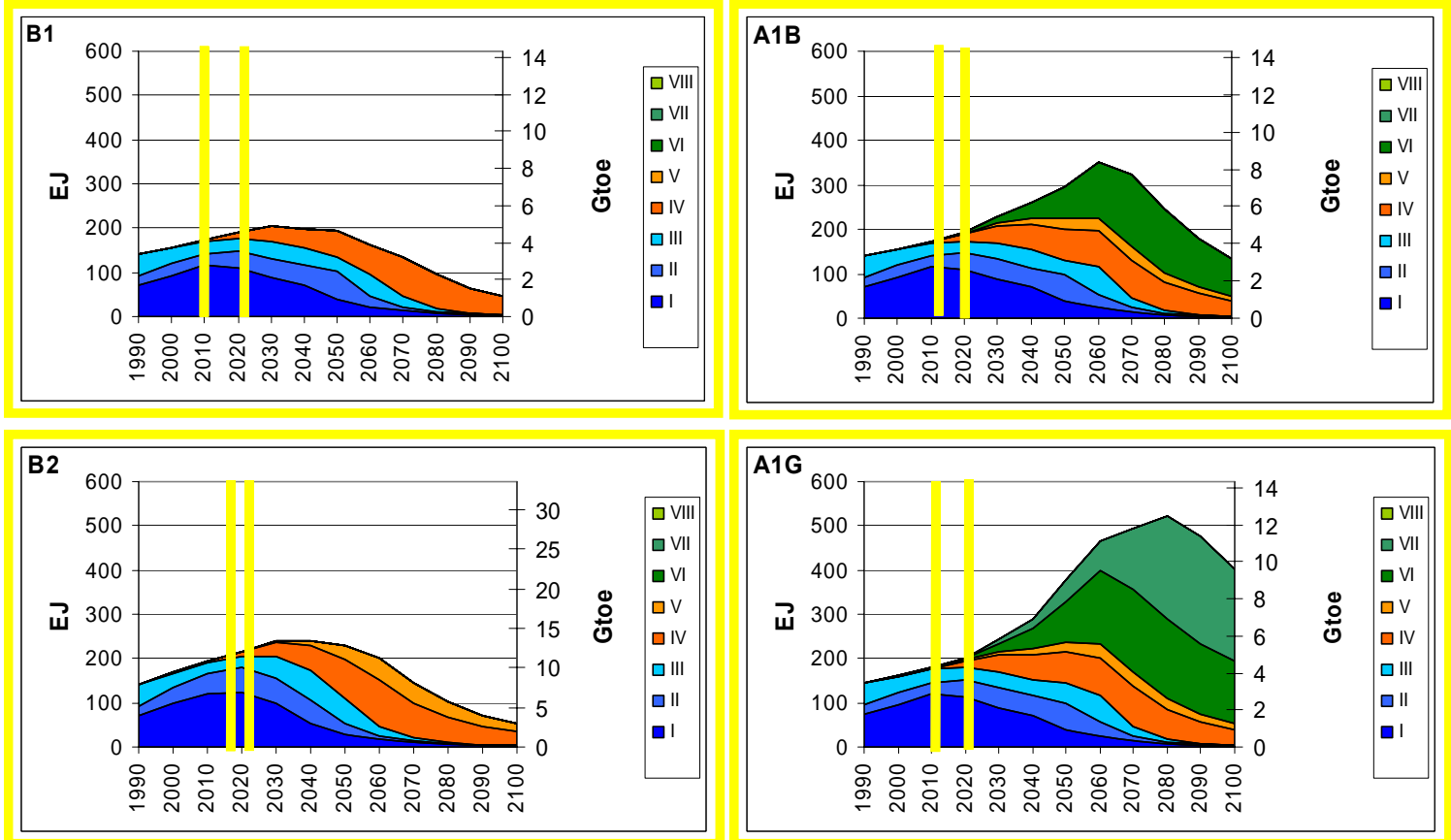

Figure 18.5 Oil Extraction and Depletion in Four Global Energy Scenarios 
The earth's fossil energy resources will be adequate to supply global demand for liquid fuels for the next century under almost any scenario. Such a thorough exploitation of the world's fossil resources and the release of the carbon they contain to the atmosphere would not be desirable because of the impact on the global climate. The earth's atmosphere currently contains 800 gigatons of carbon. The world's remaining conventional oil and gas resources contain 530 gigatons of carbon. If all were burned and the $\mathrm{CO}_{2}$ released, about half would remain in the atmosphere. This alone would not be enough to raise the concentration of $\mathrm{CO}_{2}$ above 550 parts per million (ppm). However, the carbon in the world's coal resources is 6 to 10 times the amount currently in the atmosphere, enough to raise atmospheric carbon levels above $1,000 \mathrm{ppm}$ (Figure 18.6). Worse yet, the world's unconventional fossil fuel resources are far larger than the coal resources. Were the world's energy system to transition to massive use of unconventional fossil carbon resources and release that carbon to the atmosphere, the climatic impacts could be disastrous.

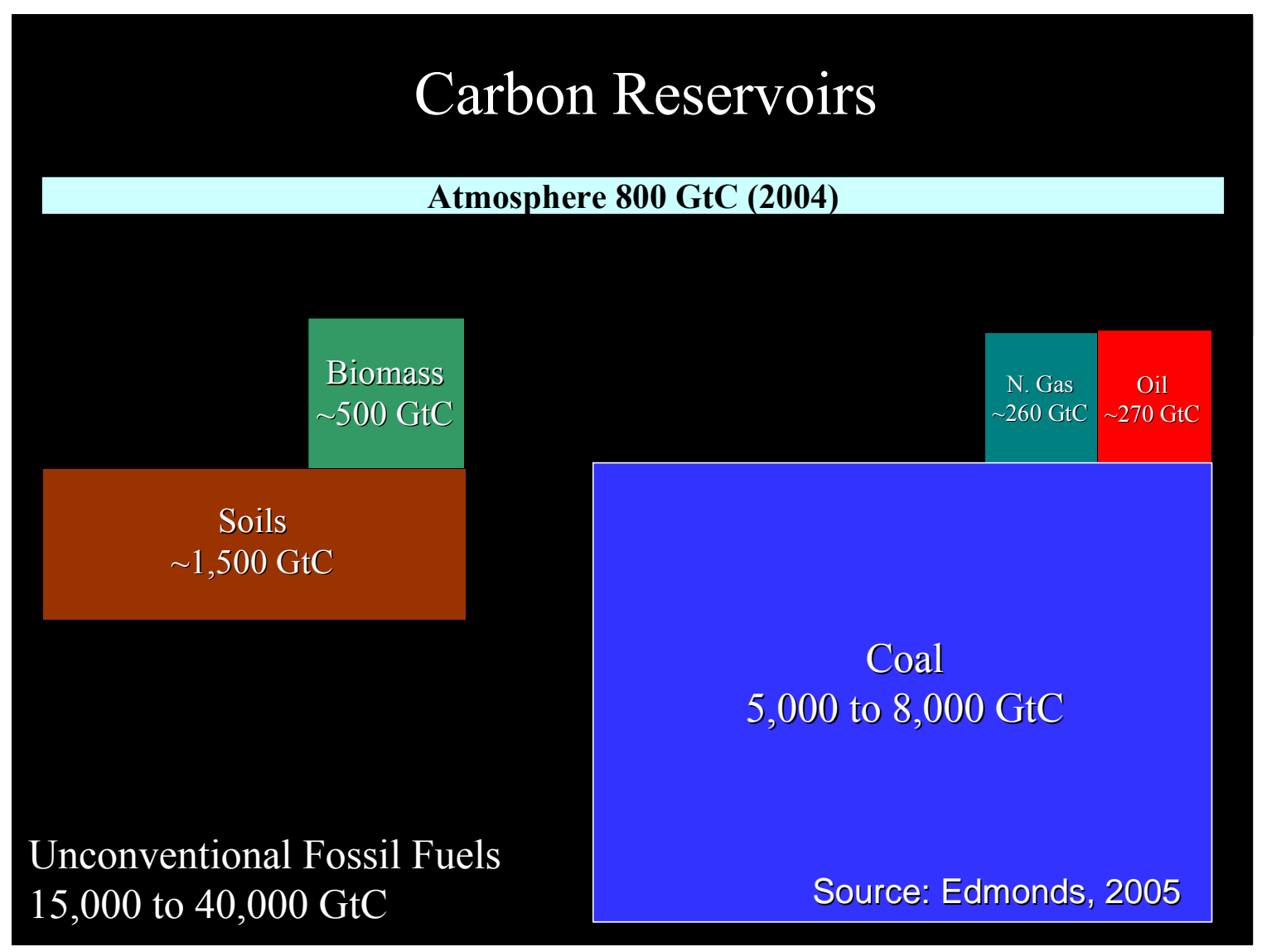

\section{Figure 18.6 The World's Carbon Reservoirs}

The world is indeed facing profound energy transitions. Our task is to find a path to a sustainable energy future, one that simultaneously meets the five great energy challenges of the $21^{\text {st }}$ Century:

1. Providing access to modern forms of energy for developing economies, a necessity to reach the Millennium Development Goals.

2. Satisfying a growing demand for energy services,

3. Making massive investments in energy R\&D and deployment, 
4. Insuring the security and reliability of energy supply, and

5. Making deep reductions in $\mathrm{CO}_{2}$ and all greenhouse gases.

The magnitude of the changes that will be required is truly enormous. A paradigm shift is needed, a transition to an energy system based on energy end-use efficiency, renewables, new nuclear energy, and carbon capture and storage.

\section{REFERENCE}

Nakićenović, N., A. Grübler and A. McDonald, 1998. Global Energy Perspectives, Cambridge University Press, Cambridge, UK. 


\title{
SESSION 6: MODELING GLOBAL ENERGY TRANSITIONS \& THEIR ENVIRONMENTAL EFFECTS
}

\author{
PART I: MODELING OIL DEPLETION \\ Dolf Gielen, International Energy Agency, Chair
}

\section{RESOURCE DEPLETION: MODELING AND FORECASTING OIL PRODUCTION}

\author{
Michael R. Smith \\ Energyfiles
}

The key difference between models of oil peaking and energy market models is not the use of the Hubbert Curve. Good oil peaking models focus on production rates rather than quantities of reserves and resources. They focus on how reservoirs behave rather than on the interaction of supply and demand and so give a real, technical view on future output, not influenced by wishful thinking or political preference.

There is a great deal of uncertainty surrounding the question of oil peaking. To an extent this arises from conflicting estimates of oil resource quantities, which are, in fact, largely irrelevant. Numbers in the public domain tend to be misleading for a variety of reasons. Bias is one. Some numbers, such as proved reserves in the United States, may be underreported by the oil industry for regulatory reasons. But a company may also over-state certain numbers to maximize the value of its assets. Some governments may over-report to make themselves appear more important or to attain higher production quotas. Geologists sometimes characterize their estimates as "optimistic" when a more realistic appraisal would give a lower estimate.

Part of the uncertainty can be traced to ambiguity. For many important numbers there are no standard, universally accepted definitions. The treatment of unconventional oil resources varies and can have an enormous impact (e.g., Canadian OS can be counted as proven reserves or unconventional resources). Estimates always come with a degree of technical uncertainty. The terms probable and possible themselves bespeak uncertainty. Some terms almost beg to be misinterpreted, for example, reserve-to-production $(\mathrm{R} / \mathrm{P})$ ratios measured in years. These numbers are widely misinterpreted as the number of years of adequate production remaining. More accurately, they are a measure of quantity denominated in time units. In fact, the production peak is not dependent on reserves at all, but on rates. The quantity of reserves is only truly known after a field has been abandoned. The timing of the peak can be known well before that.

Consider the following ideal model of a sedimentary basin anywhere in the world. The first few fields are large and relatively easy to find. On average they come on stream within 3-4 years of discovery. Every field has a production profile determined by the following five factors:

1. reservoir characteristics (e.g., porosity, permeability, etc.),

2. fluid type (gas, oil, viscosity, etc.), 
3. pressure and temperature,

4. production environment (e.g., onshore, offshore, etc.); and

5. level and timing of investment.

Generally for each field, output rises to a plateau within 2-3 years, is stable for 2-3 years, and then declines at a rate of $5 \%$ to $15 \%$ per year, depending on the five factors listed above. As time passes and more fields are discovered, field size becomes progressively smaller. This process is illustrated for thirty fields in a hypothetical sedimentary basin in Figure 19.1.

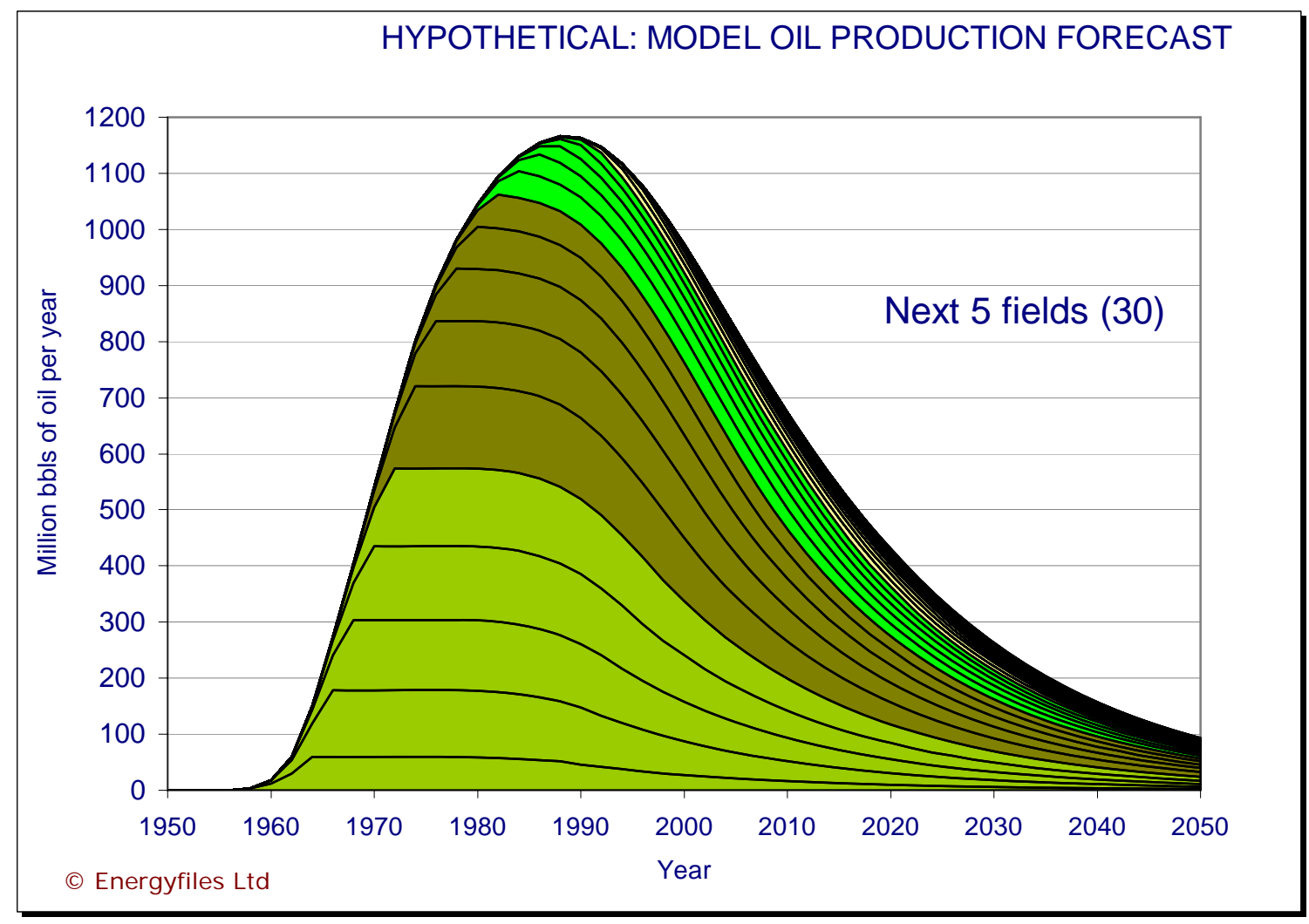

Figure 19.1 Ideal Model of Oil Production from an Oil-Bearing Sedimentary Basin

It is clear from this simple model that the last half or so (last 15) of the thirty fields illustrated in Figure 19.1 do not affect the timing of the peak in any significant way. Nor does enhanced recovery affect the timing of the peak, since it is usually implemented after the peak has passed. Instead, later discoveries and enhanced recovery affect the rate of decline.

Furthermore it would seem that discovery leads production by approximately 25 years, as shown in Figure 19.2. The discovery peak is an early warning signal that the production peak is coming.

The ideal model also provides a means of estimating a basin's total recoverable oil resources. Cumulative discoveries are plotted versus time. The flattening of the cumulative discovery curve gives a good estimate of the basin's total resources (Figure 19.3) as well as what remains to be discovered. Given this, and that fact that production will lag discovery by approximately 25 years, a reasonable estimate of the timing of future production peaks can be made well before they occur. 


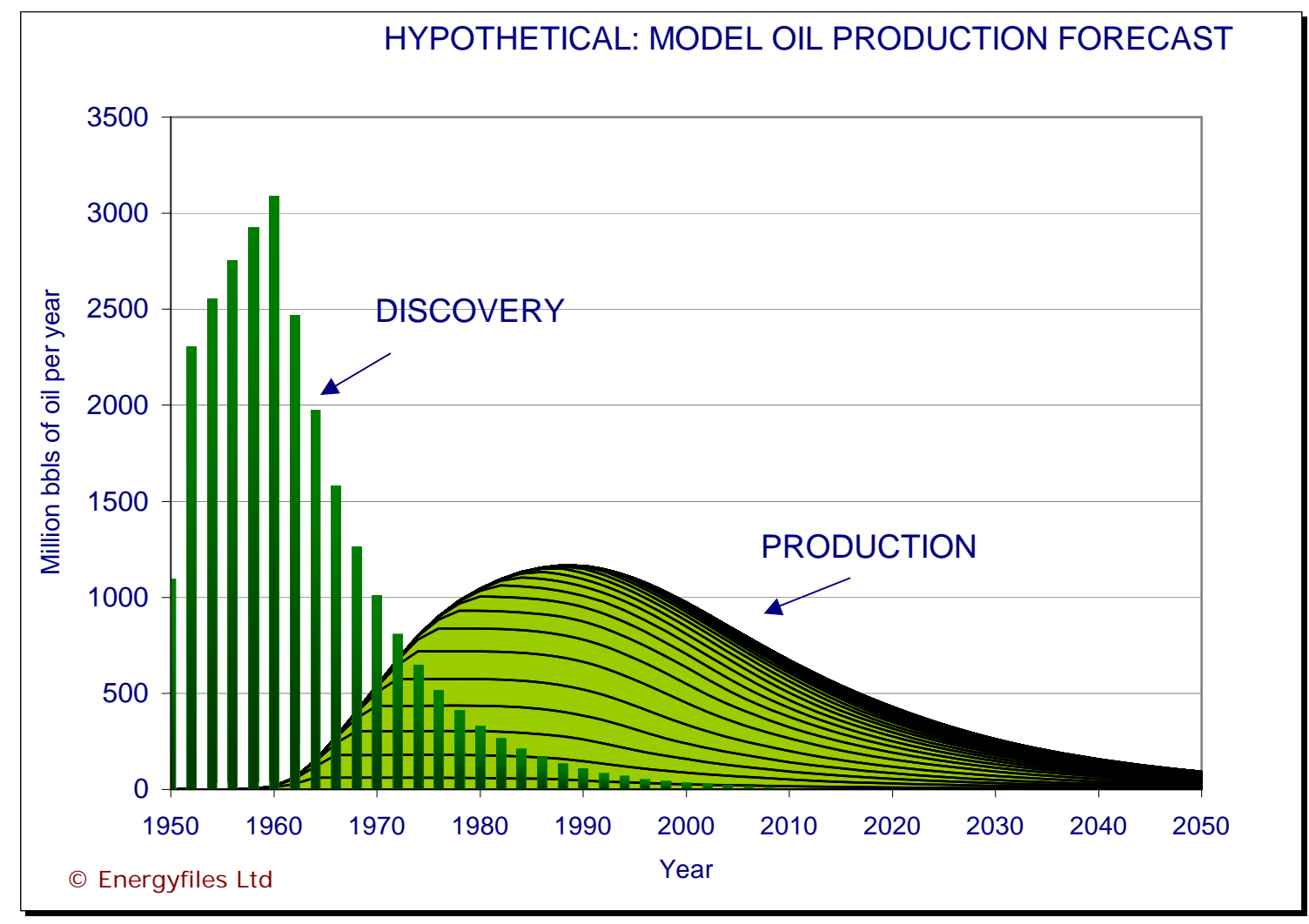

Figure 19.2 Ideal Model of Oil Field Discovery and Production in a Sedimentary Basin

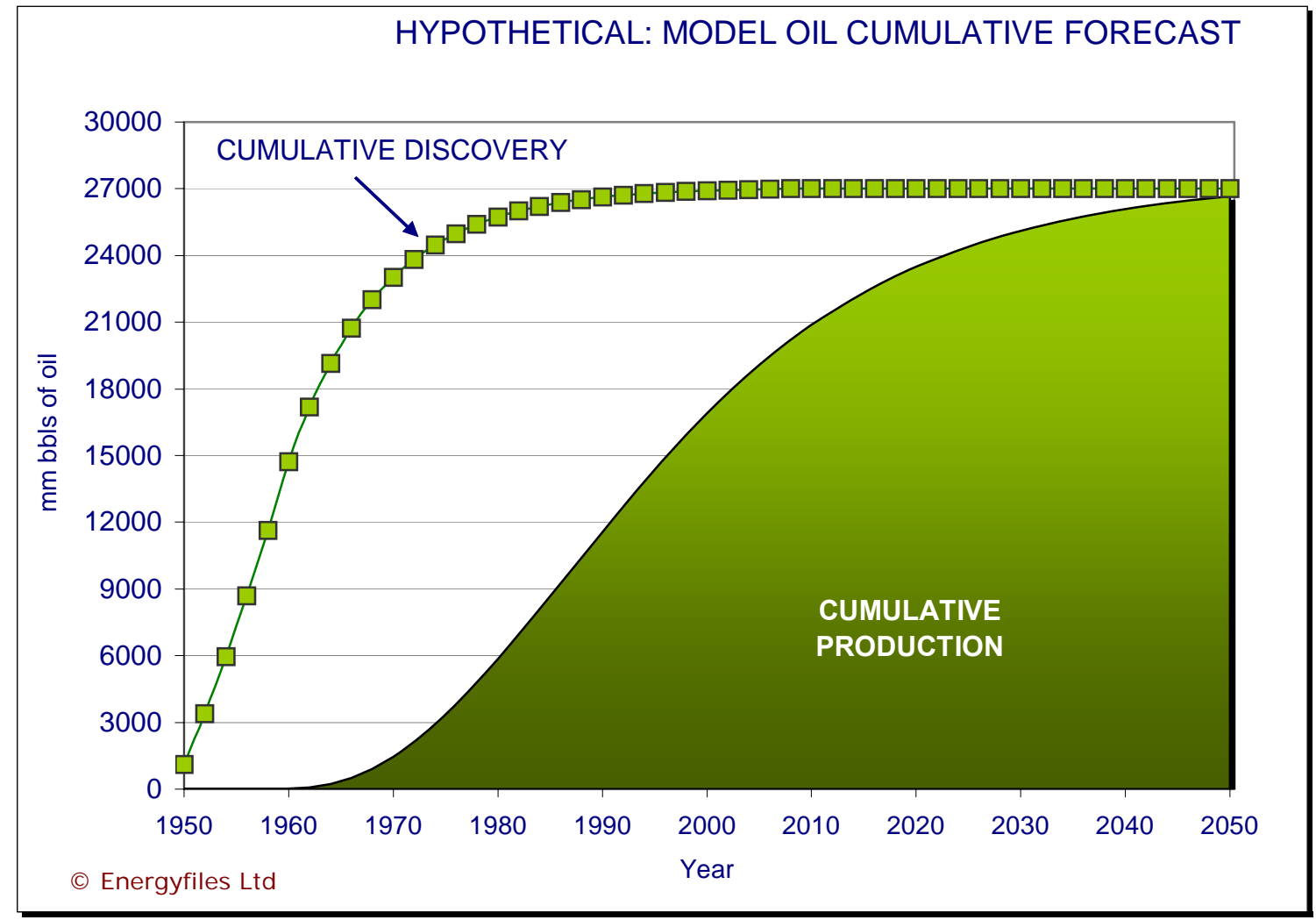

Figure 19.3 Ideal Model of Cumulative Discovery and Cumulative Production 
Data on oil production for Egypt, as an example, illustrates the effect of declining field sizes on production (Figure 19.4). The first five fields include the largest finds, the next five tend to be smaller and so on. The timing of peak production was primarily determined by the first ten fields. The next 20 fields shifted the peak by only 5 years. Recent, significant finds can only slightly slow the rate of decline.

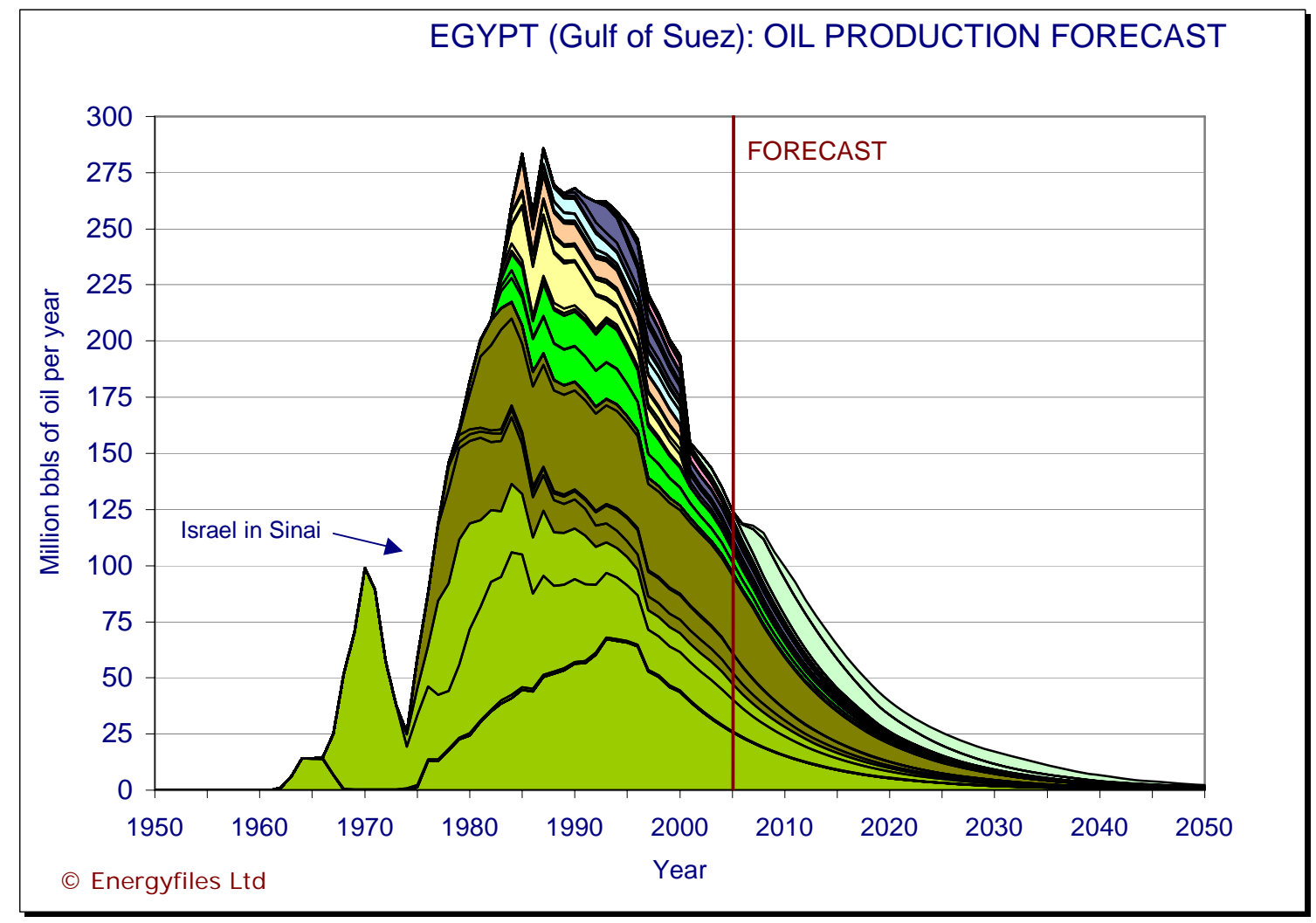

Figure 19.4 Oil Production from Egyptian Fields in Order of Discovery

Discovery and production data for the United Kingdom (U.K.) illustrate the approximately 25year lag between peak discovery and peak production (Figure 19.5). Although very large finds have occurred since 1985, the peak of production in 2000 was determined chiefly by the peak in discovery in 1975. The saddle in the middle of the United Kingdom's production curve, which undoubtedly delayed peak production by a few years, was caused by the Piper Alpha disaster and the ensuing safety and tax changes.

When M. King Hubbert predicted that U.S. oil production would peak in 1970, oil peaking was a novel concept, but this is no longer the case. The world now has ample evidence that oil peaking is real and predictable. Today, oil production has peaked in 63 countries (Table 19.1). Thirty five countries have not yet peaked. Predicting their peaking dates and rates of decline is not only possible, it is imperative. 


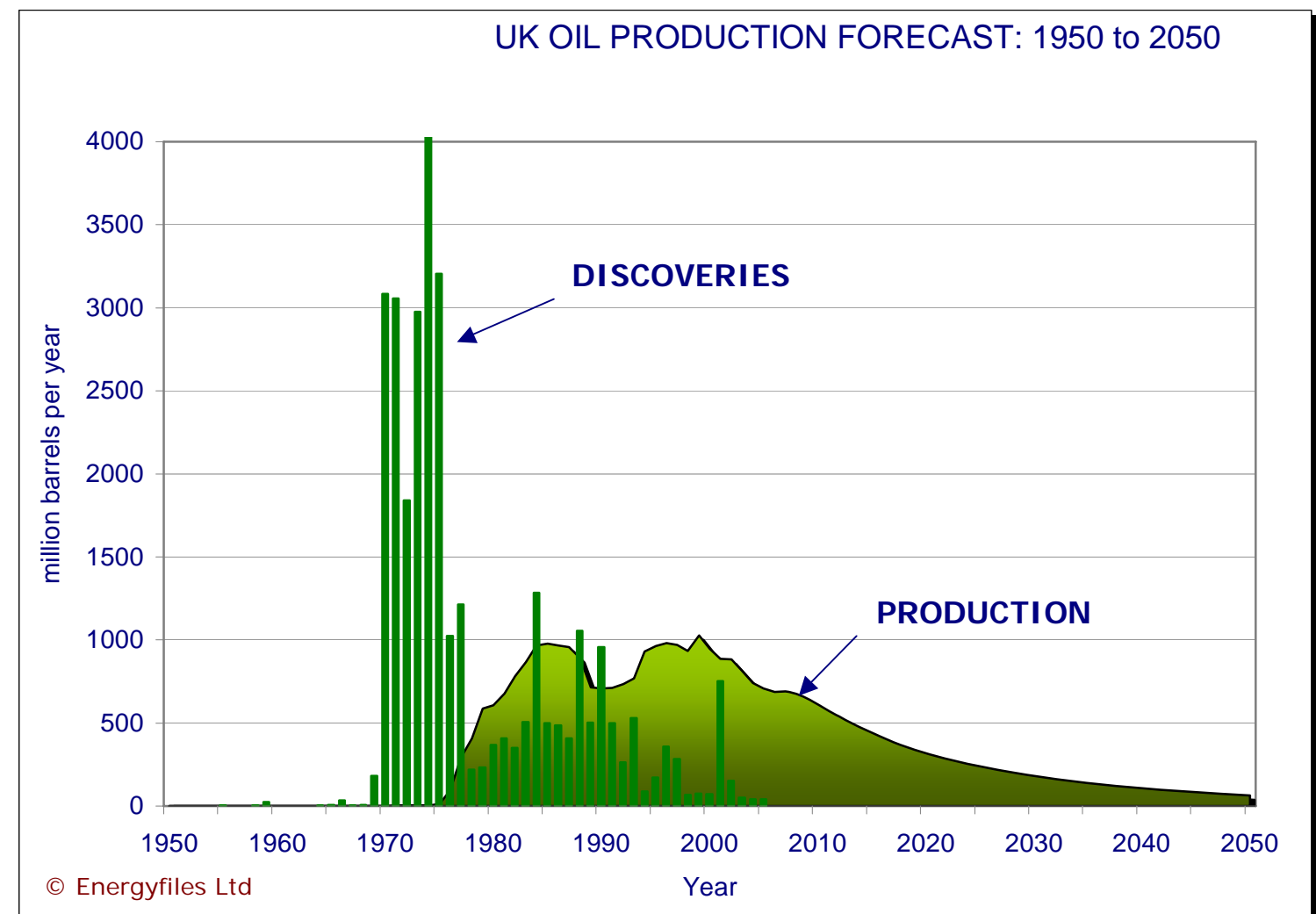

Figure 19.5 United Kingdom Oil Discoveries and Production

Table 19.1 Countries Whose Oil Production Had Peaked before 2006

$\begin{array}{cccccc}\text { Poland } & \text { Myanmar } & \text { Spain } & \text { Georgia } & \text { Kyrgyzstan } & \text { Colombia } \\ \text { Austria } & \text { Ghana } & \text { Cameroon } & \text { Russia } & \text { Syria } & \text { UK } \\ \text { Germany } & \text { Tunisia } & \text { Greece } & \text { Tajikistan } & \text { Czech Republic } & \text { Oman } \\ \text { Bulgaria } & \text { Chile } & \text { Hungary } & \text { Ukraine } & \text { Slovakia } & \text { South Africa } \\ \text { USA } & \text { Croatia } & \text { Benin } & \text { France } & \text { Gabon } & \text { Denmark } \\ \text { Bahrain } & \text { Bosnia } & \text { Netherlands } & \text { Senegal } & \text { India } & \text { Norway } \\ \text { Israel/Palestine } & \text { Serbia } & \text { Taiwan } & \text { Turkey } & \text { Italy } & \text { Bangladesh } \\ \text { Romania } & \text { Morocco } & \text { Congo Kinshasa } & \text { Japan } & \text { New Zealand } & \text { Yemen } \\ \text { Iran } & \text { Peru } & \text { Jordan } & \text { Egypt } & \text { Argentina } & \text { Australia } \\ \text { Trinidad \& Tobago Albania } & \text { Belarus } & \text { Papua New } & \text { Barbados } & \text { Guatemala } \\ & & & \text { Guinea } & \text { Uzbekistan } & \text { Surinam } \\ & & & & & \\ \end{array}$

It should be stressed that the ideal model does not apply perfectly and simply in all cases. There are important exceptions, most notably certain members of OPEC. Countries like Saudi Arabia and Kuwait do not fit the model well because they restrict production in order to use their market power to raise oil prices above the levels that would otherwise prevail. In the case of Iraq, production has additionally been restricted first by international sanctions and later by military conflicts. Production from the FSU has been affected by the lack of investment during the fall of communism. Clearly, this adds to the uncertainty concerning the date of global oil peaking but it does not diminish the validity of the concept. 
Production peaks are generally predictable if one has a good knowledge of the following factors:

1. Detailed field production and discovery rates

2. The discovery peak

3. The current depletion rate

4. Exploration and development histories

5. Political and fiscal histories

It is critical to examine individual field profiles and to consider both geological and engineering factors in each specific area.

Taking all of the above into consideration, global oil production can be analyzed and my analysis shows that it is truly due to peak between 2010 and 2020 (Figure 19.6). Onshore production (shown in green) has been on a plateau for the past 25 years, largely due to OPEC's restrictions on production. Offshore production will peak around 2015, at which time global oil production will as well. Although Figure 19.6 does not include the production of synthetic crude oil from unconventional sources, this will not come on-stream fast enough to delay peak by more than a year.

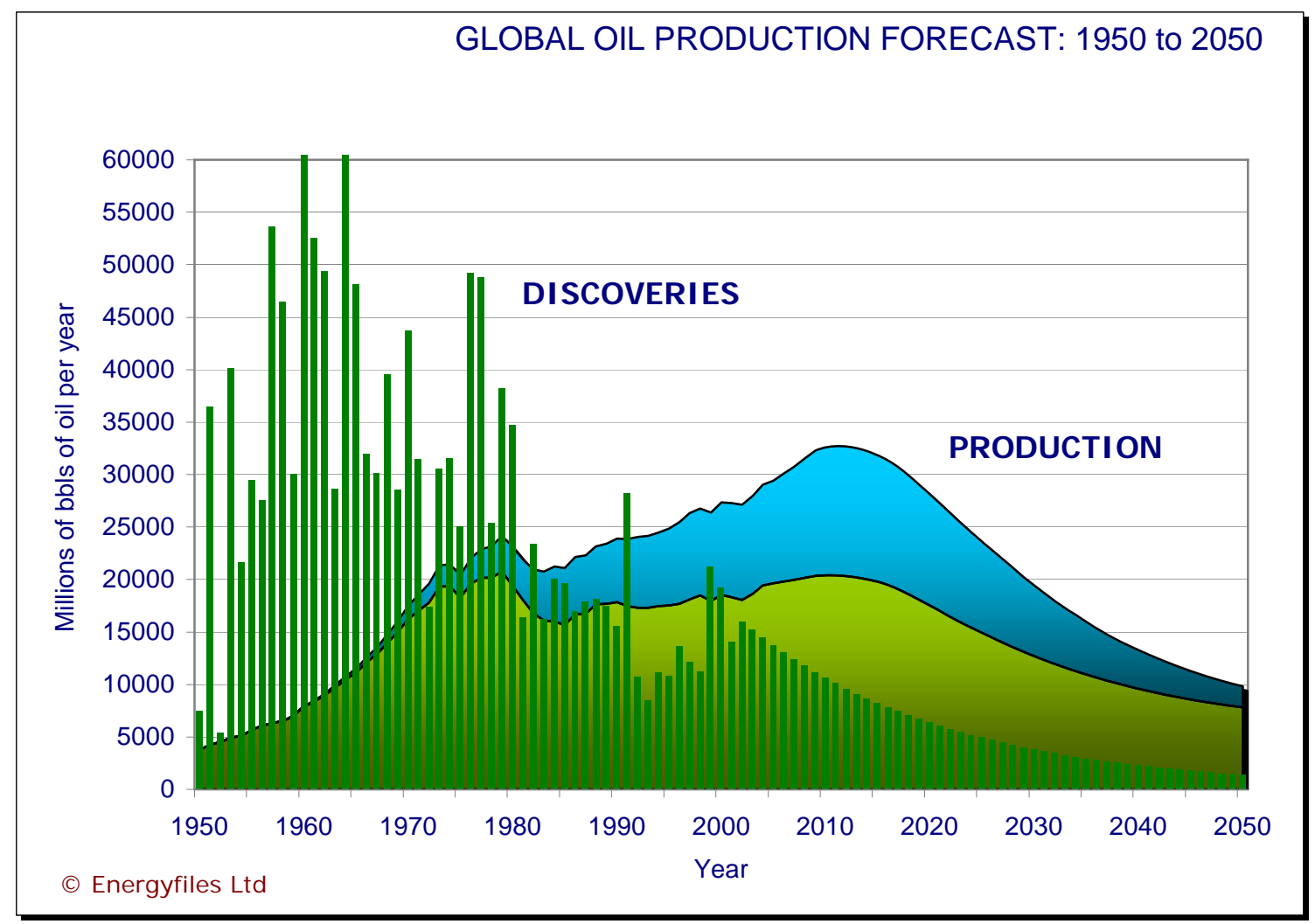

Figure 19.6 Global Oil Production and Discovery Forecast 
Depending on how rapidly petroleum demand grows, an enormous gap will rapidly open between petroleum demand and supply after 2015 (Figure 19.7). Even if demand is flat, the gap will reach nearly 4 million barrels per day by 2020 .

But if demand is growing, as it has been, at roughly $2 \%$ per year, the gap will exceed 30 million barrels per day as soon as 2020. I am not saying these figures are exactly right, but they are realistic and the message is clear and compelling. Governments and industry must take many more energy risks in the form of capital intensive projects, alternative forms of energy, alternative means of transport, and increased taxes on petroleum, even rationing systems and even at the expense of votes. Concerns about the environment, in particular global warming, can only help provide the impetus for them to do this. The need is urgent and the time is short.

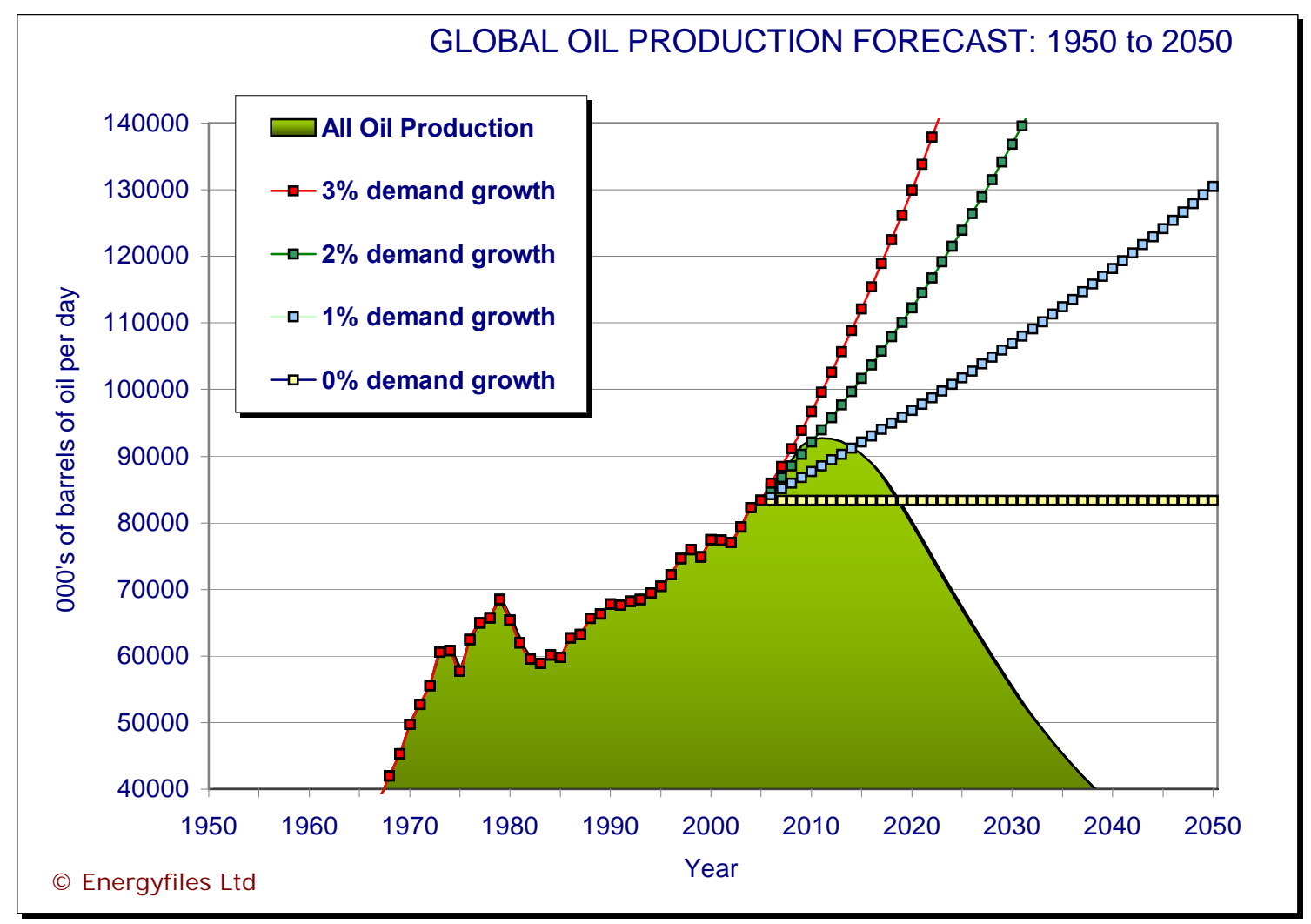

Figure 19.7 Global Oil Peaking and the Demand Gap 


\title{
20. MONTE CARLO SIMULATION OF DEPLETION AND MARKETS
}

\author{
David L. Greene \\ Oak Ridge National Laboratory
}

The ideal methodology for analyzing the transition from conventional oil to other sources of energy would combine the detailed geologic and engineering analysis described by Michael Smith with the characterization of uncertainties about resource endowments and the key impacts of technological change discussed by Dolf Gielen, Nebojša Nakićenović and Arnulf Grübler, with the energy market dynamics addressed by Hill Huntington, John Reilly and Glen Sweetnam. Unfortunately, such a model does not yet exist. In the meantime, it can be useful to assume an incomplete perspective (provided one is mindful of its limitations and biases) and work out its implications. In particular, it may be instructive to assume an optimistic perspective on the oil transition question; if even under optimistic assumptions important problems are evident, this should indicate that the question of oil peaking must be taken very seriously.

The optimist's perspective recognizes that market forces and technological change will redefine the limits of petroleum resources. It also asserts that there is likely to be more undiscovered oil than conventional wisdom would allow. It considers Hubbert curves too mechanistic and prefers a representation of supply based on the costs of production as a function of the state of depletion and the quantity of resource remaining. All of these components are reflected in the energy market models that have been and will be presented at this workshop. Inherent in the optimist's view is uncertainty. How fast and in what direction will technology progress? How much conventional oil remains to be discovered? How much unconventional oil exists and what will the future costs of production be? Will OPEC increase production and at what rate? The analysis presented below adds explicit representations of these key uncertainties to a simplified oil market model by means of Monte Carlo simulation. Despite the considerable uncertainties, it is clear that massive changes in the supply of petroleum are coming and relatively soon.

The distinction between conventional and unconventional oil is key to this analysis. It is true that technology will (and has already in the case of Canadian OS and Venezuelan heavy oil) bring unconventional oil into the oil market. The distinction remains important, however, because of the magnitude of investments required to develop unconventional oil, the potential for significant local impacts and the long-term implications for climate change. Conventional oil is defined as liquid hydrocarbons of light and medium gravity and viscosity, in porous and permeable reservoirs. To this, oil available via EOR and natural gas liquids (NGLs) are arbitrarily added in this analysis. Unconventional oil is defined as deposits with a density greater than water (heavy oil), with viscosities greater than 10,000 centipoises (OS), and in tight formations (oil shale). To this, synthetic petroleum produced by CTL processes is added.

The key data for this analysis come from the USGS's year 2000 global oil resource assessment. This assessment covers the entire globe with a consistent methodology, carefully quantifies uncertainty, and for the first time includes estimated "reserve growth," the anticipated increase in the oil recoverable from discovered reservoirs over time due to increased knowledge of the reservoir and technological advances. Estimated resources of oil and natural gas liquids are shown in Table 20.1. Uncertainty is reflected in the $5^{\text {th }}$ a $95^{\text {th }}$ percentile estimates which are provided in addition to the mean, or expected value, and median or $50^{\text {th }}$ percentile. Although the 
assessment was published in 2000, the base year for the assessment and the cumulative production total is 1995. In this analysis, natural gas liquids are included with oil.

\section{Table 20.1 USGS 2000 Estimates of Ultimate Oil and Petroleum Resources (billions of barrels)}

\begin{tabular}{lrrrrrrrrrrrr}
\hline & \multicolumn{4}{c}{ Oil } & \multicolumn{4}{c}{ Natural Gas Liquids } & \multicolumn{4}{c}{ Total Petroleum } \\
\cline { 2 - 13 } & $95 \%$ & $50 \%$ & $5 \%$ & Mean & $95 \%$ & $50 \%$ & $5 \%$ & Mean & $95 \%$ & $50 \%$ & $5 \%$ & Mean \\
\hline Undiscovered & 394 & 683 & 1202 & 725 & 101 & 196 & 387 & 214 & 495 & 879 & 1589 & 939 \\
Res. Growth & 255 & 675 & 1094 & 675 & 26 & 55 & 84 & 55 & 281 & 730 & 1178 & 730 \\
Proved Res. & 884 & 884 & 884 & 884 & 75 & 75 & 75 & 75 & 959 & 959 & 959 & 959 \\
Cum. Prod. & 710 & 710 & 710 & 710 & 7 & 7 & 7 & 7 & 737 & 737 & 737 & 717 \\
TOTAL & 2244 & 2953 & 3890 & 2994 & 210 & 334 & 553 & 351 & 2454 & 3287 & 4443 & 3345 \\
\hline
\end{tabular}

Three additional resource types are recognized in addition to proved reserves. Undiscovered oil up to the $50^{\text {th }}$ percentile is considered estimated additional resources; the difference between the $50^{\text {th }}$ and $95^{\text {th }}$ percentiles is assigned to "speculative resources." All estimated additional resources are assumed to exist while the fraction of speculative resources assumed to exist is a random variable with mean 0.5 , an optimistic assumption. No oil resources are assumed to be off limits to production for any reason, again an optimistic assumption (from the perspective of world oil supply).

There is even greater uncertainty about the quantities of unconventional oil resources. The data used here are a synthesis of estimates from the USGS, WEC and IEA. They indicate vast quantities of unconventional resources. Interestingly, the most readily exploited, OS and heavy oil, appear to be concentrated in Canada, LAM and the countries of the FSU. Likewise, oil shale resources appear to be concentrated in the United States, the Middle East and North Africa (MEA) and the Pacific OECD (PAO) countries (especially Australia). Regions are dominated by either one type of resource or the other. For coal resources, WEC estimates were used (Figure 20.1).

A resource accounting model was constructed to track depletion of the several types of resources. Production is always taken from proved reserves, but proved reserves are augmented over time by additions from estimated additional resources and reserve growth. Estimated additional resources, in turn, can be augmented by additions from speculative resources. The costs of conventional and unconventional oil from each region were calculated using depletion cost curves whose parameters changed over time to represent technological progress. Thus, while depletion tends to push up costs, technological progress tends to decrease costs, the net result depending on the parameters assumed (Figure 20.2). Unfortunately, little is known about these parameters, which are represented in the simulation by random variables.

CTL production costs via gasification and synthesis are based on a study done for the U.S. DOE. The cost of synthetic petroleum is a linear function of the price of coal ( $\mathrm{x}$ in Figure 20.3), and credit can be given for the fact that petroleum synthesized via the Fischer-Tropsch process may require little or no further refining and may have superior properties to fuel refined from conventional petroleum. 


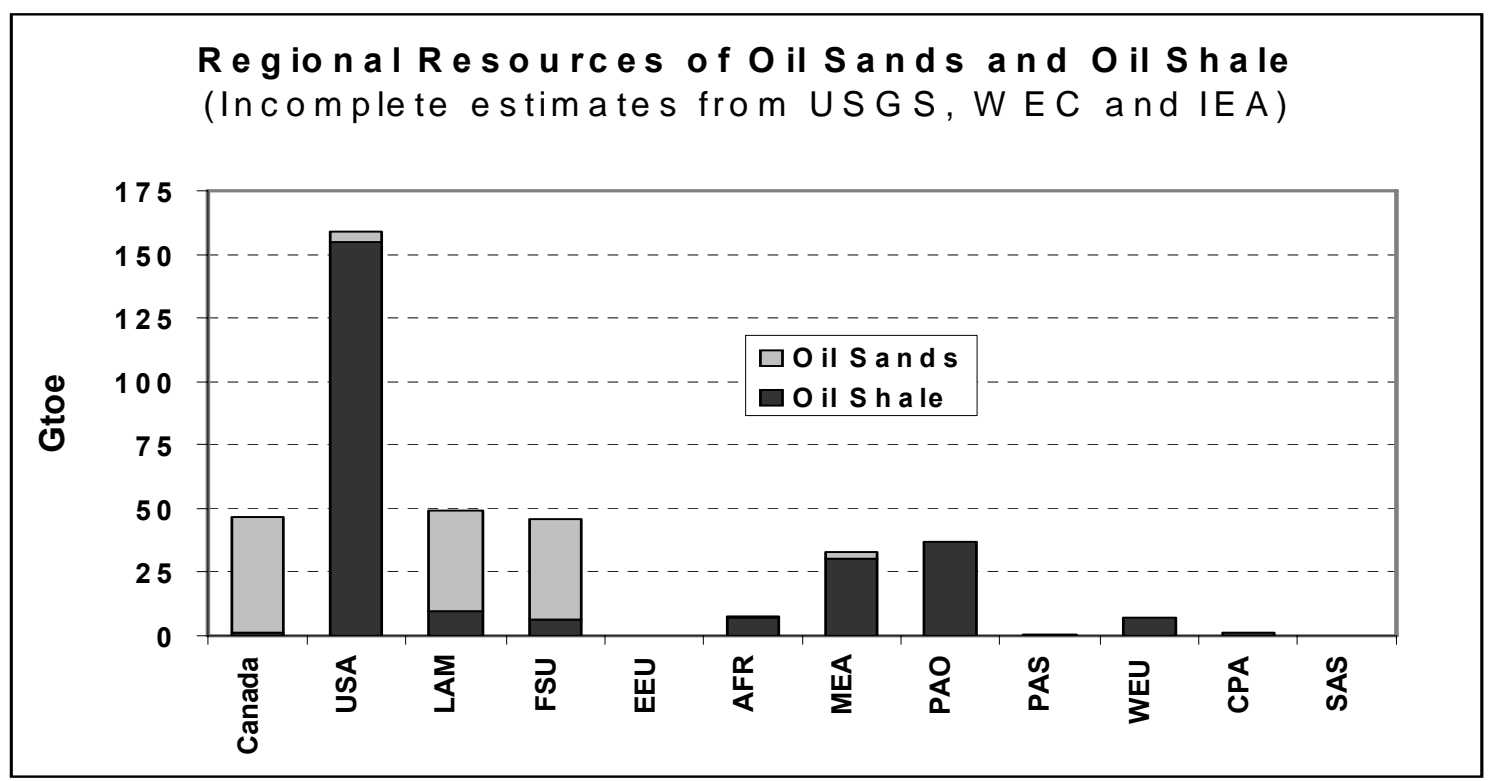

Figure 20.1 Estimated Unconventional Oil Resources (“Oil Sands” includes Heavy Oil) (1 Gtoe $\approx 20$ million barrels/day)

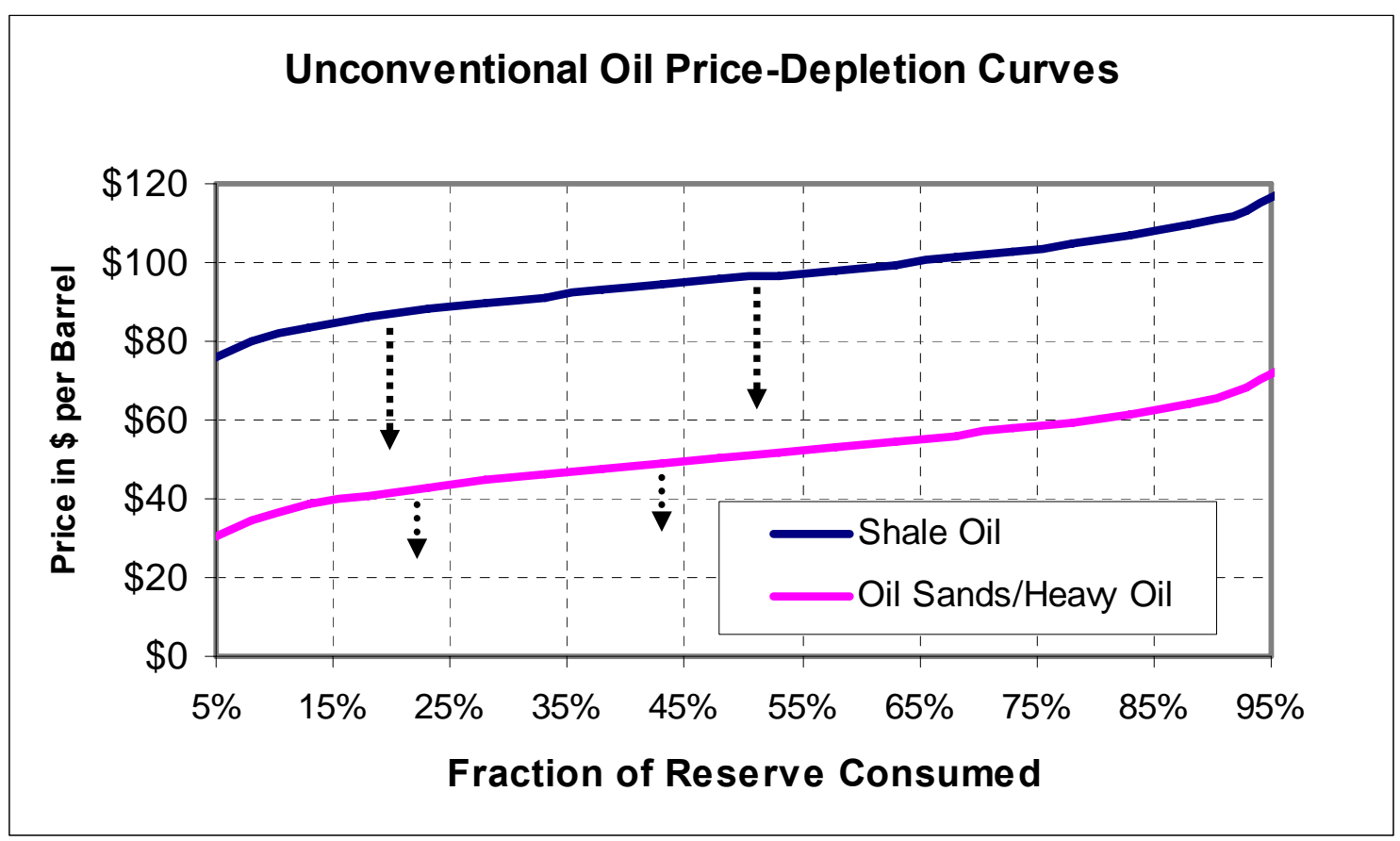

Figure 20.2 Typical Depletion Cost Curves for Unconventional Oil Resources 


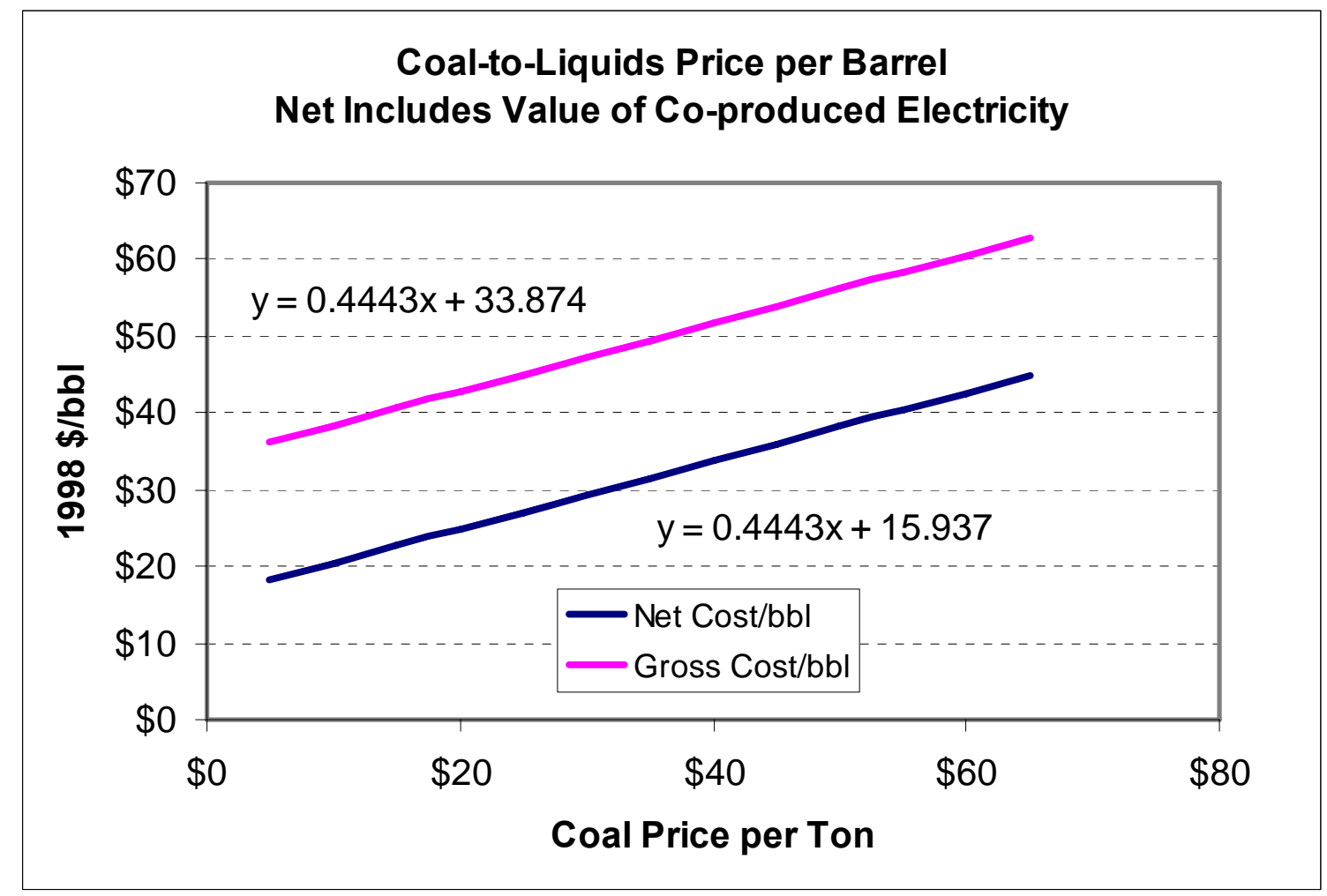

Figure 20.3 Equations for Predicting the Cost of Synthetic Petroleum from Coal

A simple linear simultaneous equation model, calibrated to the U.S. EIA's AEO 2005 Reference Case and IIASA/WEC A1 scenario from the Global Energy Perspectives study, is used to represent the world oil market. Each region has its own lagged adjustment supply and demand equations, except for MEA, whose production is specified by an assumed annual growth rate.

No Hubbert curves are used in the supply model. Regions can continue to increase conventional oil production until a specified $\mathrm{R} / \mathrm{P}$ is reached. The $\mathrm{R} / \mathrm{P}$ ratio is intended to represent the point at which further investment in capacity expansion would not be economical because the remaining resources will not last for the useful life of the investment. In theory, the useful life of an investment in oil production should depend (inversely) on the price of oil. In the simulation presented below, R/P values between 10 and 20 are selected at random.

When a region is not able to meet the oil supply level called for in the scenarios from its conventional reserves, a deficit is created. Deficits from all regions are then pooled and may be supplied from unconventional oil or CTL from any region depending on each regions supply function. A world oil price is solved for that equates demand to total petroleum supply from all sources. In this Base Case, world oil demand grows at 1.8\% per year through 2050.

The first results presented are for a Base Case which uses the central values of all parameters. Monte Carlo simulation results will follow. In the Base Case, using the central values of all parameters, world conventional oil production does not so much peak as plateau in about 2020 (Figure 20.4). Afterwards, unconventional petroleum supply expands rapidly, reaching approximately 3 giga tonnes of oil or 60 million barrels per day by 2050. OPEC oil production continues to expand at an assumed rate of $1.5 \%$ per year throughout the period. 


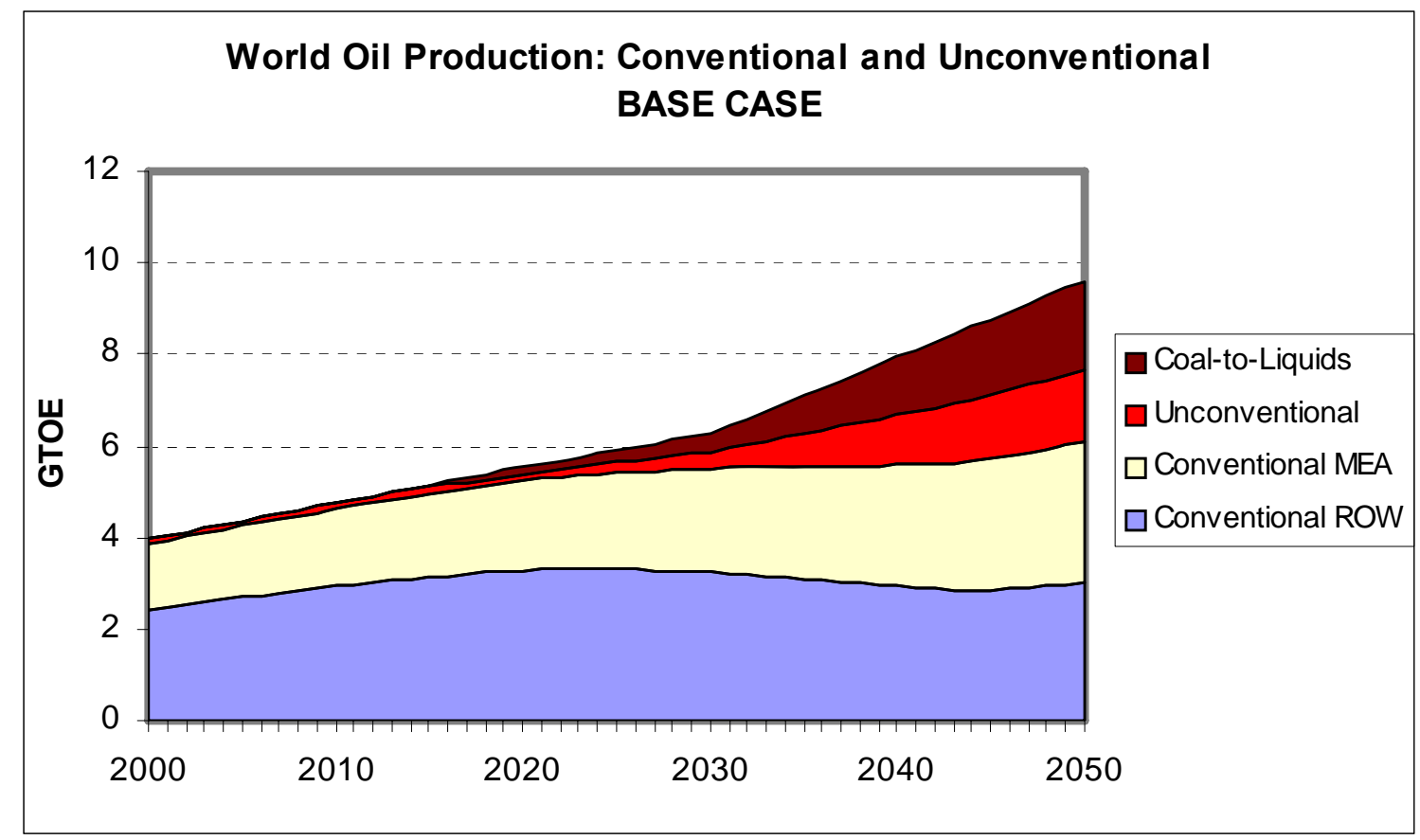

Figure 20.4 World Conventional and Unconventional Oil Production to 2050: Base Case

OS production comes predominantly from Canada and later in the period from the FSU, while heavy oil production is chiefly from LAM. Oil shale production is overwhelmingly from the United States. By 2050 the United States is producing $7 \mathrm{mmbd}$ of shale oil. CTL supplies, on the other hand, could come from many different regions (Figure 20.5). By 2050, world CTL production is almost $40 \mathrm{mmbd}$.

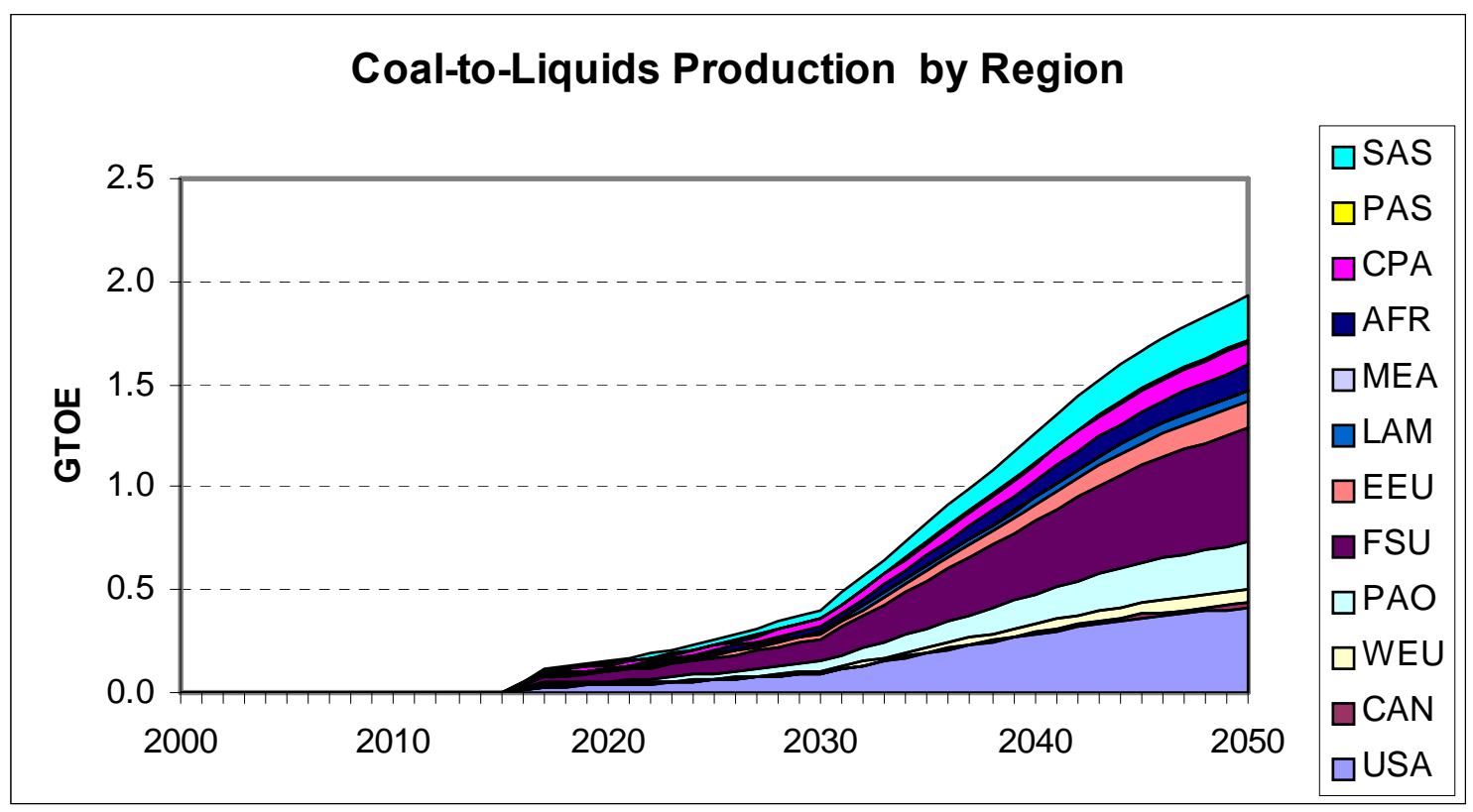

Figure 20.5 Base Case Coal-to-Liquids Production by Region 
Due to the fact that no oil resources are off limits, U.S. conventional petroleum production which peaked in 1972 (crude oil + NGLs) increases until 2013 due to increased supply from Alaska and offshore areas (Figure 20.6). After a brief plateau, conventional oil production declines and unconventional production takes off rapidly, reaching almost $15 \mathrm{mmbd}$ by 2050 .

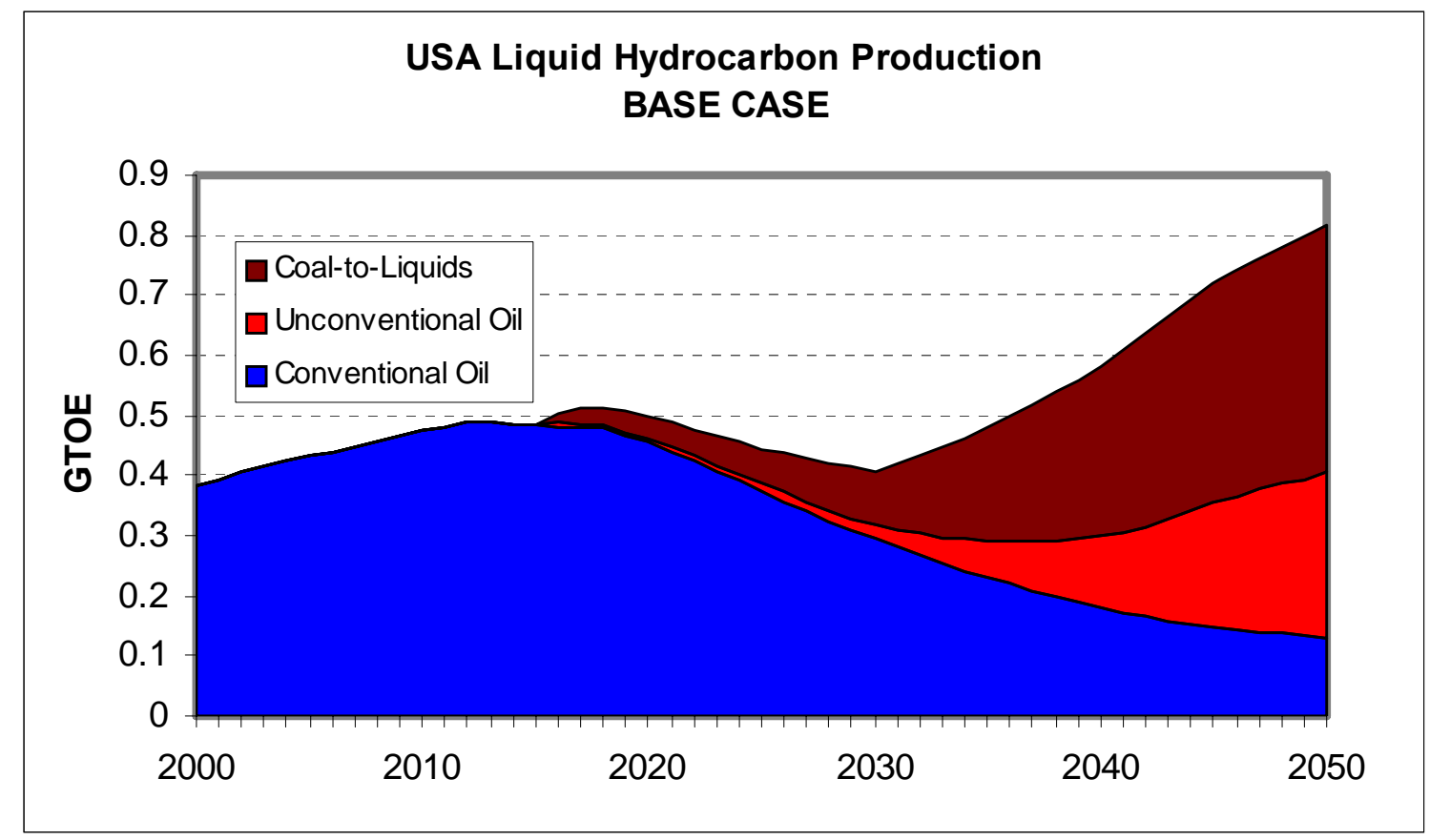

Figure 20.6 U.S. Liquid Hydrocarbon Production through 2050: Base Case

As a result, U.S. oil imports first decline as Alaska and offshore sources come on line, then increase as they peak and begin to decline, then decline sharply again as unconventional sources more than replace conventional supply (Figure 20.7). If neither shale oil nor CTL resources are developed, U.S. oil imports increase dramatically, approaching $90 \%$ by 2050 .

The peaking of oil consumption and transition to unconventional resources does not reduce OPEC's share of total (conventional + unconventional) world oil supply (Figure 20.8). Assuming OPEC increases it conventional oil output by $1.5 \%$ per year, OPEC would still supply approximately $40 \%$ of the world oil market in 2050 . Given that marginal supply would be coming from capital intensive unconventional sources, this suggests that OPEC's market power would be undiminished. 


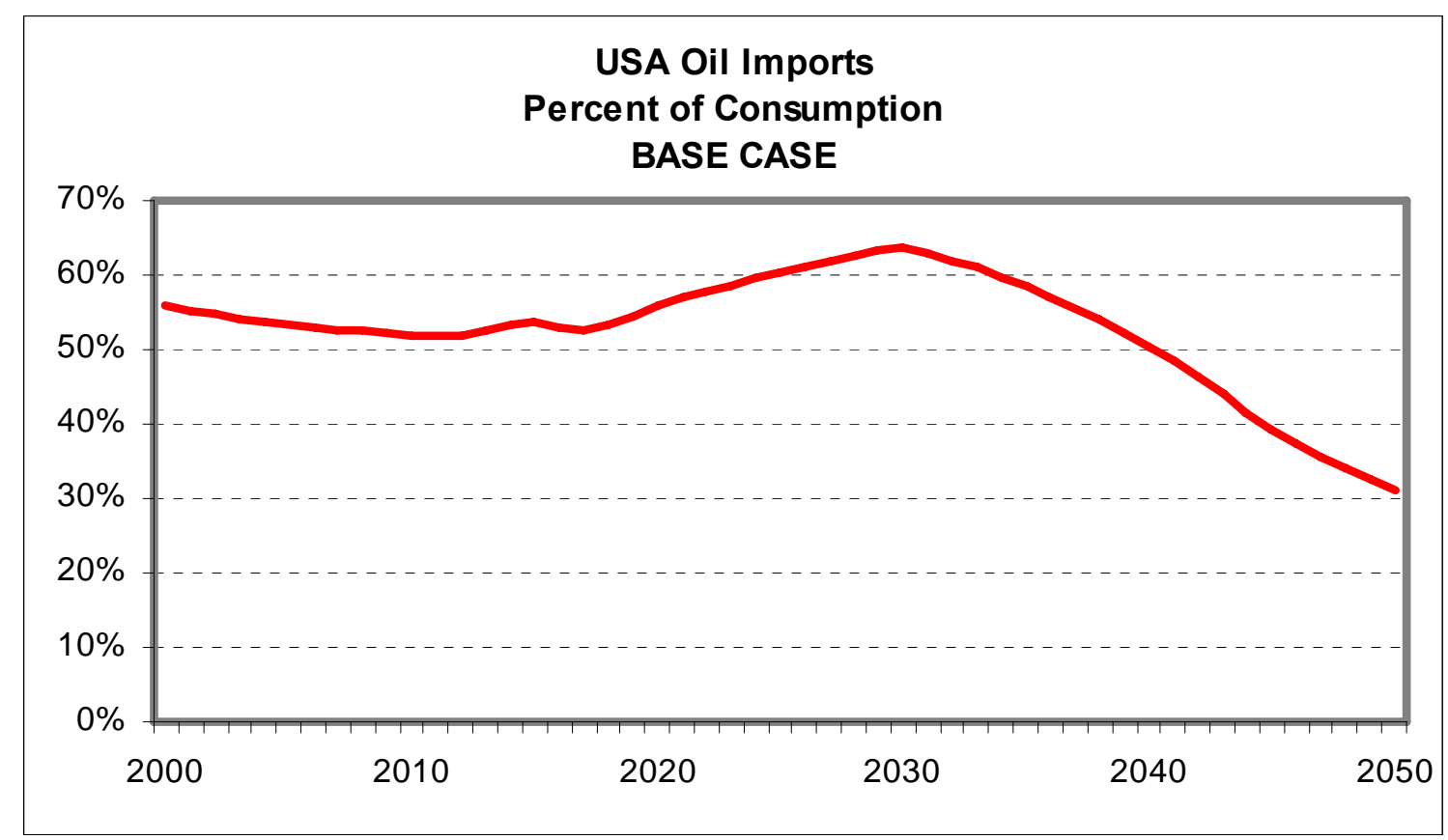

Figure 20.7 U.S. Oil Imports in Base Case

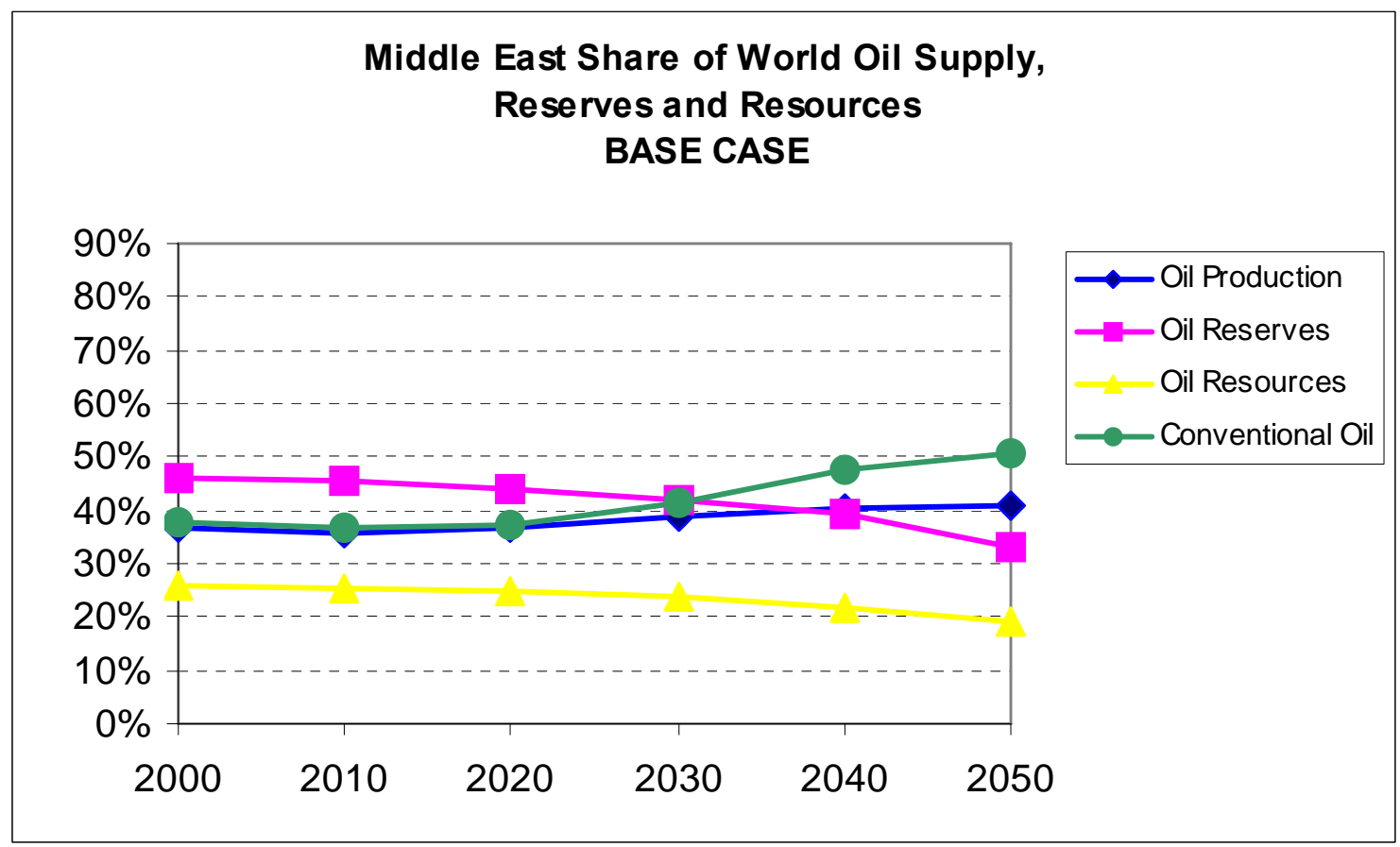

Figure 20.8 Middle East Share of World Oil Supply through 2050: Base Case

The Monte Carlo simulation reveals the enormous uncertainty that should be attached to the results just presented. Based on 5,000 simulations, the peak year for non-OPEC conventional oil production could be anywhere from 2011 to 2050, or later (Figure 20.9). A 95\% confidence interval (based on the simulation results) ranges from 2017 to 2050 . To a large extent, this reflects the fact that any small tilting of the plateau illustrated in Figure 20.4 could substantially alter the date of the peak. It would not, however, alter the conclusion that vast quantities of 
unconventional supply would be require to allow the demand for petroleum to continue to increase. The bimodal distribution is also suggested by Figure 20.4.

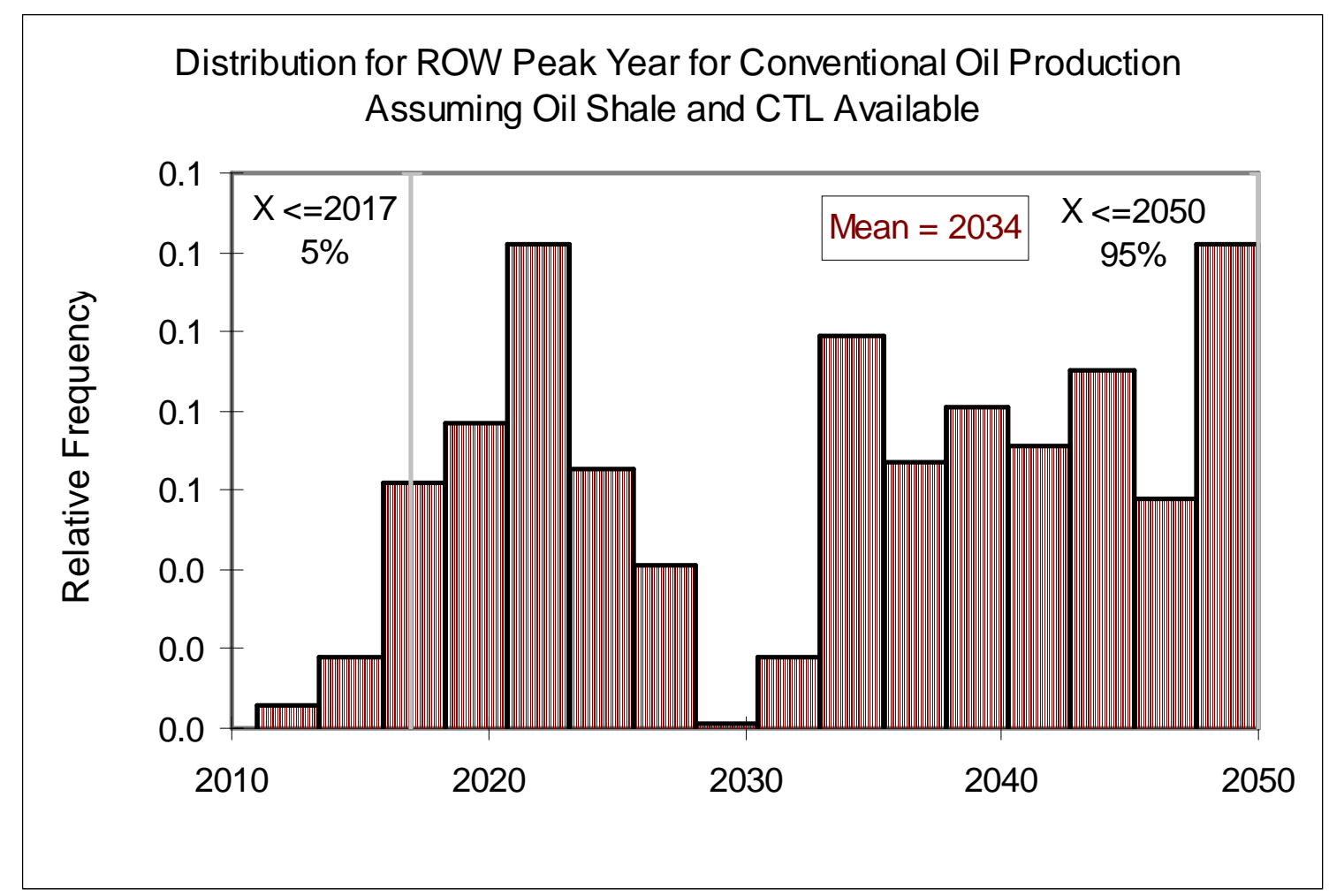

Figure 20.9 Distribution of ROW Peak Year for Conventional Oil Production

Uncertainty about the quantities supplied by the three kinds of unconventional sources is at least as great. A 95\% confidence interval (based on the simulation) for synthetic petroleum from shale oil ranges from essentially 0 to almost $17 \mathrm{mmbd}$ (Figure 20.10). Production from CTL appears to be only somewhat less uncertain, reflecting greater familiarity with the conversion process (Figure 20.11). Moreover, these simulations do not reflect the total range of uncertainty, since they do not consider the possibility of restrictions on carbon emissions, or fluctuations in other sources of demand for coal, among other factors. Nonetheless, they do convey the enormous uncertainty facing those who must decide whether or not to invest in alternatives to petroleum. Given the enormous degree of uncertainty described by the simulation analysis and given the huge investments that will have to be made to permit demand for petroleum to continue to grow at rates in the vicinity of $2 \%$ per year, it seems hardly likely that the transition process could be as smooth and undisrupted as the model's calculations. Especially in light of the continued market power Middle Eastern producers will enjoy, a disruptive transition must be considered likely. 


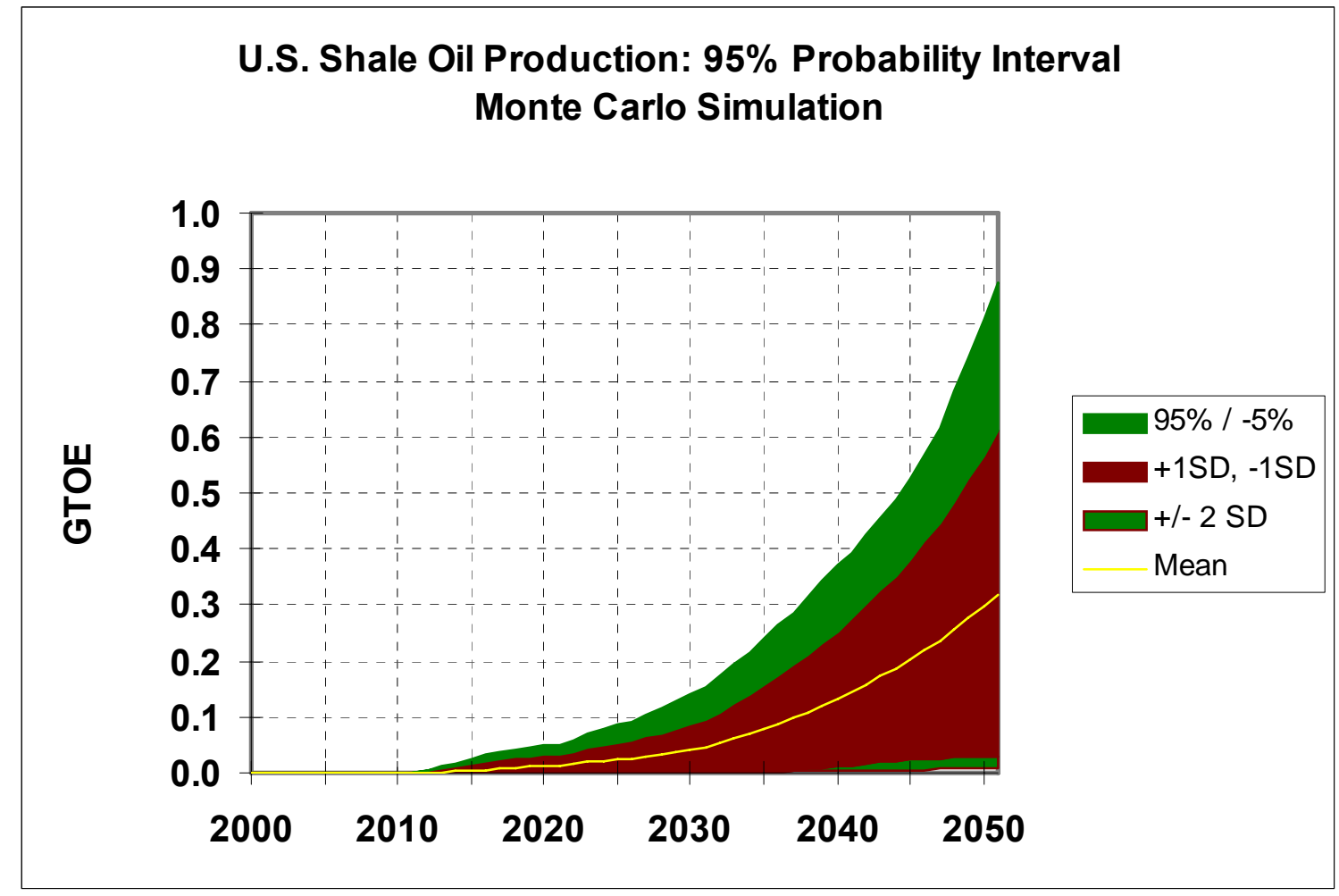

Figure 20.10 Distribution of U.S. Shale Oil Production to 2050

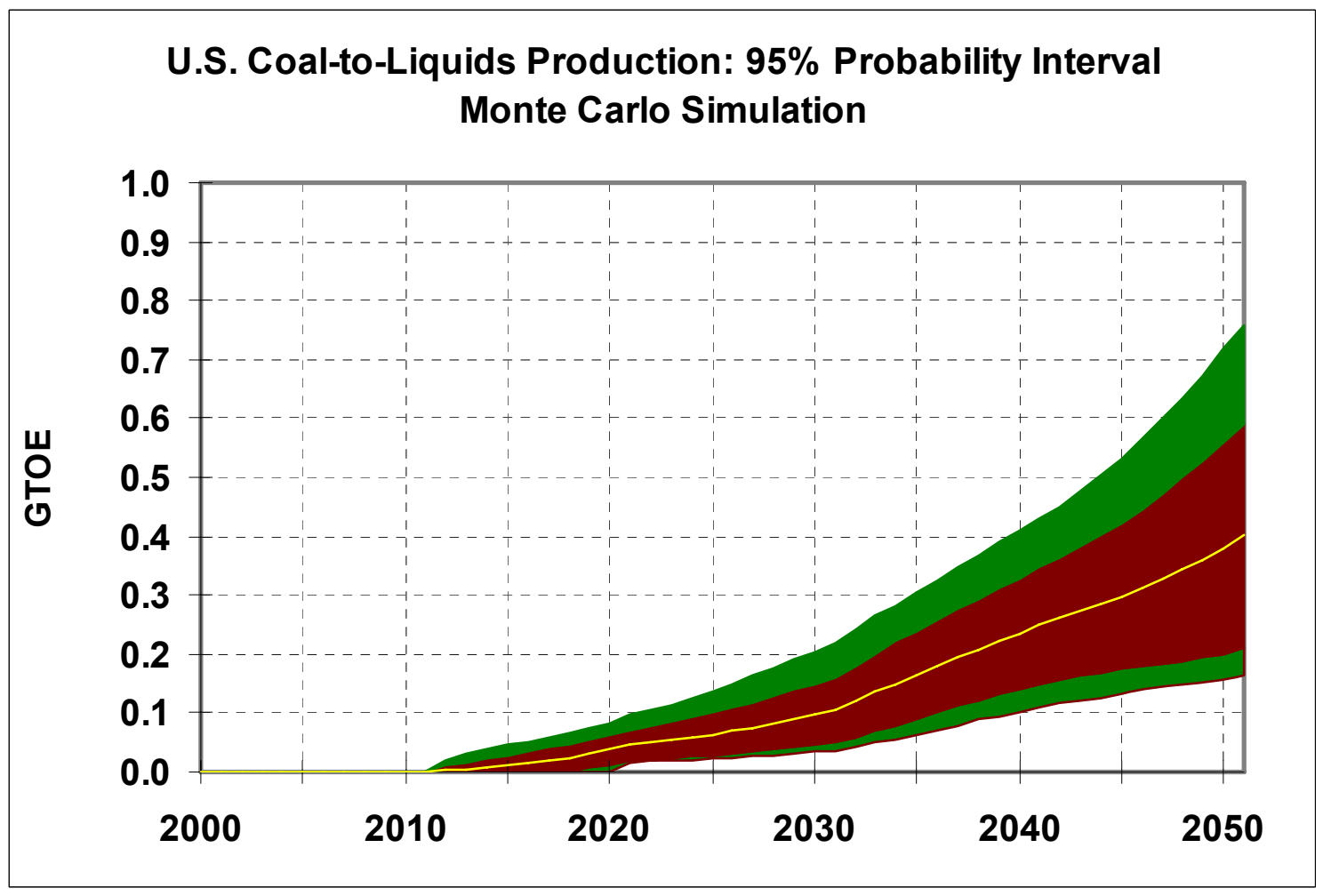

Figure 20.11 Distribution of U.S. Coal-to-Liquids Production to 2050 
Even this intentionally optimistic analysis of the transition from conventional oil indicates that major changes in the world's petroleum system are likely to begin relatively soon. The transition will almost certainly be massive, requiring huge investments to be made in a timely manner in order to avoid market disruptions. And, this must be done in the face of enormous uncertainties. Such a massive transition to unconventional fossil resources such as OS, heavy oil, shale oil and coal, would have grave implications for climate change, as previous speakers have pointed out. Through 2035 it would only maintain the status quo with respect to the U.S. dependence on petroleum. This "optimistic" assessment indicates that the oil transition will be a very serious energy problem and that it is not too soon to prepare for it. 


\title{
SESSION 7: MODELING GLOBAL ENERGY TRANSITIONS \& THEIR ENVIRONMENTAL EFFECTS
}

\author{
PART II: MODELING THE ECONOMY, THE ENERGY SECTOR AND \\ ENVIRONMENTAL IMPACTS \\ Michael Shelby, U.S. Environmental Protection Agency, Chair
}

\section{OIL MARKET: TRANSITION OR EVOLUTION? THE EMISSIONS PREDICTION AND POLICY ANALYSIS MODEL}

\author{
John Reilly*, Sergey Paltsev* \\ Massachusetts Institute of Technology \\ $\&$ \\ Frederic Choumert* \\ Massachusetts Institute of Technology and TOTAL
}

The Emissions Prediction and Policy Analysis model with disaggregation of oil production and refining sectors (EPPA-ROIL) is a recursive, dynamic computable general equilibrium (CGE) model of the world economy with international trade among regions that also represents the oil market in some detail. Originally developed to produce scenarios of greenhouse gas emissions and estimate the cost of mitigation, it forecasts to 2100 in 5-year intervals. Because of this it is useful for analyzing interactions between the oil market and the world economy, and for assessing economic effects of the transition from conventional oil to unconventional sources. The regions, sectors and factors of production represented in EPPA are shown in Table 21.1.

Like all models, the EPPA model has strengths and weaknesses. It is particularly well suited to analyzing economic issues such as investment, growth, fiscal policies and macroeconomic interactions. It has the capability to estimate both air pollutant and greenhouse gas emissions. Because it is a global modal with regional and technology detail, it is able to integrate sector and technology specific issues with macroeconomic interactions and feedbacks and to predict the effects on economic growth, or the interactions with taxes. The traditional weakness of CGE models fitted exclusively to Input-Output and National Income and Product Accounts data has been addressed by extensive development of supplemental tables on physical flows and the addition of explicit treatment of advanced technologies. The 5-year time step of EPPA makes it not well suited to analyzing issues related to business cycles. EPPA has a recursive, dynamic structure in contrast to forward looking optimization methods, and it does not include endogenous technological change, such as learning-by-doing. Reports describing the EPPA model are available at http://web.mit.edu/globalchange/www/reports.html, and EPPA-ROIL is described in Technical Note No. 9 available at that WEB site.

\footnotetext{
* The views expressed are solely those of the authors and do not reflect the views of TOTAL or MIT. The authors gratefully acknowledge the financial support for this work provided by the Joint Program on the Science and Policy of Global Change through a consortium of industrial sponsors and Federal grants that have supported the development of the basic EPPA model.
} 


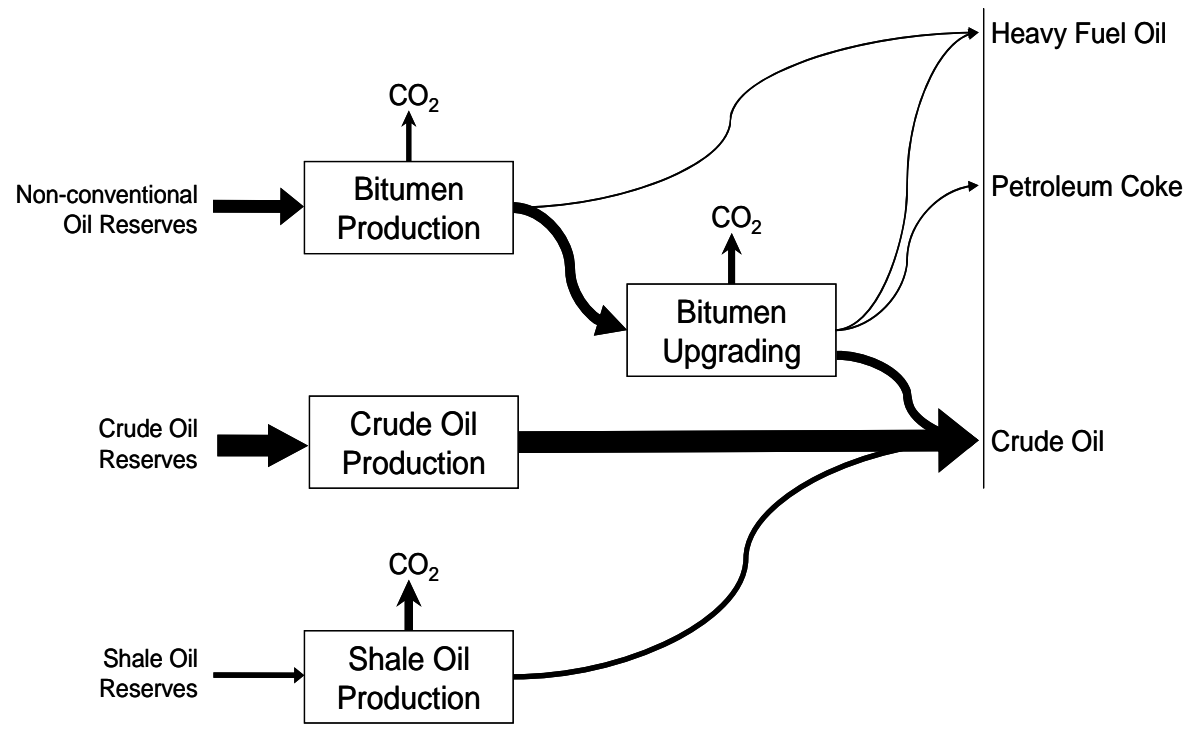

Figure 21.1 Upstream Processes Represented in the EPPA Model

Changes in the characteristics of conventional crude oil can be exogenously specified and will trigger changes in refinery configurations and corresponding investments. The future crude slate is expected to consist of larger fractions of both heavier, sourer crudes and extra-light inputs, such as NGLs. There will also be a shift towards bitumens, such as Canadian OS and Venezuelan heavy oil. These changes will require investment in upgrading, either at field level to process bitumen into medium and light synthetic crudes or at refinery level to convert refinery residues into lighter fractions.

The EPPA-ROIL model has been used to create scenarios of future liquid fuel use and petroleum supply impacts of these changes in refinery slates. Figure 21.2 shows a reference case forecast of resource supply to satisfy world demand for liquid fuels to 2050. The reference projection assumes no climate policy. Conventional oil supply peaks between 2025 and 2030 and declines gradually thereafter. First bitumens (OS and extra-heavy oil) and then shale oil and bio-fuels supplement conventional oil inputs so that world liquid fuel consumption continues to grow. By 2050 more than one third of the world's liquid fuel supplies are projected to come from unconventional sources in this RS.

The change in energy resources requires a very substantial increase in upgrading capacity, as shown in Figure 21.3. Where this upgrading capacity will be built is likely to be strongly influenced by greenhouse gas policy. The climate policy scenario considered here leads to carbon prices of $\$ 40 /$ ton of $\mathrm{CO}_{2}$ in 2025 rising to just above $\$ 60 /$ ton in 2050 in developed (Annex I) countries. We find that this level of carbon price creates substantial incentives to locate capacity expansions in regions not subject to greenhouse gas caps. This would lead to substantial "leakage," a decrease in emissions in Annex 1 countries being offset by an increase, relative to a reference case without policy, in emissions in non-Annex 1 countries. In the case of refinery emissions, EPPA-ROIL estimates the leakage effect to be on the order of $10 \%$ of Annex 1 country emissions. But for emissions from bitumen upgrading capacity, the carbon emissions from on-site enhancement of heavy unconventional fossil resources, the leakage is far greater, on the order of $80 \%$ (Figure 21.4). This means that such resources might still be exploited by the 
Annex 1 countries which have the reserves (e.g. Canada) in a greenhouse gas policy scenario, but bitumen upgrading capacity, and associated emissions, could be massively relocated to nonAnnex 1 countries, such as Asia or the Middle East.

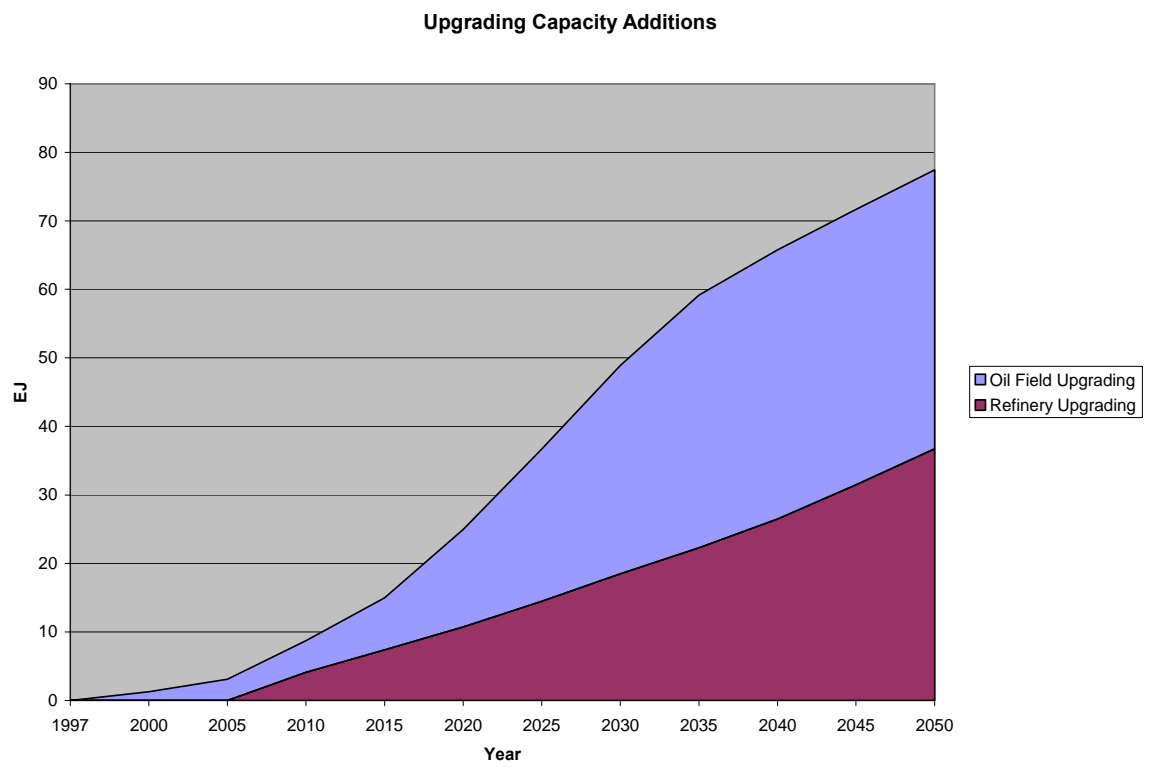

Figure 21.2 Primary Energy Production for World Liquid Fuels: Reference Case

Primary Energy Production - Liquid Fuels, Reference Case

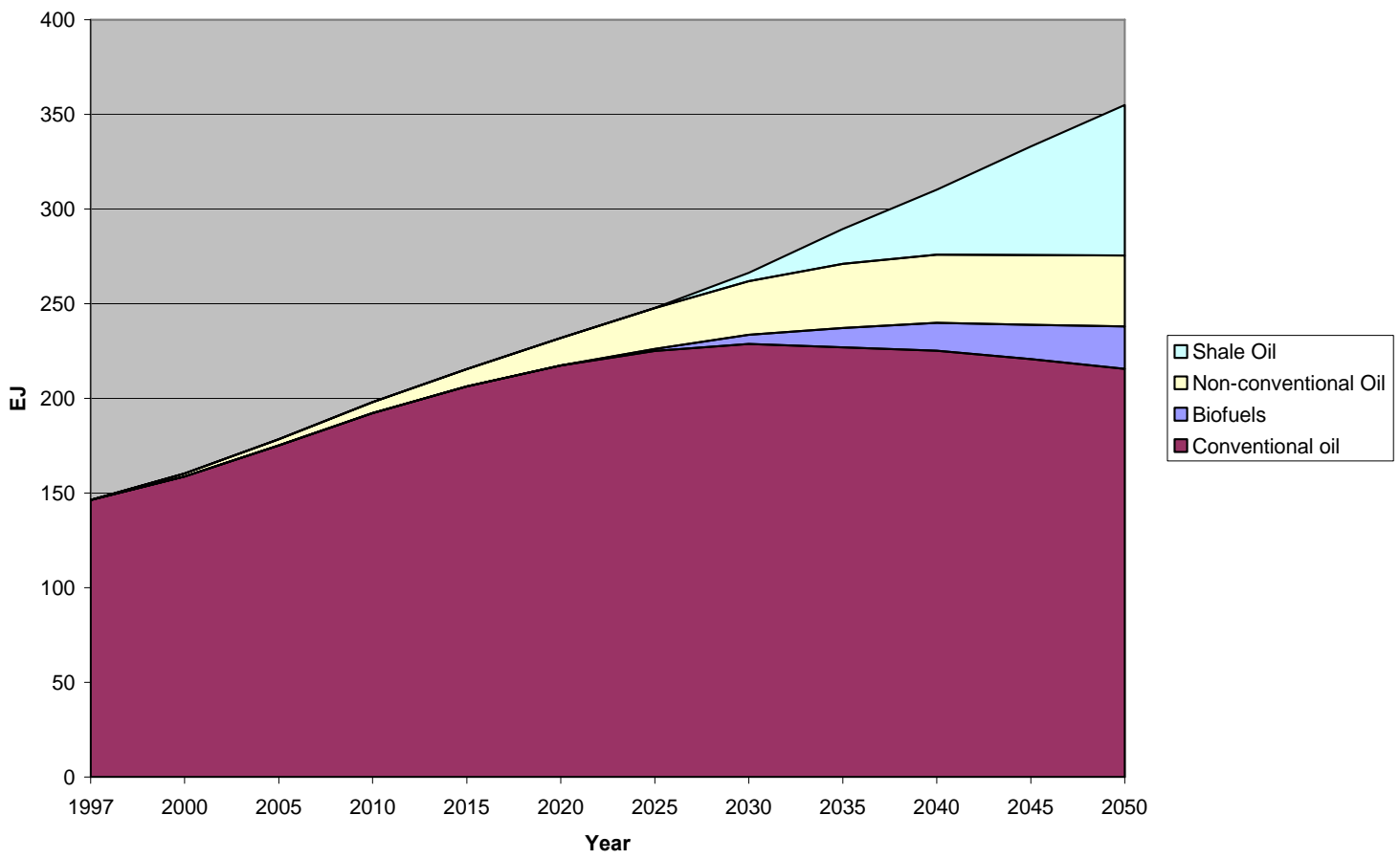

Figure 21.3 Upgrading Capacity Additions Required to Use Heavier Crudes and Unconventional Oil 


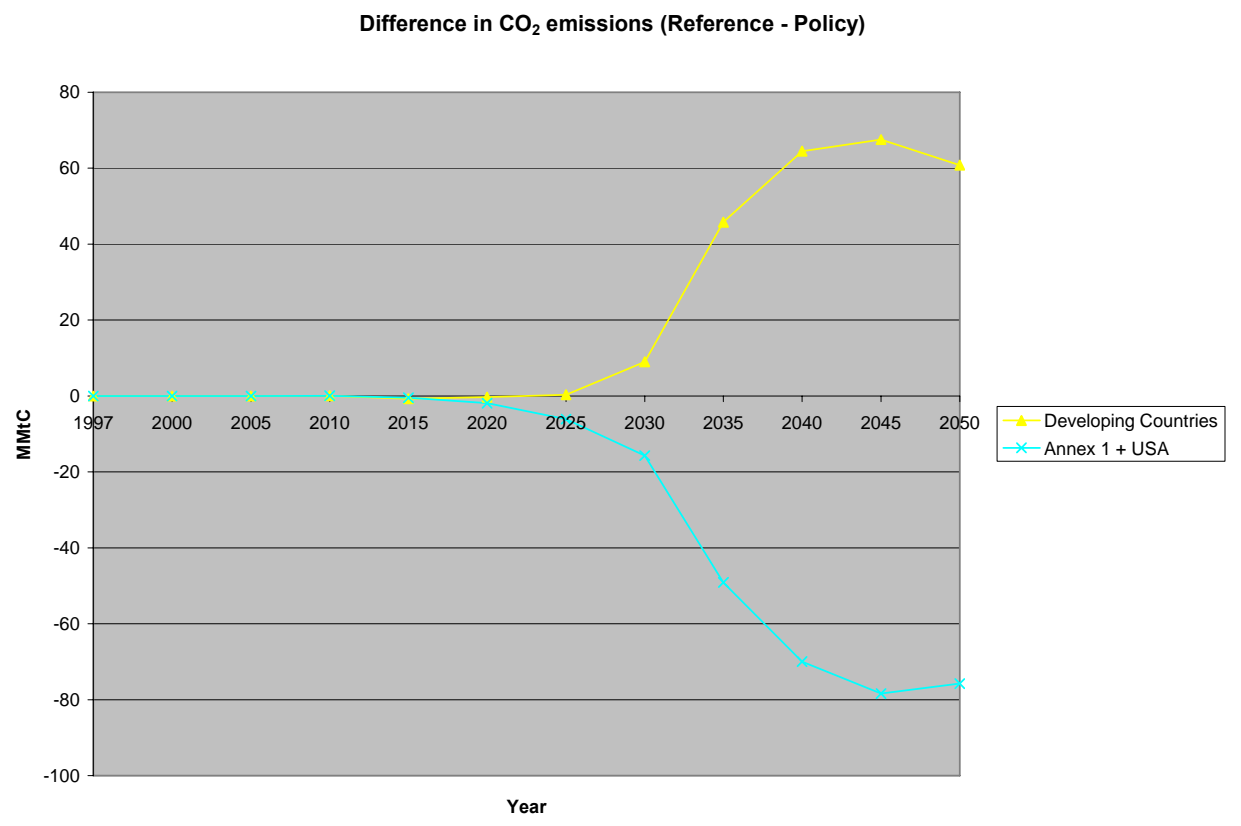

Figure 21.4 Change in Carbon Emissions due to Upgrading of Heavier Crudes and Unconventional Oil in Annex 1 and non-Annex 1 Countries

In summary, strongly increasing demand for gasoline and diesel fuel, slow or little demand growth for the heavier oil fractions, and a "heavying up" of the oil slate will create a huge need for upgrading capacity in the future. The location of this upgrading capacity is likely to depend on $\mathrm{CO}_{2}$ policy. If non-Annex I developing economies are not subject to the same carbon constraints as Annex I countries, this could create a major channel for carbon emissions leakage. The EPPA-ROIL model, which combines a consistent CGE framework for modeling the world economies and interregional trade with considerable technological detail, is able to investigate this and other issues related to the oil transition. From this perspective, the oil transition appears to be a continuing evolution of the problem of producing more light products from increasingly heavy feedstocks. 


\title{
22. REMI (MARKAL/TIMES)
}

\author{
George Treyz \\ Regional Economic Models, Inc.
}

The local and regional environmental and economic impacts of a massive transition to unconventional sources of petroleum are likely to be significant and could strongly influence the pace, extent and orderliness of the transition. Assessing these potential impacts requires regional economic models with a high degree of geographic resolution that incorporate substantial technological detail and estimate local environmental impacts.

REMI is a regional economic model of that has been applied to the United States and Europe that is in the process of being linked to MARKAL/TIMES, an economic model generator for local, national or multiregional energy systems which provides a high-level of energy technology detail for estimating energy market dynamics over a long time horizon. MARKAL/TIMES estimates the minimum global cost of supplying energy services. Its technology detail also allows estimation of a wide range of environmental impacts. Considerable progress has been made in linking the REMI and MARKAL/TIMES model but a working version had not been completed at the time of the Modeling the Oil Transition Workshop. At this point it is only possible to describe the models and their capabilities.

The REMI model integrates the full range of demand for economic output with demographic and economic data and determines labor and capital demand, wages, prices and production costs, as well as market shares (Figure 22.1).

The MARKAL/TIMES model permits a detailed representation of primary energy supply, energy conversion, energy end use and energy services demand (Figure 22.2). Each process can represent technologies and energy forms in almost any desired level of detail.

MARKAL balances the supply and demand for energy, insuring that the least total cost processes are used in throughout the economy. It monitors the capital stock turnover process so that the market penetration of new technologies can be accounted for. It also insures that environmental controls and related policies are adhered to.

How MARKAL solves for energy supply, demand and price is illustrated in Figure 22.3 for electric power. A supply curve is constructed from detailed information on the full cost of supplying electricity by various technologies. Full costs may include the disposal of wastes (environmental residuals) as well as the costs of energy, capital, operation and maintenance. The least cost (maximum surplus) solution is found at the point where the supply function intersects the demand curve for electricity. 


\section{REMI Model Linkages (Excluding Economic Geography Linkages)}

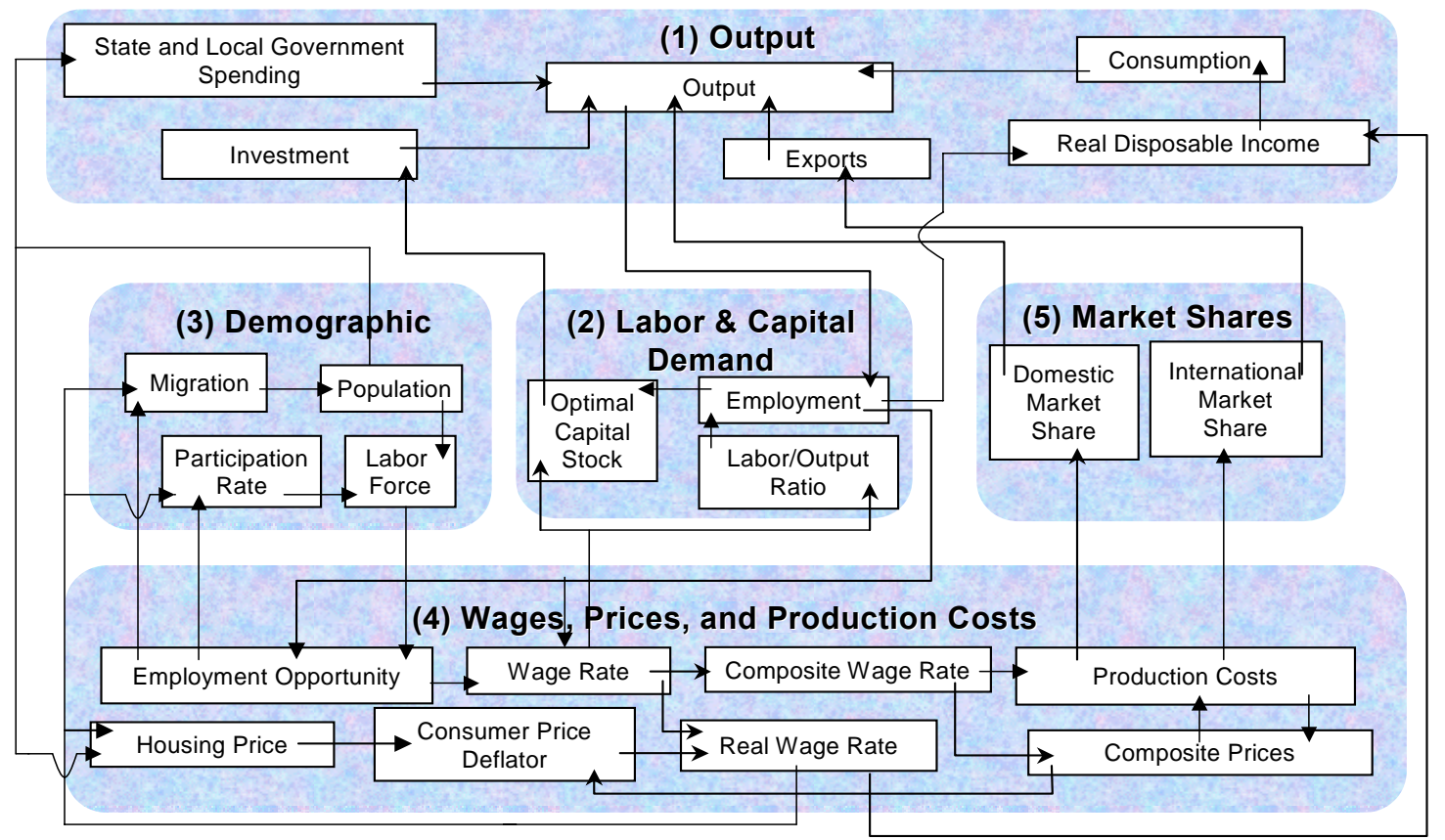

Figure 22.1 Basic Structure of the REMI Model

Primary Energy Supply

\begin{tabular}{|c|c|}
\hline $\begin{array}{c}\text { Conversion } \\
\text { Technologies }\end{array} \quad \begin{array}{c}\text { End-Use } \\
\text { Technologies }\end{array}$ \\
\hline
\end{tabular}

Demand for
Energy Service

(Useful Energy)

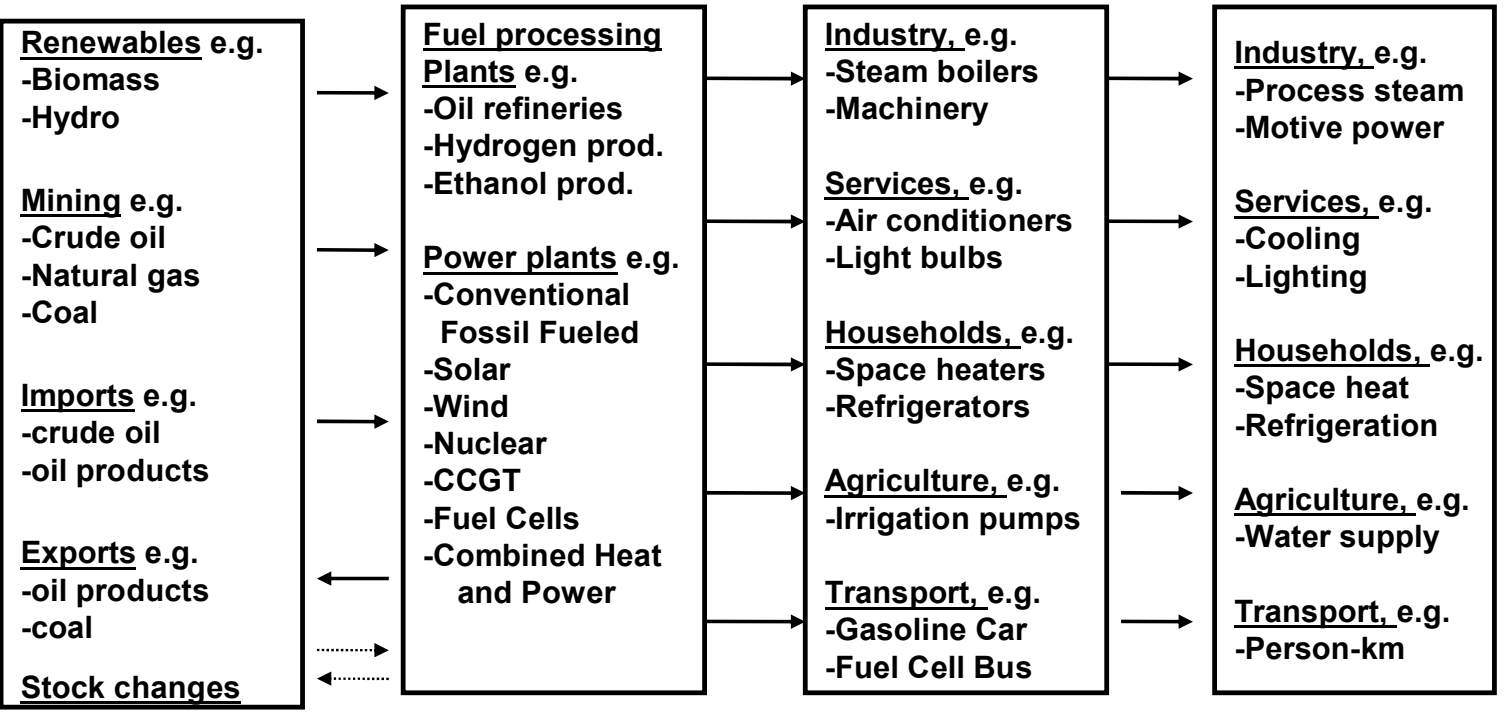

Figure 22.2 Basic Structure of the MARKAL Model 


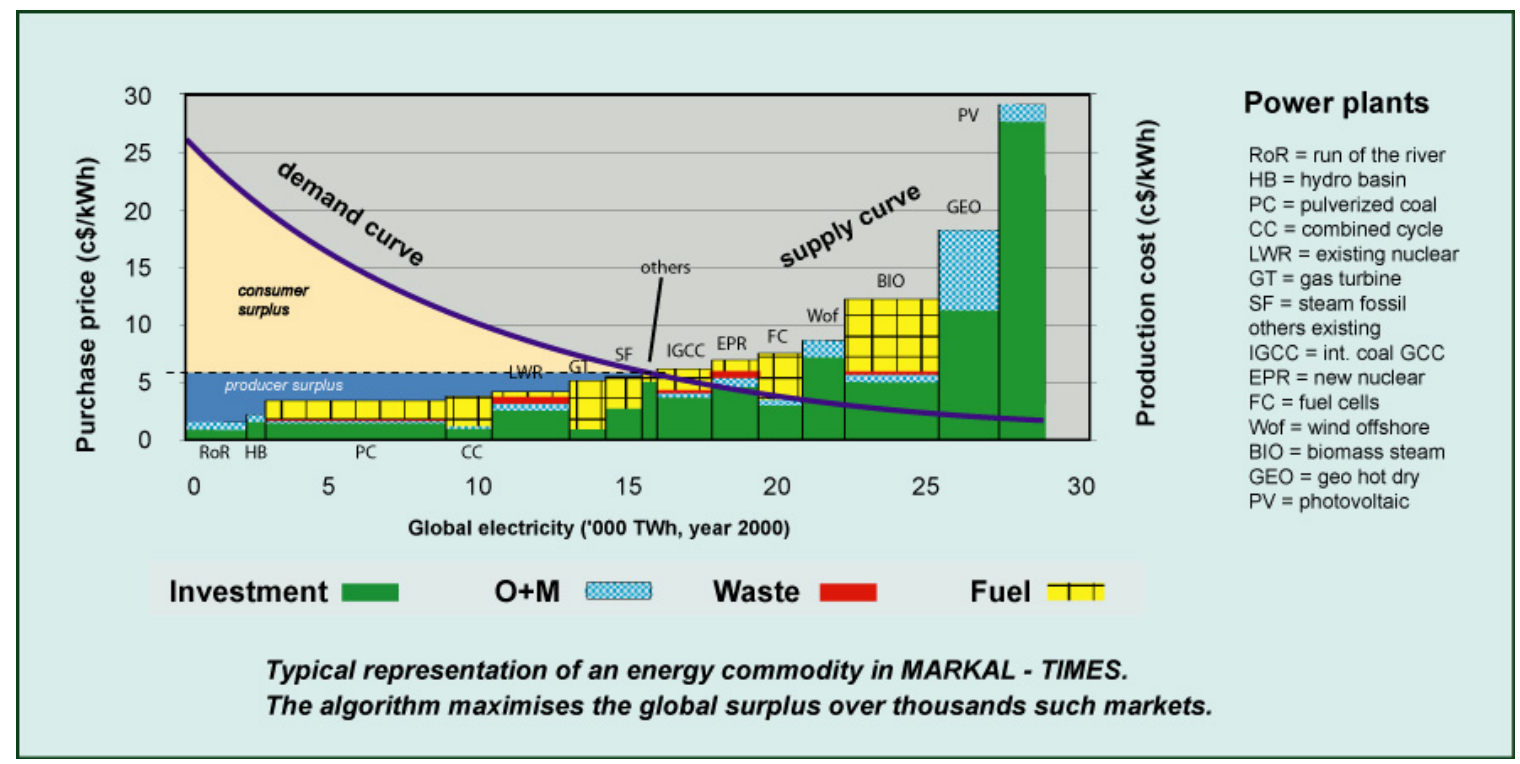

Figure 22.3 Determination of Supply-Demand Equilibrium in MARKAL and Technology Detail

MARKAL/TIMES can be linked to other models to assess regional issues, such as models of the dispersion of environmental residuals, models of agricultural and forestry impacts, and more detailed regional econometric models. MARKAL/TIMES and the regional models exchange key inputs and outputs while iterating to a mutual solution. This is the approach being taken in linking MARKAL/TIMES to REMI (Figure 22.4). The linked models will be able to assess the economic and environmental impacts of alternative energy policies and technologies with a high degree of geographic resolution. Such analysis is critical because local environmental, economic and social impacts will be key factors in determining the pace, extent and orderliness of the transition from oil to alternative energy resources.

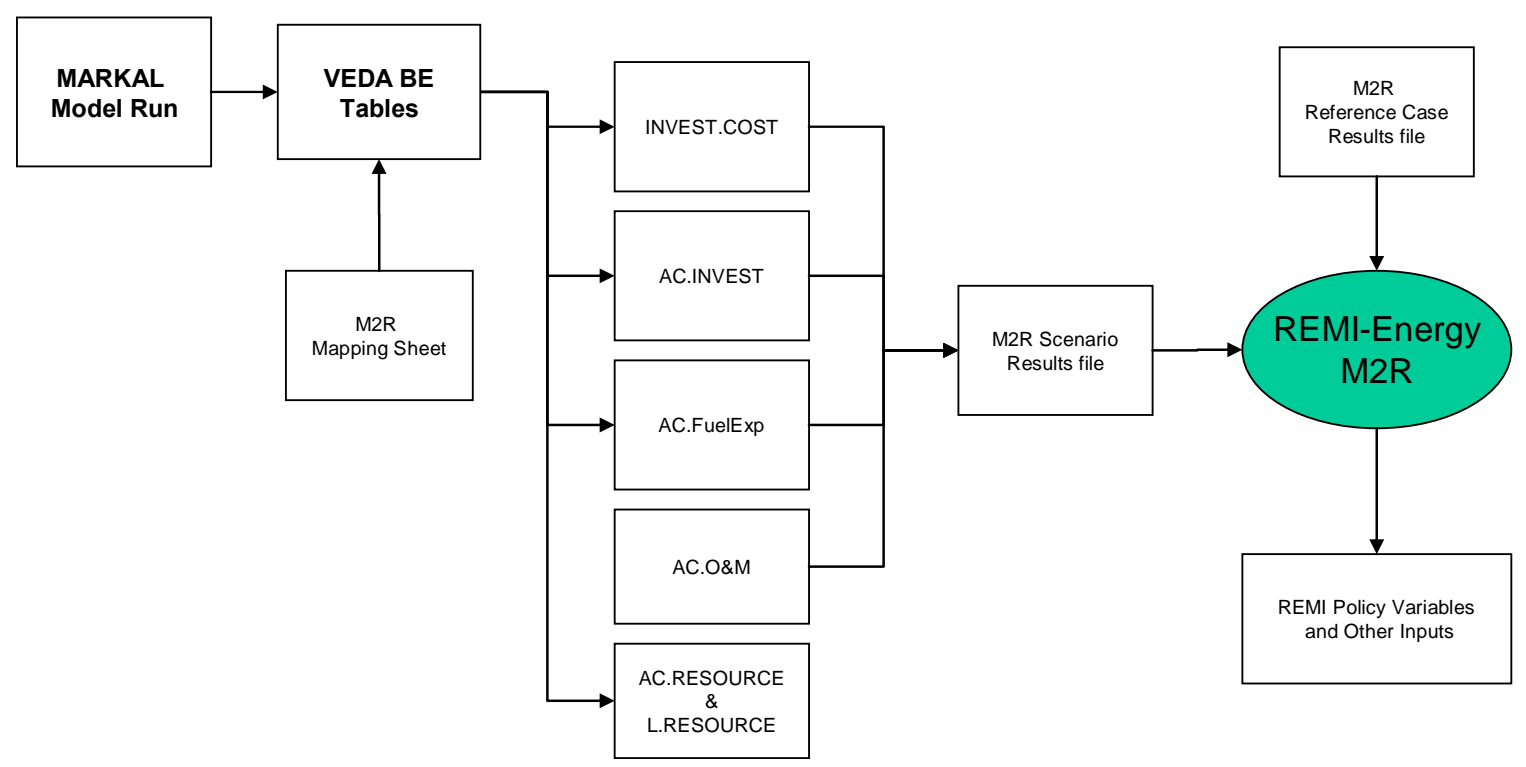

Figure 22.4 Schematic Diagram of the Linkage between REMI and MARKAL/TIMES 


\title{
23. THE CONTRIBUTION OF ECONOMIC MODELS TO THE OIL TRANSITION AND TO CLIMATE POLICY: A REVIEW OF THE AMIGA MODELING SYSTEM
}

\author{
Skip Laitner \\ American Council for an Energy-Efficient Economy, AMIGA
}

Energy-economic models have a number of shortcomings that limit their ability to provide useful insights about energy transitions. Models are inherently simplifications of reality, yet they must represent the critical elements of the real world that pertain to the question at hand in order to be useful. The following are five serious deficiencies existing energy-economic models share with respect to evaluating the oil transition.

1. Technology characterization is often limited or even inappropriate - for both the demand and the supply-sides of the equation;

2. Capital flows are not sufficiently disaggregated to provide meaningful policy assessments;

3. Many model assumptions about consumers and firms may be unrealistic and give misleading insights about policy options;

4. The economic accounting of investments and technology choices are limited or poorly represented; and

5. All models reviewed in this workshop, including our own AMIGA model, have no ability to anticipate unexpected outcomes or disruptions in ways that inform policymakers about appropriate steps for more robust policy initiatives.

Many but not all of these shortcomings are addressed in the latest version of AMIGA 4.2, a comprehensive model integrating energy markets, technologies and policies. Its capabilities include,

- Estimating the impact of changes in more than 200 individual sectors (in terms of both dollar measures and physical units).

- Integrating a detailed energy market specification within a structural economic model.

- Allowing firms to maximize net wealth and consumers to maximize intertemporal utility. (In the absence of perfect foresight, agents act on approximate intertemporal rules.)

- Calculating both prices and macroeconomic variables, such as consumption, investment, GDP, government spending, and employment.

- Provides equilibrium paths for 21 world regions, from the present through the year 2050, with the capability of extending the time horizon out to 2100 ,

- Estimating GHG concentrations, atmospheric feedback, and temperatures using the MAGICC model.

The heart of the AMIGA model is an Input/Output model of the economy, a disaggregated representation of household demand, and representations of energy service demands (Figure 23.1). This interacts with energy resource supply functions. Energy conversion models take resources and convert them into energy products that are delivered to the I/O-Demand model. 
The I/O-Demand model interacts with capital stock models to track the size and technical composition of energy using equipment.

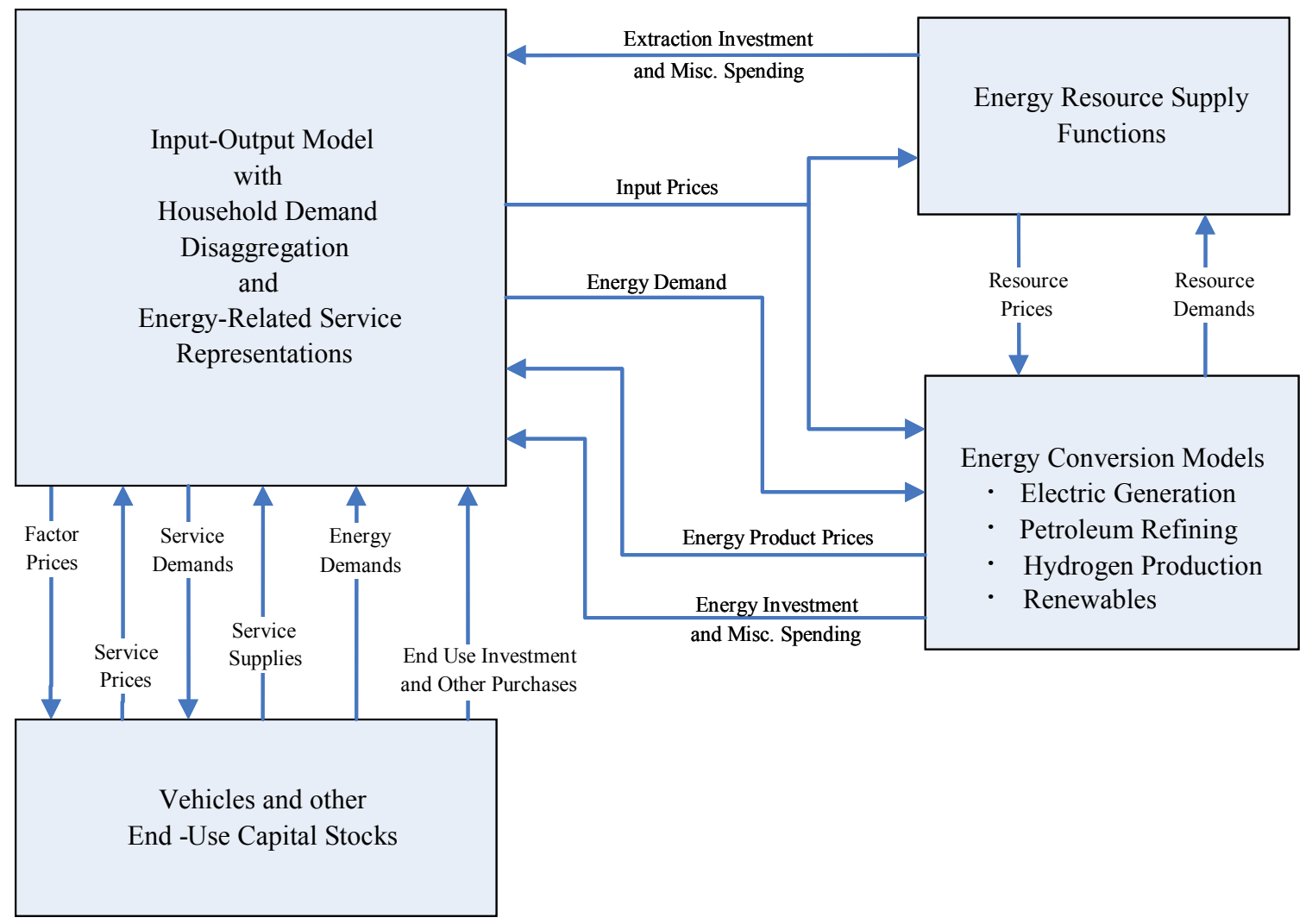

Figure 23.1 Structure of the AMIGA Model

The AMIGA model pays special attention to characterizing energy efficiency technologies. This is critical because since 1970 energy efficiency improvements have met $75 \%$ of the increase in demand for energy services. The magenta (lowest) line in Figure 23.2 shows actual energy use. The blue line represents a typical energy demand forecast, while the red line shows the energy that would have been required to supply the actual level of energy services at 1970 energy efficiencies. Without energy efficiency improvements, U.S. energy use would be three times what it actually is today. The implication is clear: energy efficient technology is likely to be more important than energy resource availability in satisfying future energy needs. Therefore, in modeling the oil transition, correctly characterizing energy efficient technologies is at least as important as accurately modeling resource depletion. 


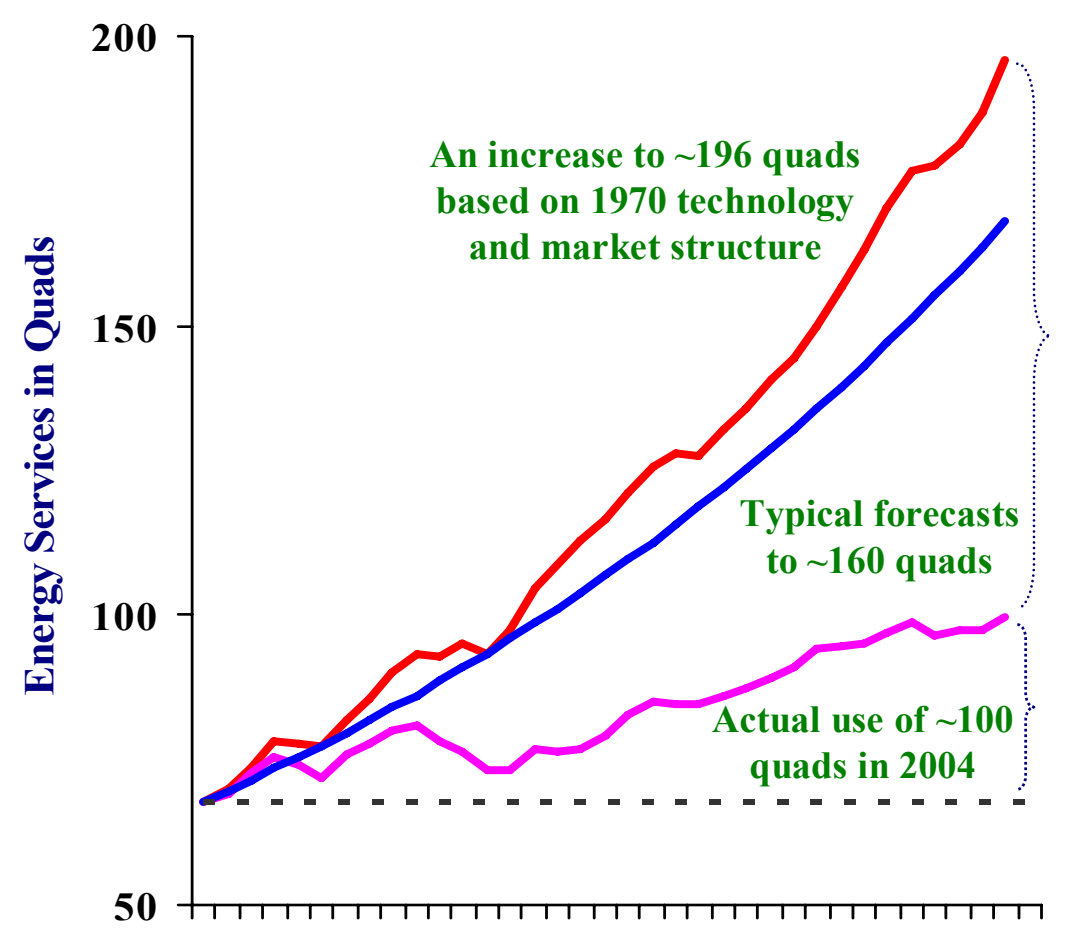

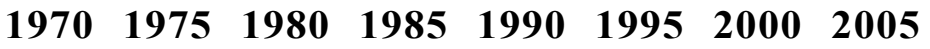

Figure 23.2 Analysis of Impact of Energy Efficiency Improvements on Energy Use

It is therefore important to adequately represent new (and presumably more efficient) energy supply technologies, new energy conversion technologies and new energy end-use technologies, since all may yield important efficiency gains as well as supply energy from new sources. AMIGA includes a detailed representation of existing powerplants based on the E-GRID database, and adds new capacity from eight advanced technologies.

1. New coal units -4 types of re-powering and gasification technologies, with SO2, NOx, and mercury controls;

2. Nuclear - evolutionary and advanced designs;

3. Gas - both conventional and advanced natural gas combined Cycle (NGCC) units, peakers, and advanced turbines;

4. Municipal solid waste;

5. Large industrial combined heat and power (CHP) units by fuel type, such as natural gas or biomass;

6. Fuel cells systems;

7. Other distributed generation; and

8. Renewable technologies, including wind, geothermal, hydroelectric, biomass cofiring, biomass gasification combined cycle, building integrated PV, solar, and others.

AMIGA also now has a Macro Analysis of Refining Systems (MARS) submodel to better represent how changing feedstock characteristics, changing product demands and changing refining technology could affect future costs and energy use. The MARS simulation model includes the following functions. 
1. Represents 26 primary \& secondary refinery processes.

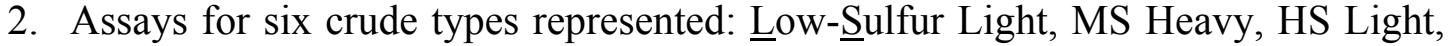
HS Heavy, HS Very-Heavy, SynCrude.

3. Includes processes for upgrading heavy oils and OS (including natural gas consumption and hydrogen production and use).

4. Also includes representation of CTL co-production.

5. Includes eight major refinery products including gasoline, diesel \& jet fuel, and evaluates range of product shares.

On the energy end use side, AMIGA also incorporates technological and consumer demand detail.

- With technology characterization based on

- Engineering cost-of-energy estimates,

- Supply function analysis, and

- Consumer preferences based on a distribution of hurdle rates unique to end-use sector, energy service, and fuel type.

- Including

- Light and heavy duty vehicles for both passenger and freight services,

- Industrial processes, and

- Building service demands.

In particular, transportation technologies are broken down into vehicle classes so that technologies can be better matched to the applicable vehicle type. Demand for vehicles of different types depends on their attributes, including price, performance, size, fuel economy and luxury features. Advanced vehicle technologies, such as fuel cell vehicles, are described in terms of expected attributes and are assigned a date of market introduction. Uncertainty in these assumptions can be explored via sensitivity analysis.

The second key shortcoming of existing models is inadequate disaggregation of capital flows. The technological opportunities for capital-energy substitution via advanced technology vary substantially among subsectors within economic sectors. To optimize investments requires a high degree of disaggregation of capital stocks. AMIGA includes a fine level of disaggregation of energy-using capital.

A third area of weakness for energy-economic models is their adoption of the simplistic assumptions of elementary economic theory, e.g., that all markets are perfectly competitive, that tastes are immutable, that consumers are perfectly informed and perfectly rational, etc. In fact, there is ample evidence that energy markets deviate significantly from the perfect economic model. An outstanding example is that of refrigerator energy efficiency. Refrigerator efficiency standards implemented in 1975 have not produced a trade-off between energy efficiency versus price and utility, as the elementary economic model would predict, but lower prices, more utility and drastically reduced energy use (Figure 23.3). This is not magic but a correction of the failure of refrigerator markets to accurately value energy savings. Models that fail to acknowledge that energy markets can be inefficient are likely to overlook superior energy market outcomes. AMIGA allows for high hurdle rates in energy investments but also recognizes the opportunity to reduce these hurdle rates through a variety of policy actions, such as the following. 
1. Voluntary and information programs that impact both service demands, such as vehicle or ton-miles traveled, or technology characterization such as Energy Star products.

2. Experience curves or learning from adoption.

3. Research and Development programs.

4. Renewable portfolio standards.

5. Appliance, Equipment and Corporate Average Fuel Economy Standards (CAFE) standards (including tradable permits for standards).

6. System of tradable emission permits (including banking, borrowing, and interpollutant trading).

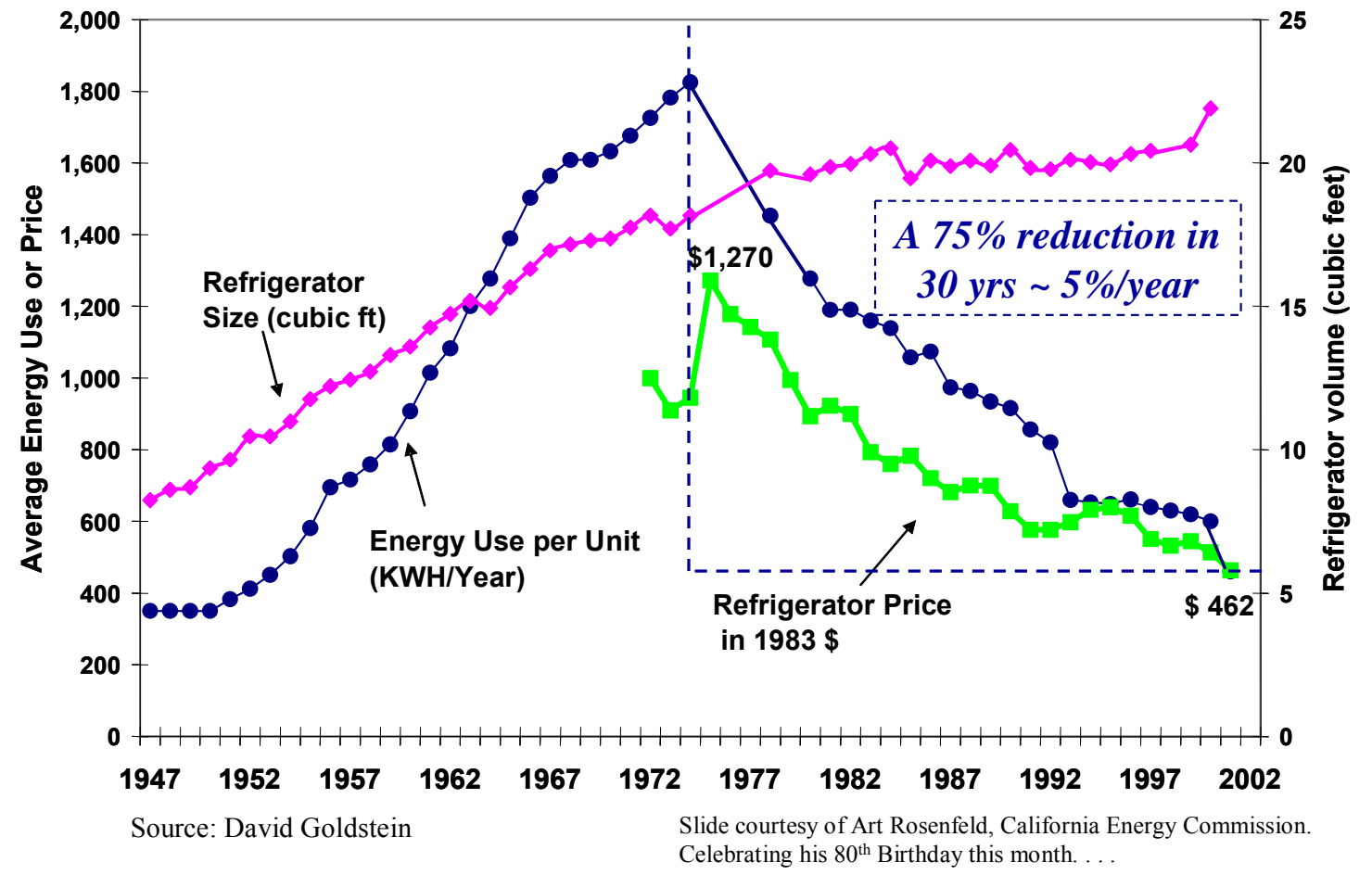

Figure 23.3 Refrigerator Price, Size and Efficiency in the U.S., 1947-2002

A fourth area in which current models are deficient is the failure to account for the full range of costs and benefits associated with a change in the energy system. For the most part, this is a failure to adequately account for external costs, such as the cost of energy security or of environmental externalities. But it is also a consequence of the third problem area, a failure to recognize market failures. For example, suppose that refrigerator purchasers appear to require a one-year energy payback, but refrigerators are made to use technology up to a six-year payback. If it is assumed that the market is efficient, this is an economic loss. If a market failure is acknowledged, it is an economic benefit.

The fifth problem area is perhaps the most difficult of all from a methodological perspective: the inability of existing models to reflect unexpected outcomes or inconvenient disruptions. Existing models are incapable of predicting whether the oil transition will be disruptive or orderly. And if it were disruptive, the models would not be able to predict the nature and impacts of the disruptions. This is extremely important since in addition to the greenhouse gas impacts of the oil transition, its potential to be disruptive may be the key public policy issue. A possible 
solution is to make use of scenario analysis. A scenario analysis of disruptive oil market futures using the AMIGA model led to the following insights.

1. Low energy prices can sustain a higher level of economic growth, but so can a smart investment path - one that emphasizes a balanced portfolio of both energy efficiency and advanced energy supply or energy conversion technologies.

2. Today's public and private choices, along with unexpected or often unanticipated external events (the so-called Black Swan), will affect the cost of managing the oil transition and responding to the unexpected future.

3. A productive technology investment strategy - begun early - will better position the economy and the environment to respond to unexpected challenges ahead.

Hence, one task of near-term modeling exercises should be to identify the mix of early technology investments that will satisfy multiple social goals (national security, environmental quality, equity, and a robust economy) - given conditions of deep uncertainty. To accommodate these scenario evaluations, there is a pressing need to complete the assessment of model shortcomings begun in this presentation. The improved model performance can provide useful rather than misleading policy insights. 


\title{
SESSION 8: MODELING GLOBAL ENERGY TRANSITIONS \& THEIR ENVIRONMENTAL EFFECTS
}

\author{
PART III: HYBRID MODELS AND SCENARIO ANALYSIS \\ Hill Huntington, Stanford University, Energy Modeling Forum, Chair
}

\section{UNDERSTANDING AND MODELING THE EFFECTS OF HIGH OIL PRICES AND THE DEVELOPMENT OF SAGE AT EIA}

\author{
Glen Sweetnam \\ U.S. Department of Energy, Energy Information Administration
}

High oil prices are the key signal for change in world oil markets. The EIA has significantly raised its oil price outlook over previous years, with important implications for energy efficiency, the development of unconventional sources of petroleum fuels, and biofuels. To a large extent, EIA's change in outlook can be attributed to OPEC's apparent reluctance to increase oil supply as much as previously thought. In addition, impediments to investment in oil production in all areas persist, despite two years of high oil prices. In part, this is because exploration and development costs have increased. Although EIA does not see the increased production costs as a depletion issue, EIA is following the "peak oil" issue closely.

The AEO 2006 Reference Case oil price projection is about \$10-\$15 per barrel higher than the corresponding International Energy Outlook (IEO) 2005 projection (Figure 24.1). Higher oil prices can be expected to affect economic growth, fuel switching and the efficiency of oil use, conventional and unconventional liquid fuel supplies from non-OPEC countries, and the world's demand for conventional oil from OPEC producers. The EIA's energy models can shed light on all these questions.

The AEO 2006 considered three very different oil prices paths (Figure 24.2). From the impacts of these different price paths, much can be learned about the effects of higher oil prices.

U.S. GDP is relatively insensitive to the price of oil. In the High Oil Price Case, crude oil prices are $80 \%$ above Reference Case levels by 2030 . U.S. GDP initially falls by about $1 \%$ over the 2010-2015 period but then recovers to be only $0.25 \%$ below the Reference Case level in 2030 (Figure 24.3). Gauging the maximum impact during 2010-2015, it appears that a roughly 50\% increase in the price of oil leads to a roughly $1 \%$ decrease in GDP for a (temporary) elasticity of -0.02. In the long run (2030) the impact is far smaller, indicating an elasticity of GDP with respect to the price of oil of only -0.003 . 


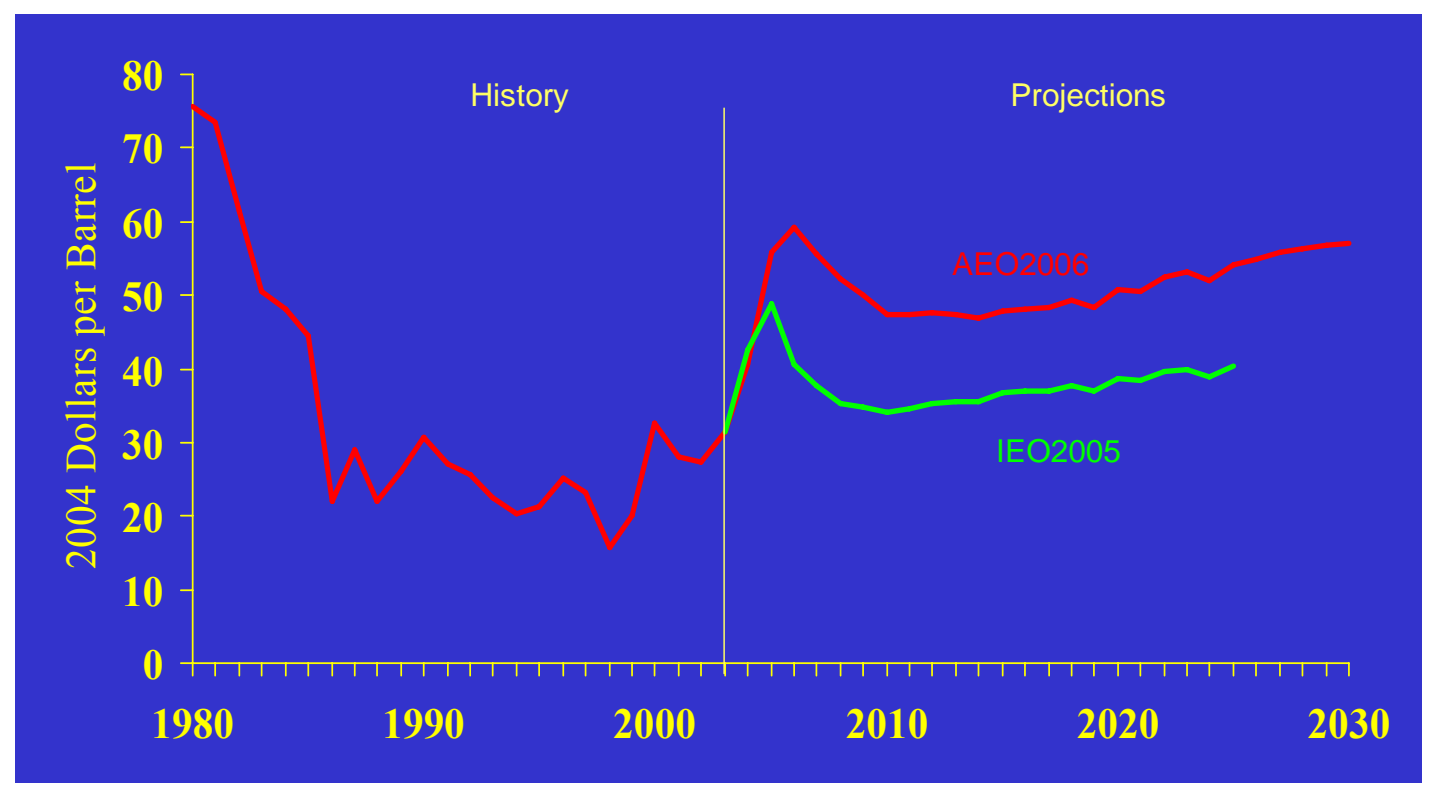

Source: EIA, IEO2005 and AEO2006

Figure 24.1 AEO 2006 and IEO 2005 Reference Case Oil Price Projections

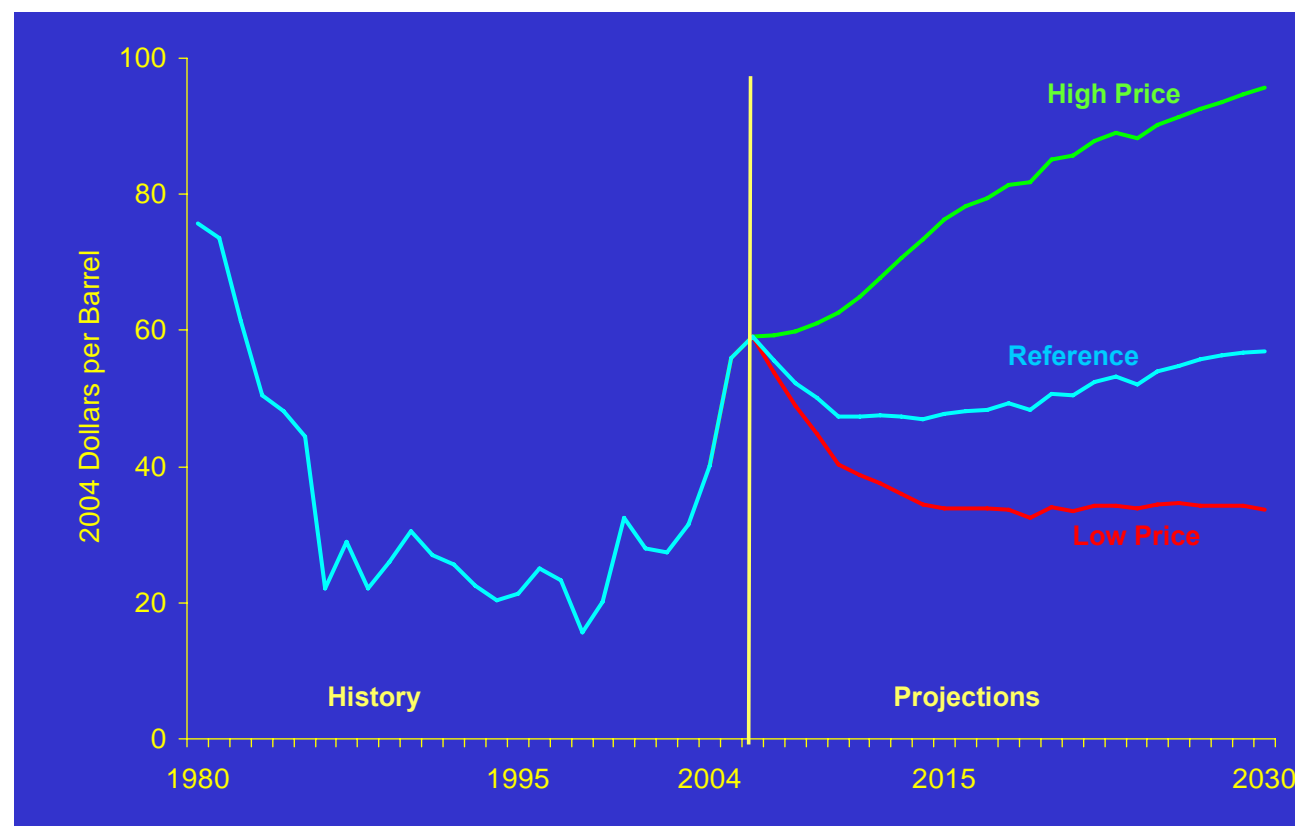

Figure 24.2 World Oil Prices in Three AEO 2006 Cases, 1980-2030 


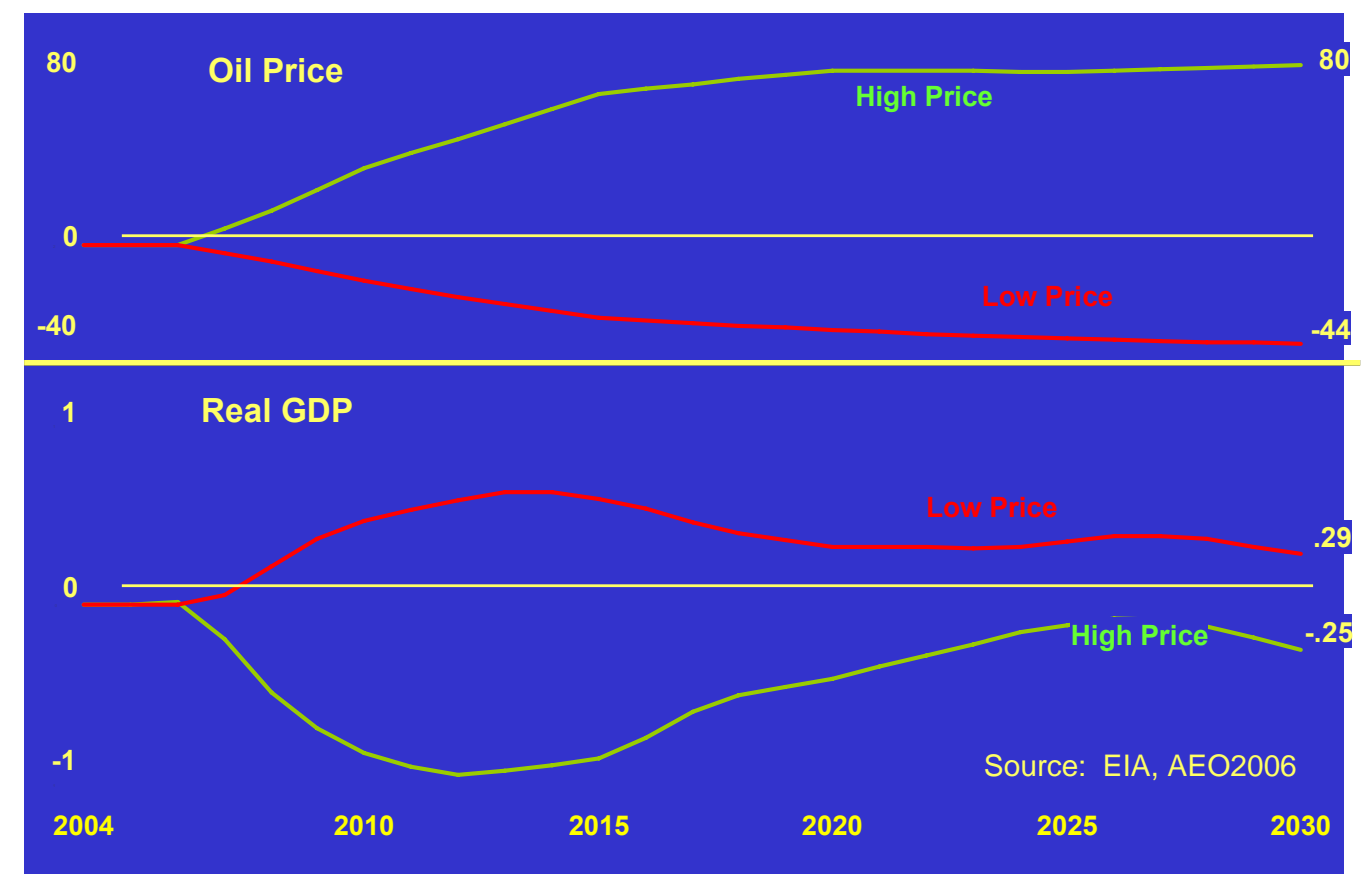

Figure 24.3 U.S. GDP in High and Low World Oil Price Cases (percent difference from Reference Case)

The higher oil prices also cause increased adoption of energy efficient technologies in LDVs. In 2025, new LDV MPG reaches 28.8 in the 2006 AEO Reference Case, 1.9 MPG (7\%) higher than in the 2005 AEO Reference Case. In the 2006 AEO Low Oil Price Case, LDV MPG is estimated to be 27.5 MPG, while in the High Oil Price Case it is 14\% higher, 31.4 MPG (Table 24.1). Higher oil prices also stimulate increased ethanol use by highway vehicles. In the 2005 AEO, only 0.4 quads of ethanol are projected to be consumed by transport vehicles in 2025 . This increases to 1.0 quads in 2025 in the 2006 AEO due to recently enacted policies such as the Renewable Fuels Standard. In the Low Oil Price Case ethanol use decreases to 0.9 quads, while in the High Oil Price Case it increases to 1.2 quads. From the Low Oil Price Case to the High Oil Price Case, U.S. oil production increases by $2.5 \mathrm{mmbd}$. This reflects highly inelastic oil supply. Using the Reference Case as the midpoint and the arc elasticity formula indicates a longrun elasticity of about 0.25 . Supply of unconventional petroleum, on the other hand is relatively sensitive to the price of crude oil. From zero, in the low oil price case, production of petroleum from sources such as CTL, gas-to-liquids and oil shale increases to $1.2 \mathrm{mmbd}$ (Figure 24.4).

Table 24.1 Impacts of Oil Prices in the 2006 AEO Projections

\begin{tabular}{lccc}
\hline & Low Oil Price & Reference & High Oil Price \\
\hline World Oil Price (2004 \$ / barrel) & $\$ 28$ & $\$ 54$ & $\$ 85$ \\
New Light-Duty Miles per Gallon & 27.5 & 28.8 & 31.4 \\
Ethanol Use (quads) & 0.9 & 1.0 & 1.2 \\
U.S. Oil Production (mmbd) & 8.2 & 8.8 & 10.7 \\
U.S. Unconventional Oil (mmbd) & 0.0 & 0.6 & 1.2 \\
U.S. Petroleum Imports (mmbd) & 18.0 & 15.7 & 12.8 \\
\hline
\end{tabular}

( $1 \mathrm{mmbd}=2.117$ quads $)$ 


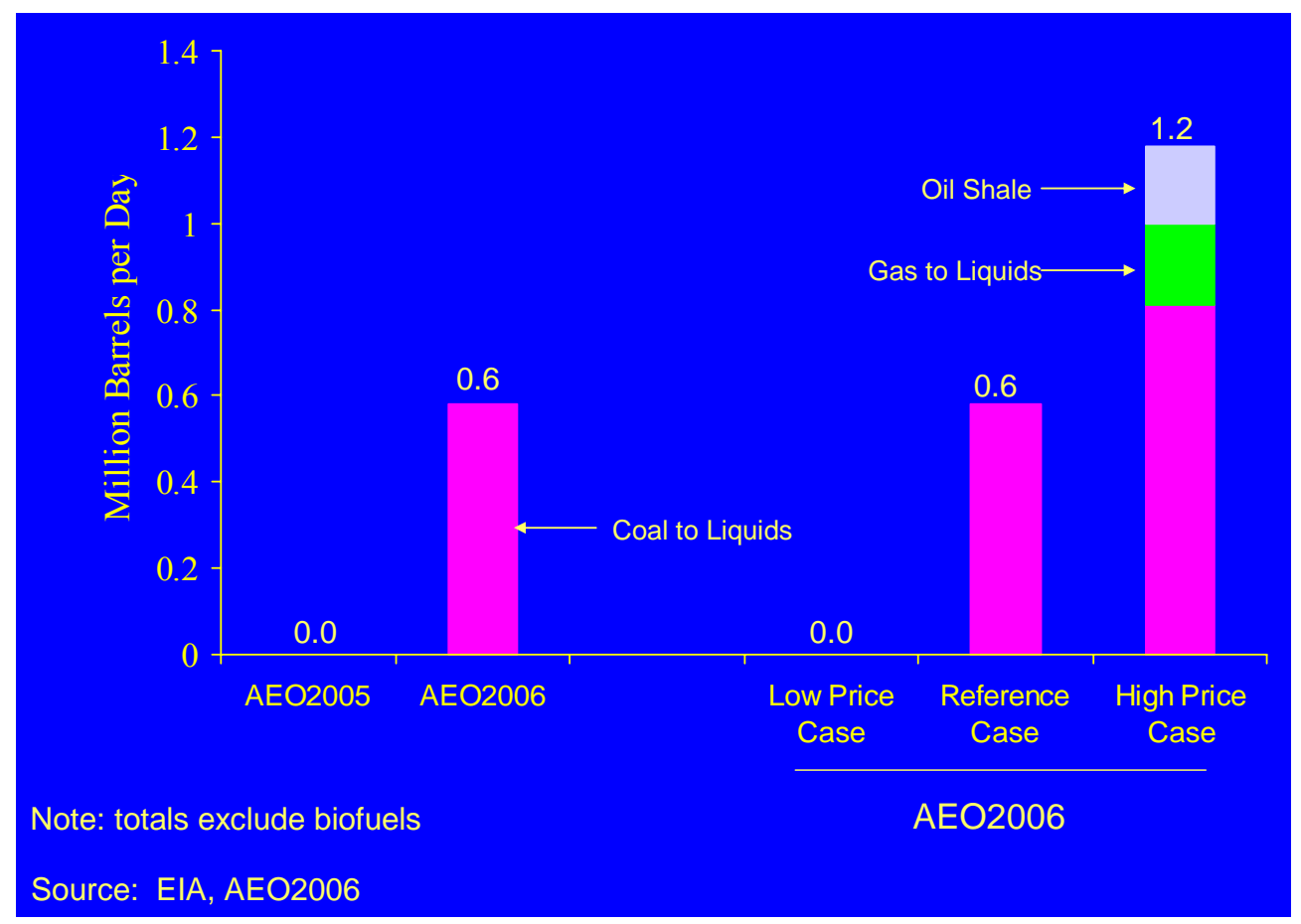

Figure 24.4 Unconventional Liquids Production in 2025 in the 2006 AEO

U.S. $\mathrm{CO}_{2}$ emissions increase substantially in all three oil price cases as increased use of coal partially offsets the reduced consumption of petroleum when oil prices increase (Figure 24.5). Some of the increased coal consumption comes from increased CTLs production. In addition, natural gas prices are higher in the High World Oil Price Case which also encourages very substantial substitution of coal for natural gas in electricity generation.

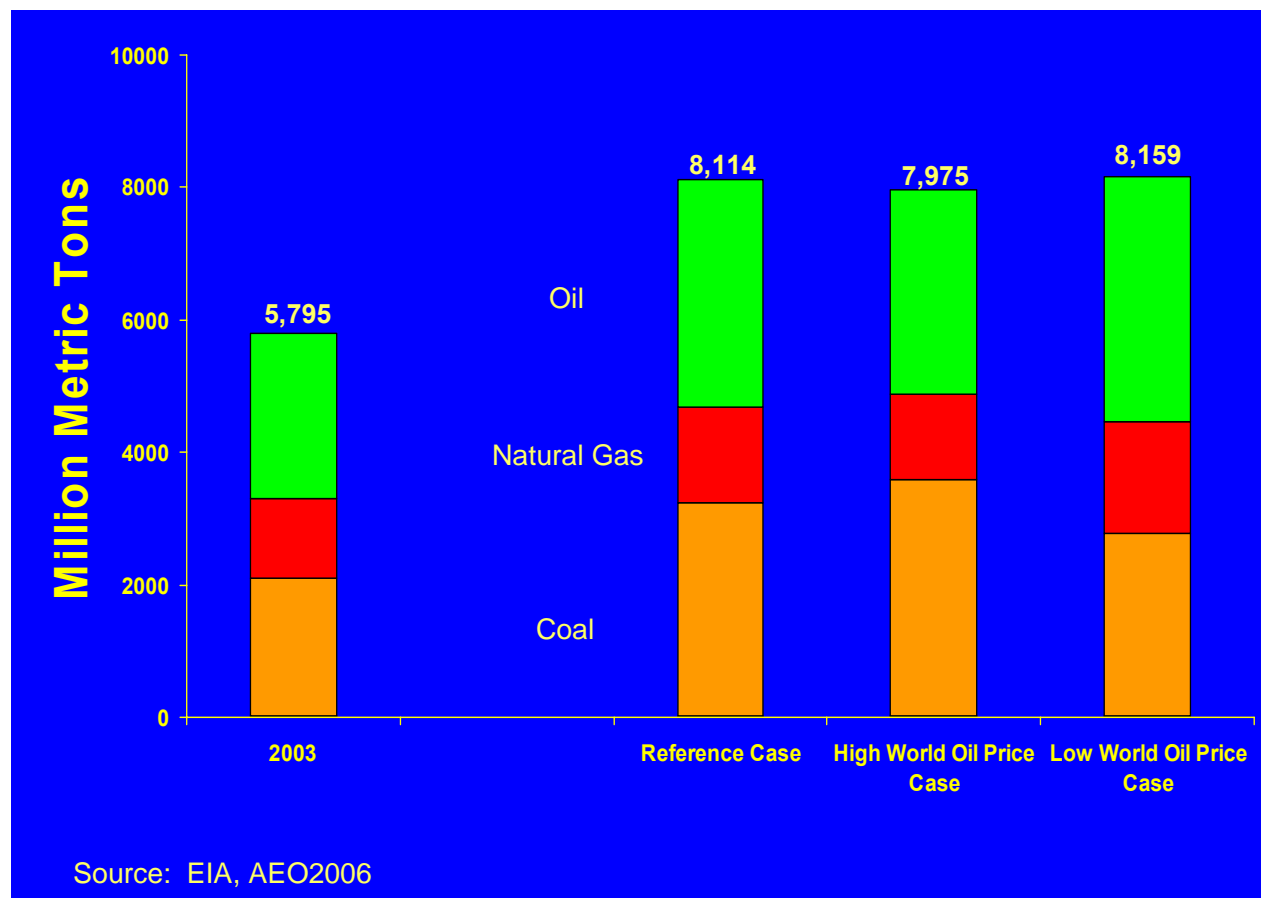

Figure 24.5 U.S. $\mathrm{CO}_{2}$ Emissions in Three Oil Price Cases, 2003 and 2030 
The varying oil price cases raise important questions about impacts on energy use and energy supply outside of the United States.

- How will regional economic growth be affected?

- How much fuel switching will occur?

- How much gain in efficiency can be anticipated?

- What will be the impact on non-OPEC liquid supplies - both conventional and unconventional?

- What will happen to the demand for OPEC oil?

The System for the Analysis of Global Energy Markets (SAGE), under development by EIA will provide answers to these questions. SAGE is an integrated set of MARKAL models that provide a technology-rich basis for estimating world energy consumption. It includes 42 categories of end-use service demands in 16 regions. Residential, commercial, industrial and transportation demands are driven by macroeconomic and demographic projections. SAGE forecasts in 5-year time steps to 2030. It has provided forecasts published in the IEO since 2003.

Several enhancements to the SAGE model are planned for the near future.

- Implement a market sharing algorithm in two sectors

- electricity

- personal vehicles

- Enhance the Reference Energy System

- eliminate unnecessary complexity (e.g., blast furnace gas)

- correct co-generation representation

- Improve Refining Representation

- Update ethanol supply curves

- Calibrate to a "normalized", rather than historical year

These improvements will enable the EIA to better predict the global response to fundamental changes in world oil markets. 


\title{
25. ENERGY SECTOR EVOLUTIONS: A SCENARIO PERSPECTIVE FROM MINICAM
}

\author{
Leon Clarke \\ Pacific Northwest National Laboratory
}

\begin{abstract}
MiniCAM is a century-scale energy-agriculture-economy-land-use integrated assessment model that is useful for exploring alternative energy futures and their implications for greenhouse gas emissions and atmospheric concentrations. Stabilization of atmospheric carbon concentrations will require sweeping changes in world energy systems over the next 100 years. There are ample fossil resources available to support world energy demand for the next century and it seems likely that these resources will be used unless actions are taken to curb carbon emissions. Stabilization will induce differential changes in different sectors. For example, many analyses indicate that decarbonization of electricity production is likely to proceed much more rapidly than decarbonization of transportation. Substantial use of bio-energy as a transport fuel raises important questions about the valuation of terrestrial carbon stocks, since these could be reduced by massive production of biomass for transport fuels.
\end{abstract}

The MiniCAM model calculates a partial energy-agriculture-economy market equilibrium for fourteen world regions from the present to 2095, typically in 15-year steps. Key inputs include assumptions about demographic and technological change (Figure 25.1). The model is relatively detailed with respect to its representation of energy supply and energy conversion technologies, and it is becoming increasingly technologically detailed over time with respect to end use technologies. It has a fully integrated agriculture and land use model, and also includes an integrated climate assessment mode (MAGICC). Fossil fuel resources are explicitly represented by type (e.g., coal, natural gas, petroleum) by the quantities available in differing grades.

A RS was constructed to illustrate how the world's energy system and greenhouse gas emissions might evolve in the absence of significant efforts to stabilize atmospheric greenhouse gas concentrations. The demographic assumptions underlying this scenario combine elements of the UNs medium scenario and the Millennium Assessment Techno-Garden Scenario developed by IIASA. World population increases to 9 billion in 2065 and then begins to decline (Figure 25.2). World GDP grows continuously from \$50 trillion in 2020 to exceed \$200 trillion in 2095.

World energy end-use in the RS reaches 1,000 Exa-joule (EJ) by 2095 (Figure 25.3). Electricity's share of buildings and industrial energy use increases steadily, while end-use of coal and biomass in these sectors disappears. Transportation, which experiences the greatest growth in energy use, remains heavily dependent on liquid fuels. Hydrogen use grows slowly over the century, still accounting for less than 10\% of total transportation energy use in 2095. 


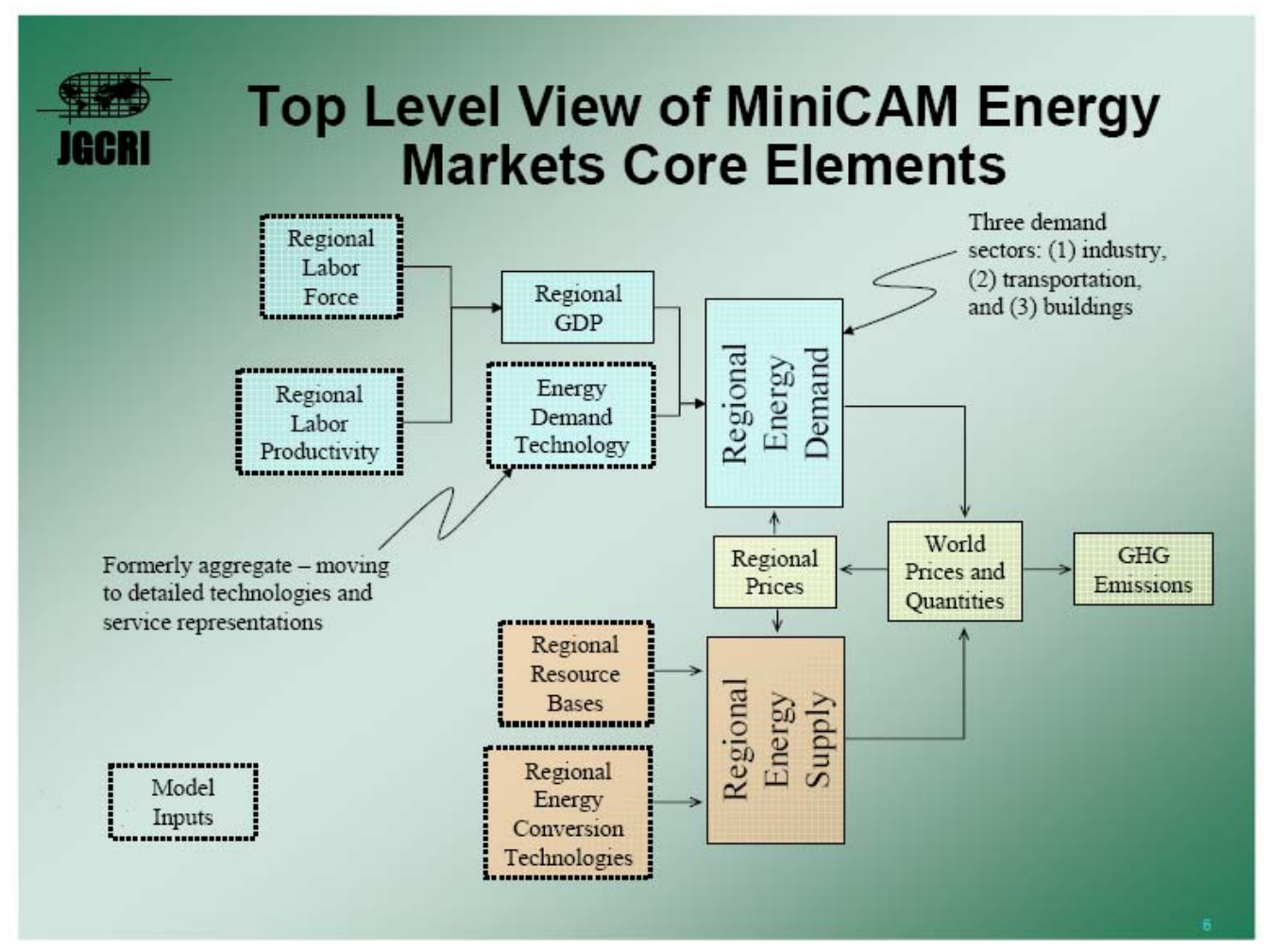

Figure 25.1 Schematic Diagram of the MiniCAM Model

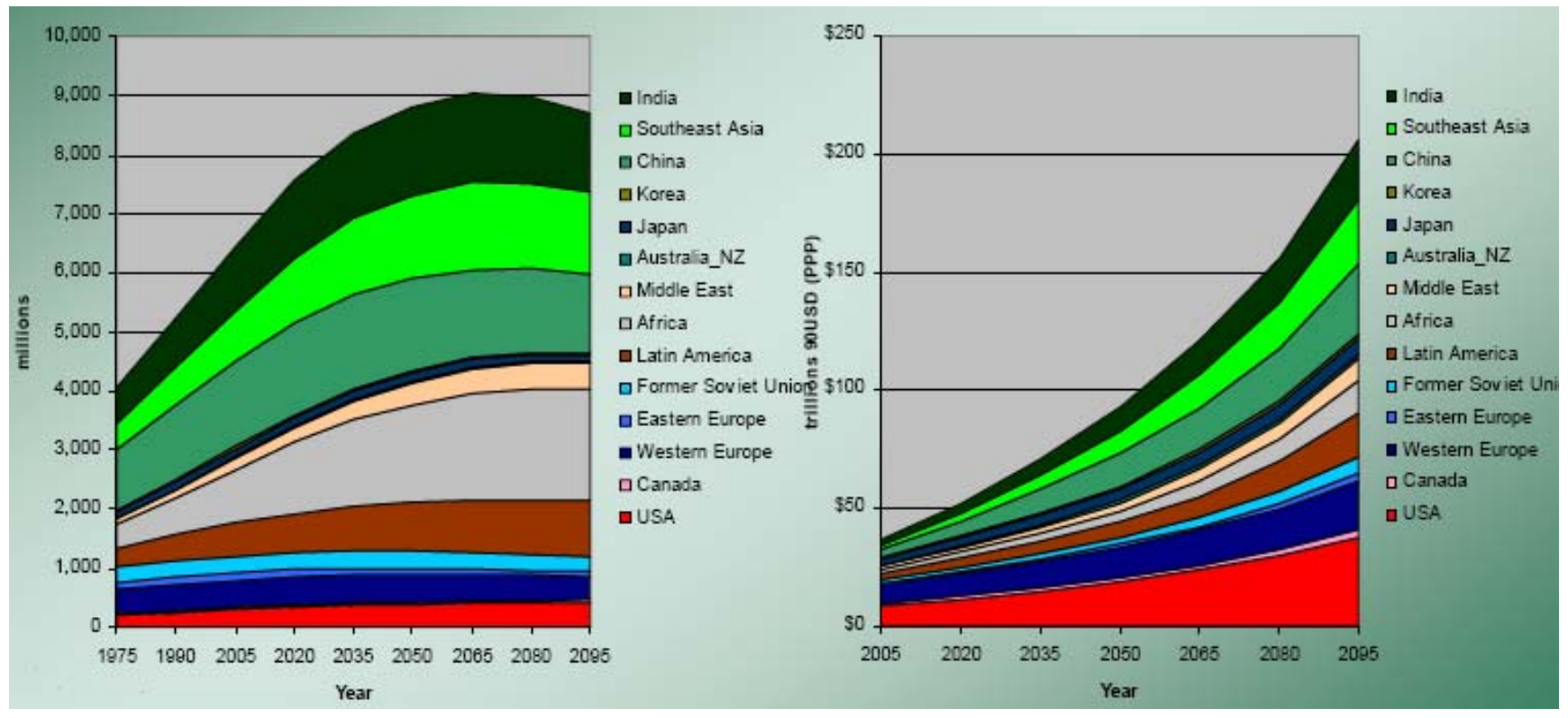

Figure 25.2 Demographic and Economic Changes by Region in the Reference Scenario 

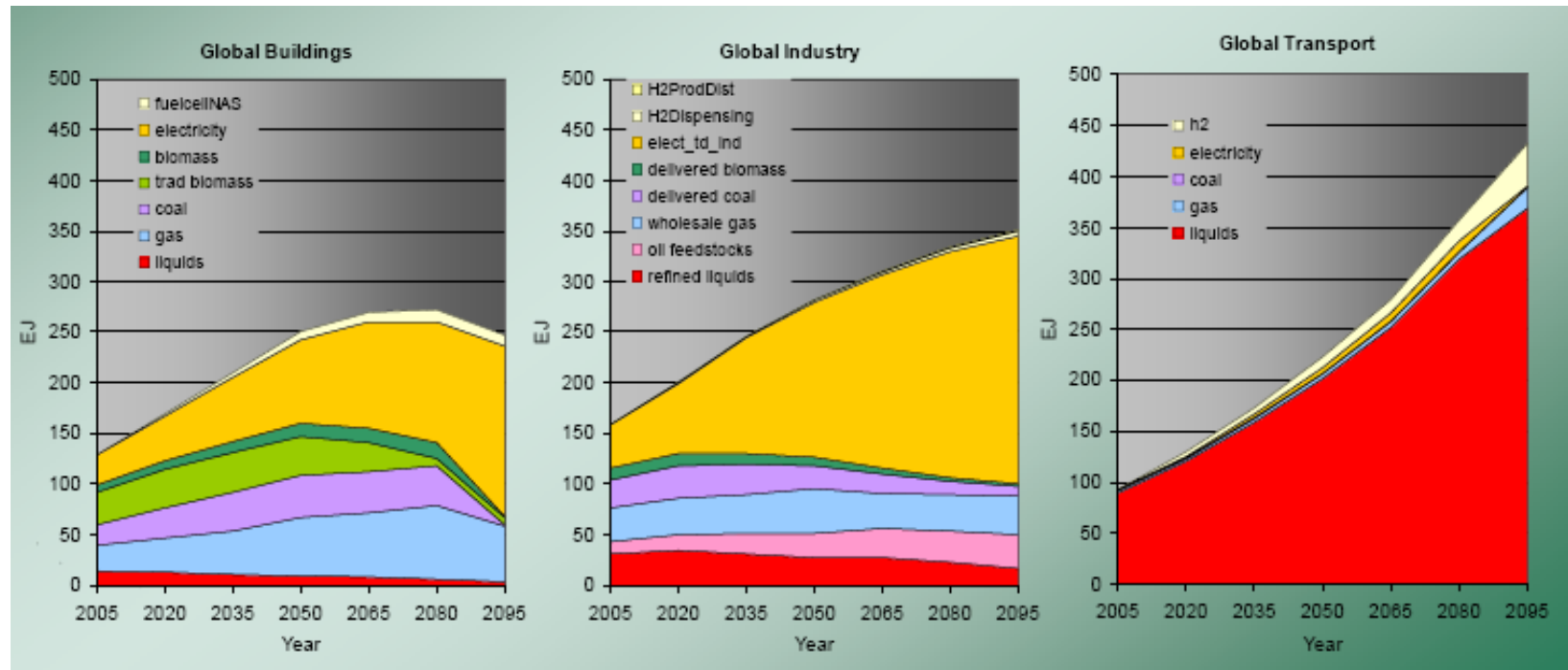

Figure 25.3 Global Energy Use by Sector, Reference Scenario

The end-use of energy shown in Figure 25.3 requires 1,500 EJ of primary energy (Figure 25.4). Conventional oil production reaches a plateau by about 2020, where it remains until nearly the end of the century. Even in 2095, the world has not "run out" of conventional oil, but the volume has substantially declined.

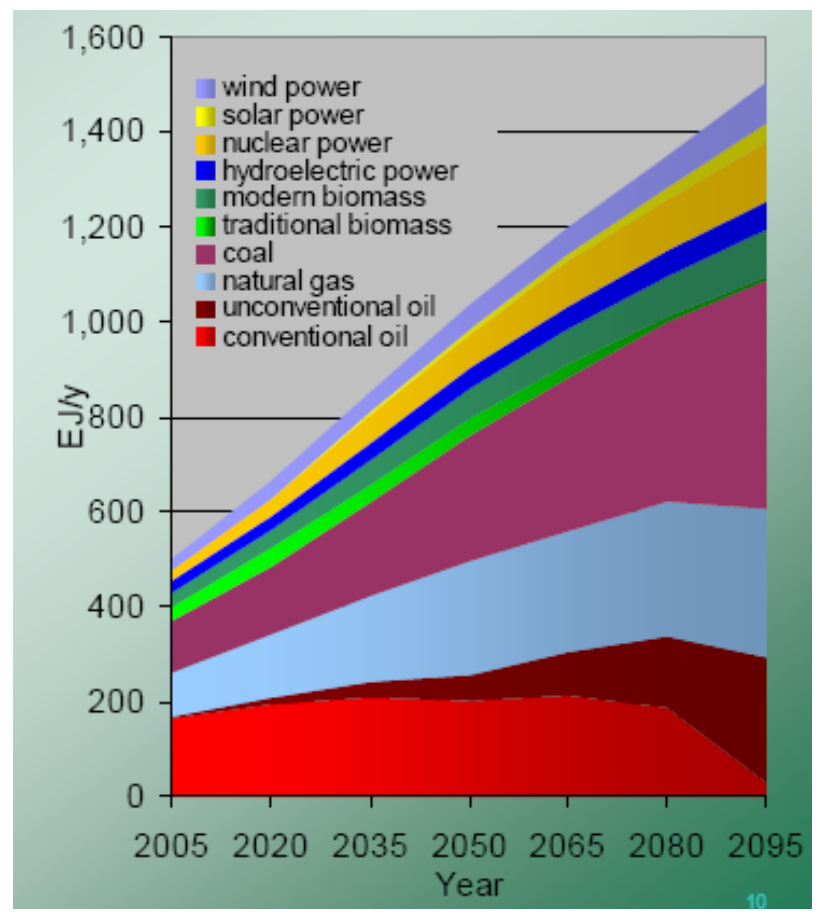

\section{Figure 25.4 World Primary Energy Use, Reference Scenario}

Most of the difference between conventional oil supply and growing demand is made up by unconventional oil, but a substantial amount also comes from CTL with relatively small amounts of biomass and gas-to-liquids (Figure 25.5). 


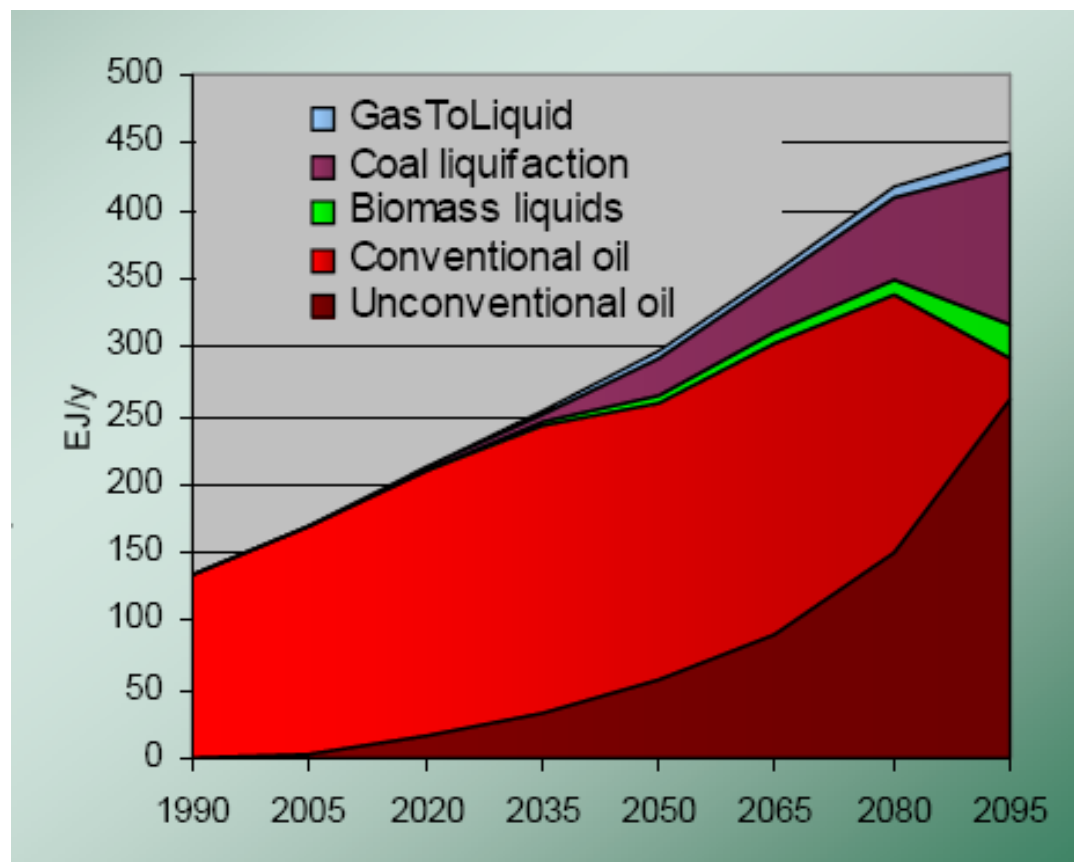

Figure 25.5 Global Evolution of Resources Converted to Liquid Fuels

In the RS there is no shortage of fossil fuels. The resource base for conventional oil is 18,000 EJ (3 trillion barrels), with much more unconventional oil available at $\$ 55-\$ 70$ per barrel. At $250,000 \mathrm{EJ}$, coal resources greatly exceed conventional oil resources, and CTL technology becomes economical at prices in the vicinity of \$60-\$70 per barrel. All this conversion and combustion of fossil fuels causes CO2 emissions to grow to over 25 Gt by 2100 (Figure 25.6). In turn, this produces atmospheric $\mathrm{CO} 2$ concentrations reaching $800 \mathrm{ppm}$, more than double the present level and more than four times pre-industrial levels, by 2100.

In order to stabilize atmospheric $\mathrm{CO} 2$ concentrations below $550 \mathrm{ppm}$, dramatic changes in the energy system must be made. Figure 25.7 shows the new configuration of total primary energy production associated with the $550 \mathrm{ppm}$ stabilization goal. First, efficiency improvements and conservation reduce the total quantities of energy required (grey). Next, the shares of nuclear energy and renewables, especially commercial biomass, are substantially increased. A key step is the replacement of unconventional oil and CTL with biofuels and energy efficiency in the transport sector. Next carbon sequestration is applied to coal, natural gas, and petroleum fired electricity generation. 

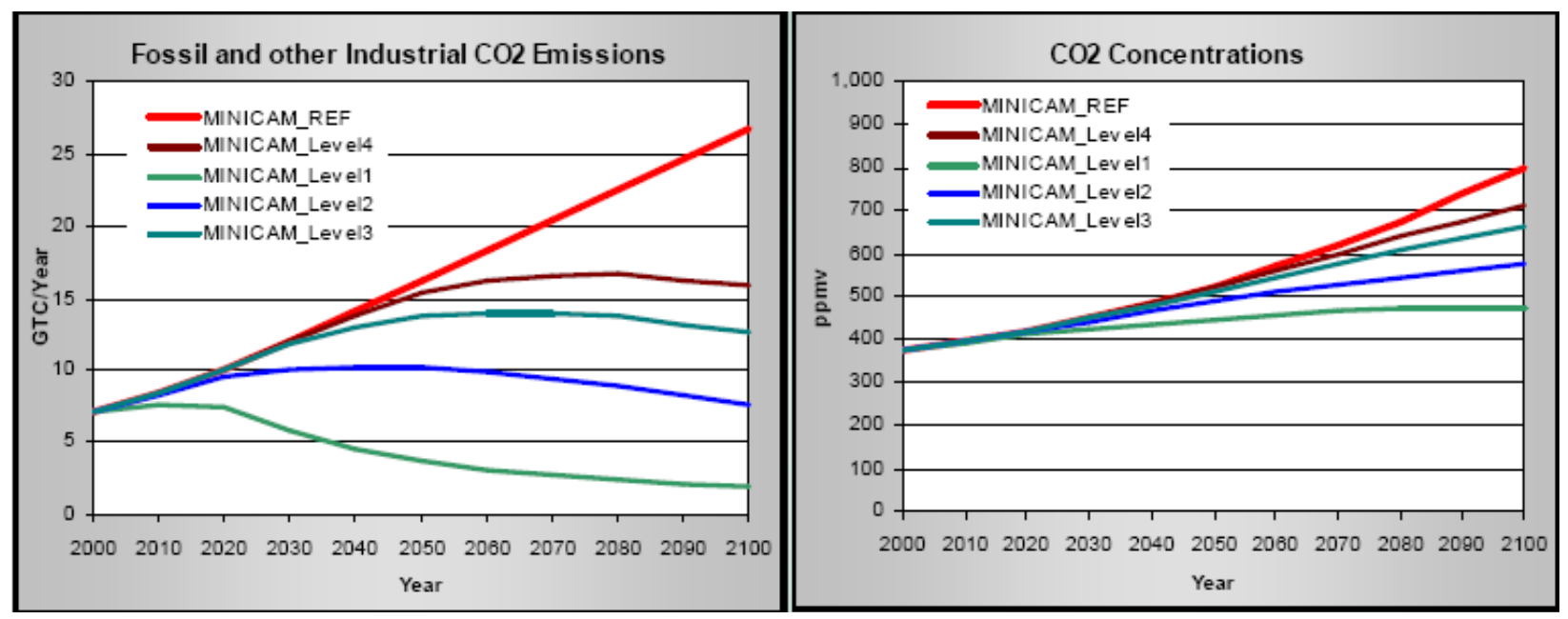

Figure 25.6 Annual Global $\mathrm{CO}_{2}$ Emissions and Resulting Atmospheric Concentrations

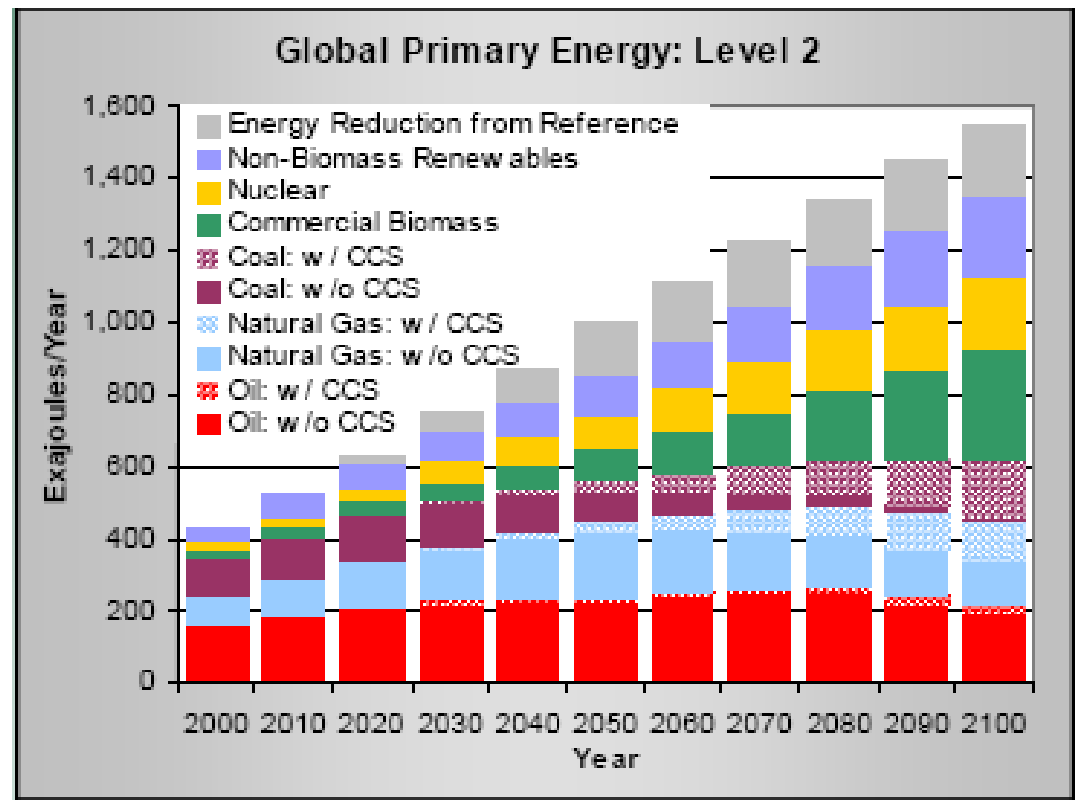

Figure 25.7 Pattern of Global Primary Energy Use Stabilizing $\mathrm{CO}_{2}$ Concentration at 550 ppm

In the stabilization case transportation energy use decreases by only about $10 \%$, and liquid fuels are still the overwhelmingly dominant source of energy but unconventional oil use is drastically reduced and biofuels replace CTL (Figure 25.8).

Land use changes resulting from the very large increase in biofuels production can have unfortunate implications for terrestrial carbon storage. For illustration of this dynamic, terrestrial carbon emissions are not valued in the scenarios that presented here. As a consequence, there is no counterbalance to the expansion of biomass production into unmanaged lands and the associated carbon emissions. The result is a substantial increase in terrestrial carbon emissions at the lower ppm stabilization levels (Figure 25.9). Clearly, the terrestrial emissions resulting from other actions taken to mitigate greenhouse gas emissions must be accounted for in designing climate policy should biofuels prove an economically viable transportation option. 


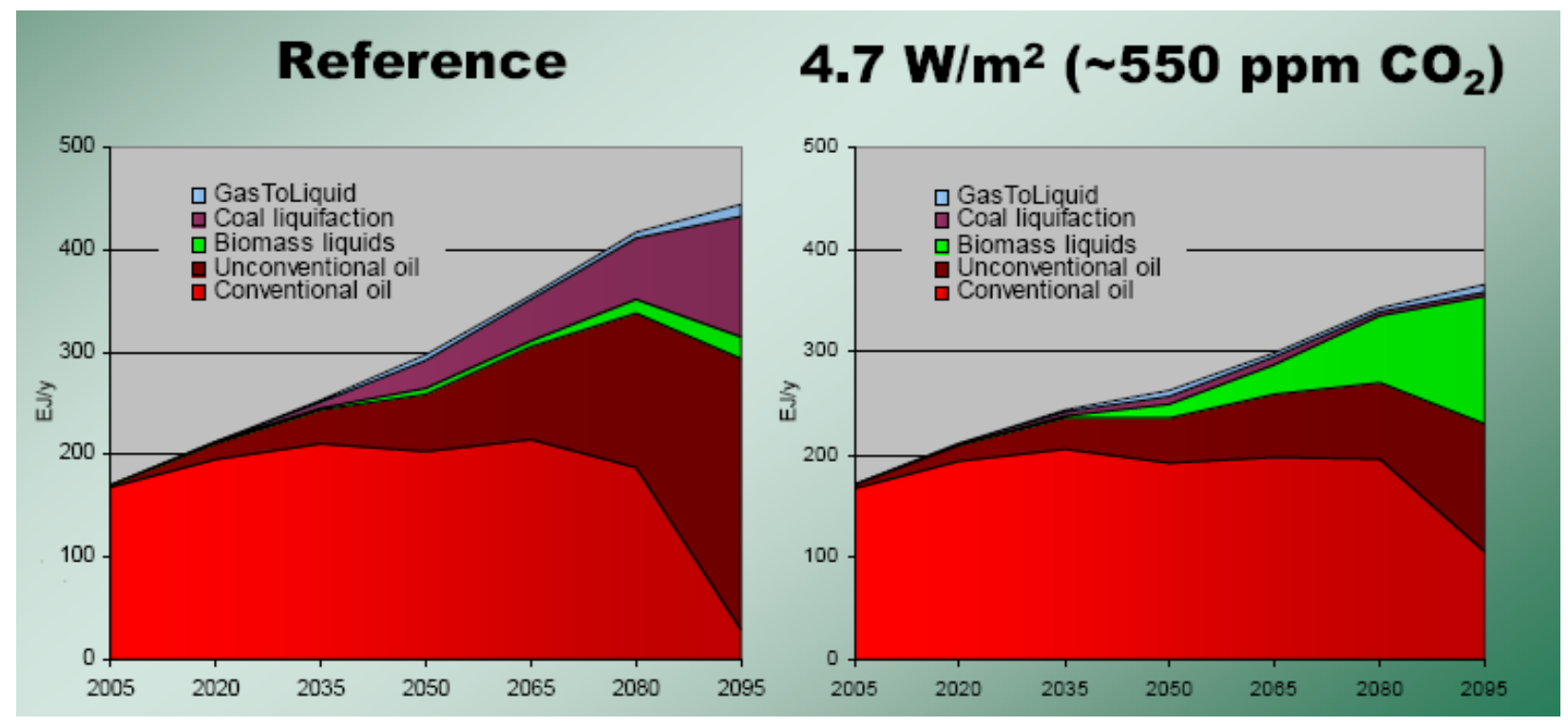

Figure 25.8 Global Liquid Fuels Supply in Reference and 550 ppm Stabilization Scenarios

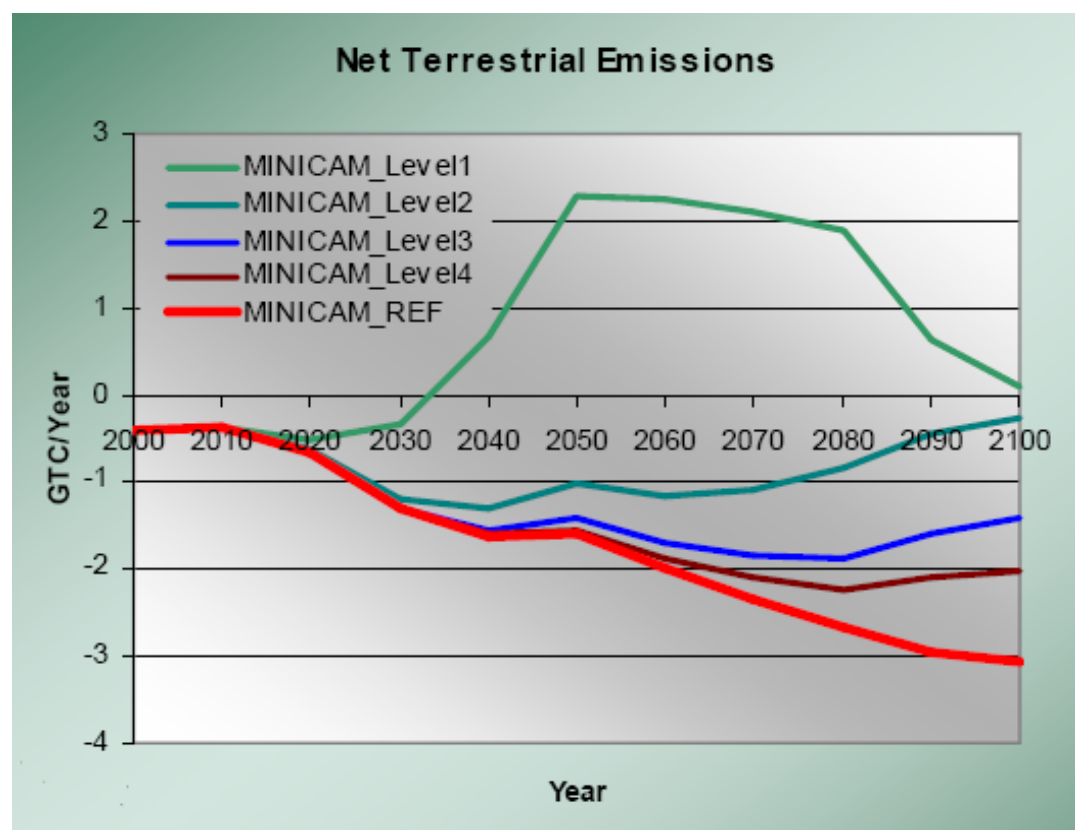

Figure 25.9 Implications of Stabilization Scenarios for Terrestrial $\mathrm{CO}_{2}$ Emissions 


\title{
26. SCENARIO ANALYSIS UNDER DEEP UNCERTAINTY
}

\author{
Robert Lempert \\ RAND Corporation
}

A more complete exposition of "Robust Decision Making" can be found in Lempert, Popper and Bankes, Shaping the Next 100 Years: New Methods for Quantitative, Long-Term Policy Analysis, RAND, Santa Monica, California.

Uncertainty makes modeling the oil transition a significant challenge. Because of the many different perspectives on the oil transition issue, the likelihood that it will evolve over decades with consequences lasting a century or more, and the certainty of unpredictable technological, social and economic changes over such time scales, the oil transition problem confronts decision makers with deep uncertainty. Problems of deep uncertainty are those in which the key decision makers do not know or cannot agree on the system model, prior probabilities, and/or the "cost" function. If decision makers assume the future is well characterized when in fact it is not, decisions can go awry:

- Uncertainties are underestimated,

- Competing analyses can contribute to gridlock,

- Misplaced concreteness can blind decision makers to opportunities and surprise.

The decoupling of energy use and GDP growth after the world energy crisis of 1973-74 aptly illustrates an unanticipated, novel future. Since the late $19^{\text {th }}$ century, total U.S. energy use had evolved in nearly direct proportion to U.S. Gross National Product (GNP). Anticipating the future impacts of the energy crisis, forecasters in 1975 constructed a range of scenarios intended to bind the possible future paths of energy use as a function of GNP. What actually came about, of course, was entirely outside the envelope of what was believed to be possible (Figure 26.1).

Scenarios are useful tools for dealing with uncertainty. They can break barriers to thinking about the future and enrich debate by widening the strategic conversation. They can encourage buy-in from participants and trigger genuine strategic planning. By making risks more visible scenarios can enhance the resilience of the plans that are developed. But scenarios also have important limitations. Often no more than a few alternative scenarios are developed, too few to capture the possibilities in deeply uncertain situations. As a result, scenario analysis may not provide the opportunity to systematically compare options. Scenario analysis often fails to engage decision makers' mental models, missing out on a key component of deep uncertainty. And scenario analysis frequently generates insights but does not allow for the evaluation of actionable steps.

A more appropriate tool for situations of deep uncertainty is Robust Decision Making (RDM), an iterative analytic process for identifying strategies that perform reasonably well compared with alternatives across a wide range of plausible futures. RDM also allows decision makers to discover and characterize the typically small number of irreducible trade-offs inherent in the choice among robust strategies. The central feature of RDM is a methodology for identifying the scenarios that are most important to the choices faced by decision makers by means of statistical analysis of datasets created by many model runs. The resulting scenarios relate the most 
important vulnerabilities of the strategies under consideration to the key choices decision-makers face.

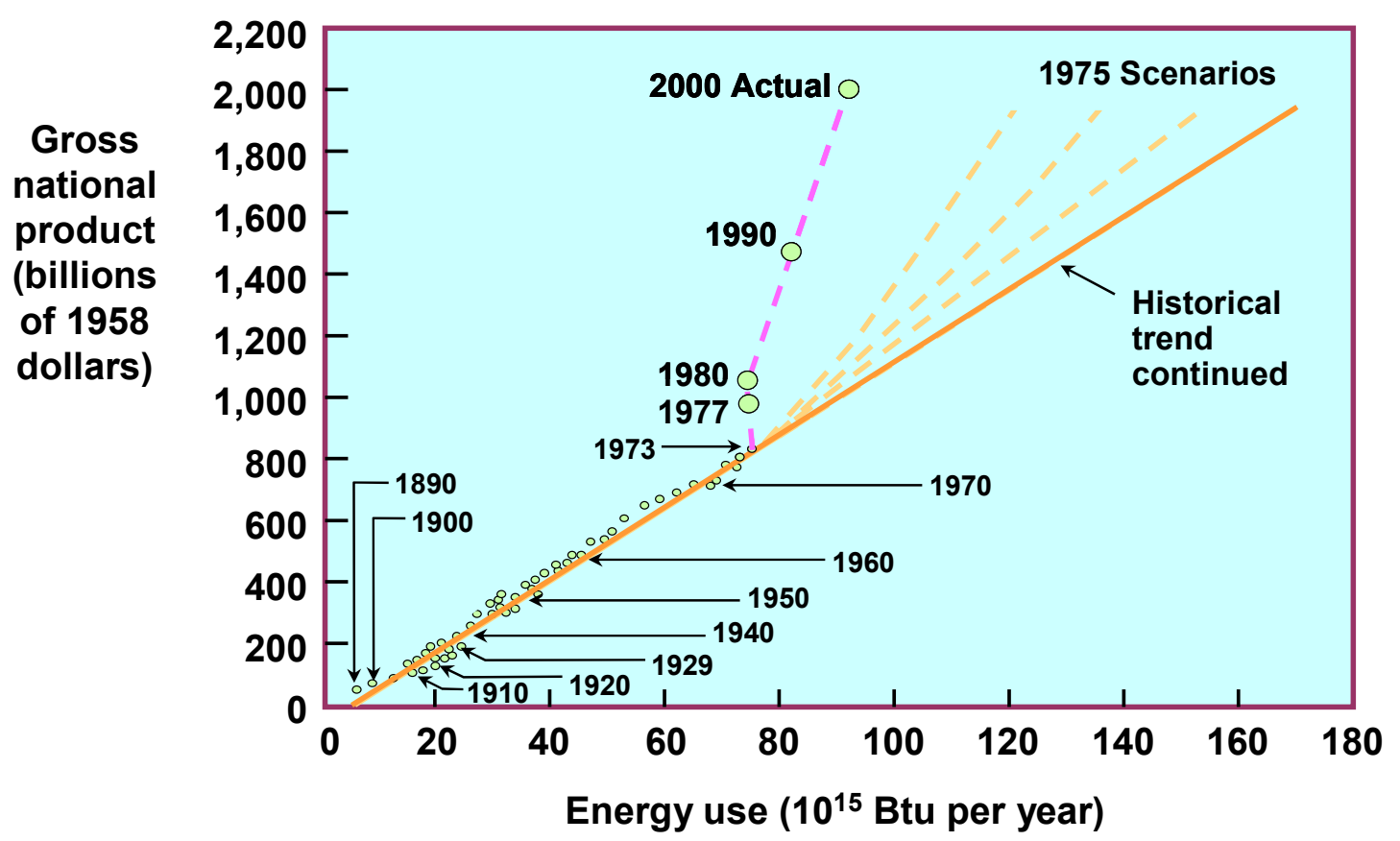

Figure 26.1 The Unexpected Decoupling of U.S. Energy Use and GNP after 1973

RDM begins with one or more potential policy actions. Policy actions may perform well in some futures and poorly in others. The goal is to find those strategies whose performance is insensitive to the uncertainties of the future. An essential step in RDM is therefore to identify those factors that may cause strategies to perform poorly, that is, to identify the strategies' vulnerabilities. Methods such as "red teaming" use expert judgment to identify potential vulnerabilities. These might include, for example, a change in technology that completely decouples emissions and economic growth, a plague that decimates world population for twenty years, or future generations whose well being is completely disconnected from the environment.

Computer simulation models are used to generate large ensembles of plausible alternative futures. Utility metrics measure the "regret" of the proposed strategy in each scenario. A data mining method is then used to identify low dimension regions of the parameter input space ("clusters") in which strategies perform relatively poorly. These low dimension regions define the key scenarios by identifying the factors responsible for poor performance.

Various methods, including search algorithms, interactive visualization and statistical analysis, can then be employed to help decision makers identify those uncertainties most important to the performance of policy actions and to find robust strategies whose performance is largely independent of those uncertainties.

A key findings of RDM analysis is that fixed policy strategies generally turn out not to be robust; they almost always have large areas of considerable to severe regret. As an illustration, consider 
strategies designed to achieve both global economic development and environmental quality. A two-dimensional "regret surface" for policy strategies is measured over the scenario space defined by the rate of decoupling of emissions and GDP and the economic growth rate. Any given scenario is a point in this space (Figure 26.2). Initially, assume that a fixed policy strategy is chosen by one generation and handed off to the next, which may change or continue it. In Figure 26.2, two hypothetical strategies, "Stay the Course" and "Crash Effort" experience more than mild regret over half or more of the scenario space.
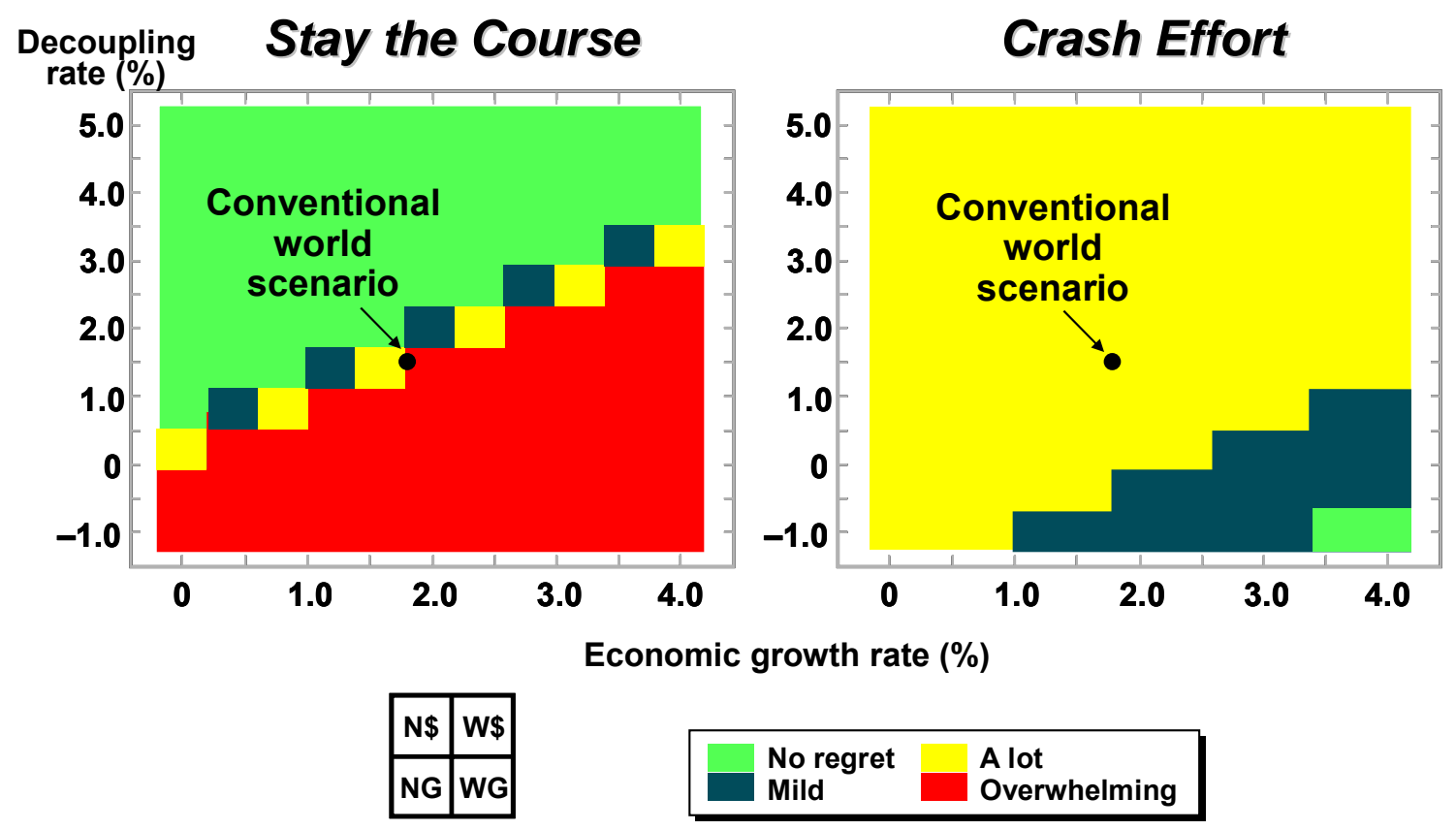

Figure 26.2 Distributions of Regret for Two Alternative, Fixed Strategies

Now consider a strategy with a safety valve, a mechanism for periodic re-evaluation and modification of goals, if necessary. The Safety Valve strategy turns out to be robust over the range of plausible scenarios (Figure 26.3).

RDM provides a systematic means of identifying a small number of useful scenarios that summarize a multiplicity of possible futures and embody the critical vulnerabilities facing policy actions. These scenarios can then be used to find solutions that work well over a wide range of plausible futures and even in the presence of surprises. 


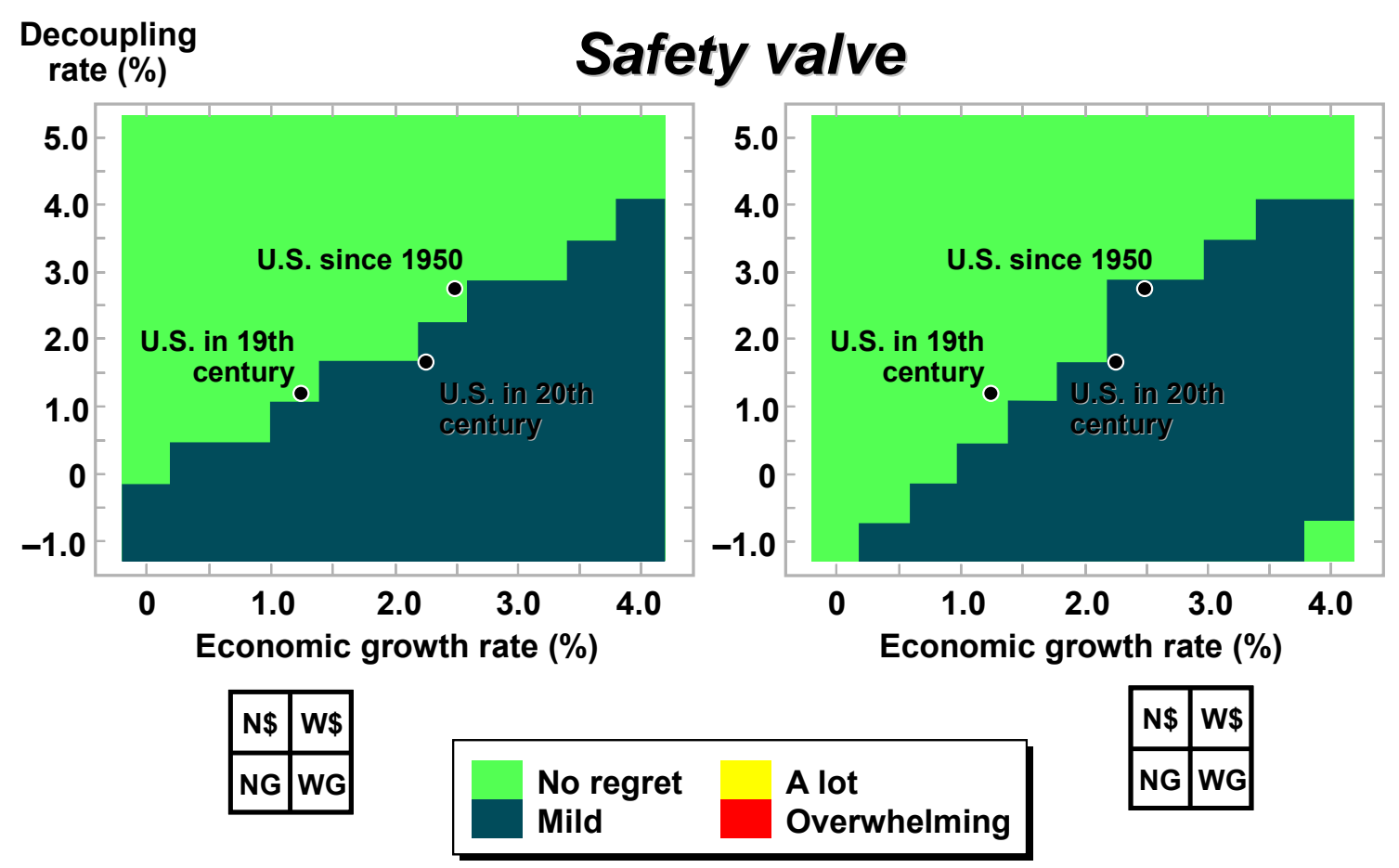

Figure 26.3 Distributions of Regret for Adaptive "Safety Valve" Strategy

A goal of modeling the oil transition should be to identify robust shaping strategies to help navigate through it. The concept of the oil transition presents the likelihood of a novel future. In such cases, model forecasts are likely to be wrong. However, models can play a constructive role by serving as scenario generators that aid in identifying and testing potentially robust nearterm strategies. Unfortunately, in practice, model-generated scenarios often scan a narrow range of relatively safe futures. By deliberately imagining surprises, the range of potential futures can be meaningfully broadened. Re-conceiving scenarios as vulnerabilities of candidate strategies can make them powerful tools in the development of robust strategies. The RDM method provides a structured framework for identifying the most useful scenarios and finding those strategies that perform robustly in the face of deep uncertainties, such as presented by the oil transition. 


\title{
ROUNDTABLE DISCUSSION: METHODOLOGICAL CHALLENGES AND OPPORTUNITIES FOR IMPROVING ENERGY TRANSITION MODELING
}

\author{
Francisco C. de la Chesnaye, Chief Climate Analysis Branco, \\ U.S. Environmental Protection Agency, Facilitator
}

The final session of the workshop provided an opportunity for a roundtable of modelers to identify, elaborate on and discuss key issues.

\section{ENDOGENOUS TECHNOLOGICAL CHANGE}

\author{
Nebojsa Nakićenović \\ IIASA and Vienna University
}

The study of historical energy transitions reveals that endogenous technological change is a critical element of energy transitions. Unfortunately, our ability to predict endogenous technological change in the context of future transitions is weak.

Consider the technologies of lighting in the United Kingdom over the past two centuries (Figure 27.1). Three technologies experienced significant and rapid cost reductions, with electricity eventually winning the race. The cost curves seem to reflect the effects of learning-by-doing.

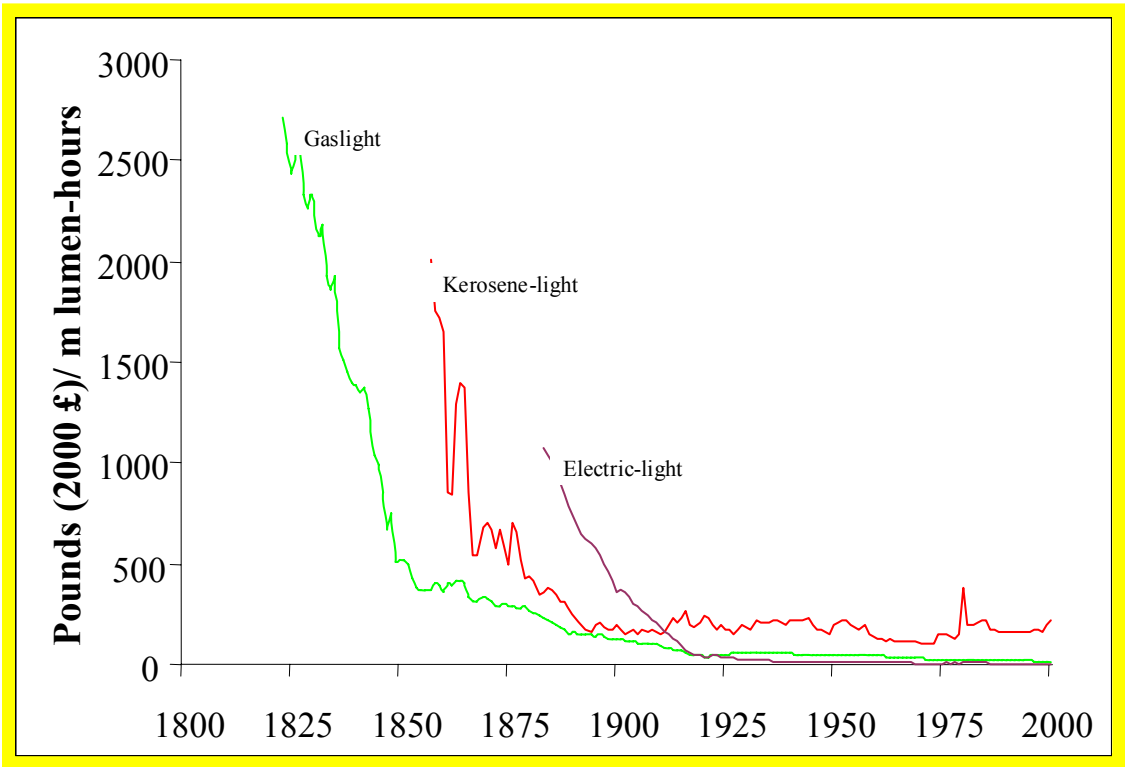

Figure 27.1 Cost of Lighting by Alternative Technologies in the United Kingdom, 1800-2000

Electric lighting, which required a new energy infrastructure, gained a small market share after 1910, when its cost neared those of kerosene lamps and gas lights. But only after its cost fell 
below those of its competitors did its market share take off (Figure 27.2). All of this is clear in retrospect, but how much of this was predictable in advance?

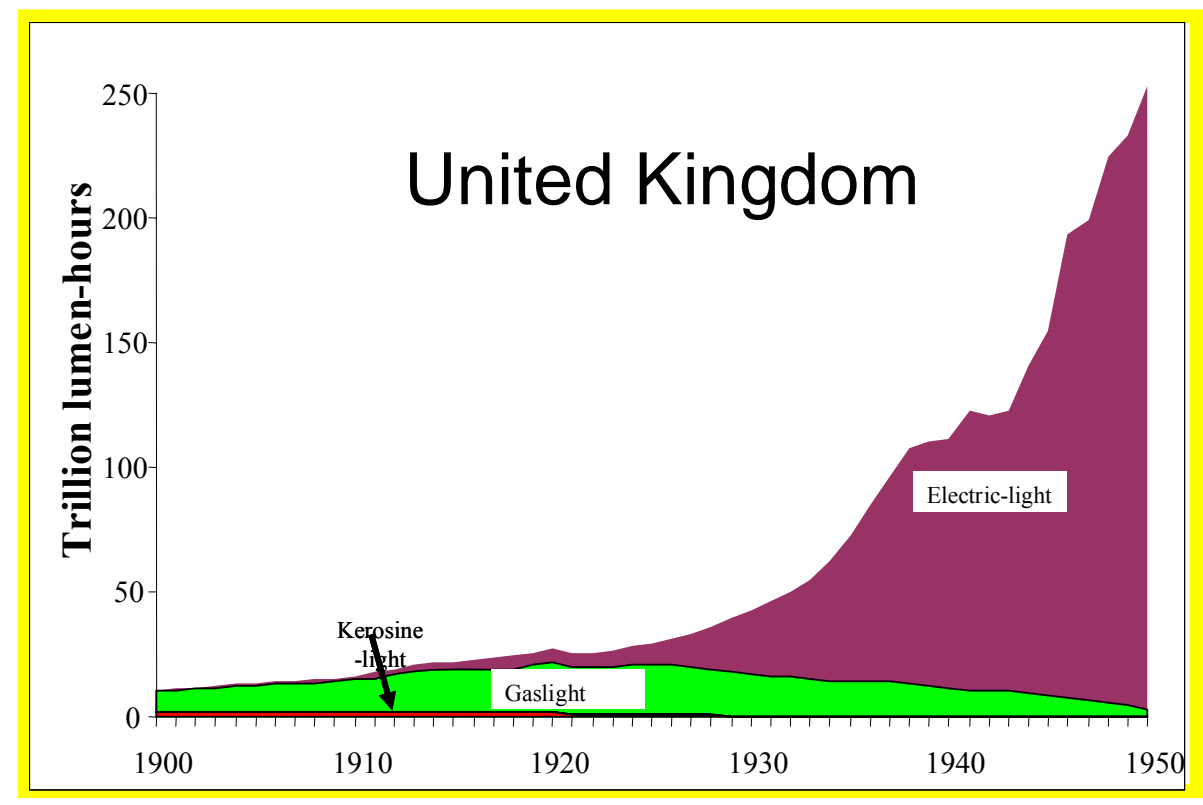

\section{Figure 27.2 Market Shares of Alternative Lighting Technologies in the United Kingdom, 1900-1950}

In fact, predicting the effects of learning-by-doing for technologies that have yet to succeed is fraught with uncertainty. Few technologies are successful; most fail. While it is usually a simple matter to fit a learning curve to historical data for a successful technology, practical methods for predicting which technologies will succeed and what their learning curves will be do not exist. Technological change is a systems concept. In general, not just one but multiple technologies are involved, and it is the interaction of many technologies that ultimately determines successful diffusion of technological change. In addition, multiple agents with diverse behaviors influence the diffusion process; technologies often vary geographically as well as over time, all of which makes technological change an enormously complex process.

Even for successful technologies, learning rates can vary enormously. A study of 115 successful technologies found an average learning rate of $-20 \%$ per doubling of cumulative production (a progress ratio of 0.8 ). A $90 \%$ confidence interval includes a wide range of possible rates: cutting costs in half might require from 2 to 7 doublings of cumulative production (Figure 27.3).

One approach for gaining insights about the future given the uncertainties about technological change is to simulate many alternative futures with differing assumptions about rates and extent of technological change. Figure 27.4 shows the distribution of global carbon emissions derived from such a simulation of 130,000 alternative futures. Of these, approximately 13,000 are "optimal", that is, they provide the best combinations of objectives (e.g., high economic growth, low carbon emissions, etc.). By studying the se optimal futures we can discern the directions in which we would like technology to evolve. New methodologies, such as agent-based modeling may yield new insights into how technologies are likely to evolve, but at present predicting the 
direction and pace of technological change remains perhaps the most difficult challenge for energy modelers.

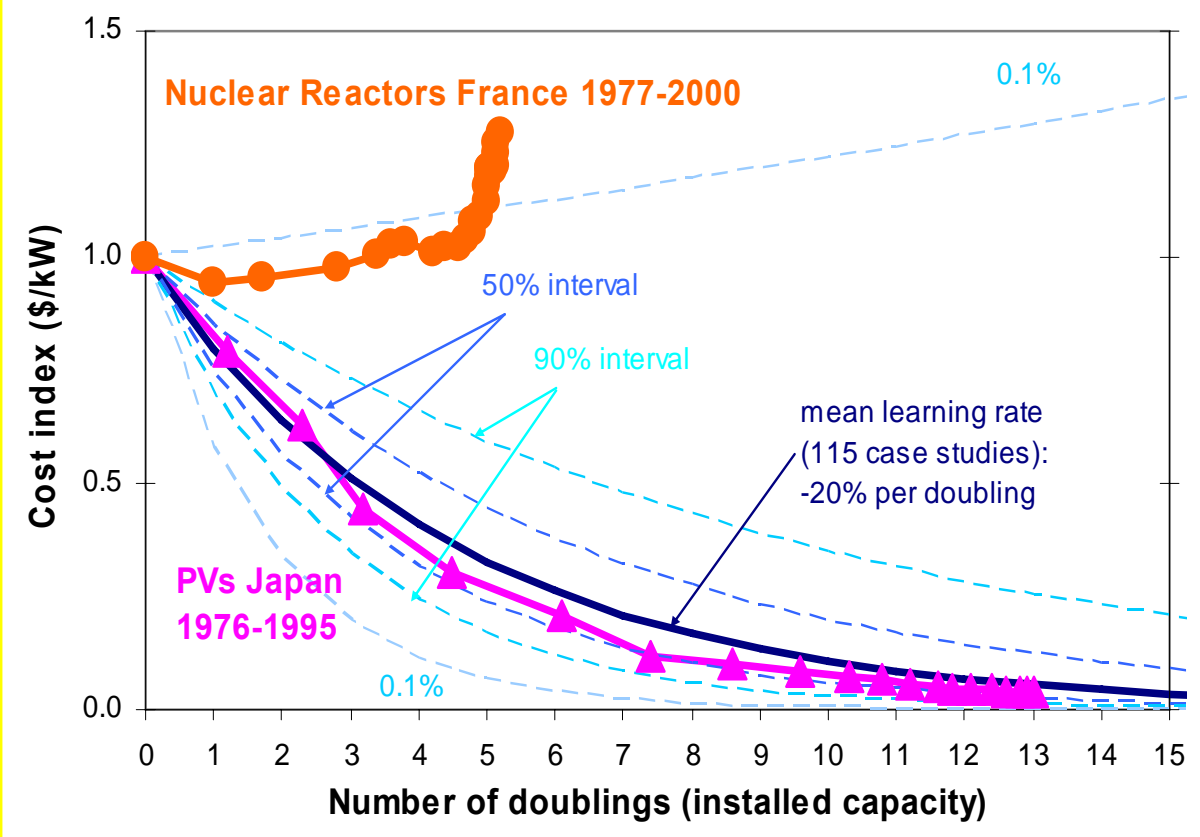

Figure 27.3 Distribution of Historical Rates of Learning-by-Doing

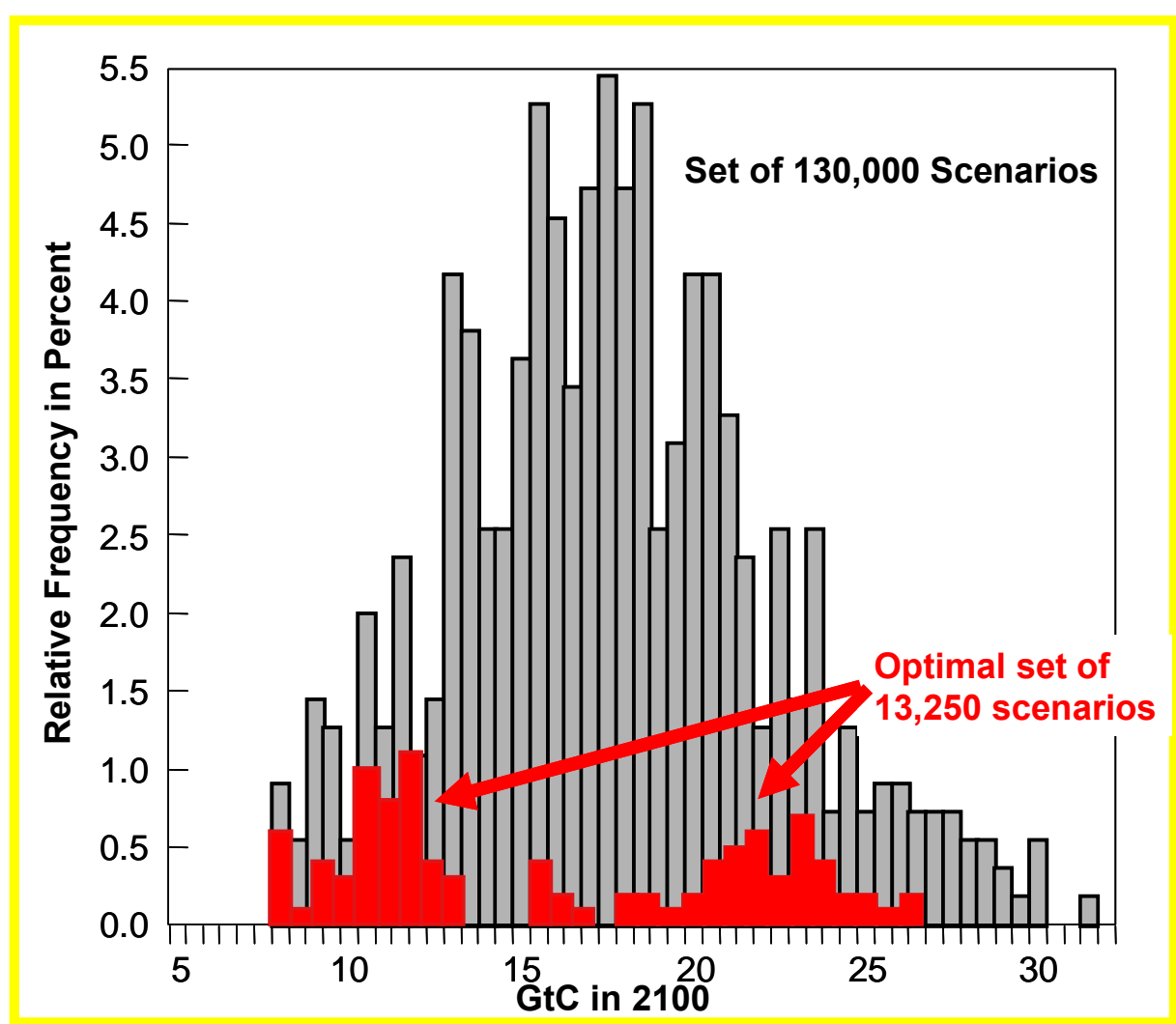

Figure 27.4 $\mathrm{CO}_{2}$ Emissions from Scenarios with Technological Uncertainty 


\title{
28. ENDOGENOUS MARKET TRANSITIONS
}

\author{
Paul Leiby \\ Oak Ridge National Laboratory
}

Energy transitions for motor vehicles involve significant barriers to technological change. Transition to a novel energy source faces the "chicken or egg" problem: manufacturers will be reluctant to invest in producing vehicles for which there is little or no fuel infrastructure and fuel suppliers will be unwilling to invest in a fuel infrastructure when there is no market for the fuel. Consumers will initially find the novel technology less attractive because of high cost, lack of fuel availability and lack of diversity of choice. At the same time, manufacturers must struggle to make progress down the learning curve and achieve economies of scale. When the primary benefits of the new energy source are public rather than private goods (e.g., reduced greenhouse gas emissions), significant public policy intervention will likely be required to achieve a sustainable transition. In the absence of such intervention, transition to unconventional sources of petroleum compatible with the existing fuel and vehicle infrastructure would seem to be the most likely outcome.

The significance of these market barriers was brought to light in analyses of the potential for alternative fuel vehicles in the United States. Long-run, static equilibrium models predicted substantial market shares for many alternative fuels. Dynamic models taking account of initial, temporary, transition barriers such as lack of fuel availability, economies of scale, and lack of make and model choice diversity for alternative fuel vehicles, predicted that no such market would evolve (Figure 28.1). This analysis did not include a representation of learning-by-doing, which would add yet another hurdle for novel fuel and vehicle technologies to overcome.

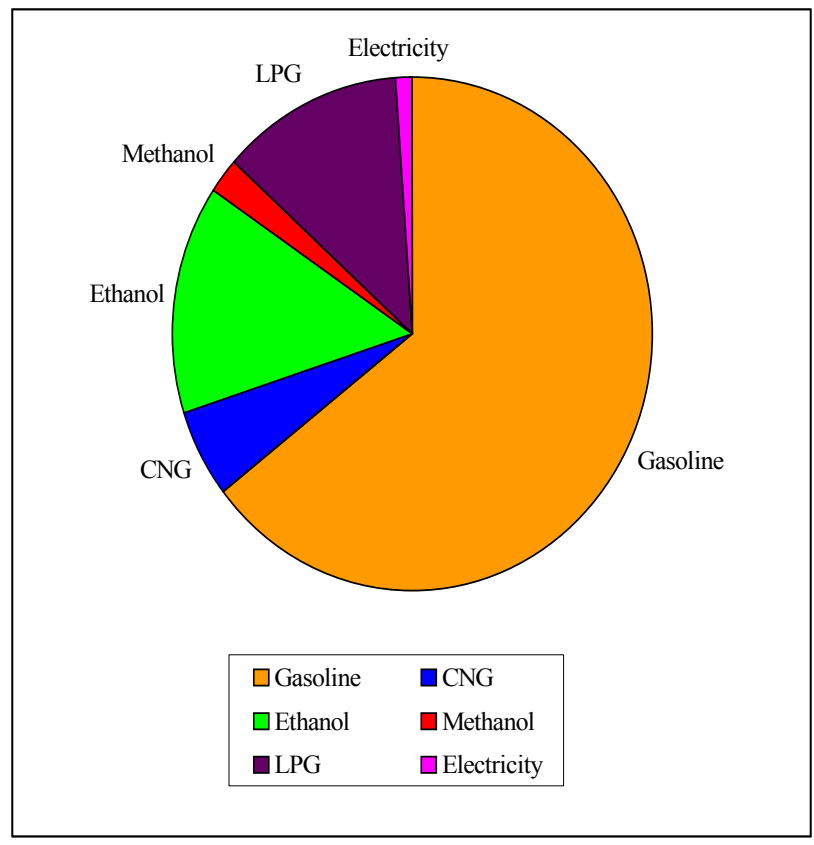

Transitional Analysis With Barriers

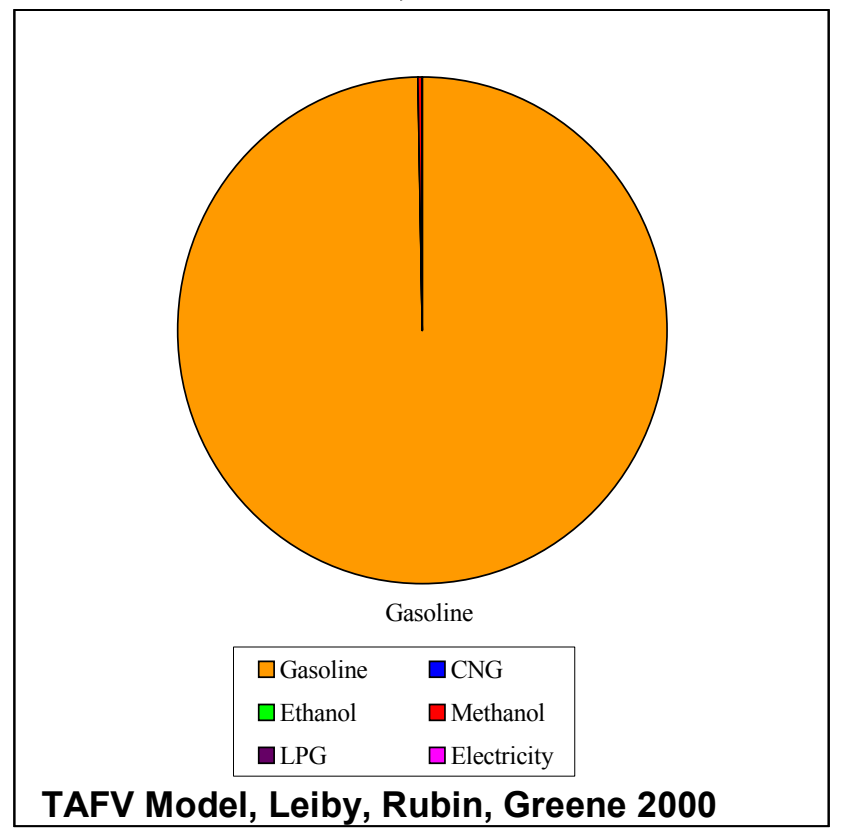

Figure 28.1 Alternative Fuel Vehicle Market Predictions Without (left) and With (right ) Market Barrier to Transition 
A more recent effort to model the possible transition to hydrogen-powered vehicles using a multi-period optimization methodology to simulate market behavior has produced two additional insights. First, advanced technologies that are compatible with existing infrastructure, such as the hybrid-electric vehicle, can succeed as a result of technological progress alone. Given a superior technology, market agents foresee future profits and make the necessary initial investments to drive the technology down the learning curve and achieve both scale economies and diversity of choice. In Figure 28.2, the market success of hybrid vehicles comes about unaided by public policies other than investment in R\&D and the resulting technological advances. On the other hand, the success of the fuel cell vehicle shown in Figure 28.2 requires a substantial initial subsidy, sustained over a period of a decade or more before a sustainable transition is attained. These model outputs are presented for illustrative purposes only and they are not intended to be either predictions or a definitive policy analysis. The model on which they are based is still under development. They are presented only to show that it is possible to represent the complex interaction of these natural barriers to technology transitions in the context of a market-based model. What we can say with confidence at this point is that these barriers are important and can prevent a transition to alternative fuels and vehicle technologies in the absence of meaningful policy measures.

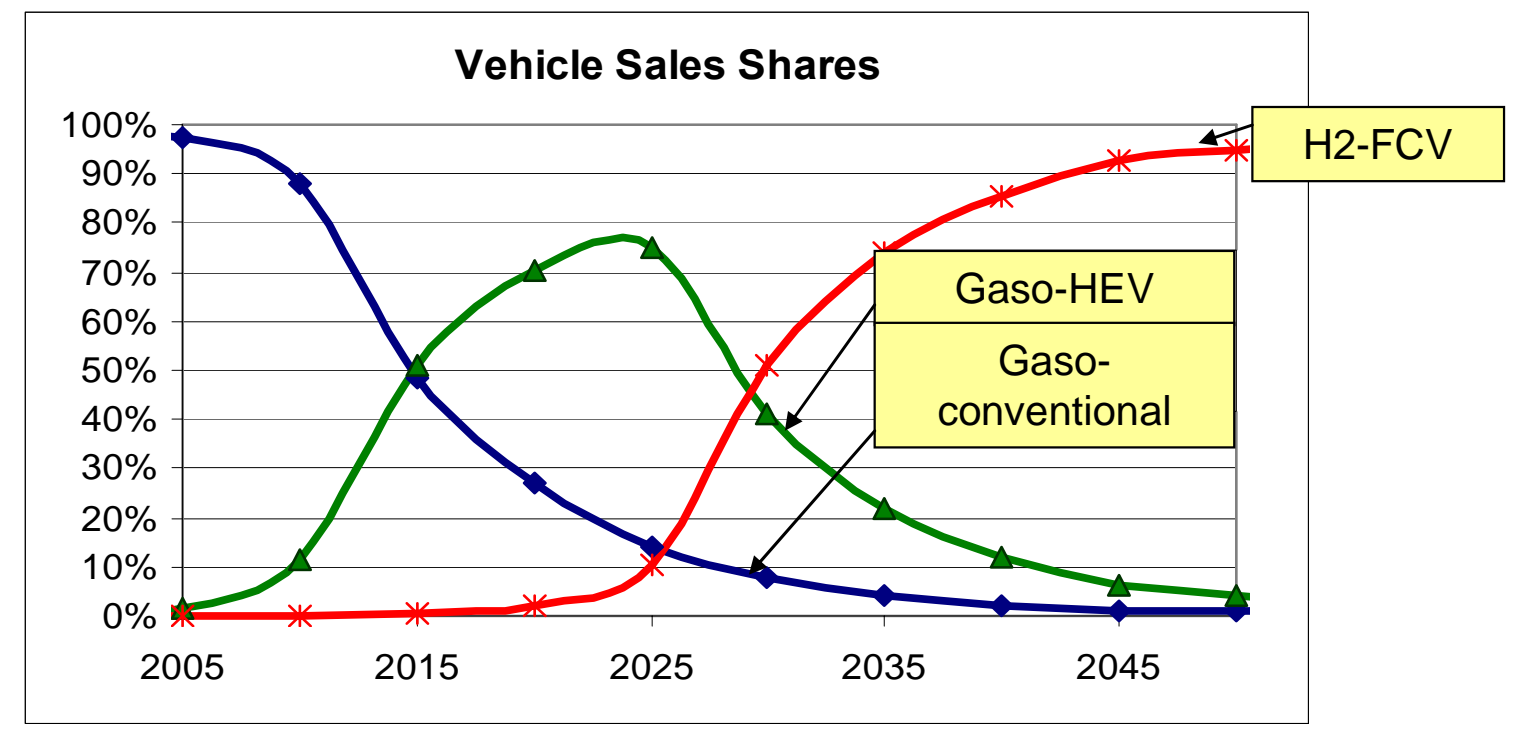

Figure 28.2 One Scenario of Vehicle Technology Transitions in Which a Transition to Hybrid Electric Vehicles is Driven by Pure Technological Change and a Transition to Hydrogen Fuel Cell Vehicles is Aided by Public Policies 


\title{
29. MODELING GROWTH IN NEW ENERGY TECHNOLOGIES: THE IMPORTANCE OF CONSTRAINTS
}

\author{
Carmen Difiglio \\ U.S. Department of Energy
}

Engineering-economic models compete advanced technologies against existing technologies to estimate future energy use patterns. A critical issue is how fast new technologies can penetrate the market and replace existing technologies. The rate at which new energy technologies can be introduced would be especially important in a transition driven by resource limitations. Some foresee the peaking of conventional oil production as just such a transition.

Part of this problem is solved with vintage capital models. These models reflect the fact that capital investments will rarely be abandoned before the end of their useful life. However, very often the rate of turnover of the energy-related capital stock is not the limiting factor for the rate of market penetration. Availability of human capital, technical expertise, can be limiting, and so can risk aversion and access to capital. One way to handle these difficult to model yet important issues is to impose arbitrary constraints on the rate of growth of new energy technologies.

Historical experience provides evidence about both maximum and normal rates of growth for new energy technologies. Figure 29.1 shows the growth of gasification plants for all purposes. The maximum annual rates observed were $27 \%$ and $13 \%$ in the early stages of transition. Growth rates in the vicinity of $2 \%$ to $4 \%$ are common in the later years.

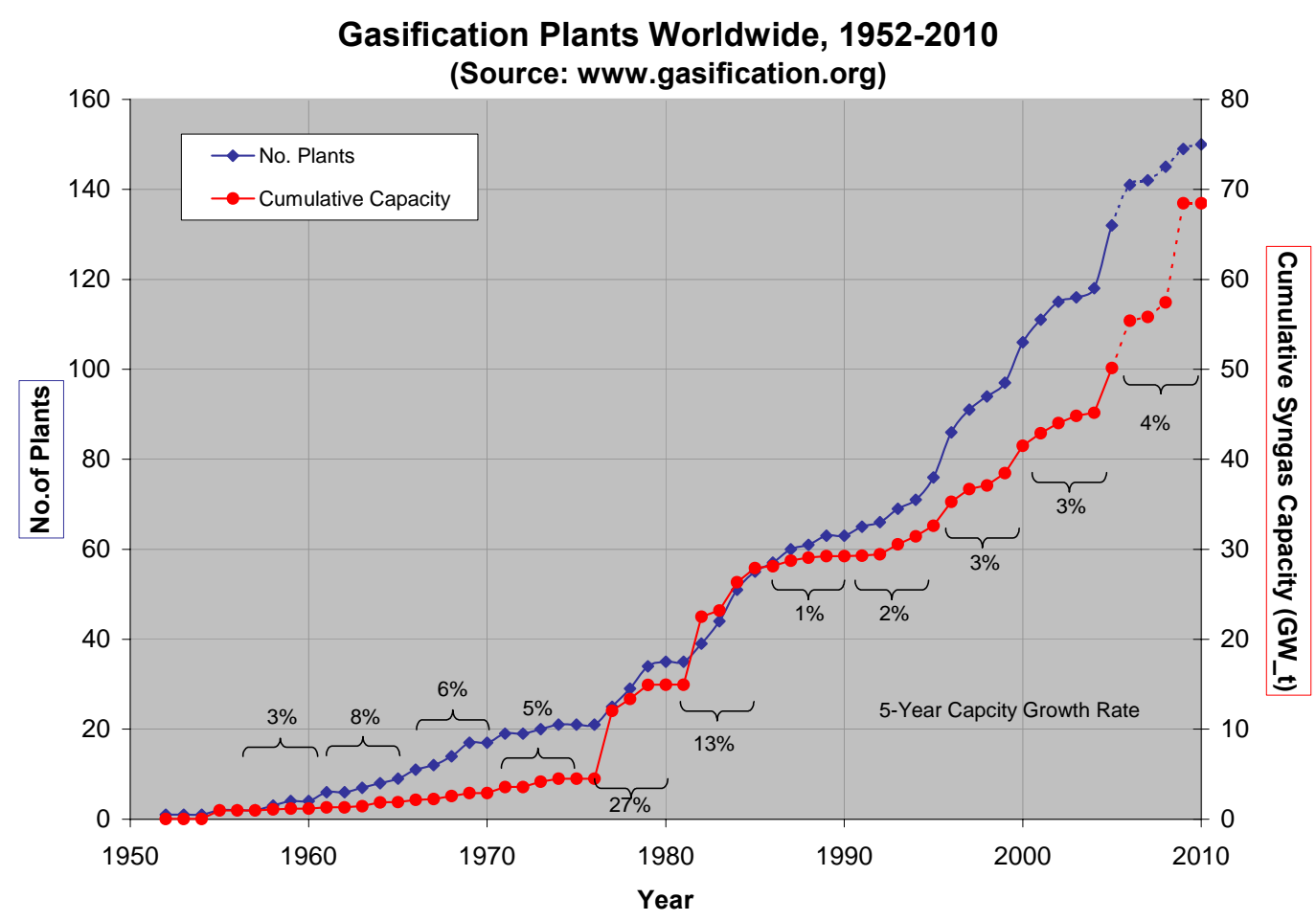

Figure 29.1 Growth of Gasification Plants Worldwide: 1952-2010 
The growth profiles of nuclear generating plants and capacities in the United States and France trace S-shaped curves that provide data on early rates, rates during rapid expansion, and rates as the market becomes saturated (Figure 29.2).

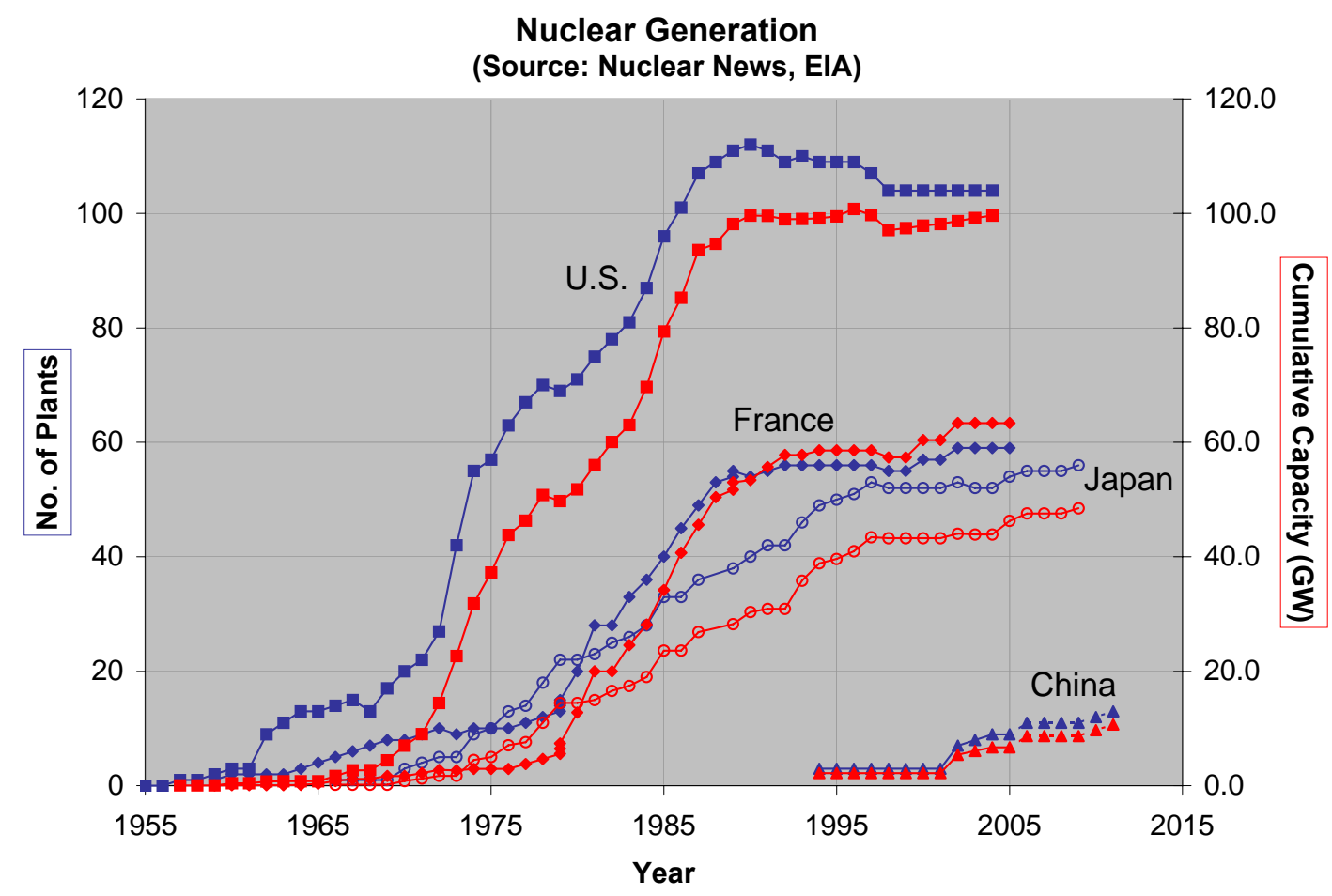

Figure 29.2 Growth in Nuclear Electricity Generation in Four Countries

The data for two renewable energy sources, ethanol from biomass and electricity from wind energy, indicate that we are still in the early stages of growth for these technologies (Figures 29.3 and 29.4).

Imposing constraints limiting the rates of growth of new energy technologies may not be the ideal methodology, but it is essential for producing realistic forecasts. Modeling the oil transition will require better understanding of the constraints on rates of change and the ability to predict the rates at which new energy sources can be expanded. 


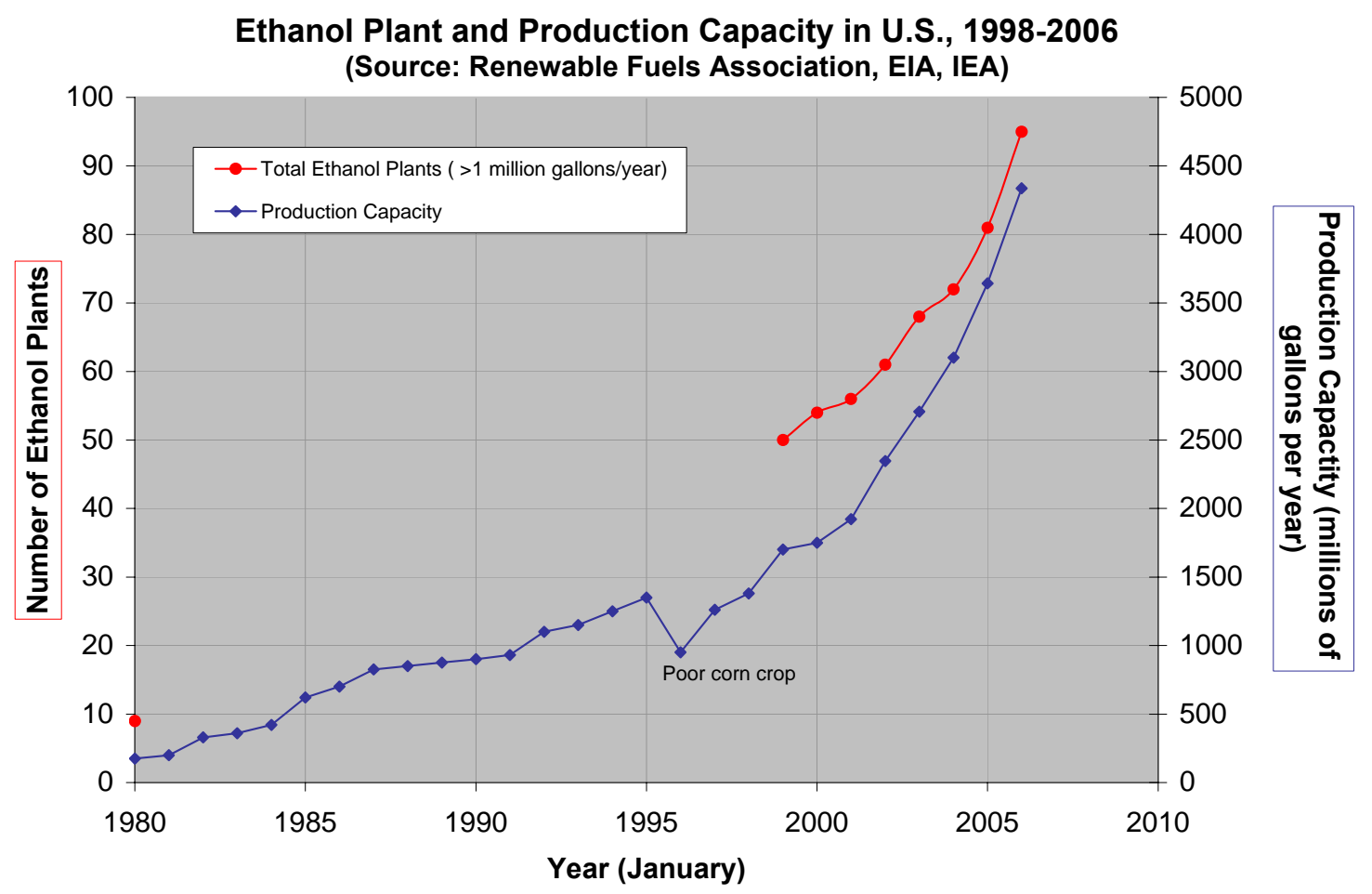

Figure 29.3 Growth of Ethanol Production in the United States: 1998-2006

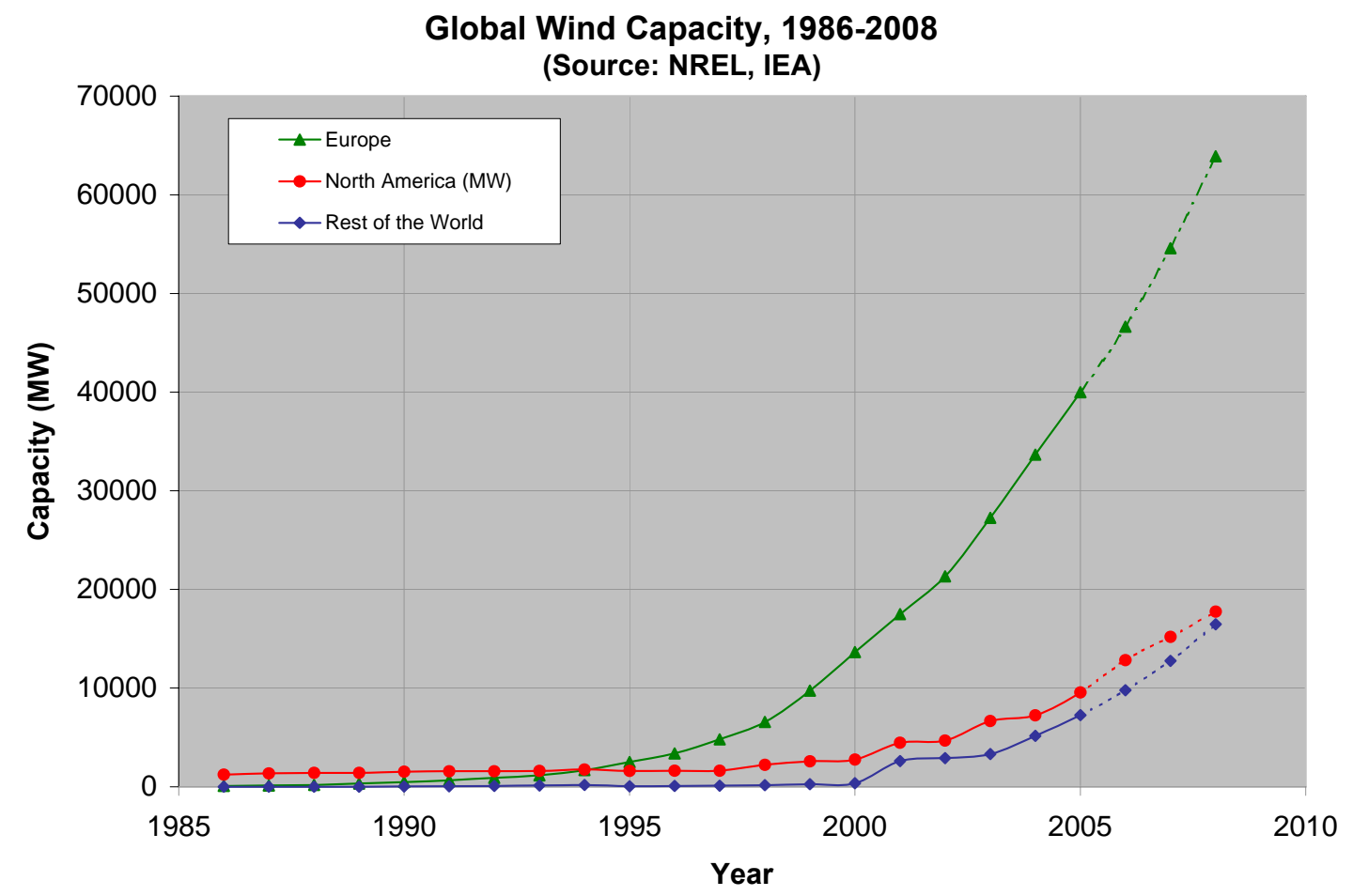

Figure 29.4 Growth of Global Wind Generating Capacity: 1986-2008 


\title{
30. RESOURCE DEPLETION: THE GLOBAL PEAK IN THE PRODUCTION OF CONVENTIONAL OIL
}

\author{
Roger Bentley \\ Visiting Research Fellow, Department of Cybernetics, University of Reading
}

Once the world passes its conventional oil production peak, within 10 years the world's supply of conventional oil will be $40 \mathrm{mmb} / \mathrm{d}$ short of the business-as-usual scenario. This is because, past peak, the global production of conventional oil is calculated to fall at about $3 \%$ per annum, while business-as-usual growth in global oil production has been of the order of $2 \%$ per annum. The importance of this peak can hardly be overstated.

New oil can come from unconventional oil, of which there is a very large amount, and from gasto-liquids, CTL, and biomass. In addition, conventional oil can be substituted by increased use of gas, coal and other energies. But $40 \mathrm{mmb} / \mathrm{d}$ is a very large flow of oil, and most detailed calculations (e.g., those by Petroconsultants, PFC Energy, Energyfiles Ltd., R. Miller at BP, and the BGR in Germany) find that non-conventional oil and the oil substitutes will not be able to come on-stream fast enough to make up for the increasing shortfall in the production of conventional oil. Modeling this transition requires good data and high-quality analysis.

Most current calculations indicate that for the non-OPEC producers, the conventional oil peak will occur sometime between now and 2008. The global conventional oil peak will most likely occur between 2010 and 2015 (Figure 30.1 illustrates one such analysis, and indicates that the total oil-plus-gas peak - non-conventional, as well as conventional - may be before 2020).

Peaking is counterintuitive. As demonstrated by the oil-producing countries now past their resource-limited oil production peak, peaking occurs when there are still large amounts of proved reserves in the ground, when there is significant scope for technology to increase production in existing fields, and when new discoveries are being realized and more are expected. Our entire experience with world oil supply appears to have been one of increasing abundance, punctuated during the past thirty years by price shocks. Yet if one looks closely at oil discoveries and production in oil producing countries or regions - using industry-quality proved-plus-probable ('2P') reserves data - the pattern of peaking is unmistakable. Integrating these $2 \mathrm{P}$ discovery and production profiles for the entire world leads to the conclusion that global oil production will peak, and soon.

Note, however, that we may yet see a minioil glut on world markets before the global peak occurs. Increased supplies from deepwater offshore, Russia, the Caspian region, Canadian tar sands, and Iraq are likely to cause a temporary excess of supply. But even factors such as "reserves growth" or large "yet-to-finds" are only second-order effects, and high estimates for these will delay the peak by relatively few years. 


\section{Uppsala/Campbell Production Forecast 2002 Base Case Scenario}

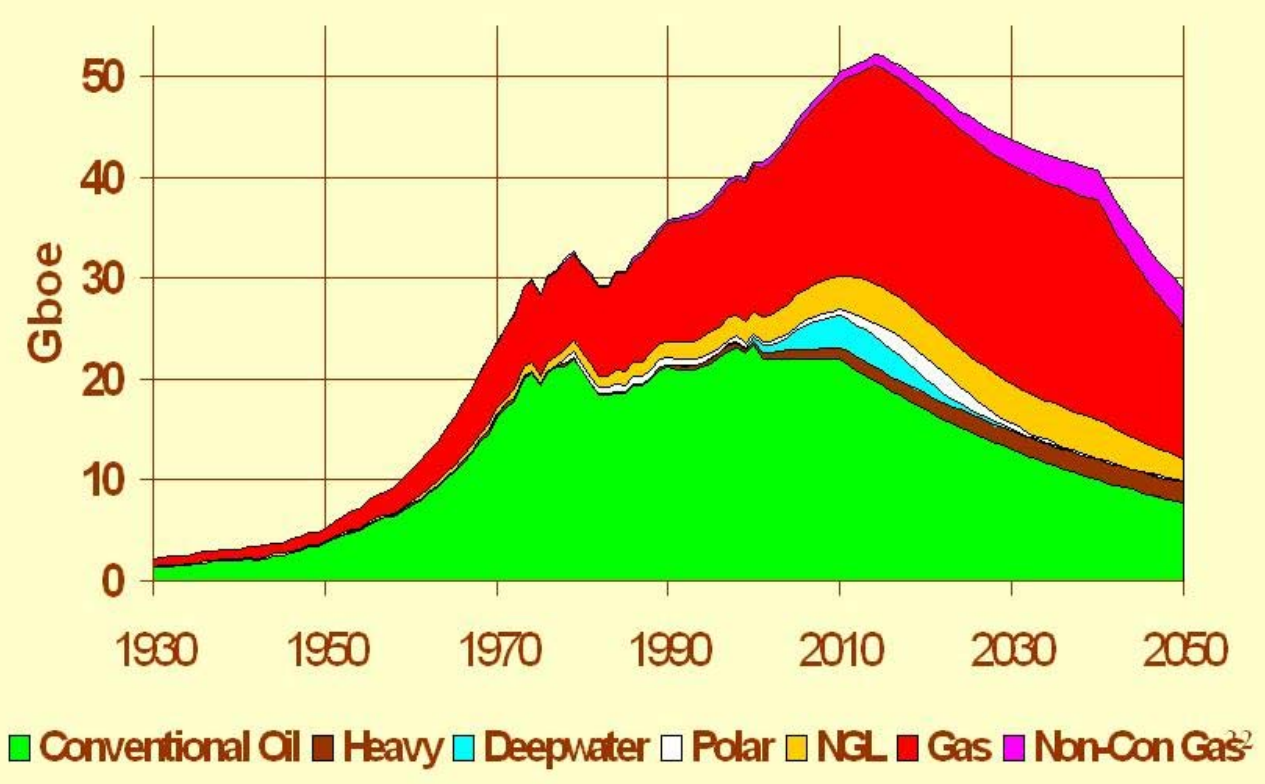

Figure 30.1 Uppsala/Campbell Oil and Gas Production Forecast, 2002 Base Case Scenario

There is no shortage of historical evidence of oil peaking. Today, some 64 countries have gone over their resource-limited peak of conventional oil production. . For example, U.S. discoveries peaked in the mid 1930s, and production peaked in 1971. U.K. discoveries peaked in the mid 1970s, and production peaked in 1999. World discoveries peaked in the mid 1960s and world oil production of conventional oil will peak around 2010. In my view, the following dates appear to be pretty solid for the expected timing of the world's oil and gas peaks.

\begin{tabular}{lll} 
& \multicolumn{1}{c}{ Date of peak } & \\
Non-OPEC peak: & Conventional oil & now -2008 \\
Global peak: & Conventional oil & $2010-2015$ \\
& All oil & $2010-2020$ \\
& Oil + Gas & $2015-2020$ \\
& Gas & $2020-2025$
\end{tabular}

The study of peak oil leads to several important conclusions for all energy modelers:

1. Do not use proved reserves to represent recoverable oil resources. Depending on who is reporting and for what purpose, proved reserves are under, over and even not reported. The result is highly unreliable data.

2. Never use an R/P ratio for modeling oil depletion. Instead, use mid-point peaking.

3. Oil depletion is a matter of rates of production, not quantities of resource. 
Appreciation of the reality and significance of oil peaking is growing. An increasing number of energy modelers and oil market analysts are recognizing the phenomenon and including it in their oil market forecasts (Figure 30.2). Still, there is need for a much wider understanding of oil depletion issues, most critically at the IEA and the EIA, and also a continuing need globally to improve data and modeling methods.

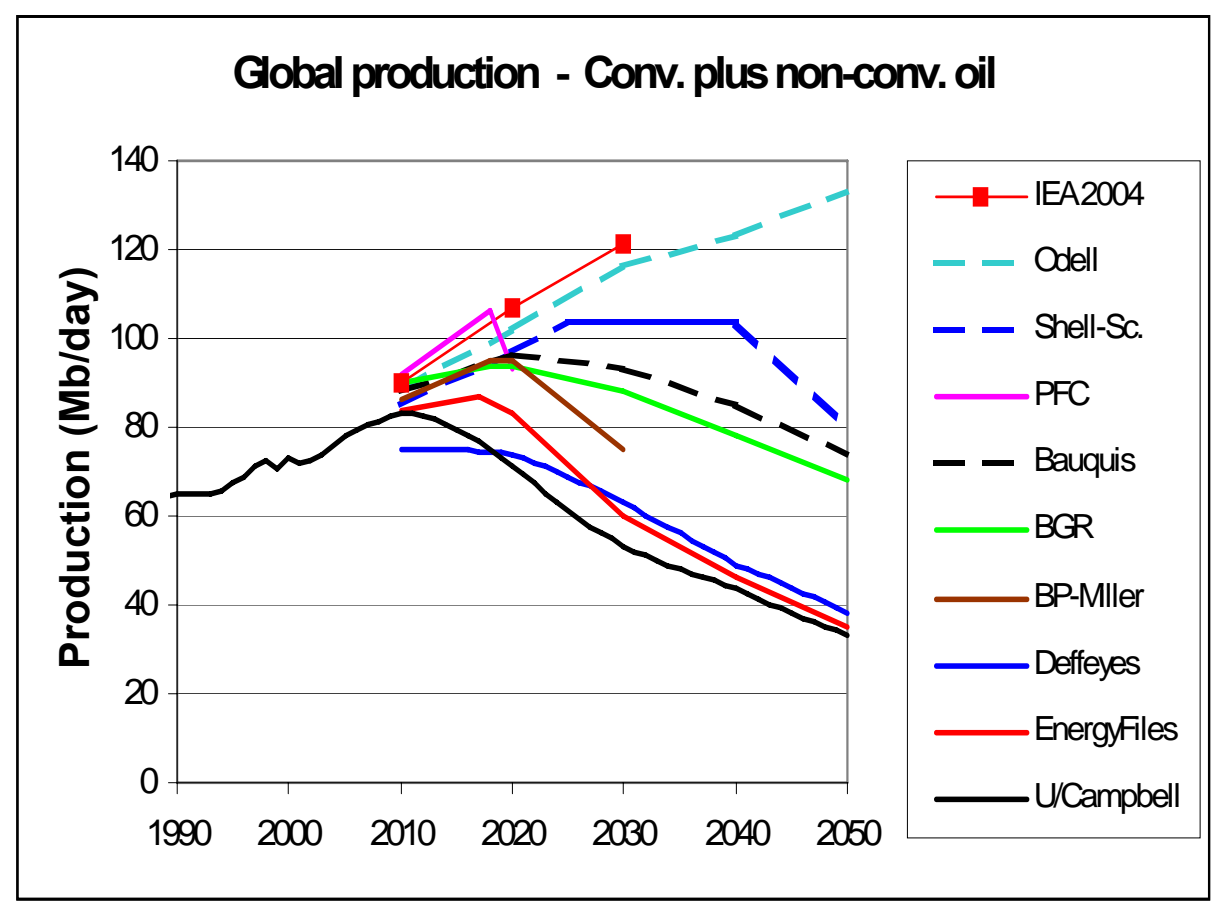

Figure 30.2 Alternative Global Oil (Conventional + Non-Conventional) Production Projections 